\title{
Earthworm communities in arable land: effects of crop residue management and field margins
}

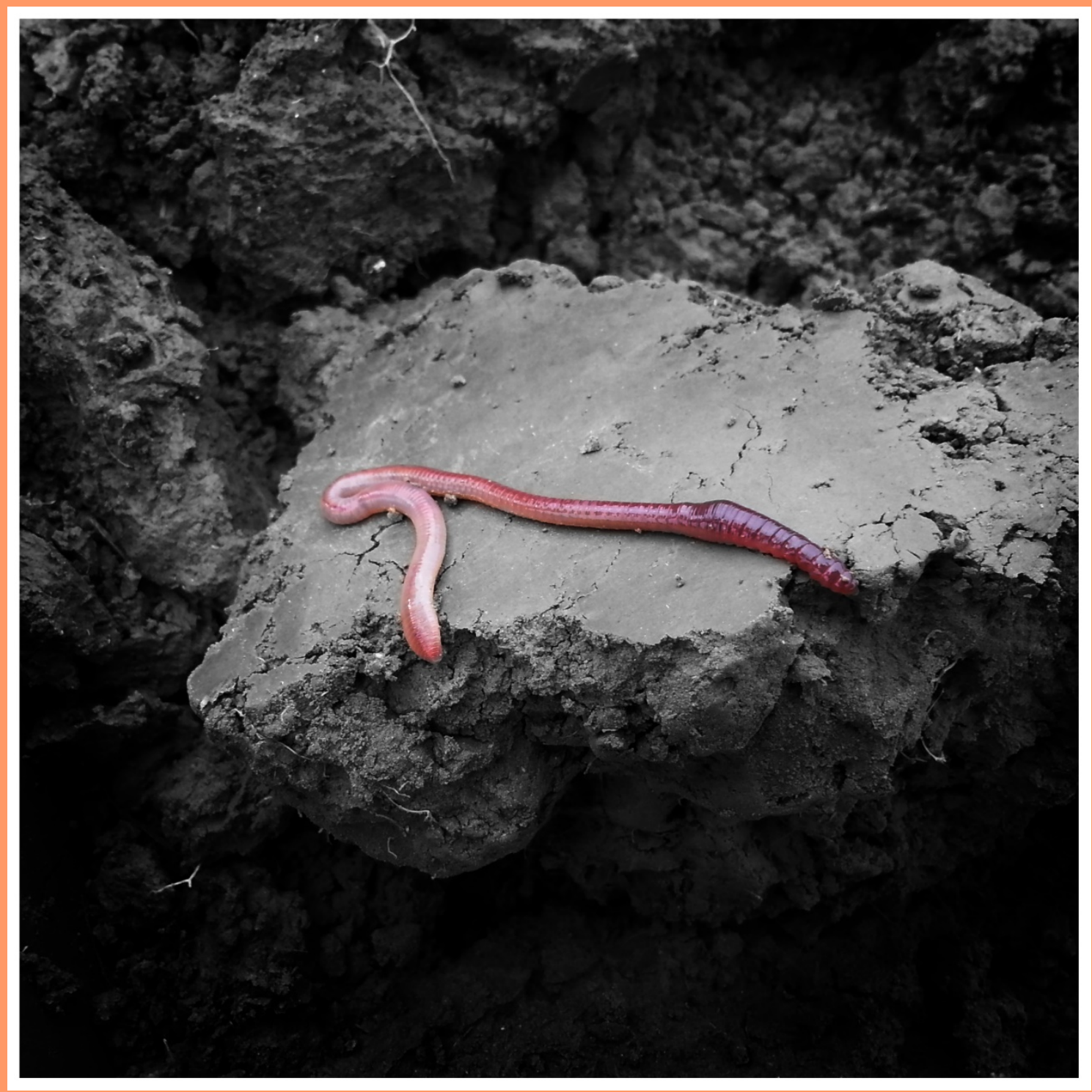

Joana Frederica Teixeira de Aguiar Frazão 
Earthworm communities in arable land: effects of crop residue management and field margins 


\section{Thesis committee}

\section{Promotor}

Prof. Dr L. Brussaard

Professor Emeritus, Soil Biology Group

Wageningen University \& Research

\section{Co-promotors}

Dr R.G.M. de Goede

Assistant Professor, Soil Biology Group

Wageningen University \& Research

Dr J.H. Faber

Senior Scientist and Team Leader of Animal Ecology

Wageningen University \& Research

Dr M.M. Pulleman

Senior Researcher, Soil Biology Group

Wageningen University \& Research

\section{Other members}

Prof. Dr D. Kleijn, Wageningen University \& Research

Dr F.J.J.A. Bianchi, Wageningen University \& Research

Dr G. Pérès, Agrocampus Ouest, INRA, Rennes, France

Prof. Dr J.H.C. Cornelissen, VU University, Amsterdam

This research was conducted under the auspices of the C.T. de Wit Graduate School for Production Ecology and Resource Conservation (PE\&RC). 


\title{
Earthworm communities in arable land: effects of crop residue management and field margins
}

\author{
Joana Frederica Teixeira de Aguiar Frazão
}

\author{
Thesis \\ submitted in fulfilment of the requirements for the degree of doctor \\ at Wageningen University \\ by the authority of the Rector Magnificus, \\ Prof. Dr A.P.J. Mol, \\ in the presence of the \\ Thesis Committee appointed by the Academic Board \\ to be defended in public \\ on Tuesday 11 June 2019 \\ at 4 p.m. in the Aula.
}


Joana Frederica Teixeira de Aguiar Frazão

Earthworm communities in arable land: effects of crop residue management and field margins, 218 pages.

$\mathrm{PhD}$ thesis, Wageningen University, Wageningen, The Netherlands (2019)

With references, with summary in English

ISBN: 978-94-6343-931-2

DOI http://dx.doi.org/ 10.18174/474539 


\section{Table of contents}

1. General Introduction $\quad 7$

2. Earthworm communities in arable fields and restored field margins, as related to management practices and surrounding landscape diversity

3. Soil structure formation and organic matter distribution as affected by earthworm species interactions and crop residue placement

4. Responses of earthworm communities to crop residue management after inoculation of the earthworm Lumbricus terrestris

5. Body-weight distributions of earthworm communities are affected by crop residue management under different tillage systems

6. General Discussion

References

Summary

Samenvatting

Sumário

Acknowledgements

Short biography

PE\&RC Training and Education Statement 

Chapter 1

General Introduction 



\section{General Introduction}

\subsection{Community assembly in arable land}

In the past decades, the study of community patterns in natural and managed ecosystems has been central in ecology, with the crucial goal of understanding and predicting biodiversity responses to global change. Biodiversity is increasingly acknowledged as one of the major drivers of ecosystem functioning (Millennium Ecosystem Assessment, 2005), and therefore, current environmental changes, which threaten biodiversity, are expected to have large consequences for ecosystem functioning. A deeper understanding of how ecosystems function and change and of the role of biodiversity in providing those functions is consequently urgent, which implies the need to better understand community assembly patterns.

Community assembly processes are controlled by large-scale (dispersal and environmental constraints) and local small-scale processes that successively filter species that occur at a given site, the actual species pool (Belyea and Lancaster, 1999). Historical, biogeographical and evolutionary constraints select species to form the total species pool. The geographical species pool is the subset of the total species pool that is able to disperse to a given site, and therefore available for population establishment. The habitat species pool is another subset of the total species pool, and consists of species that are able to colonize the site given its environmental conditions. Species belonging to the intersection of the habitat and the geographical species pools form the ecological species pool. While both the habitat and the geographical species pools contain species that are potential colonizers of a given site, only species belonging to both pools are capable of colonizing it. Internal community factors, such as biotic interspecific interactions, then filter the ecological species pool to form the actual species pool, the species that comprise a community (Belyea and Lancaster, 1999). Species traits are central in understanding these pools, since they reflect species adaptations and responses to the environment (Violle et al., 2007) and operate at different temporal and spatial scales (Southwood, 1977).

Agricultural intensification has severe effects on biodiversity, and it occurs at different spatial scales, from the field to the landscape (Ettema and Wardle, 2002). While at the landscape scale it relates to the ongoing loss of natural or semi-natural areas due to land conversion for arable 
production, at the field scale it relates to intensive management practices, such as mechanical tillage and use of synthetic fertilizers and pesticides. The habitat and consequently, the ecological species pools of agroecosystems are therefore filtered by environmental factors that comprise land-use constraints (e.g., an arable field is often annually ploughed, whereas a productive grassland is not) and abiotic constraints (e.g., soil properties) (Decaëns et al., 2008).

\subsection{Earthworms in arable fields}

Earthworms (family: Lumbricidae, the focus of this thesis) belong to the subclass Oligochaeta, phylum Annelida (Sims and Gerard, 1999). They are tube-shaped hermaphrodites that vary considerably in size, reproductive output and strategy, rate of maturation, habitat and food preferences. They inhabit soils, and show distinct burrowing behaviours, both in terms of burrow shape and depth. They have been classified according to their life strategies into broad ecological groups by Bouché (1977): epigeics are small species that reproduce fast and feed on fresh organic matter available on the soil surface, and are known to have limited burrowing habits; anecics are large species with a slow reproductive rate, dig deep permanent and rather vertical burrows, and come to the surface to feed on detritus that is available on the soil surface; and finally, endogeics are species that ingest soil and acquire their nutrition from organic matter associated to soil mineral particles. They burrow horizontally, creating branched temporary and rather horizontal galleries. Several authors, however, recorded intermediate behaviours for some species (Briones and Álvarez-Otero, 2018; Hendrix et al., 1999; Lavelle, 1983; Pérès et al., 2010; Vos et al., 2014).

In arable agroecosystems, earthworms are known to be affected by several abiotic factors, including soil properties ( $\mathrm{pH}$, soil texture, organic matter and soil moisture (Curry, 2004)), arable management practices (e.g., tillage (Chan, 2001), food availability (Curry, 2004) and pesticide use (Pelosi et al., 2014)) and though less studied, the surrounding landscape (Flohre et al., 2011). Conventional tillage, i.e., mouldboard ploughing, inverts the soil while burying crop residues to $20-40 \mathrm{~cm}$ depth, eliminating it from the reach of surface-feeding earthworms. Simultaneously, earthworms may be damaged or killed, besides being subjected to increased predation (Cuendet, 1983). Anecic earthworm burrows are destroyed, and re-establishing those occurs at high costs of energetic investment (Petersen and Luxton, 1982). In a meta-analysis, Briones and Schmidt 10 
(2017) showed that under reduced tillage systems, earthworm abundance and biomass significantly increased compared to conventional tillage systems, particularly under no-till and conservation agriculture (mean abundance increase of $137 \%$ and $127 \%$, respectively; mean biomass increase of $196 \%$ and $101 \%$, respectively). Epigeics and anecics were shown to be the most sensitive ecological groups to conventional tillage. Under reduced tillage, their abundance increased on average $117 \%$ and $123 \%$, respectively, among 39 studies. Endogeics, however, have been reported in several studies as positively affected by, or non-responsive to conventional tillage (Crittenden et al., 2014; de Oliveira et al., 2012; Nieminen et al., 2011), while Briones and Schmidt (2017) reported a slight increase in their abundance under reduced tillage.

The effects of pesticides on earthworms have been extensively reviewed by Pelosi et al. (2014), and focus was given to substances authorized in the European context. The authors assessed the effects of several types of pesticides on earthworms, and concluded that those can negatively impact earthworms from the physiological to the community levels. Furthermore, the authors identified several knowledge gaps, which were related to the model species used, to the difficulty in scaling-up from physiological to community level, and in scaling-up from laboratory to field conditions. Finally, the authors also claimed that the short duration of laboratory studies may hamper extrapolations to realistic field conditions, since continuous exposure in the field may augment the negative effects.

Earthworms are known to have limited dispersal ability, and depending on the species and landuse type, dispersal rates summarized by Eijsackers (2011) varied between 1.5 and $14 \mathrm{~m} \mathrm{yr}^{-1}$, in (grazed) grasslands and arable fields. Nevertheless, there is a growing interest in the influence of the surrounding landscape on earthworm communities of arable fields, and particularly in the last decade, earthworm ecologists have studied the effects of the presence of field margin strips adjacent to arable fields on the communities of those. Field margin strips are one example of agro-environmental schemes that are part of the European Commission's strategy to reverse negative effects of landscape-scale agro-intensification (EU-Commission, 2005), and ecologists are generally interested in their potential as source populations to colonize arable fields. A number of studies have researched earthworm communities in field margins and arable fields, and in general they concluded that although field margins harbour higher densities and richness, the spill-over effect to arable fields was negligible (Crittenden et al., 2015; Roarty and Schmidt, 
2013; Smith et al., 2008). However, it remains unclear why this occurs, and whether landscape at larger scales can play a role in shaping earthworm communities of arable fields.

\subsection{Earthworms and soil functioning}

Earthworm feeding, burrowing and casting activities strongly impact soils. Several aspects of soil functioning with relevance for arable cropping are acknowledged to be, at least partly, earthworm-mediated (Bertrand et al., 2015). Their feeding habits stimulate decomposition of dead plant material and soil organic matter and thereby enhance nutrient mineralization (Lubbers et al., 2017) and availability for plant growth (Lavelle et al., 2004; Scheu, 2003; Vos et al., 2014). In a meta-analysis, van Groenigen et al. (2014) demonstrated that they increase crop production by $25 \%$ on average. Furthermore, they can also promote organic matter stabilization, by protecting it in their casts in which soil micro and macro-aggregates can be formed (Bossuyt et al., 2004; Bossuyt et al., 2006; Hedde et al., 2013; Pulleman et al., 2005). Several studies have shown that those casts are more stable than the surrounding soil aggregates, particularly if the casts have dried or aged (Marinissen and Dexter, 1990; Shipitalo and Protz, 1988). Earthwormmediated carbon stabilization processes could therefore counteract the gaseous losses $\left(\mathrm{CO}_{2}\right.$ and $\mathrm{N}_{2} \mathrm{O}$ ) resulting from mineralization. Lubbers et al. (2013) demonstrated, however, in a quantitative review that earthworms can increase $\mathrm{CO}_{2}$ and $\mathrm{N}_{2} \mathrm{O}$ emissions by $33 \%$ and $42 \%$, whereas SOC stocks remained unaffected. The impasse between earthworm-induced net effects of greenhouse gas emissions and soil carbon stabilization persists, and those authors urged for more studies that involve growing plants, with longer time-spans.

Besides playing an important role in decomposition and nutrient cycling, earthworm feeding, burrowing and casting activities have also been recognized to affect soil structure (Lee and Foster, 1991). The already mentioned effects on soil aggregate stability seem to be larger through the activities of endogeic earthworms than anecics or epigeics (Lavelle and Spain, 2001; Six et al., 2004), and Lee and Foster (1991) suggested that a combination of endogeics with anecics is most favourable for soil structural quality. Both ecological groups are known to dig galleries through the soil matrix, thereby contributing to soil macroporosity, which in turn affects hydraulic conductivity and gas exchange in soils (Lee and Foster, 1991). Anecic vertical burrows, which initiate at the soil surface, promote water infiltration (Spurgeon et al., 2013), and 
in a mesocosm experiment under field conditions, the presence of the anecic Lumbricus terrestris (Linné, 1758) counteracted negative effects of intense rainfall on plant growth (Andriuzzi et al., 2015). In the meta-analysis by Spurgeon et al. (2013), however, not only anecics, but also epigeic earthworms were positively associated to water infiltration, while endogeics did not show any effect. Epigeic activity is mostly associated to decomposition of fresh litter on the soil surface, but shallow burrows may be maintained by some species (Francis and Fraser, 1998).

\subsection{Research objectives of this thesis}

The general aim of this thesis is to better understand earthworm community assembly in agricultural soils under intensive agricultural practices. Given the importance of earthworms for soil functioning and the pressures posed by agricultural areas on those invertebrates, studying the responses of earthworms to constraints that arise in agroecosystems is highly relevant. Since agricultural intensification presents environmental filters that select species to form the ecological species pool, focus was given to land-use and abiotic constraints. Furthermore, as an actual community is then filtered by interspecific interactions, and those are intimately linked to the available resources, emphasis was given to how resources affect earthworm communities including interspecific interactions. Specific objectives were:

a) To understand the roles of landscape, management and soil properties as environmental filters for earthworm communities in arable soils with contrasting management intensities;

b) To quantify and explain the effects of crop residue position in the soil profile on the survival and performance of earthworm species with contrasting feeding habits and burrowing behaviours, and the subsequent effects on soil structure;

c) To study earthworm community responses, using several approaches (taxonomic, traitbased and ecological groups), to crop residue management in arable fields under different tillage practices, after inoculating an anecic species.

It was hypothesized that earthworm communities inhabiting soils under intensive management would be shaped mostly by management, whereas landscape and soil properties would have a larger influence in soils under less intensive management (objective a)). Therefore, the 
ecological species pools of habitat types with distinct management intensities would be different. With respect to the second objective (b), crop residue placement was expected to act as an environmental filter and therefore affect the survival and performance of earthworms, depending on their feeding habit. Consequently, crop residue placement was predicted to affect earthwormmediated soil structure formation. Finally, in relation to the last objective, it was hypothesized that crop residue management would represent an environmental filter on earthworm communities. Therefore, crop residue management was expected to affect earthworm communities through interspecific interactions, which would have consequences for the actual species pools, under different tillage systems. Moreover, trait-based and ecological group approaches were hypothesized to provide additional insights to the taxonomic approach, which would allow improving the mechanistic links between the response of earthworm communities and crop residue management.

To achieve these objectives and test these hypotheses, I made use of a combination of a controlled indoor experiment, as well as observational and manipulative field studies. Field studies took place in the Hoeksche Waard, in the south-western part of The Netherlands, and the greenhouse experiment was performed using soils from the same study area. The Hoeksche Waard consists of a set of polders that have been progressively reclaimed from the sea since the $15^{\text {th }}$ century. Soils are hydromorphic calcareous sandy loam to clay formed in marine sediments (de Bakker and Schelling, 1966). The region is further characterized by an extensive network of dikes, creeks, ditches and field margins and the main activity of the region is conventional arable cropping (Steingröver et al., 2010). The most important main crops are potato, sugar beet and wheat (Crittenden et al., 2015), and grain crops are typically followed by cover crops, such as radish, grass or mustard. Most farmers till their soils using a conventional mouldboard plough, yet some have experimented, at least for a few years, alternative practices such as non-inversion tillage.

\subsection{Outline of this thesis}

This thesis comprises six chapters: the introduction (chapter 1), four chapters about experimental work, written with co-authors (chapters 2 to 5) and the general discussion (chapter 6). Chapter 2 compares earthworm communities of arable fields to the ones of field margin strips, and reports 
the contributions of environmental filters, i.e., soil properties, management and surrounding landscape, in shaping those communities, addressing the first objective. Chapter 3 reports the effects of crop residue placement in the soil profile under controlled mesocosm conditions on the survival and performance of earthworm species representing the three broad ecological groups (Lumbricus rubellus (Ho $\square$ meister, 1843), Aporrectodea caliginosa (Savigny, 1826) and Lumbricus terrestris), alone or in species mixtures (objective b)). Moreover, the follow-up effects of those earthworms on soil structure, specifically soil porosity, soil organic matter (SOM) distribution and aggregate stability are evaluated. In chapters 4 and 5, the response of earthworm communities to crop residue amounts and placement in arable fields with contrasting tillage practices is investigated (objective c)). In chapter 4 , focus is given to the community response in terms of density, diversity, species composition, ecological groups, and functional diversity, whereas chapter 5 takes an alternative approach based on earthworm body-weight distributions as an indicator of community response. Chapter 4 also considers the effects of inoculation of a rarely found anecic species (L. terrestris) in arable fields on the native earthworm communities, and the successfulness of the inoculation in relation to crop residue management and tillage practices. In the last chapter, I summarize the results of the experimental chapters, embed them in current literature and discuss their implications for earthworm ecology and arable management. 



\section{Chapter 2}

\section{Earthworm communities in arable fields and restored field margins, as related to management practices and surrounding landscape diversity}

Chapter published in Agriculture, Ecosystems and Environment, 2017,

248: $1-8$

Joana Frazão, Ron G.M. de Goede, Lijbert Brussaard, Jack H. Faber, Jeroen C.J. Groot, Mirjam M. Pulleman 



\title{
2 Earthworm communities in arable fields and restored field
}

\author{
margins, as related to management practices and
}

\section{surrounding landscape diversity}

\begin{abstract}
Agricultural intensification has negative impacts on biodiversity at spatial scales from field to landscape. Earthworms are important for soil functioning, so it is crucial to understand the responses of earthworm communities to agricultural management and land use. We aimed to: 1) investigate whether earthworm communities differed between relatively undisturbed field margins, and highly disturbed arable fields; and 2) quantify how earthworm communities of arable fields and field margins are affected by three environmental filters, i.e. soil properties, management practices, and composition of the surrounding landscape. Earthworms were sampled in 26 arable fields and 15 field margins, across a polder area in The Netherlands. While earthworm density, total biomass and species richness did not differ significantly among arable fields and field margins, rarefied earthworm species richness and community composition did. The three environmental filters affected earthworm communities of arable fields and field margins differently. In arable fields, earthworm communities were explained by arable management only (26\%). In contrast, all three filters contributed significantly to the variation in earthworm communities of field margins, where management practices explained a larger part of the variation (18\%) than the surrounding landscape (11\%) and soil properties $(10 \%)$. Our results suggest that soil properties and surrounding landscape can affect earthworm communities of field margins. However, in the arable fields, where more diverse lumbricid communities are desirable to improve soil functions, such influences are negated by the impact of management at field scale. We demonstrated that field margins enhance earthworm biodiversity in arable landscapes, but surrounding landscape and field margins had limited impact on earthworm communities in arable fields. Decision-making and research should focus on less intensive management options for arable fields to stimulate earthworms and earthworm-mediated soil functions.
\end{abstract}





\subsection{Introduction}

Earthworms play important roles in arable cropping systems, contributing to nutrient cycling, organic matter formation and decomposition, soil structure formation, and water infiltration (Edwards, 2004; Keith and Robinson, 2012). Their presence in agroecosystems can increase crop yields by $25 \%$ (van Groenigen et al., 2014). It is well known that earthworms are affected by several environmental filters, which constrain the earthworm species pool found in particular habitats (Decaëns et al., 2008). Examples of environmental filters acting on earthworm communities are soil properties (e.g., soil moisture, organic matter, texture and $\mathrm{pH}$ (Curry, 2004)) and agricultural management practices (e.g., tillage (Chan, 2001), pesticide application (Pelosi et al., 2014) and organic matter management (Curry and Schmidt, 2007)).

In general, agricultural intensification negatively affects earthworm communities (PostmaBlaauw et al., 2010). Although agricultural intensification occurs across spatial scales from the field to the landscape (Ettema and Wardle, 2002), landscape effects on earthworm communities have hardly been studied. Landscape-scale agro-intensification refers to the ongoing loss of (semi-) natural area, the increasing surface area for agricultural production, and consequently the homogenization of landscapes. In an attempt to reverse the effects of intensification, agroenvironment measures are being implemented in Europe (EU-Commission, 2005). These measures are partly focussed on enhancing biodiversity in agricultural landscapes, and partly on promoting alternative management practices at the field and farm scale, e.g., crop diversification and restoration of non-productive landscape elements on farm, such as field margins (EUCommission, 2005). To better understand the effects of (de)intensification of agriculture, both farm management practices and landscape characteristics need to be considered (e.g., Tscharntke et al., 2005). Most studies that considered landscape effects on earthworm communities in arable fields focussed on the relevance of (semi-)permanent field margins as potential sources for earthworm colonization of arable fields (e.g., Crittenden et al., 2015; Roarty and Schmidt, 2013; Smith et al., 2008, but see Flohre et al., 2011 and Lüscher et al., 2014 for larger scale effects). Semi-permanent field margins are edges of arable fields that have been converted and restored to non-crop area, e.g. strips sown with grass(-herb) mixtures. They are subject to a lower frequency and intensity of soil disturbance. To our knowledge, environmental filters, such as soil properties, management practices and surrounding landscape, affecting earthworm communities 
of arable fields and field margins have scarcely been studied collectively. Given the fact that fields and margins neighbour each other spatially, but strongly differ in frequency, type and intensity of disturbance, quantifying effects of environmental filters on earthworm communities of these habitats may help to support management and spatial planning at farm and landscape scales to enhance soil biodiversity (Bianchi et al., 2013).

The objectives of this study were two-fold. First, earthworm communities were compared between arable fields (hereafter named "fields") and semi-permanent field margins (hereafter named "margins") with different spatial configurations (fields had margins present or not). Second, the relative contribution of the environmental filters, soil properties (hereafter named "soil"), management practices (hereafter named "management") and composition of the surrounding landscape up to $500 \mathrm{~m}$ radius (hereafter named "landscape"), on earthworm communities of fields and margins was quantified. We hypothesized that earthworm density, species richness, and biomass would be lower in fields than margins, but not between fields with and without a margin. Furthermore, we hypothesized that earthworm communities would differ between margins and fields, but not between fields with and without a margin. We did not expect differences between fields with and without margins, because previous studies only showed limited spill-over effects of earthworms from margins to fields (e.g., Crittenden et al., 2015; Roarty and Schmidt, 2013; Smith et al., 2008). Our third hypothesis was that a higher proportion of nearby non-arable surface area would contribute to more diverse earthworm communities in margins, and not in fields. It was thus hypothesized that for fields, landscape effects would be overshadowed by management practices, because of an expected large effect of managementassociated periodic disturbance (physical, chemical and biological) on earthworms.

\subsection{Materials and methods}

\subsubsection{Study area}

Our study was carried out in the Hoeksche Waard, in the south-western part of The Netherlands. The region, with a surface area of about $324 \mathrm{~km}^{2}$ comprises a set of polders, progressively reclaimed from the sea since the $15^{\text {th }}$ century, and is dominated by prime agricultural soils for arable cropping, mostly potato, sugar beet and wheat (Crittenden et al., 2015). Soils are hydromorphic calcareous sandy loam to clay formed in marine sediments (de Bakker and 
Schelling, 1966). Daily average temperature is $10.8{ }^{\circ} \mathrm{C}$ and annual precipitation is $883 \mathrm{~mm}$ (Royal Netherlands Meteorological Institute). The region is also characterized by a large network of margins $(>400 \mathrm{~km})$ including annual flower strips and semi-permanent grass or grass-herb mixtures.

\subsubsection{Sampling design and methods}

Farm selection was aimed at an even geographic representation over the Hoeksche Waard, and was dependent on farmers' willingness to participate in the project. Twenty-six fields and 15 margins were sampled across a total of 15 farms. All fields had been under crop production for at least 25 years, and had been cultivated to winter wheat in the year of sampling. Thirteen of the 26 fields had margins, in which sampling was conducted. In addition, there were two margins sampled where the associated field was not sampled because they did not have winter wheat at the time. Sampling was done in September and October 2012, after harvest and before tillage in the arable fields. At the time of sampling, fields were covered with either wheat stubble and residue, or with a green manure of Lolium grasses or radish (Raphanus sativus subsp. oleiferus). Sampled margins had been sown with perennial grasses or mixtures of herbs and grasses between 2000 and 2010 and did not undergo soil disturbance since then. Grass(-herb) margins established later than 2010 were excluded from this study, as the time between the last ploughing event and our sampling campaign was considered too short; additionally, margins sown with annual flowers were also excluded from this study because they are ploughed and re-sown every year.

In each field, six earthworm samples were taken within a $10 \mathrm{~m}$ radius. The center of the circle was at about $40 \mathrm{~m}$ from the edge of the field or the margin, when present. In the margins, four earthworm samples were taken along the margin, $20 \mathrm{~m}$ apart. The center of the sampling areas was georeferenced to allow for further spatial analyses.

Earthworm sampling was done using the methodology described by van Vliet and de Goede (2006): a soil monolith of $20 \times 20 \times 20 \mathrm{~cm}$ was dug out and hand-sorted for earthworms, followed by the application of 0.51 of $0.2 \%$ formaldehyde solution onto the bottom of the pit, to expel burrowing anecic earthworms. Each sample of earthworms was weighed the same day upon extraction, and subsequently stored in $70 \%$ alcohol until identification. Biomass was 
measured taking into account not only whole individuals, but also pieces, heads and tails. However, only intact individuals or heads were considered for identification, and consequent quantifications of species richness, density and composition. Adult and juvenile individuals were identified using Sims and Gerard (1999) and Stöp-Bowitz (1969), respectively; $0.2 \%$ of the intact individuals could not be identified and were therefore excluded from data analysis.

Around each earthworm sampling pit, five soil cores were taken to a depth of $20 \mathrm{~cm}$ and pooled into one composite soil sample per sampling location. Samples were analysed for $\mathrm{pH}-\mathrm{H} 2 \mathrm{O}$ with a volume ratio soil:water of 1:5, and texture using laser diffraction (Buurman et al., 2001). Total nitrogen and carbon were analysed by the Stable Isotope Facility of UC Davis with a PDZ Europa ANCA-GLS elemental analyser (Sercon Ltd, Crewe, Cheshire, UK) after removal of inorganic C using the acid fumigation method (Harris et al., 2001). Soil moisture content at the time of sampling was measured gravimetrically after $24 \mathrm{~h}$ at $105^{\circ} \mathrm{C}$. For details regarding soil properties, see Tables A2.1 (with detailed explanations), A2.2 and A2.3 (with summary statistics of the explanatory variables of fields and margins, respectively) of Appendix 2A.

\subsubsection{Management}

Farmers were interviewed using standardized questionnaires about the management of the sampled fields and margins, with focus on the last rotation cycle from 2009 to 2012. Farmers were asked about the main and cover crops that were cultivated, tillage operations, crop residue management, pesticide types and number of applications, as well as types and amounts of mineral fertilizers and manure applications. A detailed description of the management-related variables of arable fields is provided in Table A2.1 of Appendix 2A, and summary statistics in Table A2.2 of Appendix 2A.

Regarding the margins, farmers were asked to provide information about the year of establishment, the sown mixture type (grass $v s$. grass-herb mixtures), the mowing frequency and whether the mown material was removed from the soil surface or not (Table A2.3 of Appendix 2A). 


\subsubsection{Landscape}

The surrounding landscape of the sampling locations in fields and margins was examined for the area corresponding to circles of four radii $(50,100,250$, and $500 \mathrm{~m})$. Our main focus was on land-use types where earthworms can potentially occur (hereafter named "inhabitable landuses"): arable land, deciduous forests, productive and semi-natural grasslands, orchards, unpaved infrastructures, cemeteries, and grass and flower field margins. Landscape was characterized in terms of relative surface area and diversity of land use types. Relative surface area was calculated based on the proportion of arable land within each radius, whereas diversity was quantified using the Shannon diversity index of the inhabitable land-uses excluding arable land surface (Tables A2.1 to A2.3 of Appendix 2A). Arable land was excluded when computing the Shannon diversity index to eliminate the high correlations between the surface area and landscape diversity metrics (Fischer et al., 2011).

Official PDOK-TOP10 topographic maps (scale of 1:10000), were complemented by GIS maps of grass and flower margins, provided by the Waterboard "Hollandse Delta". After transforming linear elements of the TOP10 maps to polygons, each land-use surface area was quantified for the four considered radii. Analysis was done using the BUFFER tool in ArcGIS 10.2.1 (ESRI Inc. Redlands, California). Margins were manually transformed to polygons a posteriori by multiplying their length by $3 \mathrm{~m}$, which is the usual width of margins in the region. Subsequently, the estimated surface area of margins was subtracted from the surface of arable land.

\subsubsection{Data analysis}

\section{$\underline{\text { Univariate analysis }}$}

To compare species richness among margins and fields with and without margins, sample- and individual-based rarefaction curves (Fig. B2.1 of Appendix 2B) were computed. Species richness among different habitats is only meaningfully comparable when a clear asymptote for each curve is reached (Gotelli and Colwell, 2001). Furthermore, because species richness increases with sample size, it can only be compared when the sample size among the habitats is equal. Rarefying species richness removes the effects of varying sample size by standardizing richness through interpolation of a sample to a smaller number of individuals, usually the total abundance of the least abundant site (Gotelli and Colwell, 2001). We rarefied earthworms to 25 individuals, 
which was the lowest total number of individuals collected in any of the habitats considered in this dataset. Differences in earthworm density, biomass and rarefied species richness (RFSR) among margins and fields with and without margins were analysed with linear models. Observed species richness (SR), based on true counts, was analysed with generalized linear models (GLM), with a Poisson distribution and a log link function. Density and biomass were expressed as number of individuals or biomass per meter square, while SR was calculated on a margin or field basis (i.e., the four or six subsamples taken in margins or fields, respectively, were pooled per site). Differences between margins and fields with and without margins were assessed with Ftests for the linear models and $\mathrm{X}^{2}$-tests for the GLM. Pairwise comparisons were computed when the overall models were statistically significant, but due to the low number of comparisons (three, in total), p-value adjustments to avoid inflation of type I error were considered unnecessary. Model residuals were inspected visually to validate distribution and variance assumptions (Zuur et al., 2009), and when the assumption of variance homogeneity was violated among treatments, a variance structure was used to allow different variance in each habitat type (Zuur et al., 2009).

\section{$\underline{\text { Multivariate analysis }}$}

Earthworm community composition differences between fields with and without margins, and between fields and margins were tested by redundancy analysis (RDA), after $\log (\mathrm{x}+1)$ transformation of the abundance data per unit of area $\left(\mathrm{m}^{2}\right)$ (ter Braak and Šmilauer, 2014) where margins and fields with and without margins were used as nominal explanatory variables. Pairwise comparisons among fields with and without margins, and margins were computed and model significance was assessed by Monte Carlo permutation tests (999 permutations, $\mathrm{p}<0.05$ ). Further statistical analysis considering the relationships between environmental filters (soil, management and landscape) and earthworm community composition was conducted separately for fields and margins, because their management-related explanatory variables were different (Tables A2.2 and A2.3 of Appendix A). Furthermore, fields with and without margins were pooled, since no significant differences were found in earthworm community composition between the differently configured fields (see section 2.3.1). The effects of the three environmental filters on earthworm community composition were tested using a 2-step approach. 
First, we estimated the most parsimonious model explaining earthworm community composition for each individual filter resulting in three models per habitat, hereafter named "separate RDA's". Second, we constructed an RDA model combining the "separate RDA's" resulting in one overall model per habitat, hereafter named "combined RDA". Explanatory variables showing strong collinearity in each of the separate RDA's were identified by calculating variance inflation factors (VIF). One by one, variables with VIF $>10$ were withdrawn from the model, starting with the variable with the highest VIF (Borcard et al., 2011; Zuur et al., 2009) (Tables A2.2 and A2.3 of Appendix 2A). Forward selection was then used to obtain the most parsimonious separate RDA's for each filter. Parsimony was achieved by applying the doublestopping criterion (Blanchet et al., 2008), i.e. alpha significance level and adjusted $\mathrm{r}^{2}$ of the separate RDA's. In the second step of the approach, to obtain the combined RDA for each habitat, the forward selection procedure was applied on all explanatory variables that were included in the parsimonious separate RDA's, which were subsequently tested for significance with 999 Monte Carlo permutation tests $(\mathrm{p}<0.05)$. To quantify the relative contribution of each filter to earthworm community composition of fields and margins, variation partitioning was computed. The proportion of variation of earthworm community composition due to each of the filters was quantified with adjusted $\mathrm{r}^{2}$ and tested for statistical significance using Monte Carlo permutation tests (999 permutations, $\mathrm{p}<0.05$ ) (Borcard et al., 2011). All analyses were performed with R 3.2.2 ( $\mathrm{R}$ Core Team, 2014), using packages nlme 3.1-128, vegan 2.3-2, biodiversityR 2.7.1 and packfor $0.0-8$.

\subsection{Results}

\subsubsection{Earthworm community metrics in fields and margins}

In total eleven species of earthworms were found. Fields hosted a total of nine and margins harboured ten species (Table 2.1). Neither earthworm total density $(F=1.172, p=0.193)$, biomass $(F=1.172, p=0.321)$, nor SR-species richness $\left(X^{2}=2.607, p=0.272\right)$ showed statistically significant differences between fields and margins, irrespective of the presence of a margin. The RFSR-species richness overall model, on the other hand, revealed significant differences $(F=4.8685, p=0.013)$, where RFSR was higher in margins than in fields both with and without margins $(\mathrm{p}<0.05)$ (Table 2.1). RDA of earthworm composition constrained by 
habitat (i.e. margins and fields with and without margins) separated margins from fields along the first RDA axis (overall model: adjusted $r^{2}=9.5 \%, p=0.001$, Fig. 2.1). The presence of margins adjacent to the fields did not affect earthworm species composition in fields $(p=0.104)$, whereas there was a significant difference in earthworm composition between margins and fields $(\mathrm{p}<0.05)$. In fields, the most abundant species were Aporrectodea caliginosa (Savigny, 1826), Aporrectodea rosea (Savigny, 1826), Lumbricus rubellus (Hoffmeister, 1843) and Allolobophora chlorotica (Savigny, 1826). In margins A. caliginosa, Lumbricus castaneus (Savigny, 1826) and A. rosea were dominant, whereas Aporrectodea limicola (Michaelsen, 1900), L. rubellus, A. chlorotica and Lumbricus terrestris (Linné, 1758) occurred relatively frequently. The least abundant species in fields were Murchieona minuscula (Rosa, 1906), L. terrestris, Eiseniella tetraedra (Savigny, 1826), A. limicola and L. castaneus (all less than 10 individuals $\mathrm{m}^{-2}$ ), and Aporrectodea longa (Ude, 1885) and Satchellius mammalis (Savigny, 1826) were not found in this habitat. In margins, the least abundant species were M. minuscula, S. mammalis and A. longa (all less than 10 individuals $\mathrm{m}^{-2}$ ), and from the pool of sampled species only E. tetraedra was not detected in this habitat (Table 2.1). 
Table 2.1 Earthworm species density (ind. $\left.\mathrm{m}^{-2}\right)$, total earthworm density (ind. $\mathrm{m}^{-2}$ ) and biomass $\left(\mathrm{g} \mathrm{m}^{-2}\right)$, and actual (SR) and rarefied (RFSR) species richness in fields with and without margins and in margins. Mean, standard errors (SE) and frequency of occurrence (Freq) are given.

\begin{tabular}{|c|c|c|c|c|c|c|c|c|c|}
\hline \multirow{3}{*}{ Species } & \multicolumn{6}{|c|}{ Fields } & \multicolumn{3}{|c|}{ Margins } \\
\hline & \multicolumn{3}{|c|}{$\begin{array}{l}\text { with margins } \\
\qquad(n=13)\end{array}$} & \multicolumn{3}{|c|}{$\begin{array}{c}\text { without margins } \\
\qquad(\mathrm{n}=13)\end{array}$} & \multicolumn{3}{|c|}{$(n=15)$} \\
\hline & Mean & SE & Freq & Mean & SE & Freq & Mean & SE & Freq \\
\hline A. caliginosa & 238.1 & 31.7 & 13 & 220.5 & 29.0 & 13 & 246.7 & 76.5 & 15 \\
\hline A. chlorotica & 45.2 & 19.7 & 8 & 3.8 & 3.5 & 2 & 35.8 & 13.8 & 8 \\
\hline A. rosea & 64.7 & 22.1 & 12 & 43.9 & 10.5 & 12 & 52.5 & 16.9 & 13 \\
\hline A. limicola & 7.7 & 7.7 & 1 & 1.0 & 0.5 & 3 & 43.3 & 23.0 & 6 \\
\hline M. minuscula & 0.3 & 0.3 & 1 & 0.6 & 0.6 & 1 & 0.4 & 0.4 & 1 \\
\hline A. longa & 0.0 & 0.0 & 0 & 0.0 & 0.0 & 0 & 9.2 & 6.5 & 3 \\
\hline L. terrestris & 3.5 & 1.8 & 4 & 1.0 & 0.7 & 2 & 31.7 & 12.3 & 9 \\
\hline E. tetraedra & 3.2 & 1.4 & 6 & 1.6 & 1.3 & 2 & 0.0 & 0.0 & 0 \\
\hline L. rubellus & 42.0 & 11.3 & 10 & 57.4 & 18.2 & 11 & 37.5 & 11.8 & 12 \\
\hline L. castaneus & 8.0 & 3.5 & 9 & 7.1 & 2.3 & 7 & 77.9 & 28.4 & 13 \\
\hline S. mammalis & 0.0 & 0.0 & 0 & 0.0 & 0.0 & 0 & 5.0 & 5.0 & 1 \\
\hline Total density & 414.1 NS & 51.2 & - & 336.9 NS & 42.2 & - & $541.3 \mathrm{NS}$ & 115.3 & - \\
\hline Total biomass & $62.3 \mathrm{NS}$ & 8.8 & - & $60.8 \mathrm{NS}$ & 7.6 & - & $96.3 \mathrm{NS}$ & 22.1 & - \\
\hline SR & $4.9 \mathrm{NS}$ & 0.3 & - & 4.1 NS & 0.4 & - & $5.4 \mathrm{NS}$ & 0.4 & - \\
\hline RFSR & $3.7 \mathrm{~B}$ & 0.3 & - & $3.4 \mathrm{~B}$ & 0.2 & - & $4.5 \mathrm{~A}$ & 0.3 & - \\
\hline
\end{tabular}

$\mathrm{SR}=$ actual number of observed species; $\mathrm{RFSR}=$ species richness based on rarefaction (rarefied to 25 individuals).

Letters indicate significant habitat type differences at $p<0.05$, NS: not significant. 


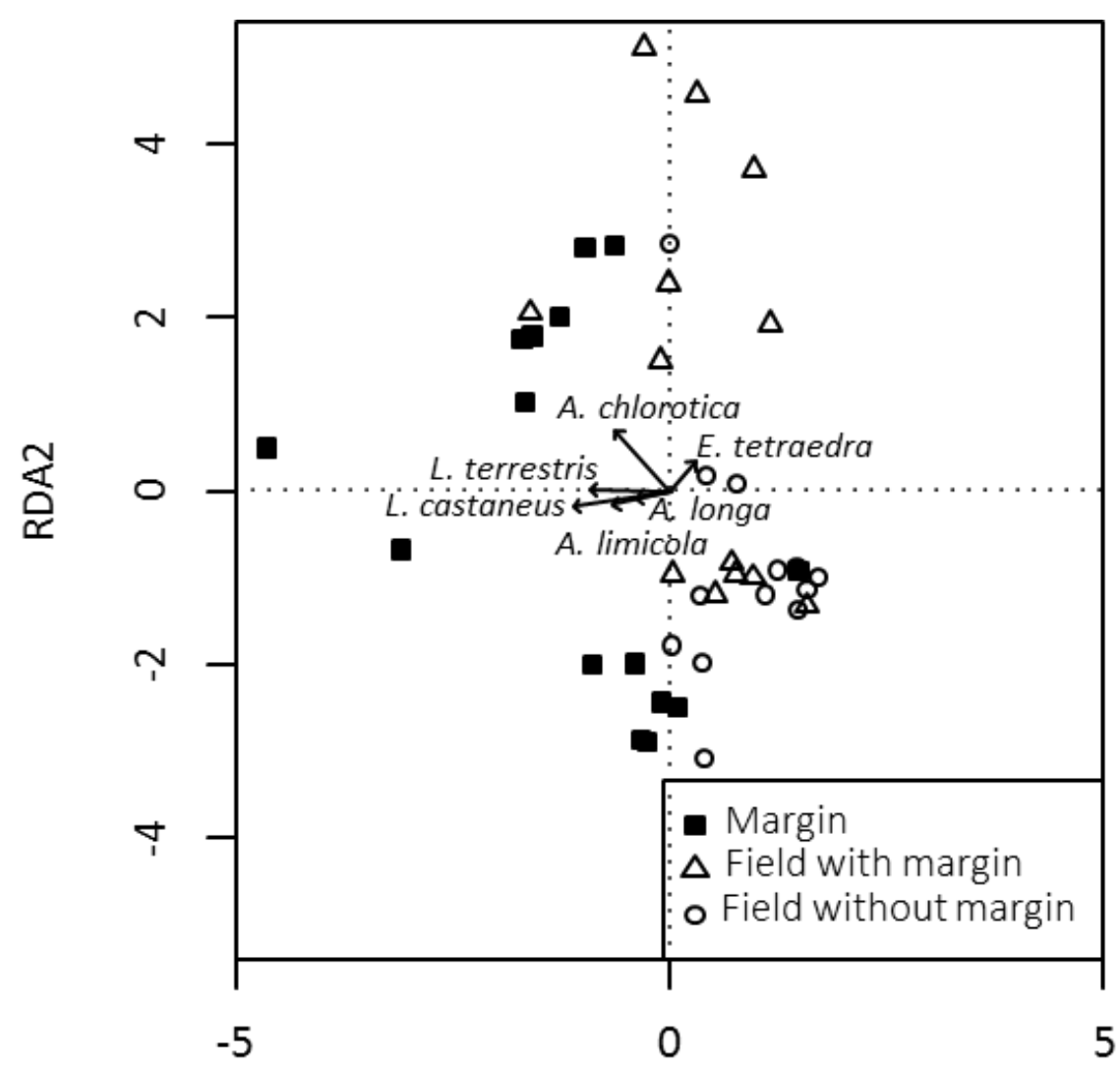

RDA1

Figure 2.1 Biplot of RDA of total earthworm species density using the sampled habitats as constraints $(\mathrm{p}=$ 0.001, 999 Monte Carlo permutations). Adjusted $r^{2}$ is $9.5 \%$, the first RDA axis explains $11.6 \%$ of the constrained variance $(p=0.001)$ and the second axis $2.5 \%(p=0.364)$. The first PCA axis explains $22.8 \%$ of the variance. Species whose variation explained by the constraints was smaller than $10 \%$ were excluded from the plot. Scaling based on species correlations.

\subsubsection{Effects of environmental filters on earthworm communities in arable fields}

In fields, only the variables representing the environmental filters management and soil explained a statistically significant part of the variation in community composition when considering RDA models for each filter separately (separate RDA models; Table 2.2). The management related variables, i.e. applications of herbicides (adjusted $r^{2}=12 \%, p=0.001$ ), fungicides (adjusted $r^{2}=8 \%, p=0.002$ ), and insecticides (adjusted $r^{2}=6 \%, p=0.012$ ), cumulatively explained $26 \%(\mathrm{p}=0.001)$ of the variation in species composition. For soil (cumulative adjusted $r^{2}=4 \%, p=0.042$ ) only clay content was selected (Table 2.2). In the 
subsequent RDA model that combined the separate models of all previously selected variables (combined RDA model), the variation explained by clay content became negligible (Table 2.2). Most earthworm species were at least weakly negatively associated with the number of applications of insecticides and/or herbicides in 2012 (Fig. 2.2). The only positive association found was an increase in density of $L$. rubellus with fungicide application rate. In particular, $A$. chlorotica, E. tetraedra and L. castaneus showed strong negative correlations with the number of herbicide applications, and A. limicola and L. castaneus with the number of insecticide applications.

Table 2.2 Percentage of variance explained (adjusted $\mathrm{r}^{2}$ ) and $\mathrm{p}$-values from Monte Carlo permutations in earthworm species abundance data from fields for separate RDA models per environmental filter and the combined RDA model combining all statistically significant relationships within the three filters.

Environmental filter

Separate RDA

Adj. $\mathbf{r}^{2} \quad p$-value

\section{Soil}

Clay

Management

Insecticide

Herbicide

Fungicide

Landscape
$4.3 \%$

0.042

$6.0 \% \quad 0.012$

$11.8 \% \quad 0.001$

$8.5 \%$

0.002

NS

\section{Combined RDA}

Adj. $\mathbf{r}^{2} \quad p$-value

NS

$6.0 \% \quad 0.012$

$11.8 \% \quad 0.001$

$8.5 \% \quad 0.002$

NS

NS: not significant. 


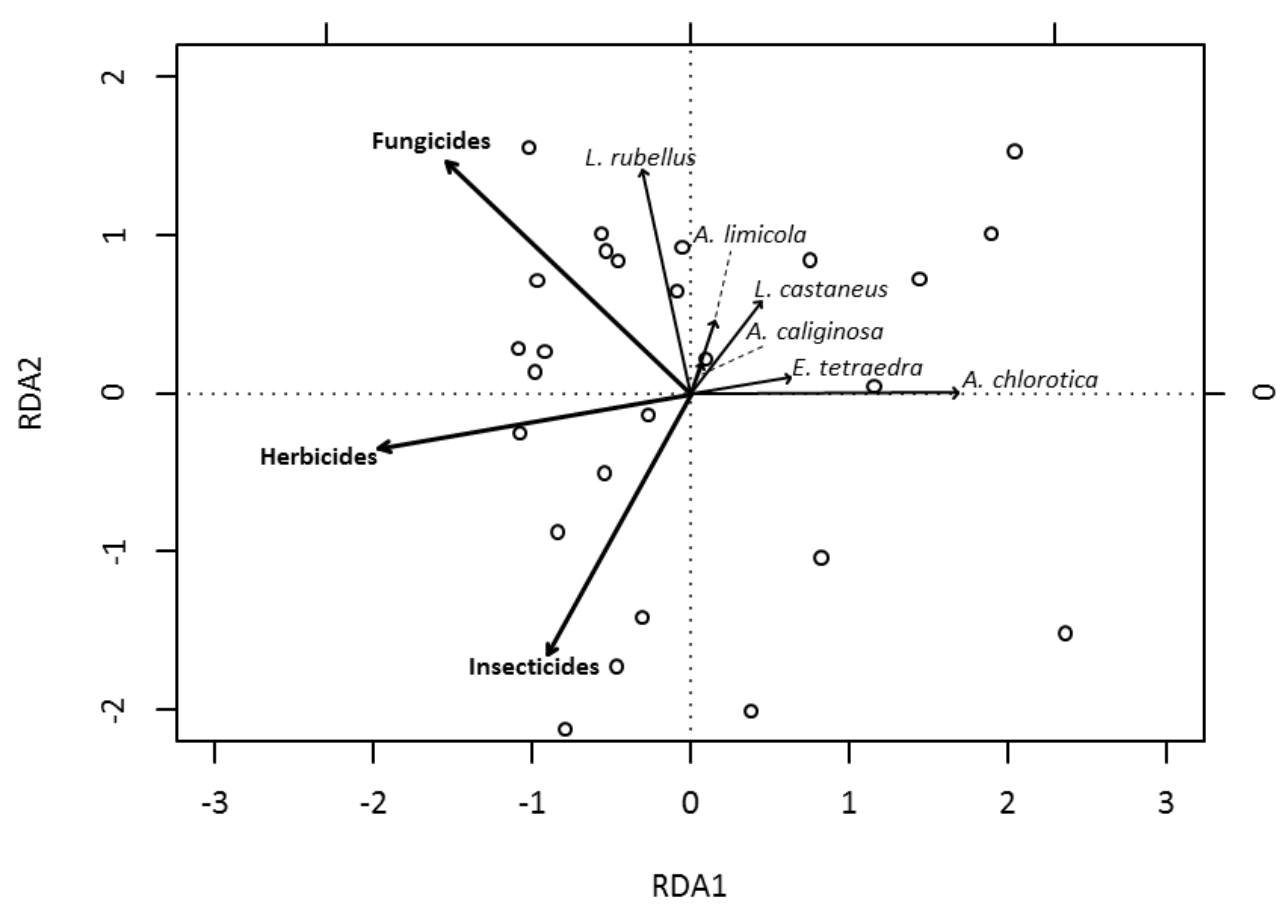

Figure 2.2 Biplot of the combined RDA model explaining 26\% (adjusted $\mathrm{r}^{2}$ ) of the variance in earthworm species abundance in fields using explanatory variables selected by forward selection as constraints. Open circles represent fields. The first and second RDA axes explain $20 \%$ and $14 \%$ of the constrained variance $(p=0.001,999$ permutations), respectively. Species whose variation explained by the constraints was smaller than $10 \%$ were excluded from the plot. Scaling based on species correlations.

\subsubsection{Effects of environmental filters on earthworm communities in field margins}

The variables representing the three environmental filters (landscape, management and soil) significantly explained part of the variation in community composition of the margins (Table 2.3). Within the separate RDA model for management, age of margin (adjusted $r^{2}=14 \%, p=$ 0.004 ) and mowing frequency (adjusted $\mathrm{r}^{2}=10 \%, \mathrm{p}=0.017$ ) were selected (cumulative adjusted $r^{2}=24 \%, p=0.001$ ). The separate RDA model for the filter soil included $\mathrm{pH}$ (adjusted $\mathrm{r}^{2}=17 \%$, $\mathrm{p}=0.002$ ). In contrast to the fields, variables representing the filter landscape were selected in the separate RDA model: the proportion of arable area within a radius of $500 \mathrm{~m}$ explained $17 \%$ $(\mathrm{p}=0.003)$ of the variation in earthworm community composition (Table 2.3). All the variables in the separate RDA models for the three filters appeared also in the RDA model that combined all filters (Table 2.3). This combined RDA model explained 45\% $(\mathrm{p}=0.001)$ of the variation in the earthworm community composition. The earthworm species A. limicola, L. terrestris, A. chlorotica, A. longa and S. mammalis were positively associated with the age of the field margin 32 
(Fig. 2.3) and negatively correlated with $\mathrm{pH}$ and surface area occupied by arable fields within a radius of $500 \mathrm{~m}$. The species L. castaneus, L. rubellus, A. rosea, A. caliginosa, and to a smaller extent M. minuscula, correlated negatively to mowing frequency of the margins.

Table 2.3 Percentage of variance explained (adjusted $\mathrm{r}^{2}$ ) and $\mathrm{p}$-values from Monte Carlo permutations in earthworm species abundance data from margins for separate RDA models per environmental filter and the combined RDA model combining all statistically significant relationships within the three filters.

\begin{tabular}{lcccc} 
Environmental filter & \multicolumn{2}{c}{ Separate RDA } & \multicolumn{2}{c}{ Combined RDA } \\
& Adj. $\mathbf{r}^{\mathbf{2}}$ & p-value & Adj. $\mathbf{r}^{\mathbf{2}}$ & p-value \\
\hline $\begin{array}{l}\text { Soil } \\
\mathrm{pH}\end{array}$ & $16.8 \%$ & 0.002 & $16.8 \%$ & 0.002 \\
$\begin{array}{l}\text { Management } \\
\text { Age of margin in 2012 }\end{array}$ & $14.0 \%$ & 0.004 & $7.6 \%$ & 0.011 \\
$\begin{array}{l}\text { Mowing frequency } \\
\text { Landscape }\end{array}$ & $10.0 \%$ & 0.017 & $10.7 \%$ & 0.006 \\
$\begin{array}{l}\text { Arable area within a radius } \\
\text { of 500 m }\end{array}$ & $16.7 \%$ & 0.003 & $10.1 \%$ & 0.004 \\
\hline
\end{tabular}

\subsubsection{Variation partitioning of environmental filters}

Since the combined RDA model for the fields only comprised variables related to management (Table 2.2), variation partitioning among environmental filters was not necessary. In the case of margins, all three environmental filters were included in the combined RDA model (Table 2.3). Variation partitioning for the three environmental filters disclosed that the earthworm community variation in margins that could be uniquely attributed to the filter management $(18 \%$, $\mathrm{p}=0.001)$ was almost twice as large as the variation attributed to the filters soil or landscape $(10 \%$ and $11 \%$, respectively, $\mathrm{p}<0.05)$ (Table 2.4$)$. Only about $6 \%$ of the variation in earthworm community composition was shared between the three filters. 


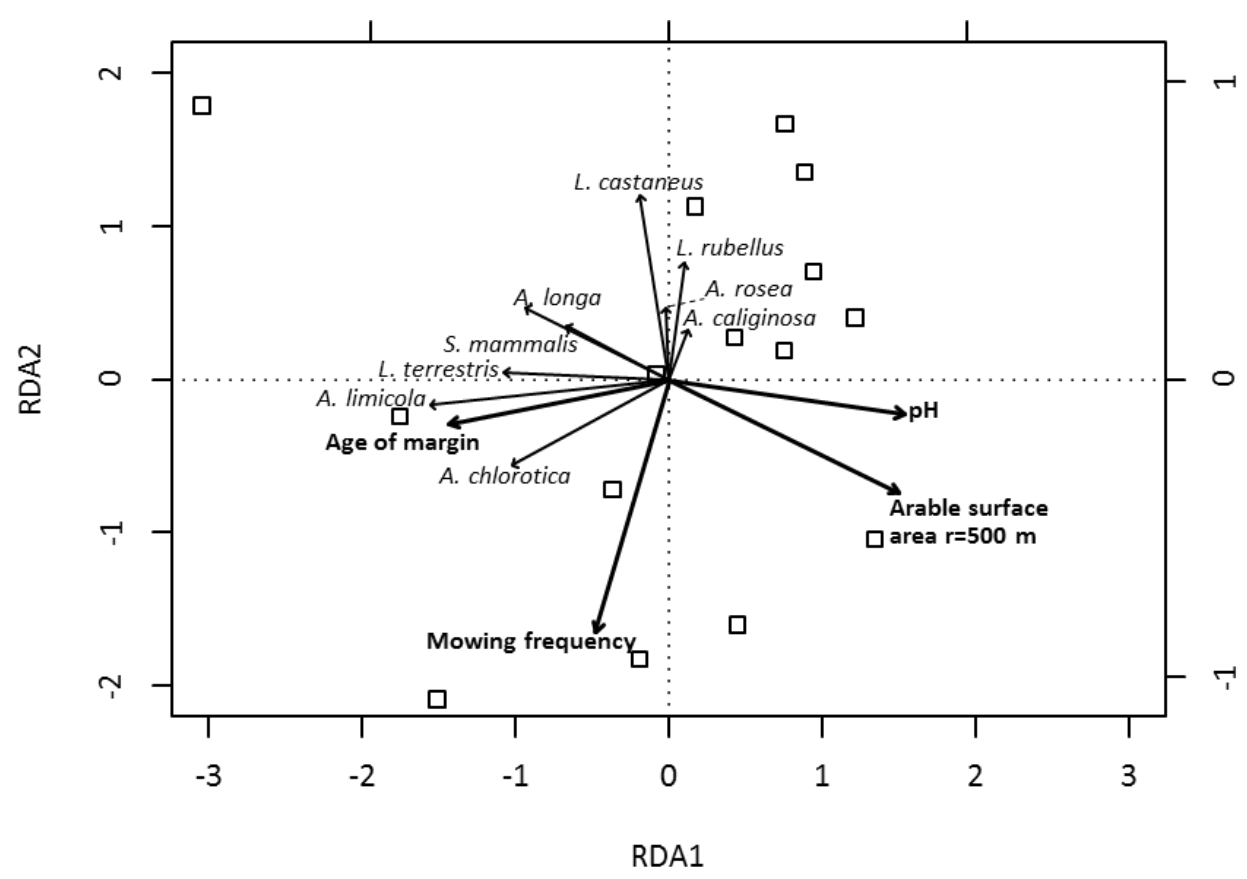

Figure 2.3 Biplot of the combined RDA model explaining 45\% (adjusted $\mathrm{r}^{2}$ ) of the variance in earthworm species abundance in margins using explanatory variables selected by forward selection as constraints. Open squares represent margins. The first and second RDA axes explain 32\% and 16\% of the constrained variance ( $p=0.001,999$ permutations), respectively. Species whose variation explained by the constraints was smaller than $10 \%$ were excluded from the plot. Scaling based on species correlations.

Table 2.4 Partitioning (partial RDA) of the variation in earthworm density data by the environmental filters, soil properties, management practices and surrounding landscape for earthworm communities in fields and margins.

\section{Variation partitioning}

\section{FIELDS}

Soil

Management

Landscape

\section{MARGINS}

Soil

Management

Landscape (500 m)

NS: not significant

\section{Total contribution}

Adj. $\mathbf{r}^{2}$

Unique contribution

Adj. $\mathbf{r}^{2} \quad p$-value

$\begin{array}{llll}- & \text { NS } & - & \text { NS } \\ 26.2 \% & 0.001 & 26.2 \% & 0.001 \\ - & \text { NS } & - & \text { NS }\end{array}$




\subsection{Discussion}

\subsubsection{Density, biomass, species richness and composition of earthworms}

The earthworm species pool found during this study was comparable to that of other studies in Dutch polders (Crittenden et al., 2014; Crittenden et al., 2015), as well as in other countries of north-western Europe (Ernst and Emmerling, 2009; Ernst et al., 2009; Nieminen et al., 2011). However, earthworm density, biomass and species richness were generally higher than reported in those studies, both in fields and in margins. In accordance with Crittenden et al. (2015), de Oliveira et al. (2012) and Nieminen et al. (2011), the endogeic species A. caliginosa was the dominant species, accounting for $46 \%$ of the total density in margins and $57 \%$ and $65 \%$ in fields with and without margins, respectively. Anecic species (L. terrestris and A. longa) were mostly found in the margins. Their densities in fields were considerably lower, probably due to mechanical soil disturbance and limited food availability (Chan, 2001; van Capelle et al., 2012). Also epigeic species were mostly found in margins, with the exception of L. rubellus, which occurred at comparable densities in margins and fields. Anecic and epigeic earthworms feed on organic matter at the soil surface (Bouché, 1977), which is likely more available in margins than in fields (Chan, 2001; van Capelle et al., 2012), and additionally, soil disturbance is lower in margins than in the annually ploughed fields. Of all encountered epigeic species, L. rubellus has the highest fecundity (up to 106 cocoons produced per year (Edwards and Bohlen, 1996)), and the resulting potential for population recovery may account for its similar densities across fields and margins. Despite dissimilarities in species distribution among the different habitats, we could not detect significant differences in earthworm total density, biomass and SR-species richness, which partially contradicted our first hypothesis. However, earthworm RFSR-species richness was higher in margins than in fields, and no differences were found between fields with and without margins, which is in partial agreement with our first hypothesis. This indicates that fields have a lower richness than margins. On the other hand, the steeper rarefaction curves of the fields compared to the ones of the margins indicate that earthworm communities of the fields are more even than those of the margins (Olszewski, 2004). Considering this, it is very relevant, though unfortunately rare in earthworm ecology studies, to include rarefaction computations when evaluating land-use and management effects on earthworm communities. Our finding of differences in earthworm community composition between margins and fields, but not between 
fields with and without margins, agrees with previous findings. Smith et al. (2008) also studied earthworm densities in margins and fields with and without margins and concluded that the presence of margins, whilst harbouring higher densities, had no spill-over effect to the adjacent field. Likewise, Crittenden et al. (2015) and Roarty and Schmidt (2013) observed no increase in earthworm density in conventionally tilled fields with decreasing distance to the margin. The latter study, however, did show that the establishment of new, uncultivated margins in between the arable fields and the already existing permanent margins resulted in similar earthworm populations in old and new margins within three years. This indicates either a spill-over effect from the permanent to the newly created margins, or that the local earthworm populations did have the chance to develop to abundances comparable to the ones in the existing permanent margins. Evidence so far suggests that margins contribute to increased earthworm biodiversity in arable landscapes, but have little influence on earthworm communities in the fields as long as these are intensively cultivated.

\subsubsection{Effects of environmental filters}

Variation partitioning allowed testing for the relative contribution of the three environmental filters, i.e. soil, management and landscape, on earthworm communities in margins and fields. Overall our results suggested that earthworm communities were affected by environmental filters operating at different spatial scales and that the effects depended on habitat disturbance. These findings are in line with those of Decaëns et al. (2008), who acknowledged that the earthworm species pool found in a particular habitat is constrained by a set of abiotic factors inherent to the land-use under focus (broad habitat and land-use constraints as referred by Decaëns et al. (2008)). For fields, management was the most important filter, and neither soil nor the landscape at any radius played a substantial role in earthworm species sorting (Table 2.4). Our results are partly in line with those of Lüscher et al. (2014) who did not find any effects of the surrounding landscape on earthworm composition of fields. However, in contrast to our findings, those authors could not demonstrate any relationship between earthworm community composition and management-related variables, either.

With respect to the margins, earthworm community composition was influenced by all three filters, where management-related variables were the most important in constraining earthworm 
species assemblages, followed ex aequo by the composition of the landscape within a radius of $500 \mathrm{~m}$, and soil properties.

\section{$\underline{\text { Soil }}$}

Although soil texture, organic matter, moisture and $\mathrm{pH}$ are well known to affect earthworms (Curry, 2004), these soil properties did not contribute to the explained variation between earthworm communities in the fields of this study area. Our research area is rather homogeneous in terms of soil texture, has dominantly been managed for crop production, and the sampled arable fields differed little in soil properties. The limited variation in soil properties was therefore likely to have only a small influence on earthworm community variation. However, in margins, $\mathrm{pH}$ contributed significantly to explaining variation in earthworm community composition (Table 2.3), even though variation in $\mathrm{pH}$ was relatively small. All species abundances in the margins decreased with increasing $\mathrm{pH}$, which in turn decreased with margin age (Fig. 2.3). The effect on earthworms was not necessarily caused by differences in $\mathrm{pH}$ per se, but rather by margin ageing, since time without disturbance would allow the establishment and development of earthworm communities.

\section{Management}

With respect to management of fields, we found that variables associated with the use of pesticides (fungicides, herbicides and insecticides) explained a large part of the variation (26\%) in earthworm community composition (Tables $2.2,2.4$ ). Not unexpectedly, increased application frequencies had a negative effect on the abundance of most species in fields (Fig. 2.2) (Baveco and de Roos, 1996). Pelosi et al. (2013b, 2014) found these three groups of pesticides to negatively affect earthworms, particularly for species living at the soil surface. For most of the species in the current research the results are in line with the observations of those authors. Only L. rubellus showed a positive correlation to the number of fungicide applications, possibly due to a competitive advantage for example for available food, combined with its relatively high population recovery rate (Edwards and Bohlen, 1996). It is also well known that earthworms are hampered by soil disturbance like tillage (Chan, 2001), or decreased food availability due to crop residue removal (Edwards and Bohlen, 1996), but that this effect is species dependent. 
Furthermore, the use of tuber crops within the crop rotation has been identified as negatively affecting earthworms, again due to the intensive soil disturbances during soil preparation and harvesting (Curry et al., 2002; Marinissen, 1994). However, in a study aiming at understanding how fast earthworm populations would recover from autumn ploughing, Crittenden et al. (2014) found populations to be similar to before ploughing by the following Spring. In our study, neither tillage, removal of crop residues, nor the use of tuber crops in the past were found to play a role in explaining the variation of earthworm composition in our data. In fact, the variation in crop rotations and crop management practices was relatively small across the farms in our research area, posing some limitations in terms of testing which crops or management practices could favour earthworm diversity in arable fields.

Among the management-related variables that explained variation in earthworm community composition in margins, age of margins (Fig. 2.3) positively affected long-lived species with low fecundity. For example L. terrestris, a species highly associated to older margins, can only produce up to 38 cocoons per year, reaching maturity after as much as 50 weeks (de Lange et al., 2013). Mowing frequency negatively affected the epigeic species found in margins (L. rubellus and L. castaneus), but had little influence on anecics (L. terrestris and A. longa). Both groups feed at the soil surface (Bouché, 1977), but the burrower L. terrestris is apparently less sensitive than the topsoil-dwelling L. rubellus and L. castaneus.

\section{Landscape}

In our study area, the landscape within a radius of $500 \mathrm{~m}$ proved to be the second most important filter in explaining earthworm community variation in margins (Table 2.4). So far, most studies have focussed on margins as a source for earthworm colonization into the fields (e.g., Crittenden et al., 2015; Roarty and Schmidt, 2013). The current study is, to our knowledge, the first attempt to quantify the relationships between the earthworm community composition of margins and soil properties, management practices and surrounding landscape together. The increase in proportion of arable area within a radius of $500 \mathrm{~m}$ revealed a negative effect on earthworm community composition in margins (Fig. 2.3), suggesting that inhabitable land-uses other than arable land could provide a source for more diverse earthworm communities, particularly for species like $A$. limicola, L. terrestris, A. chlorotica, A. longa and S. mammalis. Earthworm mobility and 
dispersal ability is considered to be limited. In earthworm-free arable land of young polders in the Netherlands, after introduction, L. rubellus and A. caliginosa dispersed only at rates of 14 and $7 \mathrm{~m} \mathrm{yr}^{-1}$, respectively (Marinissen and van den Bosch, 1992). Although slow, dispersal and therefore colonization can take place over the years (Eijsackers, 2011). Furthermore, passive dispersal by, e.g., tires of (agricultural) vehicles (Cameron and Bayne, 2014; Marinissen and van den Bosch, 1992), waterways and animals (e.g. birds) (Schwert, 1980) plays a role in earthworm movement. Although we can only speculate whether earthworm populations in the margins are a product of facilitated population development after the restoration of margins, colonization from inhabitable land-uses, or both, our data suggests that dispersal from inhabitable land-uses plays a role to some extent. As we do not have information about species composition in the surrounding habitats, their role as potential sources of earthworms into the margins remains to be investigated.

In accordance with our second hypothesis, the landscape did not explain variation in earthworm community composition in the fields at any of the studied radii. This is in agreement with the findings of Lüscher et al. (2014) who found no significant relationships between earthworm community composition of fields and characteristics of the surrounding landscape, although these authors only considered a radius of $250 \mathrm{~m}$. A plausible explanation for the lack of such effects of the surrounding landscape on earthworm communities in the case of fields could be the dominance of harsh management practices, e.g. disruption of earthworm burrows, soil compaction and water logging, pesticide application and removal or displacement of food through tillage, hampering the development of earthworm populations.

\subsection{Conclusions}

Our study clearly illustrated that although arable fields and field margins neighbour each other spatially, earthworm community composition of the two habitats was affected differently by the considered environmental filters (soil properties, management practices, and surrounding landscape). Regarding earthworm composition of arable fields, only management-related variables played a significant role, whereas for earthworm communities of field margins, all three filters were relevant. This suggests that management practices of arable fields overrule potential positive effects of the surrounding landscape and of soil properties on earthworm 
community diversity. The current growing awareness and policy-support for recovering a mosaic-like structure of arable landscapes includes restoration of semi-natural landscape elements, such as field margins. Although such elements could help promoting earthworm (re)colonization of arable fields, their re-establishment in arable landscapes will not be sufficient for restoring earthworm communities of arable fields, unless the impact of arable management practices is reduced.

\section{Acknowledgements}

We are thankful to the farmers who allowed us to sample their land and to the Foundation HWodKa (http://hwodka.nl/), which provided farmers contact information. We further thank students, student-assistants and technicians who helped in the field and in the lab, and in particular Tamas Salanki who identified the earthworms. This work is part of the research programme Biodiversiteit Werkt! with project number 841.11 .003 , financed by the Netherlands Organisation for Scientific Research (NWO). 


\section{Appendix 2A}

Table A2.1 Overview of the variables in each filter (soil properties, management practices and surrounding landscape) for fields.

\begin{tabular}{|c|c|}
\hline Variable & Explanation \\
\hline \multicolumn{2}{|l|}{ SOIL } \\
\hline (lay ${ }^{1)}$ & Percent of clay particles $(<2 \mu \mathrm{m})(\%)$ \\
\hline Silt ${ }^{1)}$ & Percent of silt particles $(>2 \mu \mathrm{m}$ and $<50 \mu \mathrm{m})(\%)$ \\
\hline Sand ${ }^{1)}$ & Percent of clay particles $(>50 \mu \mathrm{m})(\%)$ \\
\hline Organic carbon ${ }^{1)}$ & Carbon contents after removing $\mathrm{CaCO}_{3}\left(\mathrm{~g} \mathrm{C} \mathrm{Kg}^{-1}\right)$ \\
\hline Total Nitrogen ${ }^{1)}$ & Total Nitrogen contents $\left(\mathrm{g} \mathrm{N} \mathrm{Kg}^{-1}\right)$ \\
\hline $\mathrm{pH}^{1)}$ & Soil pH (in water) \\
\hline Soil moisture ${ }^{1)}$ & Gravimetric soil moisture content (\%) \\
\hline
\end{tabular}

\section{MANAGEMENT}

No. of pesticide applications in 2012

Total $^{2)}$

Insecticide $^{2)}$

Herbicide $^{2)}$

Fungicide ${ }^{2)}$

Growth regulator ${ }^{2)}$

\section{Inputs}

Nitrogen input (artificial fertilizer) $2012^{2)}$

Nitrogen input (manure) 2012 2)

Carbon input (manure) 2012 2)

Estimate organic matter from main crop residues $2012^{2), 3 \text { ) }}$

Estimate organic matter from main crop residues 2011-2012 2), 3)
No. of pesticide applications in 2012 (includes insecticide, herbicide, fungicide and growth regulator)

No. of insecticide applications in 2012

No. of herbicide applications in 2012

No. of fungicide applications in 2012

No. of growth regulator applications in 2012

Input of nitrogen due to the use of artificial fertilizers in $2012\left(\mathrm{Kg} \mathrm{N} \mathrm{ha}^{-1}\right)$

Input of nitrogen due to the use of manure as fertilizer in $2012\left(\mathrm{Kg} \mathrm{N} \mathrm{ha}^{-1}\right)$

Input of carbon due to the use of manure as fertilizer in $2012\left(\mathrm{Kg} \mathrm{C} \mathrm{ha}^{-1}\right)$

Estimate of fresh organic matter input due to residues of winter wheat in 2012 (takes into account whether winter wheat residues were removed or not) $\left(\mathrm{Kg} \mathrm{ha}^{-1}\right)$

Estimate of fresh organic matter input due to residues of winter wheat in 2012 (takes into account whether winter wheat residues were removed or not) added to the effective organic matter input due to residues of crop cultivated in $2011\left(\mathrm{Kg} \mathrm{ha}^{-1}\right)$ 
Table A2.1 (cont.)

\begin{tabular}{ll}
\hline Variable & Explanation \\
\hline $\begin{array}{l}\text { Estimate organic matter from } \\
\text { manure 2012 } 2), 3)\end{array}$ & $\begin{array}{l}\text { Estimate of fresh organic matter input due to manure } \\
\text { additions in } 2012\left(\mathrm{Kg} \mathrm{ha}^{-1}\right)\end{array}$ \\
$\begin{array}{l}\text { Estimate organic matter from } \\
\text { main and cover crops residues } \\
\text { and manure 2011-2012 } 2 \text { ), 3) }\end{array}$ & $\begin{array}{l}\text { Estimate of fresh organic matter input due to a) manure } \\
\text { additions in } 2012, \mathrm{~b}) \text { residues of winter wheat in } 2012 \\
\text { (takes into account whether winter wheat residues were } \\
\text { removed or not) added to the effective organic matter input } \\
\text { due to a) residues of crop cultivated in } 2011 ; \mathrm{b}) \text { residues of } \\
\text { cover crop cultivated in } 2011 \text { (if any) }\left(\mathrm{Kg} \mathrm{ha}^{-1}\right)\end{array}$ \\
\hline
\end{tabular}

Estimate organic matter from cover crop residues $2011^{2}$ ), 3)
Estimate of effective organic matter input due to residues of cover crop cultivated in 2011 (if any) $\left(\mathrm{Kg} \mathrm{ha}^{-1}\right)$

\section{Main crop}

Occurrence legume 2009-2012 2)

Occurrence tuber 2009-2012 2)

Occurrence grass 2009-2012 2)

Occurrence grain 2009-2012 2)

Crop 2011 (grain, tuber, other) $^{2)}$

\section{Cover crop}

Occurrence 2009-2012 (yes, no) 2)

Cover crop 2012 (grass, radish or none) ${ }^{2)}$

Occurrence legume 2009-2012 (yes, no) ${ }^{2)}$

Cover crop 2011 (radish or none) ${ }^{2)}$
Frequency of occurrence of legume cultivation between 2009 and 2012 (\%)

Frequency of occurrence of tuber crop cultivation between 2009 and 2012 (\%)

Frequency of occurrence of grass ley cultivation between 2009 and 2012 (\%)

Frequency of occurrence of grain crop cultivation between 2009 and 2012 (\%)

Main crop cultivated the year before sampling (other crop occurred twice and was onion or alfalfa)

Frequency of cover crop cultivation between 2009 and $2012(\%)$

Cover crop cultivated the year of sampling

Frequency of occurrence of legume cultivation as a cover crop between 2009 and 2012 (\%)

Cover crop cultivated the year before sampling (\%) 
Table A2.1 (cont.)

\begin{tabular}{l} 
Variable \\
\hline Residue management \\
Occurrence residue removal all \\
crops 2009-2012 (yes, no) \\
Occurrence residue removal \\
grain crops 2009-2012 (yes, no) \\
2)
\end{tabular}

Residue removal 2012 (yes, no) 2)

\section{Explanation}

Frequency of crop residues removal considering all types of crops between 2009 and 2012 (\%)

Frequency of crop residues removal considering only grain crops between 2009 and 2012 (\%)

Frequency of winter wheat crop residues removal in the year of sampling $(\%)$

\section{Tillage}

Occurrence reduced tillage

Frequency of occurrence of reduced tillage between 2008

2008-2011 (yes, no) ${ }^{2)}$ and 2011. Reduced tillage includes subsoiler, cultivator and paragrubber $(\%)$

Reduced tillage in 2011 (yes, Occurrence of reduced tillage the year of sampling (\%) no) ${ }^{2)}$

Tillage depth in $2011^{2)}$

Depth of tillage operations the year of sampling $(\mathrm{cm})$

\section{LANDSCAPE}

Arable area within a radius of $50,100,250$ or $500 \mathrm{~m}^{4), 5)}$ Shannon diversity index with earthworm inhabitable land-uses in a radius of $50,100,250$ or $500 \mathrm{~m}^{4), 5)}$
Proportion of arable area in a radius of 50, 100, 250 or 500 $\mathrm{m}(\%)$ Shannon diversity index with earthworm inhabitable landuses (deciduous forests, productive and semi-natural grasslands, orchards, unpaved infrastructures, cemeteries, and grass and flower margins) in a radius of 50, 100, 250 or $500 \mathrm{~m}$

1) Laboratory analysis

2) Standardized questionnaires and interviews to farmers

3) de Haan and van Geel (2013)

4) Flower and grass margins maps from Waterboard "Hollandse Delta"

5) Official TOP10 maps from PDOK 
Table A2.2 Summary of explanatory variables of the three investigated filters of earthworm communities in fields: soil properties, management practices and surrounding landscape. For detailed explanations see Table A2.1.

\begin{tabular}{|c|c|c|c|}
\hline Fields & Mean \pm SD & Range & $\mathbf{N}$ \\
\hline \multicolumn{4}{|l|}{ SOIL } \\
\hline Clay $(\%)^{1)}$ & $13.5 \pm 2.8$ & $8.0-18.4$ & - \\
\hline Silt (\%) ${ }^{1)}$ & $52.4 \pm 8.9$ & $38.5-72.7$ & - \\
\hline Sand $(\%)^{2)}$ & $34.1 \pm 11.2$ & $11.0-53.5$ & - \\
\hline Organic carbon $\left(\mathrm{g} \mathrm{C} \mathrm{Kg}^{-1}\right)^{1)}$ & $15.4 \pm 4.0$ & $10.1-23.9$ & - \\
\hline Total Nitrogen $\left(\mathrm{g} \mathrm{N} \mathrm{Kg}^{-1}\right)^{3)}$ & $1.9 \pm 0.4$ & $1.2-2.5$ & 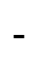 \\
\hline $\mathrm{pH}^{1)}$ & $8.2 \pm 0.1$ & $8.0-8.4$ & - \\
\hline Soil moisture $(\%)^{1)}$ & $25.0 \pm 3.5$ & $20.3-36.3$ & - \\
\hline
\end{tabular}

\section{MANAGEMENT}

\section{No. of pesticide applications in 2012}

Total ${ }^{3)}$

Insecticide ${ }^{1)}$

Fungicide ${ }^{1)}$

Growth regulator ${ }^{2)}$
Herbicide ${ }^{1)}$

$\begin{array}{ll}12.2 \pm 2.7 & 7-18 \\ 1.1 \pm 0.6 & 0-3 \\ 5.4 \pm 2.0 & 2-10 \\ 2.4 \pm 0.9 & 1-4 \\ 3.4 \pm 0.8 & 2-5\end{array}$

$142.0 \pm 72.2 \quad 0-246.3$

$167.2 \pm 148.9 \quad 0-639.0$

$654.5 \pm 700.1 \quad 0-3080.0$

$6469 \pm 1637 \quad 5200-8500$

$7493 \pm 1708 \quad 5500-10140$

$1309 \pm 1400$

$0-6160$

$8870 \pm 2027 \quad 5500-13245$

$\left(\mathrm{Kg} \mathrm{ha}^{-1}\right)^{3)}$

Estimate organic matter from main and cover crops residues and manure 2011-2012 $\left(\mathrm{Kg} \mathrm{ha}^{-1}\right)^{1)}$

Estimate organic matter from cover crop residues $2011\left(\mathrm{Kg} \mathrm{ha}^{-1}\right)^{4)}$

No. of fields 
Table A2.2 (cont.)

\begin{tabular}{|c|c|c|c|}
\hline Fields & Mean \pm SD & Range & No. of fields \\
\hline \multicolumn{4}{|l|}{ Main crop } \\
\hline Occurrence legume 2009-2012(\%) & $10 \pm 16$ & $0-50$ & $\begin{array}{l}\text { yes: } N=8 \\
\text { no: } N=18\end{array}$ \\
\hline Occurrence tuber 2009-2012(\%) ${ }^{3)}$ & $25 \pm 16$ & $0-50$ & $\begin{array}{l}\text { yes: } \mathrm{N}=21 \\
\text { no: } \mathrm{N}=5\end{array}$ \\
\hline Occurrence grass $2009-2012(\%)^{1)}$ & $3 \pm 11$ & $0-50$ & $\begin{array}{l}\text { yes: } \mathrm{N}=2 \\
\text { no: } \mathrm{N}=24\end{array}$ \\
\hline Occurrence grain 2009-2012(\%) ${ }^{1)}$ & $53 \pm 16$ & $25-75$ & $\begin{array}{l}\text { yes: } \mathrm{N}=26 \\
\text { no: } \mathrm{N}=0\end{array}$ \\
\hline Crop $2011^{4)}$ & - & - & $\begin{array}{l}\text { grain: } N=4 ; \\
\text { tuber: } N=20 \text {; } \\
\text { other: } N=2\end{array}$ \\
\hline \multicolumn{4}{|l|}{ Cover crop } \\
\hline Occurrence 2009-2012 (\%) (yes, no) ${ }^{1)}$ & $30 \pm 29$ & $0-100$ & $\begin{array}{l}\text { yes: } N=16 \\
\text { no: } N=10\end{array}$ \\
\hline Cover crop $2012^{1)}$ & - & - & $\begin{array}{l}\text { grass: } \mathrm{N}=9 \text {; } \\
\text { radish: } \mathrm{N}=4 \text {; } \\
\text { none: } \mathrm{N}=13\end{array}$ \\
\hline Occurrence legume $2009-2012(\%)^{4)}$ & $2 \pm 7$ & $0-25$ & $\begin{array}{l}\text { yes: } N=2 ; \\
\text { no: } N=24\end{array}$ \\
\hline Cover crop $2011(\%)^{4)}$ & $8 \pm 27$ & $0-100$ & $\begin{array}{l}\text { radish: } \mathrm{N}=2 \text {; } \\
\text { none: } \mathrm{N}=24\end{array}$ \\
\hline \multicolumn{4}{|l|}{ Residue management } \\
\hline $\begin{array}{l}\text { Occurrence residue removal all crops } 2009 \text { - } \\
2012(\%)^{3)}\end{array}$ & $36 \pm 24$ & $0-75$ & $\begin{array}{l}\text { yes: } N=21 \\
\text { no: } N=5\end{array}$ \\
\hline $\begin{array}{l}\text { Occurrence residue removal grain crops } \\
2009-2012(\%)^{3)}\end{array}$ & $70 \pm 41$ & $0-100$ & $\begin{array}{l}\text { yes: } \mathrm{N}=21 \\
\text { no: } \mathrm{N}=5\end{array}$ \\
\hline Residue removal $2012(\%)^{1)}$ & $62 \pm 50$ & $0-100$ & $\begin{array}{l}\text { yes: } \mathrm{N}=16 \text {; } \\
\text { no: } \mathrm{N}=10\end{array}$ \\
\hline \multicolumn{4}{|l|}{ Tillage } \\
\hline $\begin{array}{l}\text { Occurrence reduced tillage 2008-2011 (\%) } \\
\text { 3) }\end{array}$ & $26 \pm 25$ & $0-100$ & $\begin{array}{l}\text { yes: } \mathrm{N}=18 \\
\text { no: } \mathrm{N}=8\end{array}$ \\
\hline Reduced tillage in $2011(\%)^{1)}$ & $50 \pm 51$ & $0-100$ & $\begin{array}{l}\text { yes: } \mathrm{N}=13 \text {; } \\
\text { no: } \mathrm{N}=13\end{array}$ \\
\hline Tillage depth in $2011(\mathrm{~cm})^{1)}$ & $27 \pm 7$ & $10-40$ & - \\
\hline
\end{tabular}


Table A2.2 (cont.)

\begin{tabular}{llll}
\hline Fields & Mean \pm SD & Range & No. of fields \\
\hline
\end{tabular}

\section{LANDSCAPE}

Arable area (\%) within a radius of:

$$
\begin{aligned}
& 50 \mathrm{~m}^{1)} \\
& 100 \mathrm{~m}^{1)} \\
& 250 \mathrm{~m}^{1)} \\
& 500 \mathrm{~m}^{1)}
\end{aligned}
$$

$\begin{array}{lll}88.8 \pm 10.1 & 56.6-100.0 \\ 79.2 \pm 13.5 & 44.6-100.0 \\ 71.3 \pm 19.0 & 32.0-96.6 \\ 70.2 \pm 18.4 & 26.2-97.4\end{array}$

Shannon diversity index with earthworm inhabitable land-uses in a radius of:

$\begin{array}{llll}50 \mathrm{~m}^{1)} & 0.251 \pm 0.320 & 0-1.022 & - \\ 100 \mathrm{~m}^{1)} & 0.432 \pm 0.344 & 0-1.038 & - \\ 250 \mathrm{~m}^{1)} & 0.607 \pm 0.400 & 0-1.235 & - \\ 500 \mathrm{~m}^{1)} & 0.756 \pm 0.356 & 0.196-1.354 & -\end{array}$

Mean \pm standard deviation, range of values (minimum and maximum), and number of fields.

Usage of explanatory variables in the separate RDA models:

1) Yes

2) No, redundant variable (e.g., clay, silt and sand add to $100 \%$ )

3) No, VIF $>10$

4) No, not enough variation between sites 
Table A2.3 Summary of explanatory variables of the three investigated filters of earthworm communities in margins: soil properties, management practices and surrounding landscape. For further explanation see Table A2.1.

\begin{tabular}{|c|c|c|c|}
\hline Margins & Mean \pm SD & Range & \begin{tabular}{|l|l}
$\begin{array}{l}\text { No. of } \\
\text { margins }\end{array}$ \\
\end{tabular} \\
\hline \multicolumn{4}{|l|}{ SOIL } \\
\hline Clay $(\%)^{1)}$ & $12.0 \pm 2.2$ & $8.2-16.1$ & - \\
\hline Silt $(\%)^{1)}$ & $47.0 \pm 9.0$ & $37.2-71.6$ & - \\
\hline Sand $(\%)^{2)}$ & $41.0 \pm 10.6$ & $12.3-53.3$ & - \\
\hline Organic carbon $\left(\mathrm{g} \mathrm{C} \mathrm{Kg}^{-1}\right)^{3)}$ & $18.4 \pm 5.7$ & $10.2-30.2$ & - \\
\hline Total Nitrogen $\left(\mathrm{g} \mathrm{N} \mathrm{Kg}^{-1}\right)^{1)}$ & $2.1 \pm 0.5$ & $1.4-3.0$ & - \\
\hline $\mathrm{pH}^{1)}$ & $8.1 \pm 0.1$ & $7.8-8.3$ & - \\
\hline Soil moisture (\%) ${ }^{1)}$ & $24.5 \pm 4.3$ & $18.7-32.9$ & - \\
\hline \multicolumn{4}{|l|}{ MANAGEMENT } \\
\hline Age of margin in $2012(\mathrm{yr})^{1)}$ & $6.9 \pm 3.4$ & $2-12$ & - \\
\hline Sown mixture ${ }^{1)}$ & - & - & $\begin{array}{l}\text { grass: } \mathrm{N}=10 ; \\
\text { grass-herb: } \\
\mathrm{N}=5\end{array}$ \\
\hline Mowing frequency ${ }^{1}$ ) & $2.4 \pm 1.5$ & $0-5$ & - \\
\hline Residue removal $2012(\%)^{1)}$ & $13.3 \pm 35.2$ & $0-100$ & $\begin{array}{l}\text { yes: } N=2 ; \text { no: } \\
\mathrm{N}=13\end{array}$ \\
\hline
\end{tabular}

\section{LANDSCAPE}

Arable area (\%) within a radius of:

$\begin{array}{llll}50 \mathrm{~m}^{1)} & 69.0 \pm 17.1 & 44.1-90.0 & - \\ 100 \mathrm{~m}^{3)} & 70.6 \pm 19.9 & 36.1-93.6 & - \\ 250 \mathrm{~m}^{3)} & 67.1 \pm 17.4 & 27.8-96.0 & - \\ 500 \mathrm{~m}^{1)} & 63.7 \pm 17.9 & 24.4-97.4 & -\end{array}$

Shannon diversity index with earthworm inhabitable land-uses in a radius of:

$\begin{array}{llll}50 \mathrm{~m}^{1)} & 0.295 \pm 0.344 & 0-1.055 & - \\ 100 \mathrm{~m}^{1)} & 0.502 \pm 0.351 & 0-1.097 & - \\ 250 \mathrm{~m}^{1)} & 0.662 \pm 0.311 & 0.186-1.248 & - \\ 500 \mathrm{~m}^{1)} & 0.811 \pm 0.344 & 0.286-1.333 & -\end{array}$

Mean \pm standard deviation, range of values (minimum and maximum), and number of margins. Usage of explanatory variables in the separate RDA models:

1) Yes

${ }^{2)}$ No, redundant variable (e.g., clay, silt and sand add to $100 \%$ )

3) No, VIF $>10$ 


\section{Appendix 2B}

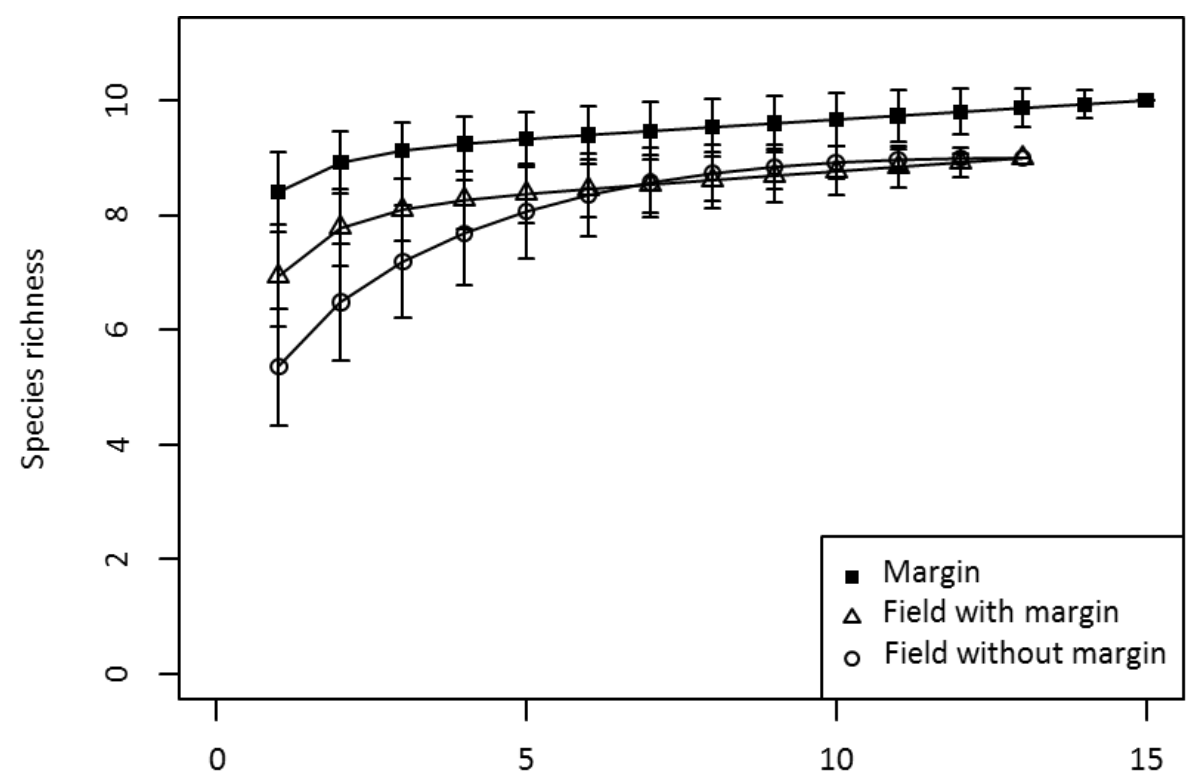

No. of arable fields or field margins

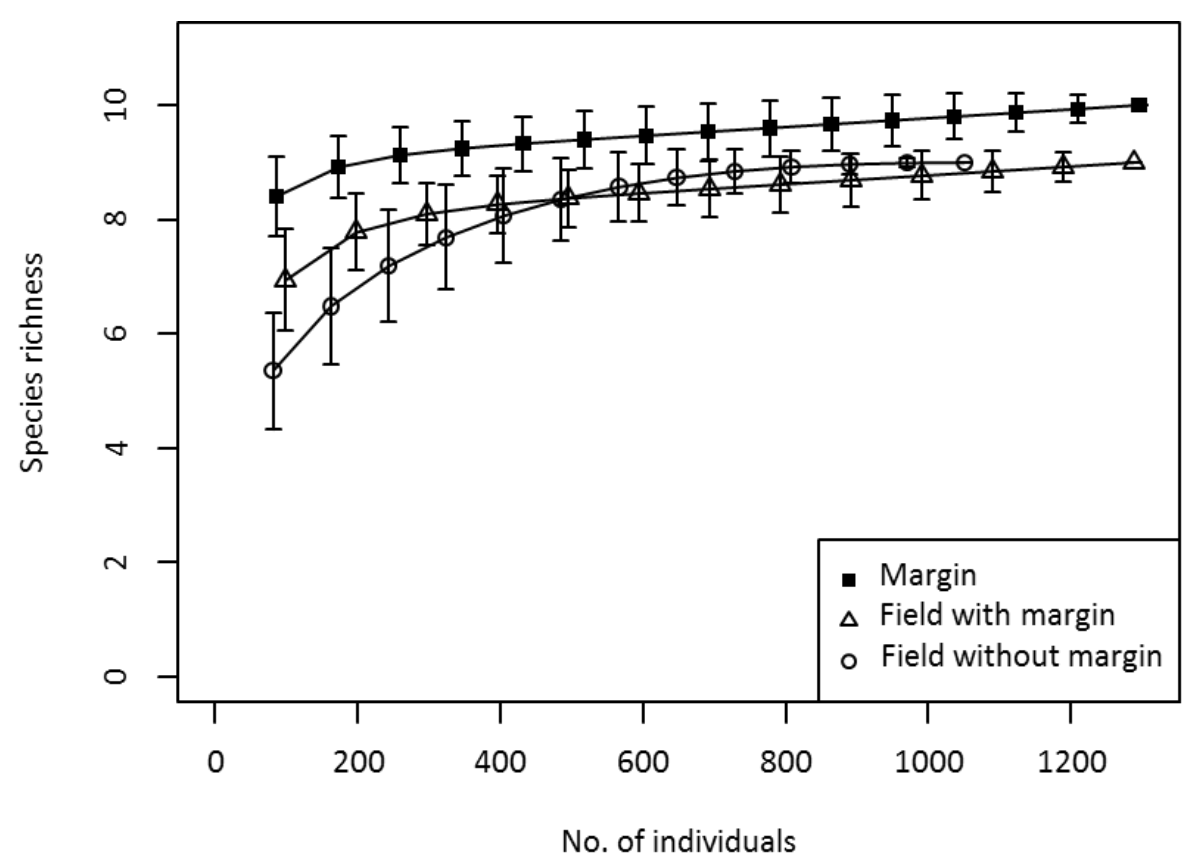

Figure B2.1 Sample- (upper panel) and individual-based (lower panel) rarefaction curves of earthworm species richness of fields with and without margins and of margins. 


\section{Chapter 3}

\section{Soil structure formation and organic matter distribution as affected by earthworm species interactions and crop residue placement}

Chapter published in Geoderma, 2019,

338: $453-463$

Joana Frazão, Ron G.M. de Goede, Yvan Capowiez, Mirjam M. Pulleman 



\title{
3 Soil structure formation and organic matter distribution as
}

\section{affected by earthworm species interactions and crop residue}

\section{placement}

\begin{abstract}
Earthworms play an important role in soil organic matter (SOM) dynamics and soil structure formation, including soil porosity and aggregate stability. Earthworms feed on organic inputs such as crop residues (CR) which are displaced by mouldboard ploughing. In a 61-day mesocosm experiment, we investigated the effects of CR placement (surface-applied vs. incorporated) and different earthworm species (combinations) on: 1) the survival and biomass of the earthworm species Lumbricus terrestris, L. rubellus, and Aporrectodea caliginosa, representing anecic, epigeic and endogeic ecological groups, respectively; and 2) earthwormmediated soil structure formation. Earthworms were present either as single species or as species mixtures combining anecics with each of the other groups. Incorporating CR reduced biomass of surface-feeders (L. terrestris: $-30 \%$ of initial body weight vs. $-9 \%$ when CR were surfaceapplied; L. rubellus: $-74 \%$ vs. $-24 \%$, respectively). L. rubellus survival was also lower when CR were incorporated (50\%) than when CR were surface-applied (92\%). In surface-applied CR treatments, the amount of particulate organic matter $(\mathrm{POM})>250 \mu \mathrm{m}$ in the soil profile was positively affected by $L$. terrestris in the soil upper $20 \mathrm{~cm}$ by $16.5 \%$. A similar but weaker effect was found when $\mathrm{CR}$ were incorporated (9\% increase). Large water-stable macroaggregates $(>2000 \mu \mathrm{m})$ increased in the upper $20 \mathrm{~cm}$ soil only when CR were surface-applied and $L$. terrestris was present (from 2.7 to $13.1 \mathrm{~g} \mathrm{~kg}^{-1}$ ). Small water-stable aggregates increased with functional groups interactions at all soil depths, irrespective of the CR placement. Surfaceapplied CR increased soil porosity at $2.5-10 \mathrm{~cm}$ depth. Large water-stable macroaggregate formation by earthworms was hampered through the incorporation of $\mathrm{CR}$, although $\mathrm{CR}$ incorporation increased porosity between 2.5 and $30 \mathrm{~cm}$ soil depth despite reduced earthworm biomass. Furthermore, small macroaggregate formation was hampered by single species, whereas combining functional groups stimulated their formation. Under field conditions residue
\end{abstract}


incorporation might result in trade-offs between the contribution of surface-feeding earthworms to soil porosity and i) their fitness, as surface-feeding earthworms' body weight loss was larger than when crop residues were surface-applied; as well as ii) large water-stable macroaggregates formation, as no increase in those was found when CR was incorporated. 


\subsection{Introduction}

Earthworms have long been recognized as soil ecosystem engineers (Jones et al., 1994; Lavelle et al., 1997). Their feeding, burrowing and casting activities strongly impact organic matter distribution and soil structure, thereby modifying soil porosity (Capowiez et al., 2015; Martin, 1982; Pérès et al., 2010), soil aggregate stability (Bossuyt et al., 2006; Hedde et al., 2013), soil organic matter (SOM) dynamics (Pulleman et al., 2003), nutrient availability (van Groenigen et al., 2014), water infiltration (Andriuzzi et al., 2015), soil aeration (Lemtiri et al., 2014) and soil fertility (Syers and Springett, 1984).

Based on their feeding habits and morphological features, Bouché (1977) classified earthworms into three main ecological groups, which reflect their burrowing and feeding habits. He distinguished anecics as detritivores feeding at the soil surface and digging deep vertical permanent burrows, epigeics also as feeding on fresh organic matter at the soil surface, but not commonly associated with burrowing activities, and finally endogeics as geophagous species obtaining their nutrition from organic matter associated to soil mineral particles and being reported to burrow horizontally, creating temporary burrows. In Dutch agricultural soils, the most common species belonging to these groups are, respectively, Lumbricus terrestris (Linné, 1758), Lumbricus rubellus (Hoffmeister, 1843), although some authors have classified this species as epi-endogeic (Hendrix et al., 1999) or epi-anecic (Briones and Álvarez-Otero, 2018), and Aporrectodea caliginosa (Savigny, 1826) (Crittenden et al., 2014; Frazão et al., 2017, chapter 2). L. terrestris, although common in pastures, is less common in arable fields, while farmers are very keen on stimulating this species due to its important role in soil structure formation and water infiltration.

In arable fields, management activities have been reported to affect earthworm communities, in particular ploughing, through mechanical soil disturbance and burial of crop residues (Chan, 2001; Crittenden et al., 2014; Ernst and Emmerling, 2009). Soil inversion due to ploughing can destroy anecic earthworm burrows. Re-establishing their burrow system occurs at the high cost of energetic investment of individual earthworm specimens (e.g., Petersen and Luxton (1982) who accounted that during soil modification earthworms respired $74-91 \%$ of assimilated carbon). Also, soil tillage, especially soil inversion, displaces crop residues to deeper soil layers, typically to about 20 to $30 \mathrm{~cm}$ soil depth in case of mouldboard ploughing. Tillage intensity has 
been found to negatively affect abundances of anecics and epigeics, but have neutral or positive effects on endogeics (Crittenden et al., 2014; de Oliveira et al., 2012; Ernst and Emmerling, 2009), despite increased exposure to predation risks in the short term (Cuendet, 1983). Thus, earthworm communities in agricultural land are subjected to complex interactions involving factors like crop residue management, changes in microclimate, exposure to predation and burrow destruction. Apart from these human-related factors, complex soil-mediated interactions such as interspecific competition and facilitation can affect their survival and growth (Uvarov, 2009).

Competition or facilitation among earthworm species that share or have contrasting feeding habits has been demonstrated in several studies (Lowe and Butt, 1999, 2002, 2003). These interspecific interactions may have consequences for soil structure formation, e.g., soil porosity (Capowiez et al., 2001) and aggregate stability, and SOM availability in arable agro-ecosystems. Moreover, the distribution of crop residues may affect the feeding behaviour of earthworm species which in turn, is likely to affect their contribution to soil structure formation (Coq et al., 2007). Indeed, several studies have shown that crop residue placement affected the specific contribution of earthworm species to soil porosity (Le Couteulx et al., 2015), SOM dynamics (Giannopoulos et al., 2010; Paul et al., 2012) and aggregate stability (Bossuyt et al., 2006). So far, these studies were restricted to either one or two soil structural features and often focussed on single species effects. Efforts to relate soil porosity, aggregate stability and SOM distribution with earthworm species of the three distinct ecological groups and their interactions, under different crop residue placement in the soil profile have been absent, to the best of our knowledge.

The objectives of this study were two-fold. First, we addressed the effects of applying crop residues on the soil surface $v s$. incorporating them in the soil profile, simulating no-tillage and conventional ploughing, respectively, on the survival and body weight of single earthworm species representing the three ecological groups. Furthermore, we focussed on species mixtures' survival and weight change: anecics were combined with either epigeic or endogeic species. Second, we investigated how crop residue placement and earthworm species (interactions) influenced soil porosity, SOM distribution and aggregate stability. 
We hypothesized that incorporation of crop residues would have strong negative effects in single species treatments on surface feeders' (model species: L. terrestris and L. rubellus), but not on soil feeders" (model species: A. caliginosa) body weight and survival. Furthermore, we expected that interspecific competition (expressed in weight loss) would occur in the case of mixtures of species with similar feeding habits (L. terrestris combined with L. rubellus), whereas facilitation (expressed in weight gain) would take place when contrasting feeding guilds were combined in earthworm species mixtures (A. caliginosa with L. terrestris). Finally, we hypothesized that i) when crop residues were surface-applied, L. terrestris would cause increased soil porosity, SOM incorporation and stable macroaggregates, aided by endogeic (A. caliginosa) and counteracted by epigeic species (L. rubellus), and that ii) when crop residues were incorporated soil porosity would be higher, but regardless of the species under focus, and with larger weight loss for surface-feeders, especially L. rubellus.

\subsection{Materials and methods}

\subsubsection{Experimental set-up}

A mesocosm experiment (61 days) was performed in the greenhouse to compare earthworm effects on SOM, aggregate stability and soil porosity, when providing crop residues either at the soil surface (simulating no-tillage) or incorporated between 20 and $30 \mathrm{~cm}$ deep (simulating conventional tillage by mouldboard ploughing). The experimental duration was chosen as a compromise between logistical constraints and expected effects (e.g., Le Couteulx et al. (2015) found earthworm-derived porosity effects after 60 days of experimental time). The earthworm effects considered here focussed on the three ecological groups (anecic, epigeic and endogeic) and interactions between anecics and epi- and endogeics. Each ecological group was represented by one model species only, as financial constraints hampered replicating the experimental set-up to consider more species within each group. Single species earthworm treatments were Lumbricus terrestris (LT), Aporrectodea caliginosa (AC), and Lumbricus rubellus (LR), twospecies treatments were L. terrestris with A. caliginosa (LT $+\mathrm{AC})$ and L. terrestris with $L$. rubellus $(\mathrm{LT}+\mathrm{LR})$ and an additional earthworm-free control treatment (0) was considered as well (Fig. 3.1). The focus on the interactions between L. terrestris and the other two species was 
triggered by farmers' large interest in the anecics, which mitigate the negative effects of intense rainfall events on e.g., plant growth (Andriuzzi et al., 2015). Crop residues used were a mixture of winter wheat (Triticum aestivum) stubble and straw and radish (Raphanus sativus subsp. oleiferus), corresponding to commonly used main and cover crops in the Netherlands. Stubble, straw and radish were chopped roughly to $2 \mathrm{~cm}$ and provided to each mesocosm in the following amounts: $4.7 \mathrm{~g}, 14.2 \mathrm{~g}, 5.1 \mathrm{~g}$, respectively, corresponding to $0.4 \mathrm{tha}^{-1}, 1.3 \mathrm{tha}^{-1}$ and $0.5 \mathrm{tha}^{-1}$. The experiment was set up in a completely randomized block design with four replicates.

Each experimental unit (mesocosm) had a total height of $49.5 \mathrm{~cm}$ and a diameter of $19 \mathrm{~cm}$. Four PVC rings with heights of 12, 20,10, and $7.5 \mathrm{~cm}$ (Fig. 3.1) were mounted on top of each other using duct-tape. Each column was closed at the bottom. In order to prevent earthworms from escaping two parallel $1 \mathrm{~cm}$ wide strips of velcro were glued on the inside of the column, a few $\mathrm{cm}$ below the top (Lubbers and van Groenigen, 2013). Additionally, each column was covered with a cotton cloth allowing gas exchange, and attached with a rubber band. Calcareous marine loam soil (de Bakker and Schelling, 1966) was collected from a conventionally tilled arable field of the Westmaas experimental farm of Wageningen University and Research, located in the southwest of The Netherlands. Soil $\left(36.9 \mathrm{~g} \mathrm{OM} \mathrm{kg}^{-1}, \mathrm{pH}\right.$ of 7.9 and a texture of $48 \%$ sand and 25 $\%$ clay) was collected to a depth of $20 \mathrm{~cm}$, sieved through a $4-\mathrm{mm}$ screen, air-dried at $25^{\circ} \mathrm{C}$ and thoroughly mixed to guarantee homogeneity. Nine days prior to the inoculation of earthworms, each column was packed with $12.5 \mathrm{~kg}$ air-dried soil at a bulk density of $1.20 \mathrm{~g} \mathrm{~cm}^{-3}$ resulting in a total depth of $37.5 \mathrm{~cm}$. Each ring was filled independently ensuring the same bulk density throughout the whole column. The upper ring did not contain soil, but only the crop residues in surface-applied treatments (Fig. 3.1). Crop residues were either incorporated in the profile between 20 and $30 \mathrm{~cm}$ deep, by mixing them thoroughly with the soil prior to filling that PVC ring or applied on the soil surface after the complete column was filled. Gravimetric soil moisture was brought to $234 \mathrm{~g} \mathrm{~kg}^{-1}$ of soil, corresponding to $65 \%$ of water-filled pore space (WFPS) and was adjusted gravimetrically once a week to maintain the soil moisture constant by applying tap water at the soil surface. All columns were incubated at a constant temperature of $15.5^{\circ} \mathrm{C}$ and a light cycle of $15 \mathrm{~h}$ light $/ 9 \mathrm{~h}$ dark.

Three to four weeks prior to the inoculation of earthworms, (sub)adult individuals of L. terrestris were commercially obtained from Starfood (Barneveld, The Netherlands), whereas adults of $A$. 
caliginosa and L. rubellus were sampled in parks in the vicinity of Wageningen University and Research Centre. Earthworms were kept in plastic containers at $2{ }^{\circ} \mathrm{C}$ with the same soil used as in the experiment and were fed with alder leaves. Two days prior to the inoculation of earthworms in each block, individuals of each species were placed in clean plastic pots at $16^{\circ} \mathrm{C}$ with moist kitchen paper to allow them to void their guts and their initial body weights were recorded to $0.1 \mathrm{~g}$ accurately. Treatments with L. terrestris (LT, LT $+\mathrm{AC}$ and LT $+\mathrm{LR}$ ) received three individuals of L. terrestris with total weight of about $15 \mathrm{~g}$, treatments with L. rubellus (LR and $\mathrm{LT}+\mathrm{LR}$ ) received three individuals of L. rubellus with total weight of about $2 \mathrm{~g}$ and treatments with A. caliginosa (AC and LT $+\mathrm{AC}$ ) received four individuals of L. rubellus with total weight of about $1 \mathrm{~g}$ (Table A3.1). A. caliginosa numbers were based on field data (e.g., Crittenden et al., 2015) and as L. rubellus and L. terrestris occur usually in lower densities, their experimental density was reduced compared to A. caliginosa. However, to ensure that survival rates would be workable, their number could not be lower than three individuals. To avoid earthworms burrowing down along the PVC walls of the mesocosm, they were placed under a $10 \mathrm{~cm}$ diameter plastic cup in the centre of the surface area of each column. In the surfaceapplied crop residue treatments, residues were carefully put aside for the earthworm inoculation, but spread evenly after the individuals had burrowed in the soil. 
Surface-applied treatments

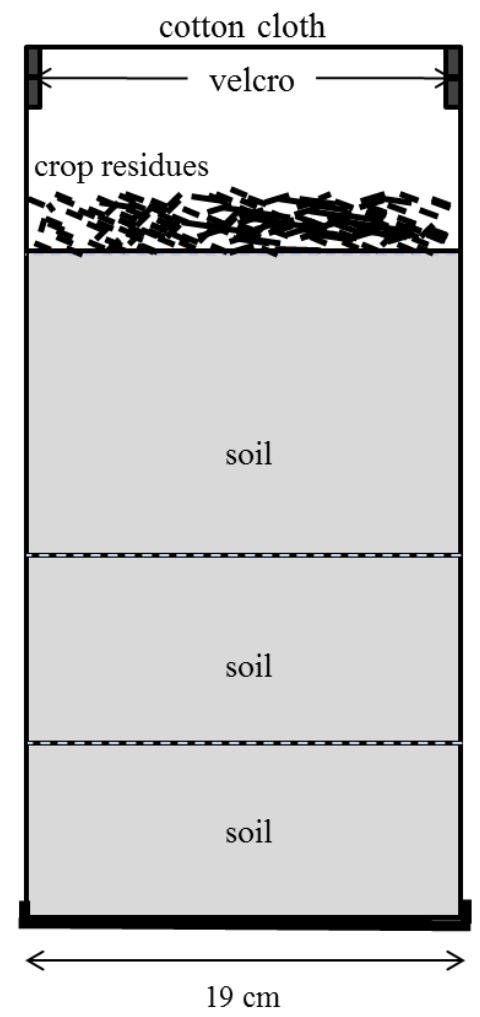

Incorporated treatments

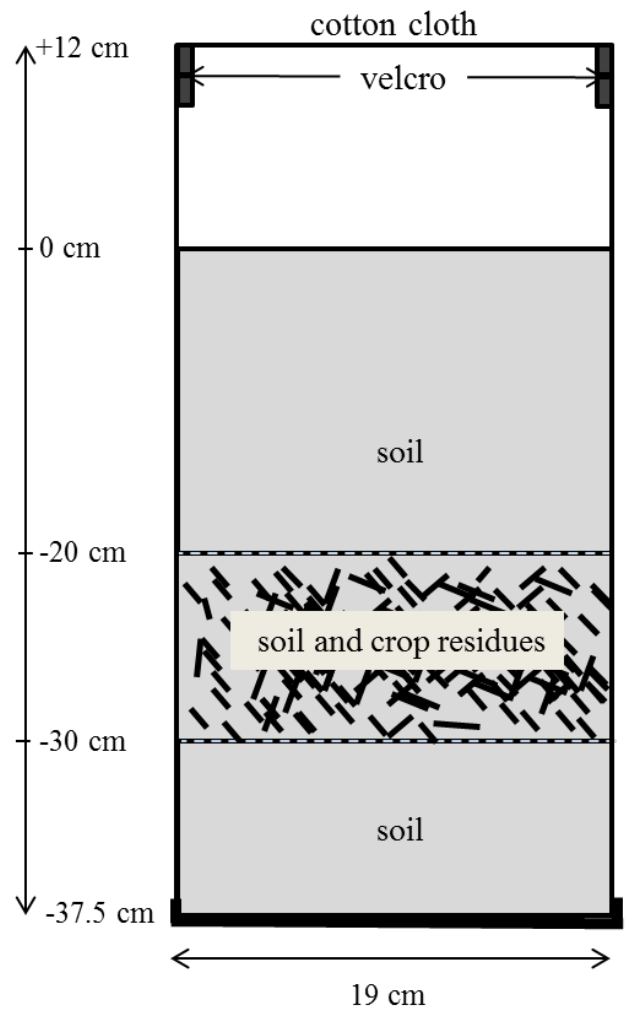

\section{Earthworm treatments}

$0 \quad$ No earthworms

AC A. caliginosa

LR L. rubellus

LT L. terrestris

$\mathrm{LT}+\mathrm{AC} \quad$ L. terrestris $+A$. caliginosa

$\mathrm{LT}+\mathrm{LR} \quad$ L. terrestris $+L$. rubellus

Figure 3.1 Scheme of the experimental mesocosms, showing crop residue placement treatments and earthworm treatments.

\subsubsection{X-ray tomography (XRT)}

Sixty-one days after the inoculation of the earthworms, two replicates of the single-species and no species treatments of both crop residue placement treatments were scanned with X-ray computed tomography. Scans were executed using the v[tome]x m (Phoenix X-ray/General Electric), with a directional X-ray tube and a tungsten target. The voltage was set to $200 \mathrm{kV}$ with a current of $30 \mu \mathrm{A}$ with a subsequent power of the Tungsten-target of $60 \mathrm{~W}$. The columns were positioned at $409.022 \mu \mathrm{m}$ from the target, which corresponds to a voxel size of $230 \mu \mathrm{m}$. Because the columns were too tall for a single vertical image, the multi-scan option was selected. Projection images of each experimental unit were taken at 1000 equidistant rotation angles between $0^{\circ}$ and $360^{\circ}$. Each image's acquisition time was $333 \mathrm{~ms}$, with a total time of $33 \mathrm{~min}$ for 
each experimental unit. After the scans were completed, the experimental units were harvested destructively to collect earthworms and soil samples for further analysis (see below).

\section{$\underline{\text { Soil porosity }}$}

Images were first transformed into 8-bit format. Greylevel histograms showed two wellseparated peaks (one for porosity and one for the soil matrix) and thus images were binarized with the same threshold value. The distribution of porosity with depth was computed for each image as the sum of the areas of all the pores for one image. Total porosity was then calculated for four soil layers $(2.5-10,10-20,20-30$ and $30-35 \mathrm{~cm})$. The upper and lower $2.5 \mathrm{~cm}$ were excluded to ensure a clear characterization of the porosity. Since the soil was sieved to $4 \mathrm{~mm}$, the porosity in the images had two origins: burrows and inter-aggregate porosity, the first being dominant. We assumed that the inter-aggregate porosity was similar for all the cores and thus we subtracted the porosity observed in the control cores without earthworms to the porosity for each soil layer.

\subsubsection{Destructive sampling}

Surface crop residues and surface casts were carefully removed from each column and ovendried at $35^{\circ} \mathrm{C}$. Each of the four PCV rings comprising one column were cut horizontally and separated, before the start of the measurements. We double-checked soil moisture contents using a sensor, TRIME PICO 64, IMKO (16 cm long sensor rods) inserted at $0 \mathrm{~cm}$ and at $20 \mathrm{~cm}$ depth, and bulk density by measuring twice the height and diameter of the soil within each PVC ring, weighing and correcting for the water content. Next, earthworms were carefully removed from the soil, while gently crumbling the soil into aggregates along natural planes of weakness and passing them through a $12 \mathrm{~mm}$ mesh, before drying at $35^{\circ} \mathrm{C}$. Earthworms were placed at $16^{\circ} \mathrm{C}$ for $48 \mathrm{~h}$ allowing them to void their guts. Each individual was cleaned, excess water was removed with a tissue, and its body weight was recorded. Representative soil subsamples were taken for i) SOM fractionation and ii) aggregate stability measurements. SOM fractionation was done for each depth layer, i.e. $0-20 \mathrm{~cm}, 20-30 \mathrm{~cm}$ and $>30 \mathrm{~cm}$ and the surface casts. However, as the amount of cast material was very small, especially in the case of A. caliginosa mesocosms, casts were pooled per treatment among blocks. Aggregate stability was measured for 0-20 and 
20-30 cm soil layers, and not for casts, as not enough cast material was available after the SOM fractionation.

\subsubsection{SOM fractions}

Between 80 and $100 \mathrm{~g}$ of soil was dispersed with $300 \mathrm{ml}$ of $0.5 \%$ solution of NaHMP $\left(5 \mathrm{~g} \mathrm{l}^{-1}\right)$ in a shaker overnight. In the case of surface casts the complete sample was used, which ranged from 25 to $80 \mathrm{~g}$. The total soil suspension was sieved through three mesh sizes to obtain SOM and mineral soil material of three size fractions: larger than $250 \mu \mathrm{m}$ (particulate organic matter (POM) plus coarse sand $>250 \mu \mathrm{m}$ : POM $>250$ ), between 53 and $250 \mu \mathrm{m}$ (POM plus fine sand 53-250 $\mu \mathrm{m}$ : POM 53-250) and silt and clay sized soil particles (SOM plus silt and clay $<53 \mu \mathrm{m}$ : $\mathrm{SOM}<53$ ). After the three size fractions were dried at $105^{\circ} \mathrm{C}$ overnight, loss of ignition (LOI) was used to determine the organic matter content of each size fraction (POM > 250, POM 53250 and $\mathrm{SOM}<53)$.

\subsubsection{Aggregate stability}

Between 30 and $40 \mathrm{~g}$ of soil subsample was used to determine water-stable aggregates (WSA) using the modified wet sieving method of Six et al. (2002), based on Elliott (1986). Three WSA classes of soil aggregates were obtained: large macro-aggregates (WSA $>2000 \mu \mathrm{m}$ : WSA > 2000), small macro-aggregates (WSA 250 - $2000 \mu \mathrm{m}$ : WSA 250 -2000), microaggregates (WSA $53-250 \mu \mathrm{m}$ : WSA $53-250$ ) and the silt and clay fraction $\mathrm{SC}<53 \mu \mathrm{m}$ : $\mathrm{SC}<53$ ). To obtain these, each soil subsample was placed on a $2 \mathrm{~mm}$ sieve and submerged in demi-water and left to slake for $5 \mathrm{~min}$. In the following $2 \mathrm{~min}$, the sieve was moved up and down 50 times to allow water and soil particles to go through the mesh. With the material that had passed through the $2 \mathrm{~mm}$ sieve, the same procedure was repeated using sieves of $250 \mu \mathrm{m}$ and $53 \mu \mathrm{m}$. The fractions collected by the sieves were carefully backwashed to pre-weighed aluminium pans, dried overnight at $105^{\circ} \mathrm{C}$ and weighed. The suspension smaller than $53 \mu \mathrm{m}$ was collected in a bucket, its volume was noted down and a subsample of known volume was dried at $105^{\circ} \mathrm{C}$ and weighed. 


\subsubsection{Statistical analysis}

Earthworm biomass (as percentage of the initial body weight) and survival were calculated per column. The single and interactive effects of crop residue placement and presence of other species (i.e. L. rubellus or A. caliginosa) on the weight change of L. terrestris were examined using linear mixed models with a normal distribution, with block as a random factor. Because the variation of $L$. terrestris' survival was very low (only three individuals died during the experiment), it was not possible to compute linear mixed models for L. terrestris' survival. For the weight change and survival of $L$. rubellus and A. caliginosa, crop residue placement and presence of $L$. terrestris were considered as fixed effects.

The single and interactive effects of $L$. terrestris (present or absent) and other earthworm species (no species, L. rubellus and A. caliginosa) on SOM size fractions per depth (0-20, 20-30, and $>30 \mathrm{~cm}$ ) and on WSA size classes at $0-20$ and $20-30 \mathrm{~cm}$ depth were analysed for each crop residue treatment separately, using linear mixed models with a normal distribution, with block as a random factor. For porosity, the fixed effects of the mixed model were slightly different, and corresponded to the (interactive) effects of single earthworm species and soil depth (intervals between 2.5 and 10,10-20, 20-30 and 30-35 cm), being analysed separately for each of the crop residue treatments, as well. Porosity was quantified after correcting for inter-aggregate porosity of the earthworm-free treatments and expressed as percentage of the total soil volume, and onetailed $t$-tests were computed to check whether mean porosity values were larger than zero $(\mathrm{p}<0.05)$. When the overall linear mixed models were statistically significant at the $p$-level of 0.05 , pairwise comparisons were computed refitting the models with the significant (interactive) fixed effects. P-values adjustments to avoid inflation type I errors were only considered necessary when the interaction between the fixed effects was significant due to the large number of pairwise comparisons (15, in the case of aggregate stability SOM and L. terrestris weight change or survival; 66, in the case of porosity). In that case, Tukey post-hoc adjustments were used. Overall models' distribution and variance assumptions were inspected visually, and if needed, a variance structure was used to avoid heteroscedasticity (Zuur et al., 2009). All analyses were performed with R 3.3.1 (R Core Team, 2014), using packages nlme 3.1-131 and lsmeans 2.27-61. 


\subsection{Results}

\subsubsection{Earthworm body weight change and survival}

All earthworm species lost weight during the 61 days of this experiment, but the extent depended on the treatments, i.e. residue placement and species: L. terrestris lost on average $30 \%$ of the initial weight when residues were incorporated in the profile, and only $9 \%$ when surface-applied $(\mathrm{p}<0.0001)$, and L. rubellus presented a similar, but stronger pattern $(74 \%$ vs. $24 \%, \mathrm{p}=0.003$, Table 3.1). Body mass of L. rubellus was reduced by the presence of L. terrestris, irrespective of crop residue placement $(-35 \%$ when alone $v s$. $-63 \%$, when together with $L$. terrestris, $\mathrm{p}=0.001$, Table 3.1). Earthworm survival was rather high, particularly for L. terrestris $(>90 \%)$ and $A$. caliginosa $(>80 \%)$. Survival of L. rubellus was higher when residues were surface-applied as compared to incorporated into the soil profile $(92 \%$ vs. $50 \%, \mathrm{p}=0.039$, Table 3.1$)$. Besides an overall body mass loss of 19-29\% during the experiment, A. caliginosa body weight or survival did not differ between the treatments (Table 3.1).

\subsubsection{SOM fractions}

When residues were surface-applied, SOM fractions were affected by L. terrestris at 0-20 and 20-30 cm depth and by L. rubellus at 20-30 cm, whereas neither A. caliginosa nor the interaction between both earthworm treatments affected SOM distribution. L. terrestris increased $\mathrm{POM}>250$ at 0 to $20 \mathrm{~cm}$ soil depth by $16.5 \%$, from $1.09( \pm 0.03)$ to $1.27( \pm 0.06) \mathrm{g} \mathrm{kg}^{-1}$ $(\mathrm{p}=0.014)$, irrespective of the presence of other species (Table 3.2), and decreased SOM $<53$ at 20 to $30 \mathrm{~cm}$ soil depth by $5 \%$, from $34.02( \pm 0.62)$ to $32.32( \pm 0.37) \mathrm{g} \mathrm{kg}^{-1}$ (overall model $\mathrm{p}=0.005$, Table 3.2). L. rubellus, irrespective of the presence of L. terrestris, increased POM $53-250$ at 20 to $30 \mathrm{~cm}$ soil depth by $26 \%$, from $2.54( \pm 0.11)$ to $3.20( \pm 0.17) \mathrm{g} \mathrm{kg}^{-1}$ (pairwise $\mathrm{p}=0.010$, Table 3.2).

When crop residues were incorporated at 20 to $30 \mathrm{~cm}$ depth, L. terrestris increased POM $>250$ in the $0-20$ soil layer by $9 \%$, from $0.98( \pm 0.01)$ to $1.07( \pm 0.03) \mathrm{g} \mathrm{kg}^{-1}(\mathrm{p}=0.043$, Table 3.3$)$, but the effect was smaller than in the surface-applied residue treatments. At 20-30 cm depth POM $>250$ was affected by the overall effect of other species $(p=0.006$, Table 3.3), yet, pairwise comparisons within that factor did not show significant effects at the level of $\alpha=0.05$. 
Due to the small amounts of surface casts recovered, those samples had to be pooled across experimental blocks, which made it impossible to test for statistically significant treatment effects. When crop residues were surface-applied, SOM content of casts of all earthworm treatments was consistently higher than when crop residues were incorporated. This was particularly noticeable for the POM $>250$ (Table 3.4). However, the amount of casts produced was consistently higher when crop residues were incorporated than when crop residues were surface-applied, particularly when L. terrestris was present (Table 3.4).

\subsubsection{Water-stable aggregates}

When residues were surface-applied, both earthworms factors significantly affected aggregate stability at 0 to $20 \mathrm{~cm}$ soil depth: when L. terrestris was present, irrespective of the presence of the other species, a five times increase in WSA $>2000$ was observed $(2.71( \pm 0.48) v s .13 .08$ $( \pm 3.31) \mathrm{g} \mathrm{kg}^{-1}$, overall model $\mathrm{p}<0.0001$, Table 3.5), whereas regardless of the presence of $L$. terrestris, WSA $>2000$ increased almost 2.5 times due to A. caliginosa, and almost 4.5 times due to L. rubellus, (pairwise $\mathrm{p}=0.004$ and $\mathrm{p}=0.016$, respectively, Table 3.5). Also WSA 2502000 were strongly affected by earthworm species, but now also by species combinations (overall model $\mathrm{p}=0.002$, Table 3.5 ). When only $A$. caliginosa was present, significantly less WSA 250-2000 were found compared to the earthworm-free treatment $(54.14( \pm 2.06) v s .67 .97$ $( \pm 0.67) \mathrm{g} \mathrm{kg}^{-1}$, pairwise $\mathrm{p}<0.0001$, Table 3.5). In contrast, L. terrestris almost doubled the amount of WSA 250-2000 when present together with L. rubellus (105.18 ( \pm 5.94$)$ vs. 67.97 $( \pm 0.67) \mathrm{g} \mathrm{kg}^{-1}$, pairwise $\mathrm{p}<0.001$, Table 3.5). In combination with $A$. caliginosa this increase was about $60 \%$ although not statistically significant different from the earthworm-free control (pairwise $\mathrm{p}=0.068$, Table 3.5). Regarding the microaggregates, the combination of $L$. terrestris with either L. rubellus or A. caliginosa resulted in a 10\% decrease of the WSA 53-250 between 0 and $20 \mathrm{~cm}$ soil depth (pairwise $\mathrm{p}=0.003$ and 0.011 , respectively, Table 3.5 for overall model), and in case of $L$. terrestris combined with A. caliginosa a $7 \%$ decrease in the $20-30 \mathrm{~cm}$ soil layer was also observed (pairwise $\mathrm{p}=0.026$, Table 3.5). The silt and clay fractions $(\mathrm{SC}<53)$ in the 0 to $20 \mathrm{~cm}$ soil layer also decreased. Now, the single species treatments with $A$. caliginosa and $L$. rubellus decreased $\mathrm{SC}<53$ from 130 to $106 \mathrm{~g} \mathrm{~kg}^{-1}$ (pairwise $\mathrm{p}=0.014$ and 0.003 , respectively, Table 3.5 for overall model). In contrast, at 20 to $30 \mathrm{~cm}$ depth, $\mathrm{SC}<53$ was generally increased 
due to L. terrestris, when present together with either of the other two species, from $119 \mathrm{~g} \mathrm{~kg}^{-1}$ to an average of $158 \mathrm{~g} \mathrm{~kg}^{-1}$ (pairwise $\mathrm{p}=0.002$ for LT-AC and 0.033 for LT-LR, Table 3.5).

When residues were incorporated, L. terrestris together with L. rubellus or A. caliginosa increased WSA 250-2000 at 0 to $20 \mathrm{~cm}$ depth, from about $65 \mathrm{~g} \mathrm{~kg}^{-1}$ in the control treatment to an average of $100 \mathrm{~g} \mathrm{~kg}^{-1}$ (overall model $\mathrm{p}<0.0001$, Table 3.5, pairwise $\mathrm{p}=0.004$ for LT-AC and 0.049 for LT-LR). In the same soil layer, the combination of L. terrestris with L. rubellus affected WSA 53-250 in the opposite direction, from about 782 in the earthworm-free treatment to $750 \mathrm{~g} \mathrm{~kg}^{-1}$ (overall model $\mathrm{p}<0.0001$, Table 3.5, pairwise $\mathrm{p}=0.006$ ), while single species, namely A. caliginosa and L. terrestris, resulted in an increase from about 780 to $810 \mathrm{~g} \mathrm{~kg}^{-1}$ (pairwise $\mathrm{p}=0.034$ and 0.004 , respectively, Table 3.5). None of the (single or mixture) species treatment showed significant shifts in WSA 53-250 compared to earthworm-free control treatments at 20 to $30 \mathrm{~cm}$ soil depth, but treatments with L. rubellus and L. terrestris alone had more WSA 53-250 (ca. $790 \mathrm{~g} \mathrm{~kg}^{-1}$ ) than mixed-species treatments $\left(720 \mathrm{~g} \mathrm{~kg}^{-1}\right.$ ) (overall model $\mathrm{p}=0.005$, pairwise $\mathrm{p}<0.05$, Table 3.5). Silt and clay fractions $(\mathrm{SC}<53)$ were generally lower with single species treatments, when compared to earthworm-free control treatments, at 0 to $20 \mathrm{~cm}$ soil depth (overall model $\mathrm{p}<0.0001$, Table 3.5, pairwise $\mathrm{p}=0.001$ for $\mathrm{LR}, \mathrm{p}<0.0001$ for AC and LT), whereas at 20 to $30 \mathrm{~cm}$ soil depth, only $A$. caliginosa showed a decrease in this fraction compared to the earthworm-free control treatment (pairwise $p=0.010$, Table 3.5). 
Table 3.1 Percentage of body weight change (from the initial body weight) and of survival (mean (SE)) of earthworms used in each of the experimental treatments (crop residue treatments: surface-applied $v s$. incorporated at 20-30 cm soil depth; and earthworm treatments: $L$. terrestris - present (LT) or absent; other species - none, A. caliginosa (AC), or L. rubellus (LR)), after 61 days. F-statistics and p-values of best fitted linear mixed model of earthworm body weight change (\% of initial body weight) and survival. $\mathrm{N}=4$, but see *

\section{L. terrestris (LT)}

\section{L. rubellus (LR)}

\section{A. caliginosa (AC)}

\begin{tabular}{lllllll} 
Treatments & $\begin{array}{l}\text { Weight change } \\
(\%)\end{array}$ & $\begin{array}{l}\text { Survival } \\
(\%)\end{array}$ & $\begin{array}{l}\text { Weight } \\
\text { change }(\%)\end{array}$ & $\begin{array}{l}\text { Survival } \\
(\%)\end{array}$ & $\begin{array}{l}\text { Weight change } \\
(\%)\end{array}$ & $\begin{array}{l}\text { Survival } \\
(\%)\end{array}$ \\
\hline Surface applied crop residues & & & & & \\
AC & - & - & - & - & $-18.9(17.0)$ & $81.3(12.0)$ \\
LR & - & - & $-0.4(8.0)$ & $100(0.0)$ & - & - \\
LT & $-13.9(12.4)$ & $91.7(8.3)$ & - & - & - & - \\
LT+AC & $-0.8(4.9)$ & $100.0(0.0)$ & - & - & $-20.8(9.1)$ & $100.0(0.0)$ \\
LT+LR & $-13.4(2.1)$ & $100.0(0.0)$ & $-46.7(4.3)$ & $83.4(9.6)$ & - & -
\end{tabular}

\section{Crop residues incorporated at $20-30 \mathrm{~cm}$ soil depth}

\begin{tabular}{lllllll}
$\mathbf{A C}$ & - & - & - & - & $-28.7(6.7)$ & $87.5(7.2)$ \\
$\mathbf{L R}$ & - & - & $-68.7(19.9)^{*}$ & $66.7(23.6)$ & - & - \\
$\mathbf{L T}$ & $-28.2(3.1)$ & $100.0(0.0)$ & - & - & - & - \\
$\mathbf{L T}+\mathbf{A C}$ & $-35.8(6.7)$ & $91.7(8.3)$ & - & - & $-29.3(4.0)$ & $93.8(6.3)$ \\
$\mathbf{L T + L R}$ & $-27.1(13.8)$ & $91.7(8.3)$ & $-79.0(15.3)$ & $33.3(23.6)$ & - & - \\
\hline
\end{tabular}




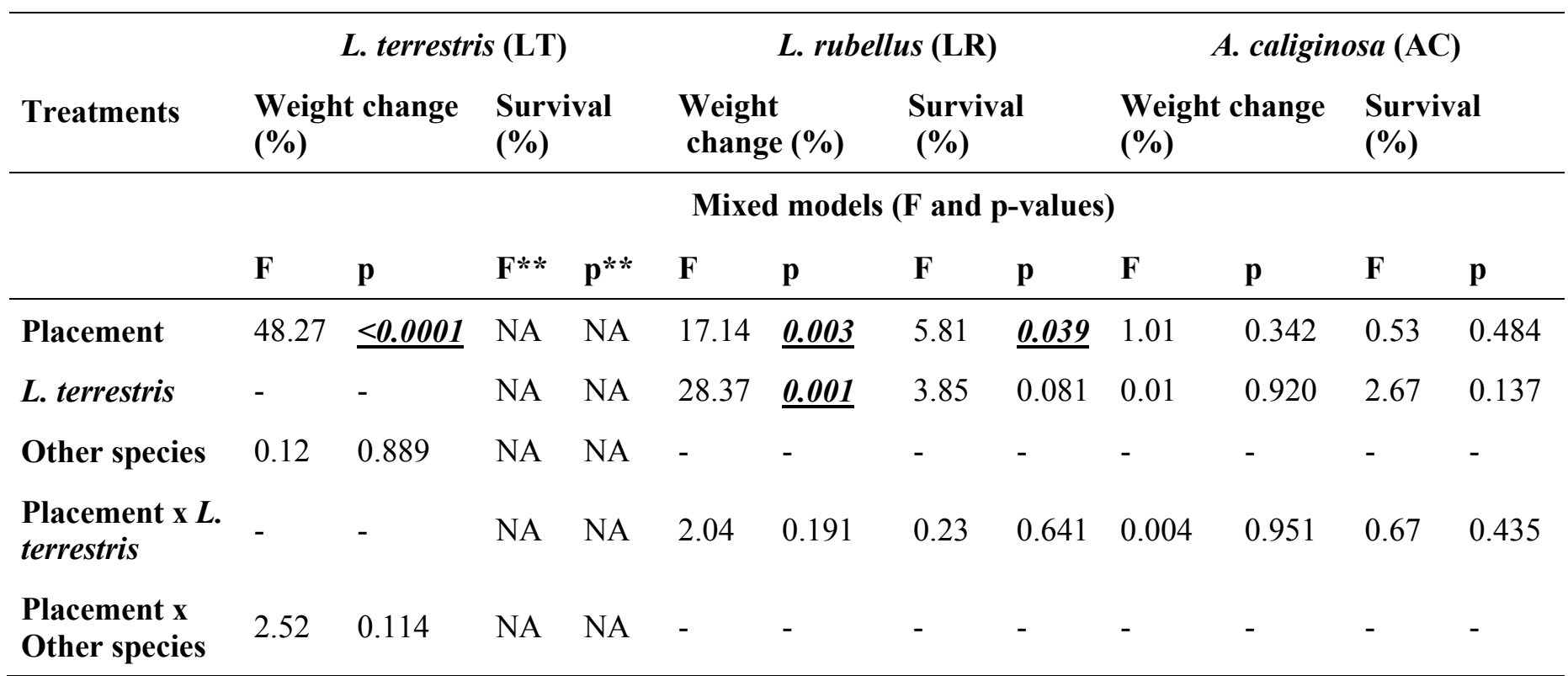

* In one of the blocks all L. rubellus died during the gut voiding-period, thus value refers to $\mathrm{n}=3$.

** Variation in survival was very low, and therefore statistics are not available (NA). 
Table 3.2 Mean and standard errors of soil organic matter (SOM) size fractions in $\mathrm{g} \mathrm{kg}^{-1}$ soil (POM > $250 \mu \mathrm{m}, \mathrm{POM} 53-250 \mu \mathrm{m}$, and $\mathrm{SOM}<53 \mu \mathrm{m})$ of surface-applied crop residues per soil depth $(0-20$, 20-30 and $>30 \mathrm{~cm}$ ) after 61 days as affected by different earthworm species and their combinations. No earthworms: 0, L. terrestris-LT, A. caliginosa-AC, L. rubellus-LR. F-statistics and p-values of best fitted linear mixed model of SOM size fractions. Different letters depict pairwise significant differences at $\mathrm{p}<0.05$ : capital letters show significant differences within the main factor L. terrestris, and small letters within the main factor Other species. $\mathrm{N}=4$.

\begin{tabular}{|c|c|c|c|}
\hline \multirow[t]{2}{*}{$\begin{array}{l}\text { SOM fraction/ } \\
\text { earthworm treatment }\end{array}$} & \multicolumn{3}{|c|}{ Soil depth } \\
\hline & $0-20 \mathrm{~cm}$ & $20-30 \mathrm{~cm}$ & $>30 \mathrm{~cm}$ \\
\hline \multicolumn{4}{|l|}{ POM $>250 \mu \mathrm{m}$} \\
\hline $\mathbf{0}$ & $1.00(0.03) \mathrm{Aa}$ & $0.99(0.05)$ & $1.03(0.04)$ \\
\hline $\mathbf{A C}$ & $1.08(0.05) \mathrm{Aa}$ & $1.00(0.03)$ & $1.09(0.06)$ \\
\hline LR & $1.20(0.05) \mathrm{Aa}$ & $0.99(0.05)$ & $1.03(0.08)$ \\
\hline $\mathbf{L T}$ & $1.30(0.09) \mathrm{Ba}$ & $1.00(0.04)$ & $1.02(0.02)$ \\
\hline $\mathbf{L T}+\mathbf{A C}$ & $1.32(0.11) \mathrm{Ba}$ & $1.08(0.06)$ & $1.07(0.06)$ \\
\hline $\mathbf{L T}+\mathbf{L R}$ & $1.19(0.10) \mathrm{Ba}$ & $0.96(0.03)$ & $1.00(0.02)$ \\
\hline \multicolumn{4}{|l|}{ POМ 53-250 $\mu \mathrm{m}$} \\
\hline $\mathbf{0}$ & $3.11(0.24)$ & $2.57(0.08) \mathrm{Aa}$ & $2.60(0.14)$ \\
\hline $\mathbf{A C}$ & $3.06(0.09)$ & $2.75(0.50) \mathrm{Aab}$ & $2.96(0.50)$ \\
\hline LR & $2.82(0.22)$ & $3.04(0.27) \mathrm{Ab}$ & $2.72(0.27)$ \\
\hline LT & $3.12(0.09)$ & $2.52(0.21) \mathrm{Aa}$ & $3.05(0.21)$ \\
\hline $\mathbf{L T}+\mathbf{A C}$ & $2.98(0.31)$ & 2.77 (0.18) Aab & $2.89(0.18)$ \\
\hline $\mathbf{L T}+\mathbf{L R}$ & $3.52(0.08)$ & $3.36(0.23) \mathrm{Ab}$ & $2.70(0.23)$ \\
\hline \multicolumn{4}{|l|}{$\mathrm{SOM}<53 \mu \mathrm{m}$} \\
\hline $\mathbf{0}$ & $33.97(1.40)$ & $32.93(0.84) \mathrm{Ba}$ & $32.60(0.98)$ \\
\hline $\mathrm{AC}$ & $32.09(0.75)$ & $35.11(1.61) \mathrm{Ba}$ & $32.02(0.85)$ \\
\hline LR & $34.79(0.64)$ & $34.02(0.44) \mathrm{Ba}$ & $33.80(0.69)$ \\
\hline LT & $32.94(0.70)$ & $32.51(0.14) \mathrm{Aa}$ & $34.15(0.98)$ \\
\hline $\mathbf{L T}+\mathbf{A C}$ & $33.82(1.11)$ & $32.84(0.45) \mathrm{Aa}$ & $32.11(1.22)$ \\
\hline $\mathbf{L T}+\mathbf{L R}$ & $33.33(0.74)$ & $31.63(1.01) \mathrm{Aa}$ & $32.97(1.35)$ \\
\hline
\end{tabular}


Table 3.2 (cont.)

\begin{tabular}{|c|c|c|c|c|c|c|}
\hline \multirow{4}{*}{$\begin{array}{l}\text { SOM fraction/ } \\
\text { earthworm treatment }\end{array}$} & \multicolumn{6}{|c|}{ Soil depth } \\
\hline & \multicolumn{2}{|c|}{$0-20 \mathrm{~cm}$} & \multicolumn{2}{|c|}{$20-30 \mathrm{~cm}$} & \multicolumn{2}{|c|}{$>30 \mathrm{~cm}$} \\
\hline & \multicolumn{6}{|c|}{ Mixed models (F and p-values) } \\
\hline & $\mathbf{F}$ & $\mathbf{p}$ & $\mathbf{F}$ & $\mathbf{p}$ & $\mathbf{F}$ & $\mathbf{p}$ \\
\hline \multicolumn{7}{|l|}{ POM $>250 \mu \mathrm{m}$} \\
\hline L. terrestris & 7.73 & $\underline{0.014}$ & 0.27 & 0.613 & 0.16 & 0.700 \\
\hline Other species & 3.45 & 0.059 & 1.03 & 0.380 & 1.36 & 0.287 \\
\hline $\begin{array}{l}\text { L. terrestris x Other } \\
\text { species }\end{array}$ & 2.18 & 0.148 & 0.67 & 0.528 & 0.03 & 0.974 \\
\hline \multicolumn{7}{|l|}{ POM 53-250 $\mu \mathrm{m}$} \\
\hline L. terrestris & 1.71 & 0.211 & 0.31 & 0.587 & 1.45 & 0.247 \\
\hline Other species & 0.29 & 0.749 & 7.69 & $\underline{0.005}$ & 0.29 & 0.754 \\
\hline $\begin{array}{l}\text { L. terrestris x Other } \\
\text { species }\end{array}$ & 2.39 & 0.126 & 0.38 & 0.688 & 0.84 & 0.451 \\
\hline \multicolumn{7}{|l|}{$\mathrm{SOM}<53 \mu \mathrm{m}$} \\
\hline L. terrestris & 0.11 & 0.741 & 10.90 & $\underline{0.005}$ & 0.17 & 0.685 \\
\hline Other species & 0.71 & 0.508 & 0.42 & 0.663 & 1.84 & 0.192 \\
\hline $\begin{array}{l}\text { L. terrestris x Other } \\
\text { species }\end{array}$ & 1.73 & 0.212 & 1.19 & 0.331 & 1.15 & 0.344 \\
\hline
\end{tabular}


Table 3.3 Mean and standard errors of soil organic matter (SOM) size fractions in $\mathrm{g} \mathrm{kg}^{-1}$ soil (POM $>$ $250 \mu \mathrm{m}$, POM $53-250 \mu \mathrm{m}$, and $\mathrm{SOM}<53 \mu \mathrm{m})$ of incorporated crop residues per soil depth $(0-20$, 20-30 and $>30 \mathrm{~cm}$ ) after 61 days as affected by different earthworm species and their combinations. No earthworms: 0, L. terrestris-LT, A. caliginosa-AC, L. rubellus-LR. F-statistics and p-values of best fitted linear mixed model of SOM size fractions. Different letters depict pairwise significant differences at $\mathrm{p}<0.05$ : capital letters show significant differences within the main factor L. terrestris, and small letters within the main factor Other species. $\mathrm{N}=4$.

\begin{tabular}{|c|c|c|c|}
\hline \multirow{2}{*}{$\begin{array}{l}\text { SOM } \\
\text { fraction/earthworm } \\
\text { treatment }\end{array}$} & \multicolumn{3}{|c|}{ Soil depth } \\
\hline & $0-20 \mathrm{~cm}$ & $20-30 \mathrm{~cm}$ & $>30 \mathrm{~cm}$ \\
\hline \multicolumn{4}{|l|}{$\mathrm{POM}>250 \mu \mathrm{m}$} \\
\hline $\mathbf{0}$ & $1.01(0.02) \mathrm{Aa}$ & $2.78(0.13)$ & $1.18(0.06)$ \\
\hline $\mathbf{A C}$ & $0.99(0.02) \mathrm{Aa}$ & $2.51(0.07)$ & $1.08(0.07)$ \\
\hline LR & $0.96(0.03) \mathrm{Aa}$ & $3.13(0.12)$ & $1.26(0.14)$ \\
\hline LT & $1.08(0.08) \mathrm{Ba}$ & $2.96(0.40)$ & $1.12(0.06)$ \\
\hline $\mathbf{L T}+\mathbf{A C}$ & $1.05(0.05) \mathrm{Ba}$ & $2.59(0.17)$ & $1.19(0.04)$ \\
\hline $\mathbf{L T}+\mathbf{L R}$ & $1.06(0.07) \mathrm{Ba}$ & $2.79(0.22)$ & $1.19(0.07)$ \\
\hline \multicolumn{4}{|l|}{ POM 53-250 $\mu \mathrm{m}$} \\
\hline $\mathbf{0}$ & $2.69(0.15)$ & $2.66(0.26)$ & $2.93(0.17)$ \\
\hline $\mathbf{A C}$ & $2.87(0.25)$ & $3.27(0.27)$ & $2.45(0.23)$ \\
\hline $\mathbf{L R}$ & $2.66(0.18)$ & $2.95(0.27)$ & $2.91(0.09)$ \\
\hline $\mathbf{L T}$ & $3.02(0.11)$ & $2.78(0.59)$ & $3.03(0.14)$ \\
\hline $\mathbf{L T}+\mathbf{A C}$ & $2.75(0.17)$ & $3.29(0.45)$ & $3.02(0.63)$ \\
\hline $\mathbf{L T}+\mathbf{L R}$ & $2.89(0.21)$ & $2.96(0.22)$ & $2.94(0.23)$ \\
\hline \multicolumn{4}{|l|}{$\mathrm{SOM}<53 \mu \mathrm{m}$} \\
\hline $\mathbf{0}$ & $34.67(2.16)$ & $33.88(0.67)$ & $35.18(1.14)$ \\
\hline $\mathbf{A C}$ & $32.95(0.90)$ & $35.17(0.92)$ & $35.11(0.70)$ \\
\hline LR & $32.73(1.31)$ & $33.27(0.51)$ & $32.35(1.33)$ \\
\hline $\mathbf{L T}$ & $33.07(1.41)$ & $34.04(1.84)$ & $34.31(0.84)$ \\
\hline $\mathbf{L T}+\mathbf{A C}$ & $33.22(1.32)$ & $33.92(0.51)$ & $33.51(0.81)$ \\
\hline $\mathbf{L T}+\mathbf{L R}$ & $35.87(0.76)$ & $34.55(1.17)$ & $35.71(1.28)$ \\
\hline
\end{tabular}


Table 3.3 (cont.)

\section{SOM}

fraction/earthworm

Soil depth

treatment

$0-20 \mathrm{~cm} \quad 20-30 \mathrm{~cm} \quad>30 \mathrm{~cm}$

Mixed models (F and p-values)

\begin{tabular}{|c|c|c|c|c|c|c|}
\hline & $\mathbf{F}$ & $\mathbf{p}$ & $\mathbf{F}$ & $\mathbf{p}$ & $\mathbf{F}$ & $\mathbf{p}$ \\
\hline \multicolumn{7}{|l|}{$\mathrm{POM}>250 \mu \mathrm{m}$} \\
\hline L. terrestris & 4.92 & $\underline{0.043}$ & 0.03 & 0.875 & 0.01 & 0.913 \\
\hline Other species & 1.23 & 0.313 & 7.42 & $\underline{0.006}$ & 3.43 & 0.060 \\
\hline $\begin{array}{l}\text { L. terrestris x Other } \\
\text { species }\end{array}$ & 0.13 & 0.879 & 0.84 & 0.451 & 1.42 & 0.272 \\
\hline
\end{tabular}

POM 53-250 $\mu \mathrm{m}$

\begin{tabular}{|c|c|c|c|c|c|c|}
\hline L. terrestris & 2.44 & 0.139 & 0.01 & 0.923 & 3.91 & 0.067 \\
\hline Other species & 0.13 & 0.881 & 1.16 & 0.340 & 1.58 & 0.239 \\
\hline $\begin{array}{l}\text { L. terrestris x Other } \\
\text { species }\end{array}$ & 0.78 & 0.476 & 0.01 & 0.990 & 0.27 & 0.769 \\
\hline \multicolumn{7}{|l|}{$\mathrm{SOM}<53 \mu \mathrm{m}$} \\
\hline L. terrestris & 0.29 & 0.601 & 4.42 & 0.053 & 0.43 & 0.523 \\
\hline Other species & 0.40 & 0.678 & 1.15 & 0.343 & 0.21 & 0.810 \\
\hline $\begin{array}{l}\text { L. terrestris x Other } \\
\text { species }\end{array}$ & 1.49 & 0.258 & 1.80 & 0.200 & 2.75 & 0.096 \\
\hline
\end{tabular}


Table 3.4 SOM fractions ( $\mathrm{g} \mathrm{kg}^{-1}$ cast) and weight of the pooled amount of the surface casts (g) after 61 days, as affected by different earthworm species and their combinations when crop residues were placed at the soil surface or incorporated in the soil profile. No earthworms: $0, L$. terrestris-LT, $A$. caliginosa-AC, L. rubellus-LR. Only means are available because casts were pooled among the four different blocks due to scarcity of cast material.

\begin{tabular}{|c|c|c|c|c|}
\hline \multirow{2}{*}{ Treatment } & \multicolumn{3}{|c|}{ SOM size fractions } & \multirow{2}{*}{$\begin{array}{l}\text { Weight of } \\
\text { casts } \\
\text { produced (g) }\end{array}$} \\
\hline & $>250 \mu \mathrm{m}$ & $>53 \mu \mathrm{m}$ & $<53 \mu \mathrm{m}$ & \\
\hline \multicolumn{5}{|c|}{ Surface applied crop residues } \\
\hline $\mathbf{A C}$ & 3.84 & 3.54 & 36.93 & 45.8 \\
\hline $\mathbf{L R}$ & 22.24 & 8.52 & 47.58 & 110.7 \\
\hline LT & 15.31 & 3.65 & 40.94 & 190.2 \\
\hline $\mathbf{L T}+\mathbf{A C}$ & 14.34 & 4.17 & 36.93 & 135.6 \\
\hline $\mathbf{L T}+\mathbf{L R}$ & 12.71 & 3.41 & 38.39 & 267.0 \\
\hline
\end{tabular}

Crop residues incorporated at $20-30 \mathrm{~cm}$ soil depth

\begin{tabular}{lllll} 
AC & 0.99 & 3.33 & 33.10 & 26.2 \\
$\mathbf{L R}$ & 1.18 & 2.69 & 32.63 & 35.6 \\
$\mathbf{L T}$ & 2.27 & 2.57 & 28.17 & 358.5 \\
$\mathbf{L T}+\mathbf{A C}$ & 1.16 & 3.66 & 33.93 & 366.2 \\
$\mathbf{L T}+\mathbf{L R}$ & 1.74 & 2.50 & 33.90 & 456.0 \\
\hline
\end{tabular}


Table 3.5 Mean amounts and standard errors of water-stable aggregate (WSA) size fractions in $\mathrm{g} \mathrm{kg}^{-1}$ soil (WSA $>2000 \mu \mathrm{m}$, WSA $250-2000 \mu \mathrm{m}$, WSA 53$250 \mu \mathrm{m}$, and silt and clay SC $<53 \mu \mathrm{m})$ of surface-applied and incorporated crop residues per soil depth $(0-20$ and $20-30 \mathrm{~cm})$ after 61 days as affected by different earthworm species and their combinations. No earthworms: 0, L. terrestris-LT, A. caliginosa-AC, L. rubellus-LR. F-statistics and p-values of best fitted linear mixed model of WSA size fractions. Different letters depict pairwise significant differences at $\mathrm{p}<0.05$ : capital letters show significant differences within the main factor L. terrestris, and small letters within the main factor Other species. When only small letters are provided, significant differences refer to the interaction between both earthworm treatments. $\mathrm{N}=4$.

Crop residue treatment and soil depth

\begin{tabular}{|c|c|c|c|c|}
\hline \multirow{2}{*}{$\begin{array}{l}\text { WSA size } \\
\text { class/earthworm } \\
\text { treatment }\end{array}$} & \multicolumn{2}{|c|}{ Surface applied crop residues } & \multicolumn{2}{|c|}{ Incorporated crop residues } \\
\hline & $0-20 \mathrm{~cm}$ & $20-30 \mathrm{~cm}$ & $0-20 \mathrm{~cm}$ & $20-30 \mathrm{~cm}$ \\
\hline \multicolumn{5}{|c|}{ WSA $>2000 \mu \mathrm{m}$ (large macroaggregates) } \\
\hline $\mathbf{0}$ & $1.18(0.15) \mathrm{Aa}$ & $1.95(0.34)$ & $1.67(0.32)$ & $11.17(1.87)$ \\
\hline AC & $3.35(0.97) \mathrm{Ab}$ & $0.87(0.47)$ & $1.00(0.27)$ & $13.27(1.47)$ \\
\hline LR & $3.60(0.64) \mathrm{Ab}$ & $5.33(3.76)$ & $3.86(1.82)$ & $12.24(2.09)$ \\
\hline LT & $4.98(0.74) \mathrm{Ba}$ & $3.62(1.59)$ & $1.31(0.68)$ & $11.01(2.89)$ \\
\hline $\mathbf{L T}+\mathbf{A C}$ & $10.95(2.08) \mathrm{Bb}$ & $1.89(1.20)$ & $1.23(0.78)$ & $18.69(5.18)$ \\
\hline $\mathbf{L T}+\mathbf{L R}$ & $23.31(7.58) \mathrm{Bb}$ & $1.89(0.34)$ & $1.07(0.53)$ & $12.05(2.26)$ \\
\hline \multicolumn{5}{|c|}{ WSA 250 - $2000 \mu \mathrm{m}$ (small macroaggregates) } \\
\hline $\mathbf{0}$ & $67.97(0.67) b$ & $73.01(6.36)$ & $65.37(4.82)$ a & $97.98(14.80)$ \\
\hline $\mathbf{A C}$ & $54.14(2.06) \mathrm{a}$ & $70.53(8.01)$ & $59.05(6.55)$ a & $87.94(14.70)$ \\
\hline LR & $64.28(9.22) \mathrm{ab}$ & $89.65(18.43)$ & $59.45(5.35) \mathrm{a}$ & $80.24(5.91)$ \\
\hline LT & $62.73(7.79) \mathrm{ab}$ & $63.16(10.95)$ & $57.82(1.70)$ a & $68.01(8.61)$ \\
\hline $\mathbf{L T}+\mathbf{A C}$ & $88.42(8.38) b c$ & $78.73(7.16)$ & $109.88(9.04) b$ & $116.86(19.47)$ \\
\hline $\mathbf{L T}+\mathbf{L R}$ & $105.18(5.94) \mathrm{c}$ & $75.11(4.65)$ & $94.38(7.52) b$ & $101.79(10.81)$ \\
\hline
\end{tabular}


Table 3.5 (cont.)

\begin{tabular}{|c|c|c|c|c|}
\hline \multirow{3}{*}{$\begin{array}{l}\text { WSA size } \\
\text { class/earthworm } \\
\text { treatment }\end{array}$} & \multicolumn{4}{|c|}{ Crop residue treatment and soil depth } \\
\hline & \multicolumn{2}{|c|}{ Surface applied crop residues } & \multicolumn{2}{|c|}{ Incorporated crop residues } \\
\hline & $0-20 \mathrm{~cm}$ & $20-30 \mathrm{~cm}$ & $0-20 \mathrm{~cm}$ & $20-30 \mathrm{~cm}$ \\
\hline \multicolumn{5}{|c|}{ WSA 53 - $250 \mu \mathrm{m}$ (microaggregates) } \\
\hline $\mathbf{0}$ & $788.12(3.03) b$ & $790.21(8.96) b c$ & $782.33(4.95) b c$ & $755.73(14.30) \mathrm{ab}$ \\
\hline $\mathbf{A C}$ & $809.33(2.84) b$ & $799.07(6.64) \mathrm{c}$ & $816.75(7.46) \mathrm{d}$ & $770.47(17.01) \mathrm{ab}$ \\
\hline $\mathbf{L R}$ & $808.34(10.53) b$ & $770.64(27.62) a b c$ & $804.54(5.50) \mathrm{cd}$ & $778.04(10.94) b$ \\
\hline $\mathbf{L T}$ & $797.16(10.04) b$ & $809.79(6.50) \mathrm{c}$ & $809.14(3.12) \mathrm{d}$ & $802.61(17.3) b$ \\
\hline $\mathbf{L T}+\mathbf{A C}$ & $736.61(16.66) \mathrm{a}$ & $744.74(4.91) \mathrm{a}$ & $738.98(16.37) \mathrm{ab}$ & $710.31(19.15) \mathrm{a}$ \\
\hline $\mathbf{L T}+\mathbf{L R}$ & $728.35(10.31) \mathrm{a}$ & $760.6(8.18) \mathrm{ab}$ & $750.36(6.30) \mathrm{a}$ & $726.73(8.36) \mathrm{a}$ \\
\hline \multicolumn{5}{|c|}{ Silt and clay fraction $\mathrm{SC}<53 \mu \mathrm{m}$} \\
\hline $\mathbf{0}$ & $129.97(3.10) b$ & $119.70(8.88) \mathrm{a}$ & $137.39(2.11) \mathrm{c}$ & $123.29(2.75) b$ \\
\hline $\mathbf{A C}$ & $109.05(2.64) \mathrm{a}$ & $107.38(1.67) \mathrm{a}$ & $102.86(1.62) \mathrm{a}$ & $106.91(2.91) \mathrm{a}$ \\
\hline LR & $104.17(5.14) \mathrm{a}$ & $110.86(10.51) \mathrm{a}$ & $116.75(2.97) b$ & $114.86(7.16) a b$ \\
\hline $\mathbf{L T}$ & $113.63(6.68) a b$ & $108.62(6.60) \mathrm{a}$ & 105.95 (2.32) ab & $98.56(13.98) a b$ \\
\hline $\mathbf{L T}+\mathbf{A C}$ & $150.73(13.86) b$ & $162.79(4.77) \mathrm{b}$ & $140.68(11.93) \mathrm{abc}$ & $143.54(10.64) b$ \\
\hline $\mathbf{L T}+\mathbf{L R}$ & $134.35(8.11) \mathrm{ab}$ & $154.22(6.13) b$ & $146.36(3.68) \mathrm{c}$ & $145.31(12.81) \mathrm{ab}$ \\
\hline
\end{tabular}




\begin{tabular}{|c|c|c|c|c|c|c|c|c|}
\hline \multirow{3}{*}{$\begin{array}{l}\text { WSA size } \\
\text { class/earthworm } \\
\text { treatment }\end{array}$} & \multicolumn{8}{|c|}{ Crop residue treatment and soil depth } \\
\hline & \multicolumn{4}{|c|}{ Surface applied crop residues } & \multicolumn{4}{|c|}{ Incorporated crop residues } \\
\hline & \multicolumn{2}{|l|}{$0-20 \mathrm{~cm}$} & \multicolumn{2}{|c|}{$20-30 \mathrm{~cm}$} & \multicolumn{2}{|c|}{$0-20 \mathrm{~cm}$} & \multicolumn{2}{|c|}{$20-30 \mathrm{~cm}$} \\
\hline \multicolumn{9}{|c|}{ Mixed models (F and p-values) } \\
\hline & $\mathbf{F}$ & $\mathbf{p}$ & $\mathbf{F}$ & $\mathrm{p}$ & $\mathbf{F}$ & $\mathbf{p}$ & $\mathbf{F}$ & $\mathrm{p}$ \\
\hline \multicolumn{9}{|l|}{ WSA $>2000 \mu \mathrm{m}$} \\
\hline L. terrestris & 39.35 & $\leq 0.0001$ & 0.32 & 0.582 & 0.10 & 0.758 & 0.55 & 0.471 \\
\hline Other species & 12.00 & $\underline{0.001}$ & 2.35 & 0.130 & 1.24 & 0.316 & 1.08 & 0.364 \\
\hline $\begin{array}{l}\text { L. terrestris x Other } \\
\text { species }\end{array}$ & 3.31 & 0.065 & 0.78 & 0.477 & 1.07 & 0.368 & 0.67 & 0.527 \\
\hline \multicolumn{9}{|l|}{ WSA 250 - $2000 \mu \mathrm{m}$} \\
\hline L. terrestris & 103.91 & $\leq 0.0001$ & 1.13 & 0.304 & 3.66 & 0.075 & 0.04 & 0.845 \\
\hline Other species & 40.42 & $\leq 0.0001$ & 1.07 & 0.368 & 5.50 & $\underline{0.016}$ & 1.74 & 0.210 \\
\hline $\begin{array}{l}\text { L. terrestris x Other } \\
\text { species }\end{array}$ & 9.52 & $\underline{0.002}$ & 1.78 & 0.203 & 21.59 & $\leq 0.0001$ & 3.43 & 0.059 \\
\hline \multicolumn{9}{|l|}{ WSA 53 - $250 \mu \mathrm{m}$} \\
\hline L. terrestris & 42.91 & $\leq 0.0001$ & 76.08 & $\leq 0.0001$ & 1.23 & 0.284 & 8.27 & $\underline{0.012}$ \\
\hline Other species & 0.26 & 0.777 & 76.22 & $\leq 0.0001$ & 42.03 & $\leq 0.0001$ & 3.01 & 0.080 \\
\hline $\begin{array}{l}\text { L. terrestris x Other } \\
\text { species }\end{array}$ & 15.24 & $\leq 0.001$ & 12.23 & $\leq 0.001$ & 48.18 & $\leq 0.0001$ & 7.76 & $\underline{0.005}$ \\
\hline
\end{tabular}


Table 3.5 (cont.)

\begin{tabular}{|c|c|c|c|c|c|c|c|c|}
\hline \multirow{3}{*}{$\begin{array}{l}\text { WSA size } \\
\text { class/earthworm } \\
\text { treatment }\end{array}$} & \multicolumn{8}{|c|}{ Crop residue treatment and soil depth } \\
\hline & \multicolumn{4}{|c|}{ Surface applied crop residues } & \multicolumn{4}{|c|}{ Incorporated crop residues } \\
\hline & \multicolumn{2}{|l|}{$0-20 \mathrm{~cm}$} & \multicolumn{2}{|c|}{$20-30 \mathrm{~cm}$} & \multicolumn{2}{|c|}{$0-20 \mathrm{~cm}$} & \multicolumn{2}{|c|}{$20-30 \mathrm{~cm}$} \\
\hline \multicolumn{9}{|c|}{ Mixed models (F and p-values) } \\
\hline & $\mathbf{F}$ & $\mathbf{p}$ & $\mathbf{F}$ & $\mathrm{p}$ & $\mathbf{F}$ & $\mathbf{p}$ & $\mathbf{F}$ & $\mathrm{p}$ \\
\hline \multicolumn{9}{|c|}{ Silt and clay fraction $\mathrm{SC}<53 \mu \mathrm{m}$} \\
\hline L. terrestris & 8.94 & $\underline{0.009}$ & 223.20 & $\leq 0.0001$ & 0.96 & 0.344 & 5.44 & $\underline{0.034}$ \\
\hline Other species & 8.37 & $\underline{0.004}$ & 14.81 & $\leq 0.001$ & 63.18 & $\leq 0.0001$ & 6.09 & $\underline{0.012}$ \\
\hline $\begin{array}{l}\text { L. terrestris x Other } \\
\text { species }\end{array}$ & 8.21 & $\underline{0.004}$ & 20.52 & $\leq 0.001$ & 66.34 & $\leq 0.0001$ & 6.28 & $\underline{0.010}$ \\
\hline
\end{tabular}




\subsubsection{Soil porosity}

When crop residues were surface-applied, porosity was significantly larger at 2.5 to $10 \mathrm{~cm}$ than between 10 and $35 \mathrm{~cm}$ soil depth, decreasing from $0.8 \%$ of total soil volume to an average of $-0.3 \%$ (overall model $\mathrm{p}=0.006$, Table 3.6, Fig. 3.2 A). Porosity in the 2.5 to $10 \mathrm{~cm}$ soil layer was the only one that was significantly larger than the earthworm-free control treatments $(t=4.36, \mathrm{p}=0.004)$. The overall effects of earthworm species and of their interactions with soil depth did not significantly affect soil porosity.

When crop residues were incorporated, porosity was larger in 2.5 to 10,10 to 20 and 20 to $30 \mathrm{~cm}$, than in the deepest considered layer, between 30 and $35 \mathrm{~cm}$ soil depth, decreasing from an average of $1 \%$ to $0.3 \%$ (overall model $p=0.011$, pairwise $p<0.05$, Table 3.6, Fig. 3.2 B). Species effects on soil porosity were largest in L. terrestris $(1.1 \pm 0.2 \%)$ and larger than in $A$. caliginosa $(0.6 \pm 0.2 \%)$ treatments (overall model $\mathrm{p}=0.025$, pairwise $\mathrm{p}<0.008$, Table 3.6). In all cases of the incorporated crop residues treatments, porosity was significantly larger than the earthworm-free control treatments $(\mathrm{p}<0.01)$.

Table 3.6 Summary of the outcomes of best fitted linear mixed model of earthworm-induced porosity (percent of porosity in relation to total soil volume after correction for porosity of control columns) after 61 days, as affected by different earthworm species and soil depth (main factors: species (L. terrestris, $A$. caliginosa, or L. rubellus), soil depths: 2.5 to 10,10 to 20,20 to 30 , and 30 to $35 \mathrm{~cm}$ soil depth). $\mathrm{N}=2$.

\begin{tabular}{lllll} 
& \multicolumn{1}{c}{$\begin{array}{c}\text { Surface applied } \\
\text { crop residues }\end{array}$} & \multicolumn{2}{c}{$\begin{array}{c}\text { Incorporated } \\
\text { crop residues }\end{array}$} \\
\cline { 2 - 6 } & $\mathbf{F}$ & $\mathbf{p}$ & $\mathbf{F}$ & $\mathbf{p}$ \\
\hline Species & 0.91 & 0.429 & 5.27 & $\underline{\mathbf{0 . 0 2 5}}$ \\
Soil depth & 7.36 & $\underline{\mathbf{0 . 0 0 6}}$ & 6.03 & $\underline{\mathbf{0 . 0 1 1}}$ \\
Species x Soil depth & 0.11 & 0.994 & 1.29 & 0.339 \\
\hline
\end{tabular}




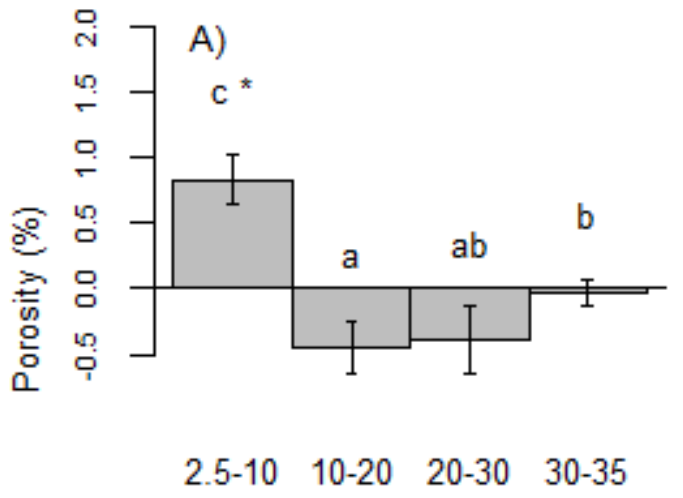

Soil depth $(\mathrm{cm})$

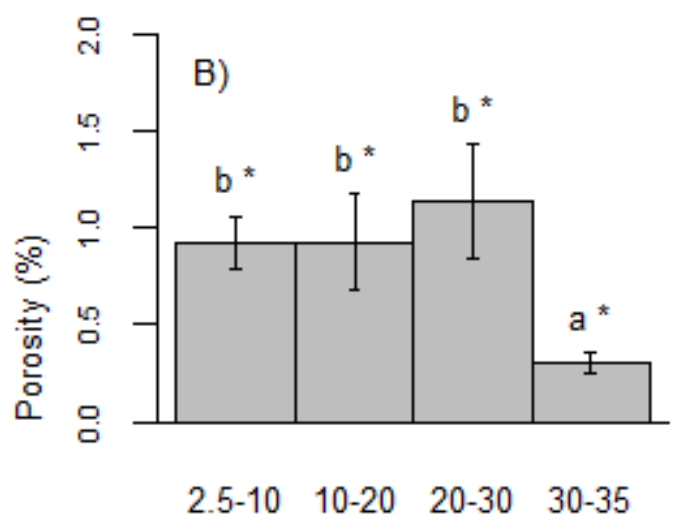

Soil depth (cm)

Figure 3.2 Means and standard errors of earthworm-induced porosity (i.e. after correction for porosity of earthworm-free treatments) averaged over earthworm treatments. A) crop residues applied at the soil surface; B) crop residues incorporated between 20-30 cm depth. Different letters depict pairwise significant differences at $\mathrm{p}<0.05$ of porosity with soil depth layers. "*" depict mean porosity values that are significantly different from 0 (one-tailed t-test). $\mathrm{N}=2$.

\subsection{Discussion}

\subsubsection{Response of earthworms to crop residue placement and SOM distribution}

Earthworm survival during the experiment was high, 91\% on average, irrespective of crop residue placement, except for LR when residues were incorporated and LT was present (33\% survival). Besides, in accordance with our first hypothesis, body weight of surface feeders LR and LT was strongly affected by crop residue placement. Incorporating the residues had stronger negative effects on those species, both in treatments with single species (LT or LR) and when both species were present together $(\mathrm{LT}+\mathrm{LR})$. The fact that most earthworms lost weight, particularly in mixtures of surface-feeding species (i.e., Lumbricus rubellus and Lumbricus terrestris), is consistent with similar studies in literature in which food was limiting as is common in field conditions under arable farming (Giannopoulos et al., 2010; Rizhiya et al., 2007). The fact that L. rubellus lost significantly more weight in the presence of L. terrestris $(-47 \%$ and $-79 \%$ when crop residues were surface-applied and incorporated, respectively, Table 
3.1) than when present alone ( $-0.4 \%$ and $-69 \%$, respectively, Table 3.1$)$ indicates inter-specific competition between both species of the genus Lumbricus, as reported earlier by Uvarov (2009). (Lowe and Butt, 1999) also observed inter-specific competition among both Lumbricus species when surface organic matter was limiting. In their study, L. rubellus constrained the growth of $L$. terrestris, whereas in our study, it was the presence of $L$. terrestris that had a negative effect on L. rubellus. However, it is important to note that Lowe and Butt (1999) started their (three times longer) mesocosm experiments with juvenile individuals. Juveniles of $L$. terrestris and $L$. rubellus are much more similar in size, and the fact that we used (sub)adult individuals could have provided an extra competitive advantage to L. terrestris in comparison to L. rubellus. It is worthwhile mentioning that despite some dispute in the literature regarding the ecological grouping of L. rubellus (e.g., Briones and Álvarez-Otero (2018) considered it an epi-anecic and Hendrix et al. (1999) an epigeic or epi-endogeic) our results indicate negative consequences for L. rubellus' survival and body weight when crop residues are incorporated especially so when together with other surface-feeders, in this case with L. terrestris. Although those fitness costs of L. rubellus do not solve the literature dispute, our results indicate that this species should not be grouped within the endogeics.

Although we expected facilitation effects between L. terrestris and A. caliginosa, particularly when crop residues were surface-applied, the presence of the former did not show any positive effects on the latter species, nor vice versa. It is worthwhile mentioning that our earthworm performance data is limited to body weight and survival, as we did not measure reproductive output during our experiment. Therefore, we cannot know if e.g. more cocoons were produced by $A$. caliginosa in the presence of $L$. terrestris, which could be a facilitation effect. Grubert et al. (2016), in contrast to our results, found a body weight gain of $A$. caliginosa of about $104 \%$ in the presence of L. terrestris. In temperate arable soils, A. caliginosa is the most common earthworm species (Crittenden et al., 2014; Frazão et al., 2017, chapter 2) and it is often assumed that it is stimulated by the incorporation of surface residues by conventional ploughing (Chan, 2001; de Oliveira et al., 2012). Our experimental design aimed at simulating such incorporation of residues, either by manual incorporation or by the activity of $L$. terrestris. However, $A$. caliginosa did not benefit from this, as shown by the similar weight change when this species was subjected alone to experimental conditions or when it was combined with $L$. terrestris, 
regardless of the crop residue placement (Table 3.1). Furthermore, irrespective of the presence of A. caliginosa, L. terrestris incorporated $\mathrm{POM}>250$ to at least $20 \mathrm{~cm}$ soil depth (Tables 3.2 and 3.3 ), and therefore increased the availability of crop residues for A. caliginosa. We can only speculate about possible reasons for the lack of benefit of $A$. caliginosa from crop residue incorporation either through tillage or LT, such as the fact that the organic matter could have been possibly too fresh for that species, and/or that the duration of our experiment was too short. On the other hand, it could very well be that the organic matter content $(3.7 \%)$ of the soil used was sufficiently high, i.e., not limiting, for $A$. caliginosa .

\subsubsection{Earthworm effects on soil structure formation}

\section{Aggregate stability}

All single earthworm species treatments (LR, AC, and LT) tended to affect WSA similarly, while single species effects were commonly opposite to those of species combinations, irrespective of crop residue placement (Table 3.5, Fig. 3.3). First, single species always reduced the silt and clay fraction $(\mathrm{SC}<53)$ and increased WSA $53-250$ and this effect was most pronounced in under incorporated crop residues for both soil depths (Fig. 3.3 B1 and B2), but least pronounced when crop residues were surface-applied and at 20-30 cm depth (Fig. 3.3 A2). Simultaneously, single species treatments never increased macroaggregates (WSA 250-2000 and WSA > 2000) (Fig. 3.3). Second, species combinations always reduced WSA 53-250 (Fig. 3.3). Intriguingly, at $20-30 \mathrm{~cm}$ soil depth, this reduction in WSA 53-250 was accompanied particularly by an increase in the silt and clay fraction $(\mathrm{SC}<53)$, irrespective of crop residue placement (Fig. 3.3 A2 and B2). However, at 0-20 cm soil depth the decrease in WSA 53-250 coincided with an increase in water-stable macroaggregates, both WSA 250-2000 and WSA $>2000$ when crop residues were surface-applied (Fig. 3.3 A1), or only WSA 250-2000 when crop residues were incorporated (Fig. $3.3 \mathrm{~B} 1$ ). It seems, therefore, that single species treatments have a stabilizing effect at the microaggregate level, whereas combinations of functional groups are more effective in formation and stabilization of macroaggregates.

The observed patterns may, however, reflect different ecological mechanisms caused by the species combinations applied. We argue the data indicate competition between LT and LR due to food shortage in the surface-applied crop residue treatments, as a result of more individuals 
within the same feeding guild, i.e. surface-feeders. The food shortage could imply that surface feeders needed to be more active while searching for food which could have resulted in a larger proportion of water-stable macroaggregates, due to larger amounts of ingested soil. This claim is supported by our earthworm performance data (see section 3.4.1 and Table 3.1), where competition between both surface feeders was demonstrated, since LR lost more weight when together with LT then when alone. In the case of incorporated crop residues the earthworm performance data did not support facilitation between LT and AC (see section 3.4.1 and Table 3.1). However, our data suggests complementarity between those species in terms of soil structure formation, as macroaggregates increased in the presence of LT and AC, at least in the upper $20 \mathrm{~cm}$ soil depth.

Our results oppose those found by Bossuyt et al. (2006), Fonte et al. (2007) and Giannopoulos et al. (2010), and, in turn, those studies also showed contrasting results among themselves. Fonte et al. (2007) did not find any effects of earthworms on any aggregate size fraction, whereas Giannopoulos et al. (2010) only found a weak significant increase in water-stable macroaggregates, from $27 \%$ to $32 \%$, with $A$. caliginosa, when residues were incorporated. Bossuyt et al. (2006) demonstrated that large water-stable aggregates increased with all earthworm treatments when crop residues were surface-applied and incorporated in the soil. In the case of Fonte et al. (2007), intact soil cores were used, whereas we repacked soil columns. As for Giannopoulos et al. (2010) who also used repacked columns, their soil pre-treatment involved sieving through $8 \mathrm{~mm}$, whereas we used a 4-mm mesh-size. Consequently, in our study, soil structure was "re-set" due to the soil sieving prior to the experiment's establishment, which could have accounted for the different experimental outcomes. The soil pre-treatment applied by Bossuyt et al. (2006) completely "re-set" initial soil structure, as they sieved their soil through $250 \mu \mathrm{m}$. After correcting for the experimental duration, earthworm density and soil volume used, their rate of WSA $>2000$ formation was between 3 and 5 times larger than ours in the case of surface-applied residues and between 20 and 70 times larger when residues were incorporated, depending on whether earthworm treatments consisted of single or two species. Caro et al. (2012) demonstrated that increasing intra-specific density increased the mobility of several earthworm species, and therefore their activity. Speculatively, we consider that the results of 
A1) Surface crop residues; depth $0-20 \mathrm{~cm}$

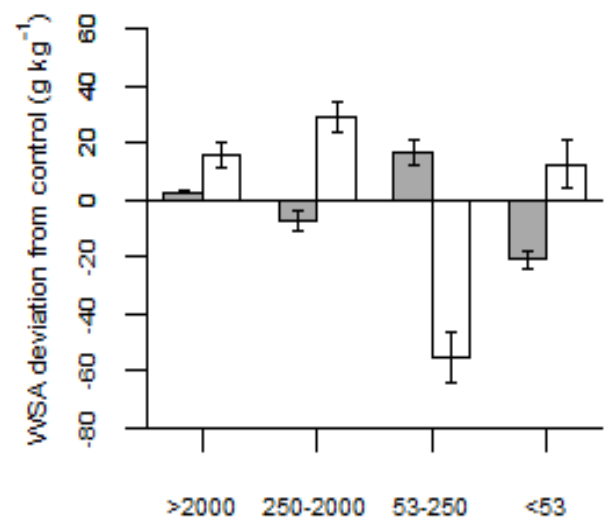

A2) Surface crop residues; depth $20-30 \mathrm{~cm}$

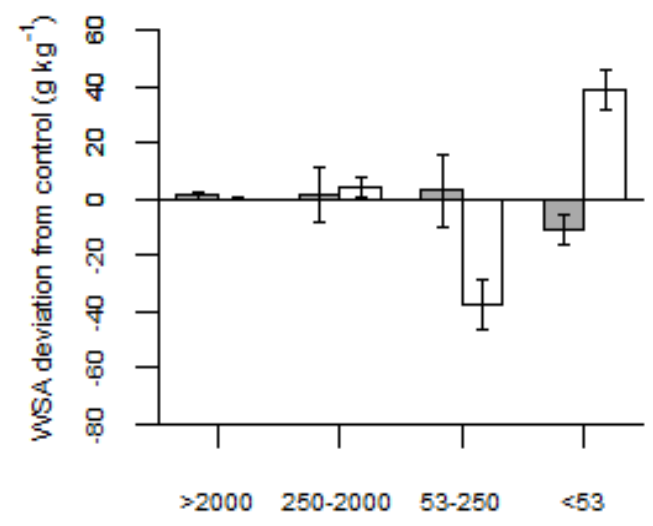

B1) Incorporated crop residues; depth $0-20 \mathrm{~cm}$

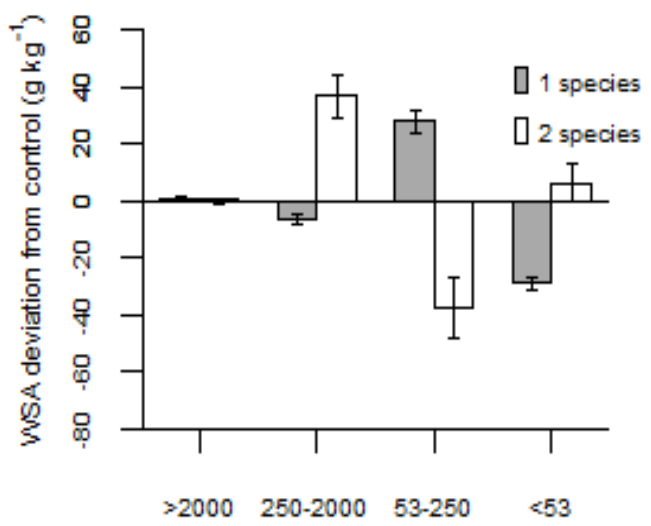

B2) Incorporated crop residues; depth $20-30 \mathrm{~cm}$

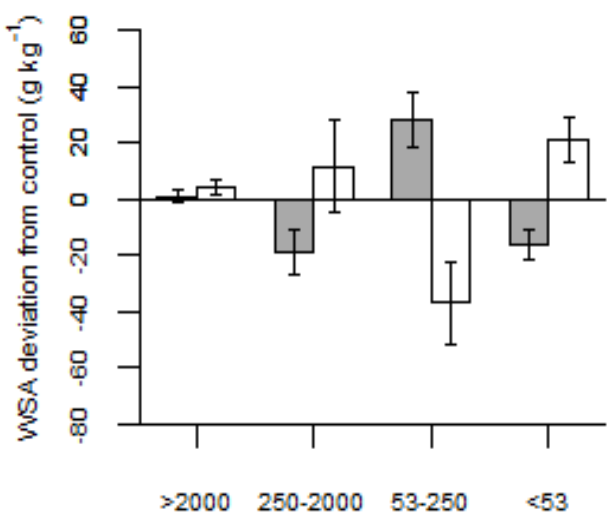

Figure 3.3 Mean and standard error of earthworm-induced water stable aggregates (WSA) size fractions (i.e. after correcting for WSA in earthworm-free control treatments), in treatments of single vs. twospecies of earthworms (grey and white bars, respectively), when crop residues were surface-applied (panels A) or incorporated (panels B), per soil depth (0-20 (panels 1) and 20-30 (panels 2) cm). 
Bossuyt et al. (2006), who used six earthworms in $500 \mathrm{~g}$ of soil (whereas we used a maximum of 0.3 earthworm per $500 \mathrm{~g}$ of soil), could also be a product of the unrealistically high earthworm density used.

\section{Porosity}

Our experiment revealed that crop residue placement may induce some plasticity in earthworm burrowing behaviour, due to the necessity of earthworms to find food. In a field study in Normandy, Pérès et al. (2010) discussed the possibility that low organic matter availability in maize arable fields would increase the number of burrows made by earthworms as a result of their search for food. Our results are in line with this explanation as we observed an increase of earthworm-mediated soil porosity with soil depth, when crop residues were incorporated in the soil profile (Fig. 3.2 B). In contrast, when crop residues were surface-applied, earthworms restricted their burrowing activity up to $10 \mathrm{~cm}$ soil depth (Fig. 3.2 A). However, it seems that the burrowing plasticity brings a trade-off, as especially $L$. rubellus lost much more weight when crop residues were incorporated (average of $69 \%$ body weight loss) than when those were surface-applied ( $0.4 \%$ of body weight loss). To our knowledge, only one study has focussed on earthworm burrowing patterns in relation to location of food (Le Couteulx et al., 2015), but it was restricted to endogeic species. It remains therefore difficult to compare our results with current available literature. Furthermore, our findings regarding $A$. caliginosa contrasted those of Le Couteulx et al. (2015), especially when crop residues were surface-applied. In their study, $A$. caliginosa was shown to increase porosity twice as much when food was mixed throughout the soil profile (approximately $0.68 \%$ porosity in the upper $10 \mathrm{~cm}$ soil depth) than when it was scattered at the soil surface $(0.34 \%)$. In our study however, porosity made by $A$. caliginosa in the upper $10 \mathrm{~cm}$ of soil depth, was approximately $0.79 \%$ when residues were incorporated $v s .0 .93 \%$ when residues were surface-applied (data not shown, as it was NS). Although species-mediated porosity was not significant when crop residues were surface-applied, our results suggest that indeed there is an increase of porosity when food is more limiting. Nevertheless, it is worthwhile mentioning that given the fact that the soil used by Le Couteulx et al. (2015) had a much lower organic matter content than ours ( $2 \%$ vs. $3.7 \%$ ), one would have expected a higher porosity with their experimental conditions, which was not the case. 


\subsubsection{Implications for field conditions}

By incorporating crop residues at ploughing depth, we did not simulate the mouldboard ploughing activity in itself, but one of its consequences, i.e. the displacement of food that would have been available for surface-feeders. In fact, the "real" consequences of ploughing could be even more severe due to the destruction of earthworm burrows and increase in mortality (Chan, 2001), e.g. due to predation. Our results regarding soil structure suggest that large water stable macroaggregates could be reduced through the incorporation of crop residues as compared to surface application. Porosity, however, was stimulated by residue incorporation, at least in single species treatments and within the time frame of 61 days, with the strongest effects for $L$. terrestris. Our data revealed some plasticity in burrowing activities in response to crop residue placement, at least for L. rubellus. A. caliginosa did not have large effects on soil porosity, stable aggregation or SOM distribution, nor was its population density or biomass affected by crop residue placement. Non-inversion, or minimum tillage practices, by providing crop residues at the soil surface seems to improve the fitness of earthworm species that feed at the soil surface with negligible effects on endogeic species, and contributes to improved soil structure due to an increase of water-stable macroaggregates in the upper $20 \mathrm{~cm}$ soil. Furthermore, the combination of anecics ( $L$. terrestris) with the other earthworm functional groups also contributes to improving soil structure, due to the increase of large and small macroaggregates.

\subsection{Conclusions}

We demonstrated that providing crop residues on the soil surface or incorporating them in the soil profile affects earthworm performance, crop residue distribution, soil porosity and aggregate stability. Because of the importance of soil structure maintenance for sustainable land use, and the key role of earthworms belonging to different functional groups in mediating these soil processes, farmers should give careful thought when taking decisions about their crop residue management practices. Those decisions should improve food supply for earthworms belonging to different functional groups. 


\section{Acknowledgements}

We are thankful to Naira Cuareli de Moura and Lur Moragues Saitua for processing soil samples to obtain the WSA data, to Jaap Nelemans, Willeke van Tintelen and Gwénaëlle Flageul for processing soil samples to obtain the SOM data, to Remco Hamoen for helping with the X-ray tomography, to Tamas Salanki and Esperanza Huerta for help in collecting earthworms and to the late Arie Brader for help in filling the columns. This work was supported by the Netherlands Organisation for Scientific Research (NWO) and is part of the research programme Biodiversiteit Werkt! With project number 841.11.003. 


\section{Appendix 3A}

Table A3.1 Initial body weight (mean (SE)) and number of individuals of earthworm species used in each of the experimental treatments. $\mathrm{N}=4$.

L. terrestris (LT)

Treatment

Body weight

(SE)

Number of individuals

\section{L. rubellus (LR)}

Body weight Number of (SE)

\section{A. caliginosa (AC)}

Body weight Number of (SE) individuals

\section{Surface applied crop residues}

$\begin{array}{lllllll}0 & - & 0 & - & 0 & - & 0 \\ \text { AC } & - & 0 & - & 0 & 0.9(0.0) & 4 \\ \text { LR } & - & 0 & 2.6(0.3) & 3 & - & 0 \\ \text { LT } & 14.1(1.2) & 3 & - & 0 & - & 0 \\ \text { LT+AC } & 14.5(1.0) & 3-4 & - & 0 & 0.9(0.1) & 3-4 \\ \text { LT+LR } & 14.0(0.6) & 3-3 & 2.3(0.1) & 3-3 & - & 0\end{array}$

\section{Crop residues incorporated at $20-30 \mathrm{~cm}$ soil depth}

\begin{tabular}{lllllll}
0 & - & 0 & - & 0 & - & 0 \\
AC & - & 0 & - & 0 & $0.9(0.0)$ & 4 \\
LR & - & 0 & $2.3(0.3)$ & 3 & - & 0 \\
LT & $16.3(2.5)$ & 3 & - & 0 & - & 0 \\
LT+AC & $15.6(1.9)$ & $3-4$ & - & 0 & $0.9(0.1)$ & $3-4$ \\
LT+LR & $14.7(2.1)$ & $3-3$ & $2.2(0.3)$ & $3-3$ & - & 0 \\
\hline
\end{tabular}





\section{Chapter 4}

\section{Responses of earthworm communities to crop residue management after inoculation of the earthworm Lumbricus}

terrestris

Accepted for publication in Applied Soil Ecology

Joana Frazão, Ron G. M. de Goede, Tamás E. Salánki, Lijbert Brussaard, Jack H. Faber, Mickaël Hedde, Mirjam M. Pulleman 



\title{
4 Responses of earthworm communities to crop residue
}

\section{management after inoculation of the earthworm Lumbricus}

\section{terrestris}

\begin{abstract}
Earthworms are important for soil functioning in arable cropping systems and earthworm species differ in their response to soil tillage and crop residue management. Lumbricus terrestris Linnaeus (1758) are rare in intensively tilled arable fields. In two parallel field trials with either non-inversion (NIT) or conventional tillage (CT), we investigated the feasibility of inoculating $L$. terrestris under different crop residue management (amounts and placement). Simultaneously, we monitored the response of the existing earthworm communities to L. terrestris inoculation and to crop residue treatments. L. terrestris densities were not affected by residue management. We were not able to infer effects of the inoculation on the existing earthworm communities since L. terrestris also colonized non-inoculated plots. In NIT and two years after trial establishment, the overall native earthworm density was 1.4 and 1.6 times higher, and the epigeic density 2.5 times higher, in treatments with highest residue application $\left(\mathrm{S}_{100}\right)$ compared to $25 \%\left(\mathrm{~S}_{25}\right)$ or no $\left(\mathrm{S}_{0}\right)$ crop residues, respectively. Residue management did not affect earthworm species composition, nor the functional trait diversity and composition, except for the proportion of bifide typhlosolis in the community. In CT, however, crop residues did have a strong effect on species composition, ecological groups and functional traits. Without crop residues $\left(\mathrm{S}_{0}\right)$, epigeic density was respectively 20 and $30 \%$ lower than with crop residues placed on the soil surface $\left(\mathrm{S}_{100}\right)$ or incorporated $\left(\mathrm{I}_{100}\right)$. Community composition was clearly affected by crop residues. Trait diversity was 2.6 to 3 times larger when crop residues were provided, irrespective of placement. Crop residues in CT also resulted in heavier earthworms and in a shift in the community towards species with a thicker epidermis and cuticle, a feather typhlosolis shape, and a higher average cocoon production rate. We conclude that earthworm communities under conventional tillage respond more strongly to the amount of crop residue than to its placement. Under non-inversion
\end{abstract}


Chapter 4

tillage, crop residue amounts affected earthworm communities, but to a smaller degree than under conventional tillage. 


\subsection{Introduction}

Earthworms contribute crucially to soil processes, including in arable cropping systems (Edwards, 2004) and have been classified into ecological groups (Bouché, 1977) to infer effects on soil functioning. Endogeic species burrow horizontally in deeper soil layers and are geophagous, feeding on soil organic matter. Epigeic species inhabit the topsoil without much burrowing and anecic species dig deep permanent burrows with important effects on continuous burrow formation and water infiltration (Keith and Robinson, 2012). Both epigeics and anecics are saprophagous and feed on plant litter on the soil surface (Curry and Schmidt, 2007).

Earthworm communities in arable fields are dominated by endogeics (e.g., Crittenden et al., 2014; Frazão et al., 2017, chapter 2), whereas epigeics and anecics usually occur at low densities, if at all. This may result in an underperformance of earthworm-mediated soil functions that are central for soil quality (Andriuzzi et al., 2015; Postma-Blaauw et al., 2006). The scarcity of epigeics and anecics in arable fields is thought to be the result of intensive conventional tillage (Chan, 2001): direct negative effects are exposure to predation and destruction of permanent burrows of deep-burrowing anecics, and indirect effects are a.o. related to crop residue incorporation into the soil profile. Residue incorporation is negative for epigeics and anecics (Frazão et al., 2019, chapter 3), but positive for endogeics, by increasing the soil organic matter in the deeper layers of the soil profile. Farmers are keen on having anecics inhabiting their arable soils, due to their contribution to soil structure formation and water infiltration (Andriuzzi et al., 2015; Bertrand et al., 2015). Previous studies have reported the effects of the anecic Lumbricus terrestris (Linnaeus, 1758) on soil porosity and other soil fauna (enchytraeids, nematodes and other earthworms) seventeen years after inoculation (Nuutinen et al., 2017).

Community response to disturbance has traditionally been analysed through taxonomic approaches, focussing on species richness and composition (Feld et al., 2009), and in case of earthworms also through broad ecological groups. However, additional information on the functional ecology of communities may reflect important patterns of community assembly and species coexistence (Mouchet et al., 2010), which can be better predictors of ecosystem function than taxonomic indicators (Gagic et al., 2015). In this respect, Ricotta and Moretti (2011) argued that community weighted means (CWM) (Garnier et al., 2004) and Rao's quadratic entropy (RaoQ) (Botta-Dukát, 2005) represent two complementary aspects of functional composition and diversity of communities, i.e. the mean and the diversity of functional traits within a given 
species assemblage, respectively. Inoculating L. terrestris in combination with improved conditions conducive to its survival, as well as stimulating epigeics through the accessibility of crop residues on the soil surface could be an alternative to amend functional diversity of earthworm communities in arable fields.

In the present study, we investigated the response of earthworm communities to crop residue amount and placement in the soil profile, in arable fields under different tillage practices: conventional mouldboard ploughing (hereafter "CT") and non-inversion tillage (hereafter "NIT"). Our objectives were: (i) to evaluate the feasibility of inoculating L. terrestris under different crop residue management in the two tillage systems; (ii) to assess how local earthworm communities (density, diversity, species composition, ecological groups, and functional diversity) are affected by crop residue management and inoculation of L. terrestris. In any traitbased approach, one of the critical aspects is trait selection. Here, we chose traits that are expected to respond to food availability and position in the soil, i.e. body weight, number of cocoons, time to maturity, reproductive strategy, typhlosolis shape, and tegument (cuticle and epidermis) thickness.

We hypothesized that i) the inoculation of L. terrestris would be more successful where crop residues were provided on the soil surface, particularly concurring with less intensive soil disturbance typical of the NIT trial; ii) crop residue management and the inoculation of $L$. terrestris would affect the earthworm community composition, with epigeics benefitting from crop residue availability on the soil surface, but being subject to competition with L. terrestris where inoculated; and endogeics being facilitated by the inoculation of L. terrestris; and iii) the availability of crop residue on the soil surface would favour trait diversity, as well as heavier earthworms with larger reproductive output, faster developmental time, with a less complex typhlosolis shape and thinner tegument. 


\subsection{Materials and methods}

\subsubsection{Study site}

In the summer of 2013, two parallel field trials were installed at the PPO Westmaas research farm of Wageningen University and Research, located in the southwest of The Netherlands. The trials were situated in two adjacent arable fields that differed in tillage practices since 2009: CT and NIT. The CT field was mouldboard ploughed annually and the NIT field was loosened without soil inversion, either with a paragrubber (2009-2012 and 2014-2015) or with a spading machine (2013). Previous samplings indicated that both fields lacked L. terrestris. The soil type is a Haplic Fluvisol (WRB, 2006), developed in calcareous marine deposits with a sandy clay loam texture (49\% sand, $24 \%$ clay) and a $\mathrm{pH}$ of 7.9 in the top $30 \mathrm{~cm}$. Daily average temperature was $11.4{ }^{\circ} \mathrm{C}$ and annual precipitation was $763 \mathrm{~mm}$ over the experimental period (Royal Netherlands Meteorological Institute). The crop rotation of both fields was as follows: winter wheat in 2013, followed by radish (Raphanus sativus subsp. oleiferus) as cover crop, sugar beet in 2014 and winter barley in 2015. Both fields received similar mineral fertilization and synthetic crop protection; no animal manure was used throughout the experimental period.

\subsubsection{Experimental design}

In August 2013, 24 plots (6x6 m) were established in the two neighbouring tillage fields, arranged in a split-plot design with two factors and replicated in four blocks. Within each block, the main plots were randomly assigned to the factor L. terrestris inoculation (two levels: "+", with inoculation and "-", without inoculation), and subplots were randomly assigned to the factor crop residue application (three levels that differed per trial). In the CT field the factor crop residue application comprised three levels: (i) no crop residues (hereafter " $\mathrm{S}_{0}$ "), (ii) incorporation of crop residues (hereafter "I $\mathrm{I}_{100}$ "), and (iii) soil surface applied residues (hereafter "S 100 "). In the NIT field, the factor crop residue application comprised the levels (i) no residues (hereafter " $\mathrm{S}_{0}$ "), (ii) $25 \%$ of crop residues placed on the soil surface (hereafter " $\mathrm{S}_{25}$ "), and (iii) $100 \%$ of crop residues placed on the soil surface (hereafter " $\mathrm{S}_{100}$ ") (Fig. 4.1A). Inherent to the tillage regimes, crop residue treatments under study were not exactly the same for the NIT and CT systems, as it was impossible to test an incorporated crop residue treatment under non-inversion tillage. 
The crop residue amounts used in $\mathrm{S}_{100}$ (CT and NIT trials) and $\mathrm{I}_{100}$ were the same and were applied annually in both trials. We kept the crop residue types as similar as possible across the years, depending on availability. In 2013 a mixture of winter wheat stubble and radish (Raphanus sativus subsp. oleiferus) was applied, as those were the crops grown in both fields. In 2014 a mixture of winter wheat straw and radish was applied after the removal of sugar beet residues, which was the crop harvested at the time, and in 2015 only winter barley stubbles were applied. Grain crop residues were applied at a rate of $4.7 \mathrm{tha}^{-1}$ and radish at a rate of $1.1 \mathrm{tha}^{-1}$ (DW) in the treatments $\mathrm{S}_{100}$ and $\mathrm{I}_{100}$ of both trials.

In October 2013, seven weeks before Fall tillage, (sub)adults of L. terrestris (Starfood, Barneveld, The Netherlands) were inoculated in the "+" plots of both fields at a density of 20 ind. $\mathrm{m}^{-2}$. For a week prior to inoculation, the individuals were acclimatized in tempex boxes with a compost substrate provided by Starfood, at $6{ }^{\circ} \mathrm{C}$ in a climate chamber. Each individual was carefully checked and the ones not appearing healthy and vigorous were discarded. In each of the “+” plots, a 3x3 grid with $2 \mathrm{~m}$ spacing (Fig. 4.1B) was established and around each of the intersects four holes were dug to $40 \mathrm{~cm}$ deep, and 20 individuals of L. terrestris were placed in each hole. Soil pits were moistened before and after introducing earthworms, and refilled with moistened soil. The order of the plots to be inoculated was a priori randomized. To prevent predation by birds, flags and cannon sounds were used and upon observing mole activity, mole traps were placed in the fields.

\subsubsection{Data collection}

\section{Earthworm sampling}

Earthworms were sampled in Spring (May) and Fall (September) 2014 and in Fall (October) 2015 in the CT and NIT trials. During the first two sampling events three soil monoliths of 30x30x20 (lxbxd) cm were collected in each plot, whereas in the last sampling event, only two monoliths were taken per plot, due to logistical constraints. After digging a monolith, 2.51 of allyl isothiocyanate (AITC) solution (1 ml AITC dispersed in $20 \mathrm{ml}$ 2-propanol added to 101 of water and mixed thoroughly) was applied to the pit, to expel deep burrowing earthworms. Andriuzzi et al. (2017) have demonstrated that this is a suitable earthworm sampling method for all earthworm ecological groups in arable systems. Individuals expelled by AITC were rinsed 94 
and collected alive for further laboratory work. Monoliths were stored separately in plastic bags for transportation and storage in the lab at $2{ }^{\circ} \mathrm{C}$ until hand-sorting.

\section{Earthworm sample processing and body weight measurements}

Earthworm samples were hand-sorted in the laboratory and individuals were kept alive in pots with moist paper tissue at $16{ }^{\circ} \mathrm{C}$ for $48 \mathrm{~h}$ to void the guts. After voiding of the guts, live body weight and developmental stage (juvenile, subadult or adult) were recorded individually for the Spring 2014 samples. Specimens were then killed in 70\% alcohol and identified to species immediately. For the hand-sorted individuals collected in Fall 2014 and 2015, some adjustments were made to reduce sample processing time. Therefore, (part of) the individuals were stored in $70 \%$ alcohol immediately after voiding of the guts. In those cases, the dead body weight was measured after placing the specimens in water for 10 minutes, to allow body rehydration. As in Spring 2014, individuals were weighed, assigned to their developmental stage and identified to species. To correct for differences in the method of body weight measurement among different samplings, 20 individuals sampled in Spring 2014 (live body weights ranging from 0.1 to $1.6 \mathrm{~g}$ ) were re-weighed after being stored for two years in alcohol. A linear regression (Equation 4.1, adjusted $\mathrm{R}^{2}=0.90 ; \mathrm{p}=1.318 \times 10^{-10}$ ) was computed between the rehydrated alcohol-conserved body weight of 2016 (BW $_{\text {ethanol }}$ in Equation 4.1) and the live body weight of 2014 (BW live $_{\text {in }}$ Equation 4.1).

$B W_{\text {live }}=B W_{\text {ethanol }} \times 1.05663+0.03372 \quad$ Equation 4.1

The regression coefficients in Equation 4.1 were used as a correction factor to express all body weight values per g live weight. For the purpose of this study, only (sub)adult individuals were used, given that trait values for juveniles are lacking and might differ from adult trait values. Adult individuals were identified using Sims and Gerard (1999) and juveniles using (StöpBowitz, 1969), and complete individuals, as well as heads, were considered for identification. Body weight was measured for intact individuals only excluding some $12 \%$ of the sampled specimens. 


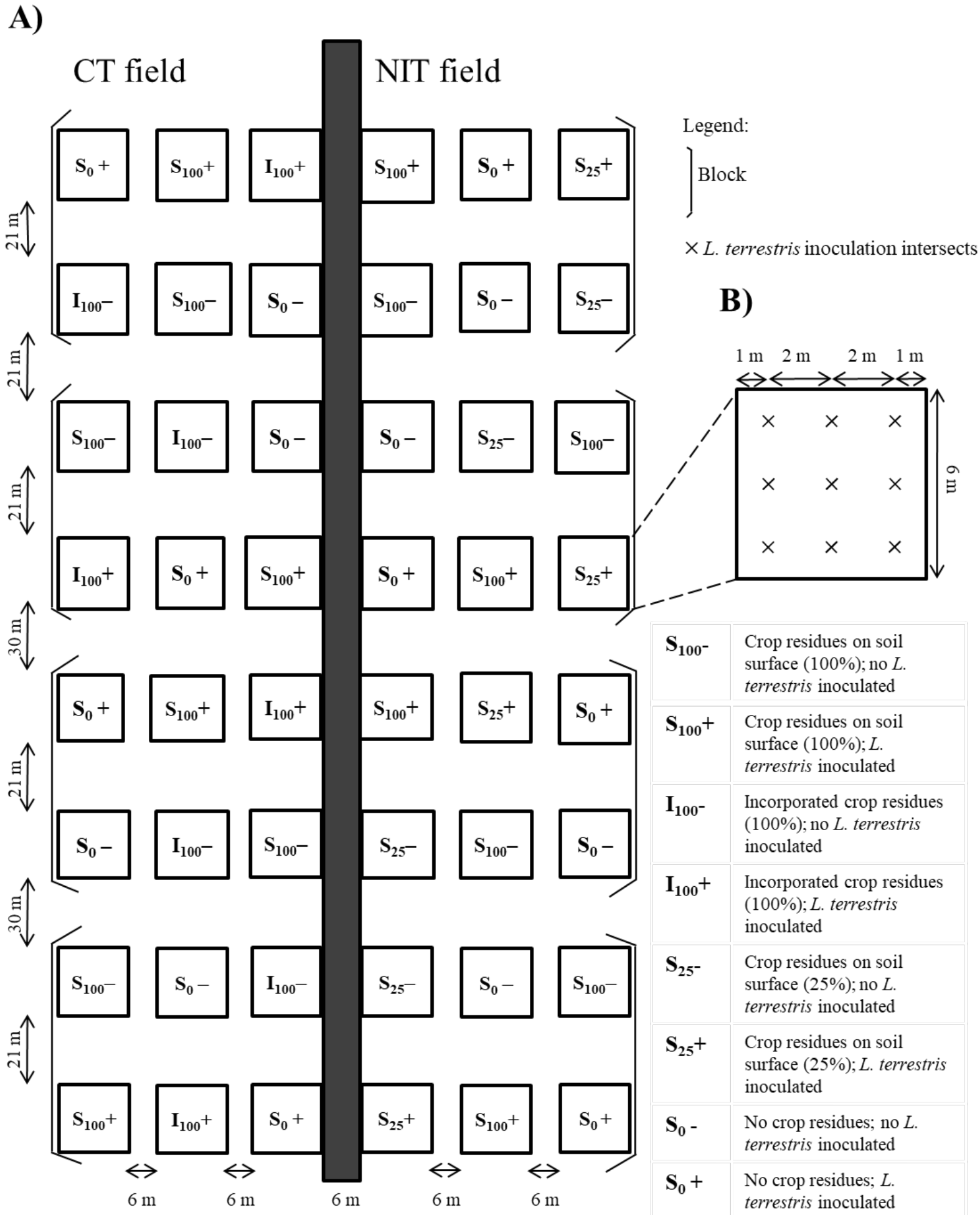

Figure 4.1 A) Scheme of the experimental design of the CT and NIT trials and list of treatments. B) Details of inoculation scheme within each + plot. 


\subsubsection{Functional traits}

We assessed seven functional traits (five continuous and two categorical) (Table 4.1) that were expected to respond to resource availability: body weight in grams (measured per individual, corrected for different weighing methods at different sampling occasions - see equation 4.1 and averaged for each species over the study duration), average number of cocoons produced per year, reproductive strategy, typhlosolis shape, average time to maturity in weeks (Hedde et al., 2012a), and cuticle and epidermis thickness in $\mu \mathrm{m}$ (Briones and Álvarez-Otero, 2018). Body weight was used as an indicator for the condition of the individuals and relates to the energetic investment in growth; reproductive strategy and number of cocoons relate to the investment in reproduction, thereby reflecting the potential for population recovery after disturbance; typhlosolis shape relates to the nutrient uptake efficiency (Pelosi et al., 2013a); time to maturity reflects the investment in individual development, and often represents a trade-off with reproductive investment (Stearns, 1976); finally, tegument thickness (cuticle and epidermis) reflects the burrowing ability of the species (Briones and Álvarez-Otero, 2018).

\subsubsection{Data analysis}

$\underline{\text { Taxonomic and ecological group approaches }}$

Earthworm species densities and ecological group densities (epigeic and endogeic) of subsamples were averaged per plot for each sampling period and expressed as number of individuals per meter square. Shannon diversity index was computed per plot, as a measure of species diversity (richness and relative abundance).

\section{Trait-based approach}

Functional diversity (FD) was assessed by community weighted means (CWM) and Rao's quadratic entropy (RaoQ). CWM was calculated for each trait, as the mean of trait values for each species in the community, weighted by the relative abundance of the species associated with that value (Lavorel et al., 2008). RaoQ was calculated for the complete set of traits as the dissimilarity between pairs of species within each plot, weighted by the product of the relative abundance of both species (Leps et al., 2006). 


\section{$\underline{\text { Statistical analysis }}$}

The taxonomic, ecological group and trait data were analysed using univariate and multivariate statistics. NIT and CT trials were considered separate datasets, to avoid statistical pseudoreplication (Hurlbert, 1984), since the sample size of each tillage system was only one. As we were interested in the effects of inoculation of $L$. terrestris, we excluded this species from the analyses. The univariate approach consisted of mixed linear models using crop residue application and inoculation treatments as fixed factors. The structure of the split-plot design was incorporated in each model by nesting the crop residue application within the inoculation factor in the random factors. Several response variables were modelled for each sampling season: (sub)adult earthworm density, Shannon diversity index, epigeic and endogeic densities, CWM for each trait, and RaoQ for all traits combined. If overall linear mixed models were statistically significant at $\mathrm{p}<0.05$, pairwise comparisons were computed. P-value adjustments to avoid inflation type I errors were considered necessary when the interaction between the fixed effects was significant due to the large number of pairwise comparisons. In those cases, post-hoc adjustments (Tukey HSD) were used. Overall models' distribution and variance assumptions were inspected visually, and if needed, a variance structure was used to avoid heteroscedasticity (Zuur et al., 2009).

The multivariate approach consisted of testing the centroid "location" (Anderson, 2001) and the "dispersion" (Anderson, 2006) of the community's species composition. An analogy towards the CWM was made with a multivariate test of the "CWM composition". The centroid "location" analysis is a non-parametric version of a multivariate ANOVA, whereas the "dispersion" analysis tests the homogeneity of multivariate dispersions (Anderson, 2006). Both analyses are based on dissimilarity matrices. For the species composition analysis, a Bray-Curtis dissimilarity matrix was used, after square root transformation of the earthworm density data. For the CWM composition analysis a Gower dissimilarity matrix was used, allowing the combination of categorical and continuous variables. If the centroid location analysis was significant, a 
Table 4.1 Literature acquired and measured (body weight) trait values of the species sampled in both trials. Earthworm species are arranged by ecological groups (first three species are endogeics; and last three are epigeics).

\begin{tabular}{|c|c|c|c|c|c|c|c|}
\hline Species & $\begin{array}{l}\text { Mean of adult } \\
\text { body weight } \\
\text { (g) } \dagger\end{array}$ & $\begin{array}{l}\text { No. of } \\
\text { cocoons } \\
\text { (per year) } t\end{array}$ & $\begin{array}{l}\text { Reproductive } \\
\text { strategy }+\end{array}$ & $\begin{array}{l}\text { Typhlosolis } \\
\text { shape }+\end{array}$ & $\begin{array}{l}\text { Time to } \\
\text { maturity } \\
\text { (weeks) } \ddagger\end{array}$ & $\begin{array}{l}\text { Cuticle } \\
\text { thickness } \\
(\mu \mathrm{m}) \S \\
\end{array}$ & $\begin{array}{l}\text { Epidermis } \\
\text { thickness } \\
(\mu \mathrm{m}) \S \\
\end{array}$ \\
\hline A. caliginosa & 0.33 & 27 & Biparental & bifide & 55 & 0.46 & 34.19 \\
\hline A. chlorotica & 0.22 & 27 & Biparental & bifide & 36 & 1.60 & 27.39 \\
\hline A. rosea & 0.18 & 35 & Parthenogetic & bifide & 55 & $0.67 \#$ & $32.68 \#$ \\
\hline E. tetraedra & 0.08 & 72 & Parthenogetic & simple & 13 & $1.74 \#$ & $27.27 \#$ \\
\hline L. castaneus & 0.20 & 65 & Biparental & feather & 24 & $1.74 \#$ & $27.27 \#$ \\
\hline L. rubellus & 0.54 & 106 & Biparental & feather & 37 & 3.21 & 39.42 \\
\hline
\end{tabular}

$\dagger$ measured in this study

\$ Hedde et al. (2012a)

$\S$ Briones and Álvarez-Otero (2018)

\# Not measured in Briones and Álvarez-Otero (2018). Expert knowledge of Prof. Dr. Maria Briones 
nonmetric multidimensional scaling (NMDS) was plotted to visualize the results. As in the univariate analysis, crop residue application and L. terrestris inoculation were used as explanatory variables, and the split-plot design structure was incorporated in a permutation scheme that considered our nested design.

We present the Fall 2015 results in the main text of this article. As most univariate and multivariate tests of Spring and Fall 2014 appeared as not significant, these are presented in the Appendix 4A (Tables A4.1 - A4.9). The raw datasets of all seasons for both experimental trials are available in Appendix 4B. All analyses were performed with R 3.3.1 (R CoreTeam, 2014), using packages nlme 3.1-131, lsmeans 2.27-61, FD 1.0-12, ade4 1.7-6 and vegan 2.4-5.

\subsection{Results}

\subsubsection{Inoculation of Lumbricus terrestris}

L. terrestris was found in both experimental trials throughout the sampling seasons, although the patterns were erratic and unrelated to the inoculation and crop residue treatments (Table 4.2). Furthermore, besides the inoculated (sub)adult individuals, juveniles were also found (Table 4.2), already in Spring 2014 (just seven months after inoculation). Highest average juvenile density of 9.3 ind.m ${ }^{-2}$ was recorded in Fall 2014 in NIT $-\mathrm{S}_{25}$ - and in CT $-\mathrm{S}_{100}+$ (Table 4.2), while highest average densities of (sub)adults reached 2.8 ind. $\mathrm{m}^{-2}$ in NIT $-\mathrm{S}_{25}+$ and 1.9 ind.m ${ }^{-2}$ in CT $-\mathrm{I}_{100^{+}}$, also in Fall 2014. By the end of the study, in Fall 2015, no (sub)adults of $L$. terrestris were found in the CT trial, nor in the non-inoculated plots of the NIT trial. However,

irrespective of the crop residue treatments, 1.4 ind. $\mathrm{m}^{-2}$ were found in the inoculated plots of the NIT trial. Juveniles were found in higher densities, particularly in the NIT trial, in erratic patterns unrelated to crop residue treatments. 
Table 4.2 Mean, standard error (SE) and occurrence in number of plots (Freq) of the density of (sub)adult and juvenile individuals of $L$. terrestris (ind. $\mathrm{m}^{-2}$ ) in the non-inversion tillage (NIT) and conventional tillage (CT) trials, for each of the sampling times (Spring 2014, Fall 2014 and Fall 2015). For legend of the treatments, see Fig. 4.1.

\begin{tabular}{|c|c|c|c|c|c|c|c|c|c|c|c|c|c|}
\hline \multicolumn{7}{|c|}{ NIT trial } & \multicolumn{7}{|c|}{ CT trial } \\
\hline & \multicolumn{2}{|c|}{ Spring 2014} & \multicolumn{2}{|c|}{ Fall 2014} & \multicolumn{2}{|c|}{ Fall 2015} & & \multicolumn{2}{|c|}{ Spring 2014} & \multicolumn{2}{|c|}{ Fall 2014} & \multicolumn{2}{|c|}{ Fall 2015} \\
\hline & Mean (SE) & Freq & Mean (SE) & Freq & Mean (SE) & Freq & & Mean (SE) & Freq & Mean (SE) & Freq & Mean (SE) & Freq \\
\hline \multicolumn{14}{|c|}{ (Sub)adult individuals } \\
\hline $\mathbf{S}_{100^{-}}$ & $0.0(0.0)$ & 0 & $0.9(0.9)$ & 1 & $0.0(0.0)$ & 0 & $\mathbf{S}_{100^{-}}$ & $0.0(0.0)$ & 0 & $0.9(0.9)$ & 1 & $0.0(0.0)$ & 0 \\
\hline $\mathbf{S}_{100}+$ & $0.0(0.0)$ & 0 & $0.09(0.0)$ & 0 & $1.4(1.4)$ & 1 & $\mathbf{S}_{100^{+}}$ & $0.0(0.0)$ & 0 & $0.0(0.0)$ & 0 & $0.0(0.0)$ & 0 \\
\hline $\mathbf{S}_{25^{-}}$ & $0.9(0.9)$ & 1 & $0.0(0.0)$ & 0 & $0.0(0.0)$ & 0 & $\mathbf{I}_{100^{-}}$ & $0.0(0.0)$ & 0 & $0.0(0.0)$ & 0 & $0.0(0.0)$ & 0 \\
\hline $\mathbf{S}_{25}+$ & $0.0(0.0)$ & 0 & $2.8(1.5)$ & 2 & $1.4(1.4)$ & 1 & $\mathbf{I}_{100^{+}}$ & $0.9(0.9)$ & 1 & $1.9(1.3)$ & 2 & $0.0(0.0)$ & 0 \\
\hline $\mathbf{S}_{0^{-}}$ & $0.0(0.0)$ & 0 & $0.0(0.0)$ & 0 & $0.0(0.0)$ & 0 & $\mathbf{S}_{0^{-}}$ & $0.0(0.0)$ & 0 & $0.0(0.0)$ & 0 & $0.0(0.0)$ & 0 \\
\hline$S_{0}+$ & $0.0(0.0)$ & 0 & $0.0(0.0)$ & 0 & $1.4(1.4)$ & 1 & $\mathbf{S}_{0}+$ & $0.0(0.0)$ & 0 & $0.0(0.0)$ & 0 & $0.0(0.0)$ & 0 \\
\hline \multicolumn{14}{|c|}{ Juvenile individuals } \\
\hline$S_{100^{-}}$ & $1.9(1.3)$ & 2 & $1.9(1.3)$ & 1 & $8.3(2.8)$ & 4 & $\mathbf{S}_{100^{-}}$ & $0.9(0.0)$ & 1 & $0.9(0.9)$ & 1 & $1.4(1.4)$ & 1 \\
\hline $\mathbf{S}_{100}+$ & $4.6(2.1)$ & 3 & $8.3(3.1)$ & 3 & $6.9(2.9)$ & 4 & $\mathbf{S}_{100}+$ & $0.9(0.0)$ & 1 & $9.3(3.0)$ & 4 & $4.2(2.0)$ & 3 \\
\hline $\mathbf{S}_{25^{-}}$ & $2.8(2.8)$ & 1 & $9.3(4.7)$ & 3 & $1.4(1.4)$ & 1 & $\mathbf{I}_{100^{-}}$ & $0.9(0.0)$ & 1 & $0.9(0.9)$ & 1 & $2.8(1.8)$ & 2 \\
\hline $\mathbf{S}_{25}+$ & $0.0(0.0)$ & 0 & $7.4(4.8)$ & 3 & $0.0(0.0)$ & 0 & $\mathbf{I}_{100^{+}}$ & $0.0(0.0)$ & 0 & $6.5(3.2)$ & 2 & $1.4(1.4)$ & 1 \\
\hline $\mathbf{S}_{0^{-}}$ & $1.9(1.9)$ & 1 & $3.7(2.9)$ & 2 & $4.2(2.0)$ & 3 & $\mathbf{S}_{0^{-}}$ & $0.0(0.0)$ & 0 & $4.6(2.5)$ & 2 & $0.0(0.0)$ & 0 \\
\hline$S_{0}+$ & $0.0(0.0)$ & 0 & $8.3(5.0)$ & 3 & $0.0(0.0)$ & 0 & $\mathbf{S}_{0}+$ & $0.0(0.0)$ & 0 & $5.6(2.2)$ & 3 & $1.4(1.4)$ & 1 \\
\hline
\end{tabular}




\subsubsection{Earthworm density}

In NIT, in Fall 2015, native earthworm (sub)adult density was higher in $\mathrm{S}_{100}$ than in $\mathrm{S}_{25}$ and $\mathrm{S}_{0}$ (60\% and 37\%, respectively, Table 4.3), whereas it was not affected by the inoculation of $L$. terrestris nor by the interaction between both factors. In CT, native earthworm (sub)adult density was not affected by L. terrestris inoculation, irrespective of residue application (Table 4.3).

\subsubsection{Species diversity and composition}

Besides the inoculated L. terrestris, (sub)adult individuals of six other earthworm species were found in the two tillage trials: Aporrectodea caliginosa (Savigny, 1826), Allolobophora chlorotica (Savigny, 1826), Aporrectodea rosea (Savigny, 1826), Eiseniella tetraedra (Savigny, 1826), Lumbricus castaneus (Savigny, 1826) and Lumbricus rubellus (Hoffmeister, 1843). Among them, only one individual of E. tetraedra was found in each trial in Spring 2014. L. castaneus was not detected during Fall 2014 (both trials), nor in Spring 2014 in the CT trial.

In both trials in Fall 2015, Shannon diversity index was low $(\leq 1.0)$ and was not affected by $L$. terrestris inoculation, irrespective of residue application (Table 4.3). Furthermore, in NIT, local earthworm community composition was not affected by L. terrestris inoculation, irrespective of residue application, whereas in $\mathrm{CT}$, earthworm community composition showed differences in terms of centroid location in the multivariate dimensional space, both with respect to the crop residue application and to $L$. terrestris inoculation (Table 4.4, Fig. 4.2). The community composition showed a separation between the surface-applied $\left(\mathrm{S}_{100}\right)$ and the incorporated $\left(\mathrm{I}_{100}\right)$ crop residue treatments $v s$. the treatment where no crop residues $\left(\mathrm{S}_{0}\right)$ were provided. The separation between L. terrestris inoculation treatments was less clear (Fig. 4.2), concurring with the p-value of 0.042 , which although significant was rather high. 
Table 4.3 Mean and standard error (SE) of earthworm (sub)adult density, density of epigeics and endogeics (ind. $\mathrm{m}^{-2}$ ) and Shannon diversity index of the non-inversion tillage (NIT) and conventional tillage (CT) trials in Fall 2015. For legend of the treatments, see Fig. 4.1. F-statistics and associated p-value of best fitted linear mixed model of earthworm densities and Shannon diversity index. Capital letters show significant pairwise differences within the main factor Crop residue application and small letters within the main factor L. terrestris inoculation.

\begin{tabular}{|c|c|c|c|c|c|c|c|c|c|c|c|c|c|c|c|c|}
\hline \multirow[b]{2}{*}{ Treatments } & \multicolumn{8}{|c|}{ NIT trial } & \multicolumn{8}{|c|}{ CT trial } \\
\hline & \multicolumn{2}{|c|}{$\begin{array}{l}\text { (Sub)adult } \\
\text { density }\end{array}$} & \multicolumn{2}{|c|}{$\begin{array}{l}\text { Shannon } \\
\text { diversity }\end{array}$} & \multicolumn{2}{|c|}{ Epigeics $\dagger$} & \multicolumn{2}{|c|}{ Endogeics } & \multicolumn{2}{|c|}{$\begin{array}{l}\text { (Sub)adult } \\
\text { density }\end{array}$} & \multicolumn{2}{|c|}{$\begin{array}{l}\text { Shannon } \\
\text { diversity }\end{array}$} & \multicolumn{2}{|c|}{ Epigeics $\uparrow$} & \multicolumn{2}{|c|}{ Endogeics : } \\
\hline $\mathbf{S}_{100-}$ & \multicolumn{2}{|c|}{$109.7(8.6) \mathrm{Ba}$} & \multicolumn{2}{|c|}{$0.9(0.1)$} & \multicolumn{2}{|c|}{$30.5(3.6) \mathrm{Ba}$} & \multicolumn{2}{|c|}{$79.2(6.9) \mathrm{Ba}$} & \multicolumn{2}{|c|}{$73.6(11.4)$} & \multicolumn{2}{|c|}{$1.0(0.1)$} & \multicolumn{2}{|c|}{$29.2(1.4) \mathrm{Ba}$} & \multicolumn{2}{|c|}{$44.4(10.9)$} \\
\hline $\mathrm{S}_{100}+$ & \multicolumn{2}{|c|}{$97.2(18.2) \mathrm{Ba}$} & \multicolumn{2}{|c|}{$0.7(0.1)$} & \multicolumn{2}{|c|}{$23.6(8.9) \mathrm{Ba}$} & \multicolumn{2}{|c|}{$73.6(11.6) \mathrm{Ba}$} & \multicolumn{2}{|c|}{$81.9(11.4)$} & \multicolumn{2}{|c|}{$0.8(0.2)$} & \multicolumn{2}{|c|}{$31.9(9.2) \mathrm{Ba}$} & \multicolumn{2}{|c|}{$50.0(9.1)$} \\
\hline $\mathbf{S}_{25^{-}} / \mathbf{I}_{100^{-}}$ & \multicolumn{2}{|c|}{$66.7(22.3) \mathrm{Aa}$} & \multicolumn{2}{|c|}{$0.7(0.2)$} & \multicolumn{2}{|c|}{$15.3(7.6) \mathrm{Aa}$} & \multicolumn{2}{|c|}{$51.4(17.0) \mathrm{Aa}$} & \multicolumn{2}{|c|}{$75.0(10.3)$} & \multicolumn{2}{|c|}{$0.6(0.1)$} & \multicolumn{2}{|c|}{$13.9(3.6) \mathrm{Ba}$} & \multicolumn{2}{|c|}{$61.1(7.5)$} \\
\hline $\mathbf{S}_{25}+/ \mathbf{I}_{100}+$ & $62.5(8$ & 9) $\mathrm{Aa}$ & $0.8(0$ & & $6.9(1$. & & 55.5 & $\mathrm{Aa}$ & 86.1( & & $1.0(0$. & & $29.2(3$ & $\mathrm{Ba}$ & 56.9 & \\
\hline $\mathbf{S}_{0^{-}}$ & $70.8(1$ & .1) $\mathrm{Aa}$ & $0.6(0$ & & $13.9(5$ & $\mathrm{Aa}$ & 56.9 & 9) $\mathrm{ABa}$ & 70.8 & & $0.7(0$. & & $6.9(2.7$ & & 63.9 & \\
\hline $\mathbf{S}_{0}+$ & $80.5(1$ & .1) $\mathrm{Aa}$ & $0.7(0$ & & $8.3(4$. & & $72.2(1$ & 2) $\mathrm{ABa}$ & 56.9( & .3) & $0.3(0$. & & $5.6(3.5$ & & $51.4(1$ & 4.1) \\
\hline & $\mathbf{F}$ & $\mathbf{p}$ & $\mathbf{F}$ & $\mathbf{p}$ & $\mathbf{F}$ & $\mathbf{p}$ & $\mathbf{F}$ & p & $\mathbf{F}$ & p & $\mathbf{F}$ & p & $\mathbf{F}$ & p & $\mathbf{F}$ & p \\
\hline $\begin{array}{l}\text { Crop } \\
\text { residues }\end{array}$ & 9.753 & $\underline{0.003}$ & 1.847 & 0.200 & 18.084 & $\underline{0.0002}$ & 5.800 & $\underline{0.017}$ & 0.859 & 0.448 & 3.616 & 0.059 & 58.560 & $\leq 0.001$ & 0.860 & 0.448 \\
\hline Inoculation & 0.015 & 0.910 & 0.035 & 0.863 & 2.073 & 0.246 & 0.091 & 0.783 & 0.038 & 0.858 & 0.450 & 0.550 & 2.140 & 0.240 & 0.212 & 0.676 \\
\hline $\begin{array}{l}\text { residues } x \\
\text { inoculation }\end{array}$ & 0.445 & 0.651 & 1.456 & 0.272 & 0.039 & 0.962 & 0.703 & 0.515 & 0.690 & 0.520 & 3.620 & 0.059 & 3.058 & 0.085 & 0.422 & 0.665 \\
\hline
\end{tabular}

$\uparrow$ Epigeic species: Lumbricus castaneus, Lumbricus rubellus

+ Endogeic species Aporrectodea caliginosa, Allolobophora chlorotica, Aporrectodea rosea 

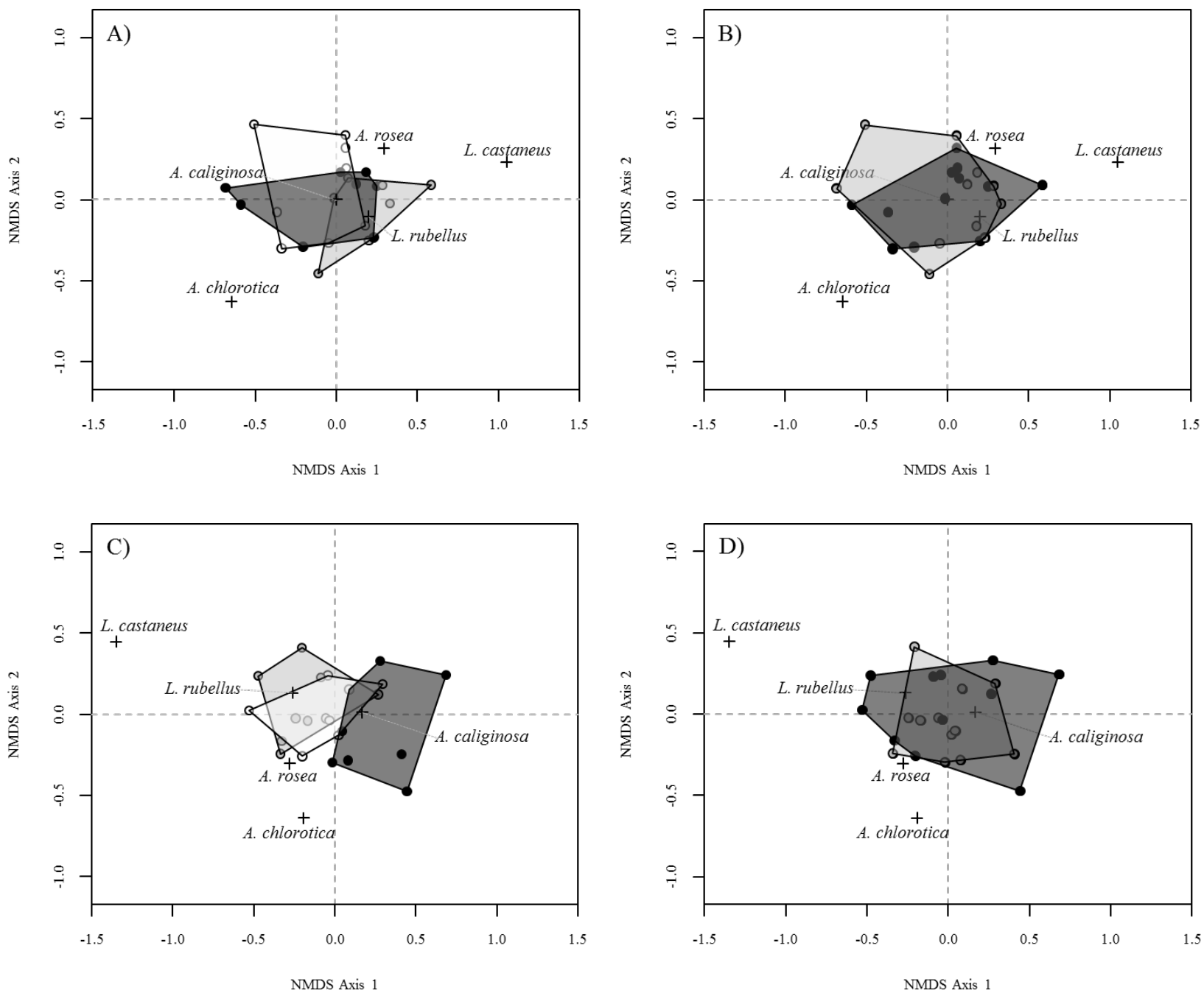

Figure 4.2 Nonmetric multidimensional scaling (NMDS) of (sub)adult earthworm communities for the main factor crop residues (panels A) and C)) and main factor inoculation of L. terrestris (panels B) and D)) of the non-inversion (NIT, panels A) and B), stress $=0.13$ ) and conventional tillage trials $(C T$, panels $C$ ) and D), stress $=0.16$ ), in Fall 2015. Dissimilarity between species composition was determined through a Bray-Curtis distance matrix and earthworm density was square root transformed. Inoculated $L$. terrestris was excluded from dissimilarity matrices. Polygons in different colours indicate different crop residues $\left(\mathrm{S}_{100}\right.$ : grey, $\mathrm{S}_{25} / \mathrm{I}_{100}$ : white, $\mathrm{S}_{0}$ : black) and inoculation levels (+: black, -: grey). 
Table 4.4 F and p-values from non-parametric permutational multivariate analysis of variance (Location) and from multivariate homogeneity of variances (Dispersion) of (sub)adult earthworm community composition for each of the main factors (crop residues and inoculation of $L$. terrestris) and their interaction in the case of Location, of the non-inversion tillage (NIT) and conventional tillage trials (CT), for Fall 2015. Inoculated L. terrestris was excluded from distance matrices. Dissimilarity matrix calculated using the Bray-Curtis distance, and densities were square-root transformed.

\begin{tabular}{llllllllll}
\hline & \multicolumn{4}{c}{ NIT trial } & \multicolumn{4}{c}{ CT trial } \\
& \multicolumn{2}{c}{ Location } & \multicolumn{2}{c}{ Dispersion } & \multicolumn{2}{c}{ Location } & \multicolumn{2}{c}{ Dispersion } \\
& $\mathbf{F}$ & $\mathbf{p}$ & $\mathbf{F}$ & $\mathbf{p}$ & $\mathbf{F}$ & $\mathbf{p}$ & $\mathbf{F}$ & $\mathbf{p}$ \\
\hline Crop residues & 1.474 & 0.082 & 0.490 & 0.520 & 3.555 & $\underline{\mathbf{0 . 0 1 3}}$ & 1.126 & 0.217 \\
Inoculation & 1.064 & 0.559 & 0.141 & 0.778 & 1.886 & $\underline{\underline{\mathbf{0 . 0 4 2}}}$ & 2.315 & 0.223 \\
$\begin{array}{l}\text { Crop residues } \\
\text { inoculation }\end{array}$ & 0.335 & 0.794 & - & - & 2.095 & 0.072 & - & - \\
\hline
\end{tabular}

\subsubsection{Ecological groups' distribution}

The NIT trial, in Fall 2015 showed a pronounced effect of surface availability of crop residues on earthworm ecological groups (Table 4.3). Epigeics' density was about 2.5 times higher in $\mathrm{S}_{100}$ than in the other treatments. Endogeics also increased significantly with crop residue availability on the soil surface, although the effect was less pronounced, and the patterns were more erratic. Endogeics were about $40 \%$ more abundant in $\mathrm{S}_{100}$ than in $\mathrm{S}_{25}$, but were not significantly different from $\mathrm{S}_{0}$ (Table 4.3). The inoculation of $L$. terrestris did not affect earthworms in terms of ecological groups (Table 4.3).

In the CT trial only epigeics responded to the crop residue treatments in Fall 2015 (Table 4.3). Epigeic density in $\mathrm{S}_{0}$ treatment was 20 and 30\% lower than when residues were applied on the soil surface $\left(\mathrm{S}_{100}\right)$ or incorporated into the soil $\left(\mathrm{I}_{100}\right)$, respectively. No significant differences in density of epigeics were found between $\mathrm{S}_{100}$ and $\mathrm{I}_{100}$ (Table 4.3). Similarly to the findings in the NIT trial, the inoculation of $L$. terrestris did not affect earthworms in terms of ecological groups (Table 4.3).

\subsubsection{Trait composition and diversity}

In the NIT trial, CWM of typhlosolis shape, body weight and epidermis thickness of (sub)adult earthworm species were significantly affected in Fall 2015 by crop residue availability on the soil surface (Table 4.5). In $\mathrm{S}_{100}$, the proportion of species with a bifide typhlosolis was 
significantly smaller (-15\%) compared to absence of crop residues, whereas $\mathrm{I}_{100}$ did not differ from other treatments (Table 4.5). Neither body weight nor epidermis thickness, although significant in the overall linear models, showed significant pairwise differences among any of the three crop residue treatments.

In the CT trial in Fall 2015, the CWM body weight, number of cocoons, typhlosolis shape, and cuticle and epidermis thickness were affected by the crop residue application. The distribution of reproductive strategies was modified by the inoculation of $L$. terrestris, and the time to maturity by the interaction of both factors (Table 4.6). CWM of (sub)adult earthworms' body weight was larger in $\mathrm{S}_{100}$ and $\mathrm{I}_{100}$ than in the $\mathrm{S}_{0}(16 \%$ and $9 \%$, respectively). CWM of the number of cocoons was $22 \%$ higher in $\mathrm{S}_{100}$ than in $\mathrm{I}_{100}$, which was, in turn, $40 \%$ higher than in $\mathrm{S}_{0}$. The proportion of species with a bifide typhlosolis was $52 \%$ and $23 \%$ higher in $\mathrm{S}_{0}$ than in $\mathrm{S}_{100}$ and $\mathrm{I}_{100}$, respectively. CWM of cuticle thickness was $33 \%$ larger in $\mathrm{S}_{100}$ than in $\mathrm{I}_{100}$, and in turn, it was $57 \%$ larger in $\mathrm{I}_{100}$ than in $\mathrm{S}_{0}$. Epidermis thickness was $4 \%$ larger in $\mathrm{S}_{100}$ and 3\% larger in $\mathrm{I}_{100}$ than in $\mathrm{S}_{0}$. Inoculation of $L$. terrestris increased biparental reproduction in the local earthworm community by $6 \%$. Finally, an interactive effect between crop residue and inoculation of $L$. terrestris was found for the CWM of time to maturity: it was $11 \%$ higher in $\mathrm{S}_{0}+$ treatments than in $\mathrm{I}_{100^{+}}$, and between 11 to $13 \%$ higher in $\mathrm{I}_{100^{-}}$and $\mathrm{S}_{0^{-}}$than in $\mathrm{S}_{100^{-}}$.

Multivariate analyses showed no significant patterns in CWM composition for NIT in Fall 2015, but in CT, plots with crop residues $\left(\mathrm{S}_{100}\right.$ and $\left.\mathrm{I}_{100}\right)$ were separated from plots without $\left(\mathrm{S}_{0}\right)$ (Table 4.7, Fig. 4.3). Although significant, trait composition as affected by the inoculation of $L$. terrestris (Table 4.7) did not show such a clear separation between plots where L. terrestris had been inoculated or not (Fig. 4.3).

Regarding trait diversity in Fall 2015, RaoQ was 2.6 and 3.0 times higher in $\mathrm{S}_{100}$ and $\mathrm{I}_{100}$ than when no crop residues $\left(\mathrm{S}_{0}\right)$ were provided in CT, while not different in NIT (Table 4.8). 
Table 4.5 Mean and standard error (SE) of community weighted means (CWM) for the trait values in the non-inversion tillage trial (NIT), for Fall 2015. Earthworm community taken into account for the computation excluded inoculated L. terrestris. For legend of the treatments, see Fig. 4.1. F-statistics and associated p-value of best fitted linear mixed model of CWM. Both categorical traits only had two trait values, therefore, only one is shown. Capital letters show significant pairwise differences within the main factor Crop residue application and small letters within the main factor L. terrestris inoculation.

\begin{tabular}{|c|c|c|c|c|c|c|c|c|c|c|c|c|c|c|}
\hline Treatments & \multicolumn{2}{|c|}{$\begin{array}{l}\text { Body weight } \\
\text { (g) }\end{array}$} & \multicolumn{2}{|c|}{$\begin{array}{l}\text { No. of cocoons } \\
\text { (per year) }\end{array}$} & \multicolumn{2}{|c|}{$\begin{array}{l}\text { Reproductive } \\
\text { strategy } \dagger\end{array}$} & \multicolumn{2}{|c|}{$\begin{array}{l}\text { Typhlosolis } \\
\text { shape } \ddagger\end{array}$} & \multicolumn{2}{|c|}{$\begin{array}{l}\text { Time to } \\
\text { maturity } \\
\text { (weeks) }\end{array}$} & \multicolumn{2}{|c|}{$\begin{array}{l}\text { Cuticle } \\
\text { thickness }(\mu \mathrm{m})\end{array}$} & \multicolumn{2}{|c|}{$\begin{array}{l}\text { Epidermis } \\
\text { thickness }(\mu \mathrm{m})\end{array}$} \\
\hline $\mathbf{S}_{100^{-}}$ & \multicolumn{2}{|c|}{$0.37(0.01) \mathrm{Aa}$} & \multicolumn{2}{|c|}{$49.02(1.55)$} & \multicolumn{2}{|c|}{$0.93(0.05)$} & \multicolumn{2}{|c|}{$0.72(0.03) \mathrm{Aa}$} & \multicolumn{2}{|c|}{$48.40(1.55)$} & \multicolumn{2}{|c|}{$1.30(0.11)$} & \multicolumn{2}{|c|}{34.87 (0.39) Aa } \\
\hline $\mathbf{S}_{100}+$ & \multicolumn{2}{|c|}{$0.35(0.02) \mathrm{Aa}$} & \multicolumn{2}{|c|}{$43.00(4.77)$} & \multicolumn{2}{|c|}{$0.95(0.03)$} & \multicolumn{2}{|c|}{$0.78(0.06) \mathrm{Aa}$} & \multicolumn{2}{|c|}{$50.37(1.43)$} & \multicolumn{2}{|c|}{$1.01(0.17)$} & \multicolumn{2}{|c|}{$34.70(0.64) \mathrm{Aa}$} \\
\hline $\mathbf{S}_{25^{-}}$ & \multicolumn{2}{|c|}{$0.36(0.02) \mathrm{Aa}$} & \multicolumn{2}{|c|}{$42.21(6.46)$} & \multicolumn{2}{|c|}{$0.95(0.04)$} & \multicolumn{2}{|c|}{$0.81(0.08) \mathrm{ABa}$} & \multicolumn{2}{|c|}{50.77 (1.69) } & \multicolumn{2}{|c|}{$1.04(0.23)$} & \multicolumn{2}{|c|}{$34.78(0.54) \mathrm{Aa}$} \\
\hline $\mathbf{S}_{25}+$ & \multicolumn{2}{|c|}{$0.33(0.01) \mathrm{Aa}$} & \multicolumn{2}{|c|}{$36.99(2.48)$} & \multicolumn{2}{|c|}{$0.92(0.05)$} & \multicolumn{2}{|c|}{$0.88(0.03) \mathrm{ABa}$} & \multicolumn{2}{|c|}{$50.14(1.35)$} & \multicolumn{2}{|c|}{$0.97(0.06)$} & \multicolumn{2}{|c|}{$33.71(0.68) \mathrm{Aa}$} \\
\hline $\mathbf{S}_{0^{-}}$ & \multicolumn{2}{|c|}{$0.36(0.02) \mathrm{Aa}$} & 41.51 & 05) & 0.96( & 02) & 0.82( & 07) $\mathrm{Ba}$ & 51.09 & $0.90)$ & $1.00(0$ & & 34.82 & 3) $\mathrm{Aa}$ \\
\hline $\mathbf{S}_{0}+$ & $0.33(0$ & 1) $\mathrm{Aa}$ & 35.37 & 59) & 0.91( & 04) & 0.90( & 05) $\mathrm{Ba}$ & 51.22 & $1.20)$ & $0.87(($ & & 33.83 & 7) $\mathrm{Aa}$ \\
\hline & $\mathbf{F}$ & $\mathbf{p}$ & $\mathbf{F}$ & $\mathbf{p}$ & $\mathbf{F}$ & $\mathbf{p}$ & $\mathbf{F}$ & $\mathbf{p}$ & $\mathbf{F}$ & $\mathbf{p}$ & $\mathbf{F}$ & $\mathbf{p}$ & $\mathbf{F}$ & $\mathbf{p}$ \\
\hline $\begin{array}{l}\text { Crop } \\
\text { residues }\end{array}$ & 4.310 & $\underline{0.039}$ & 3.746 & 0.055 & 0.044 & 0.957 & 4.710 & $\underline{0.031}$ & 1.444 & 0.274 & 1.267 & 0.317 & 4.915 & $\underline{0.028}$ \\
\hline Inoculation & 1.860 & 0.266 & 1.239 & 0.347 & 0.801 & 0.437 & 1.217 & 0.351 & 0.103 & 0.770 & 1.321 & 0.334 & 0.902 & 0.412 \\
\hline $\begin{array}{l}\text { Crop } \\
\text { residues } x \\
\text { inoculation }\end{array}$ & 0.553 & 0.589 & 0.009 & 0.991 & 0.571 & 0.580 & 0.035 & 0.966 & 0.806 & 0.469 & 0.314 & 0.736 & 1.638 & 0.235 \\
\hline
\end{tabular}

$\dagger$ Results presented for the category of biparental reproductive strategy;

$\ddagger$ Results presented for the category of bifide typhlosolis. 
Table 4.6 Means and standard errors of community weighted means (CWM) for the trait in the conventional tillage trial (CT), for Fall 2015. Earthworm community taken into account for the computation excluded inoculated L. terrestris. For legend of the treatments, see Fig. 4.1. Fstatistics and associated p-value of best fitted linear mixed model of CWM. Both categorical traits only had two trait values, therefore, only one is shown. Capital letters show significant pairwise differences within the main factor Crop residue application and small letters within the main factor L. terrestris inoculation. When only small letters are provided, significant differences refer to the interaction between both treatments.

\begin{tabular}{|c|c|c|c|c|c|c|c|c|c|c|c|c|c|c|}
\hline Treatments & \multicolumn{2}{|c|}{$\begin{array}{l}\text { Body weight } \\
\text { (g) }\end{array}$} & \multicolumn{2}{|c|}{$\begin{array}{l}\text { No. of cocoons } \\
\text { (per year) }\end{array}$} & \multicolumn{2}{|c|}{$\begin{array}{l}\text { Reproductive } \\
\text { strategy } \dagger\end{array}$} & \multicolumn{2}{|c|}{$\begin{array}{l}\text { Typhlosolis } \\
\text { shape } \leftarrow\end{array}$} & \multicolumn{2}{|c|}{$\begin{array}{l}\text { Time to } \\
\text { maturity } \\
\text { (weeks) }\end{array}$} & \multicolumn{2}{|c|}{$\begin{array}{l}\text { Cuticle } \\
\text { thickness } \\
(\mu \mathrm{m}) \\
\end{array}$} & \multicolumn{2}{|c|}{$\begin{array}{l}\text { Epidermis } \\
\text { thickness }(\mu \mathrm{m})\end{array}$} \\
\hline $\mathbf{S}_{100^{-}}$ & \multicolumn{2}{|c|}{$0.40(0.02) \mathrm{Ba}$} & \multicolumn{2}{|c|}{$61.67(5.21) \mathrm{Ca}$} & \multicolumn{2}{|c|}{$0.89(0.05) \mathrm{Aa}$} & \multicolumn{2}{|c|}{$0.57(0.07) \mathrm{Aa}$} & \multicolumn{2}{|c|}{$46.51(1.46) \mathrm{ab}$} & \multicolumn{2}{|c|}{$1.71(0.19) \mathrm{Ca}$} & \multicolumn{2}{|c|}{$35.98(0.53) \mathrm{Ba}$} \\
\hline $\mathbf{S}_{100}+$ & \multicolumn{2}{|c|}{$0.39(0.01) \mathrm{Ba}$} & \multicolumn{2}{|c|}{$55.87(7.29) \mathrm{Ca}$} & \multicolumn{2}{|c|}{$0.97(0.03) \mathrm{Ab}$} & \multicolumn{2}{|c|}{$0.63(0.10) \mathrm{Aa}$} & \multicolumn{2}{|c|}{47.26 (2.32) abcd } & \multicolumn{2}{|c|}{$1.50(0.27) \mathrm{Ca}$} & \multicolumn{2}{|c|}{$35.57(0.34) \mathrm{Ba}$} \\
\hline $\mathbf{I}_{100^{-}}$ & \multicolumn{2}{|c|}{$0.36(0.01) \mathrm{Ba}$} & \multicolumn{2}{|c|}{$41.51(2.27) \mathrm{Ba}$} & \multicolumn{2}{|c|}{$0.93(0.05) \mathrm{Aa}$} & \multicolumn{2}{|c|}{$0.82(0.03) \mathrm{Aa}$} & \multicolumn{2}{|c|}{$51.81(0.53) \mathrm{cd}$} & \multicolumn{2}{|c|}{$0.96(0.08) \mathrm{Ba}$} & \multicolumn{2}{|c|}{$35.02(0.19) \mathrm{Ba}$} \\
\hline $\mathbf{I}_{100^{+}}$ & \multicolumn{2}{|c|}{$0.38(0.01) \mathrm{Ba}$} & \multicolumn{2}{|c|}{$54.72(4.19) \mathrm{Ba}$} & \multicolumn{2}{|c|}{$0.90(0.06) \mathrm{Ab}$} & \multicolumn{2}{|c|}{$0.65(0.06) \mathrm{Aa}$} & \multicolumn{2}{|c|}{$47.65(1.18) \mathrm{ac}$} & \multicolumn{2}{|c|}{$1.47(0.14) \mathrm{Ba}$} & \multicolumn{2}{|c|}{$35.37(0.40) \mathrm{Ba}$} \\
\hline $\mathbf{S}_{0^{-}}$ & \multicolumn{2}{|c|}{$0.33(0.01) \mathrm{Aa}$} & 34.68 & 38) Aa & $0.90(0$. & 1) $\mathrm{Aa}$ & $0.91(0$. & 3) $\mathrm{Ba}$ & $52.36(1$ & 4) $\mathrm{cd}$ & $0.78(0$. & 1) $\mathrm{Aa}$ & $34.12(0$ & 8) $\mathrm{Aa}$ \\
\hline $\mathbf{S}_{\mathbf{0}}+$ & $0.35(0$. & 1) $\mathrm{Aa}$ & 34.24( & 21) $\mathrm{Aa}$ & $1.00(0$. & 0) $\mathrm{Ab}$ & $0.91(0$. & 5) $\mathrm{Ba}$ & $52.72(0$ & 9) bd & $0.75(0$. & 3) $\mathrm{Aa}$ & $34.44(0$ & 5) $\mathrm{Aa}$ \\
\hline & $\mathbf{F}$ & $\mathbf{p}$ & $\mathbf{F}$ & $\mathbf{p}$ & $\mathbf{F}$ & $\mathbf{p}$ & $\mathbf{F}$ & $\mathbf{p}$ & $\mathbf{F}$ & $\mathbf{p}$ & $\mathbf{F}$ & $\mathbf{p}$ & $\mathbf{F}$ & $\mathbf{p}$ \\
\hline $\begin{array}{l}\text { Crop } \\
\text { residues }\end{array}$ & 17.000 & $\underline{0.0003}$ & 25.566 & $\leq 0.00001$ & 0.579 & 0.575 & 53.564 & $\leq 0.0001$ & 16.291 & 0.0004 & 13.743 & $\underline{0.001}$ & 19.060 & $\underline{0.0002}$ \\
\hline Inoculation & 1.796 & 0.273 & 0.424 & 0.562 & 64.751 & $\underline{0.004}$ & 7.008 & 0.077 & 12.328 & 0.039 & 0.475 & 0.540 & 0.350 & 0.598 \\
\hline $\begin{array}{l}\text { Crop } \\
\text { residues } \mathbf{x} \\
\text { inoculation }\end{array}$ & 0.415 & 0.670 & 2.523 & 0.122 & 1.466 & 0.269 & 2.907 & 0.093 & 4.322 & $\underline{0.039}$ & 2.686 & 0.109 & 0.640 & 0.544 \\
\hline
\end{tabular}

$\uparrow$ Results presented for the category of biparental reproductive strategy;

$\$$ Results presented for the category of bifide typhlosolis. 
Table 4.7 F and p-values from non-parametric permutational multivariate analysis of variance (Location) and from multivariate homogeneity of variances (Dispersion) of CWM for each of the main factors (crop residues and inoculation) and their interaction in the case of Location, of the non-inversion (NIT) and conventional tillage (CT) trials, for Fall 2015. Inoculated L. terrestris was excluded from distance matrices. Dissimilarity matrix calculated using the Gower distance.

\begin{tabular}{llllllllll}
\hline & \multicolumn{4}{c}{ Location } & \multicolumn{2}{c}{ Dispersion } & \multicolumn{4}{c}{ Location } & \multicolumn{2}{c}{ Dispersion } \\
& $\mathbf{F}$ & $\mathbf{p}$ & $\mathbf{F}$ & $\mathbf{p}$ & $\mathbf{F}$ & $\mathbf{p}$ & $\mathbf{F}$ & $\mathbf{p}$ \\
\hline Crop residues & 0.939 & 0.262 & 0.0495 & 0.960 & 9.690 & $\underline{\mathbf{0 . 0 0 2}}$ & 1.0216 & 0.177 \\
Inoculation & 1.834 & 0.336 & 0.0433 & 0.868 & 1.306 & $\underline{\mathbf{0 . 0 4 3}}$ & 0.0513 & 0.834 \\
$\begin{array}{l}\text { Crop residues } \\
\text { inoculation }\end{array}$ & 0.085 & 0.949 & - & - & 1.779 & 0.260 & - & - \\
\hline
\end{tabular}

Table 4.8 Mean and standard error of RaoQ in the non-inversion tillage (NIT) and conventional tillage (CT) trials, for Fall 2015. Earthworm community taken into account for the computation excluded inoculated L. terrestris. For legend of the treatments, see Fig. 4.1. F-statistics and associated p-value of best fitted linear mixed model of RaoQ. Capital letters show significant pairwise differences within the main factor Crop residue application and small letters within the main factor L. terrestris inoculation.

\begin{tabular}{|c|c|c|c|c|}
\hline Treatments & \multicolumn{2}{|c|}{ NIT trial } & \multicolumn{2}{|c|}{ CT trial } \\
\hline $\mathbf{S}_{100^{-}}$ & \multicolumn{2}{|c|}{$0.10(0.01)$} & \multicolumn{2}{|c|}{$0.12(0.01) \mathrm{Ba}$} \\
\hline $\mathbf{S}_{100^{+}}$ & \multicolumn{2}{|c|}{$0.07(0.01)$} & \multicolumn{2}{|c|}{$0.10(0.02) \mathrm{Ba}$} \\
\hline $\mathbf{S}_{25^{-}} / \mathbf{I}_{100^{-}}$ & \multicolumn{2}{|c|}{$0.06(0.02)$} & \multicolumn{2}{|c|}{$0.07(0.01) \mathrm{Ba}$} \\
\hline $\mathbf{S}_{25}+/ \mathbf{I}_{100^{+}}+$ & \multicolumn{2}{|c|}{$0.06(0.01)$} & \multicolumn{2}{|c|}{$0.11(0.01) \mathrm{Ba}$} \\
\hline $\mathbf{S}_{0^{-}}$ & \multicolumn{2}{|c|}{$0.06(0.02)$} & \multicolumn{2}{|c|}{$0.04(0.01) \mathrm{Aa}$} \\
\hline \multirow[t]{2}{*}{$\mathbf{S}_{0}+$} & \multicolumn{2}{|c|}{$0.05(0.01)$} & \multicolumn{2}{|c|}{$0.03(0.02) \mathrm{Aa}$} \\
\hline & $\mathbf{F}$ & p & $\mathbf{F}$ & $\mathbf{p}$ \\
\hline Crop residues & 3.731 & 0.055 & 17.717 & 0.0003 \\
\hline Inoculation & 2.756 & 0.196 & 0.138 & 0.735 \\
\hline $\begin{array}{l}\text { Crop residues } x \\
\text { inoculation }\end{array}$ & 0.511 & 0.613 & 2.792 & 0.101 \\
\hline
\end{tabular}




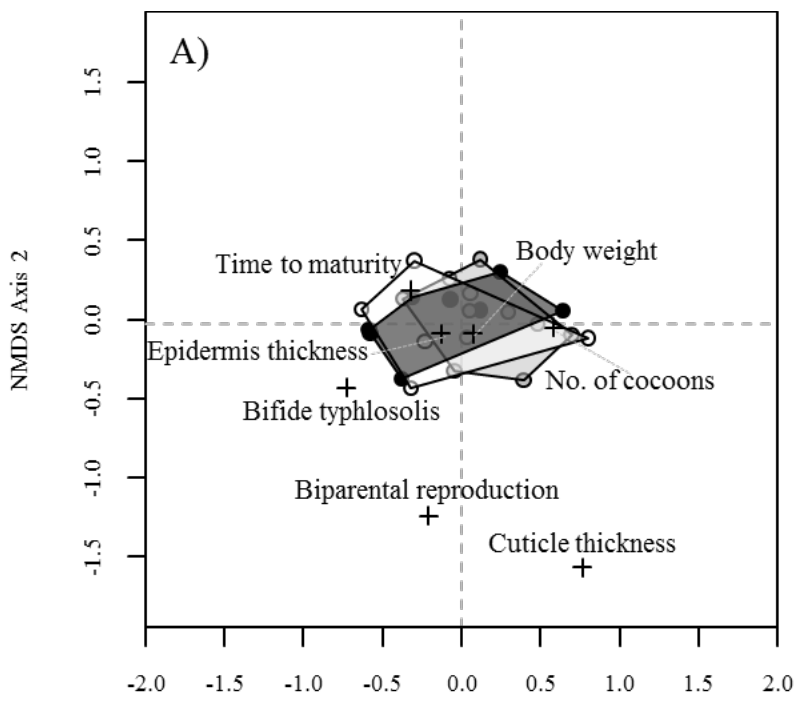

NMDS Axis 1

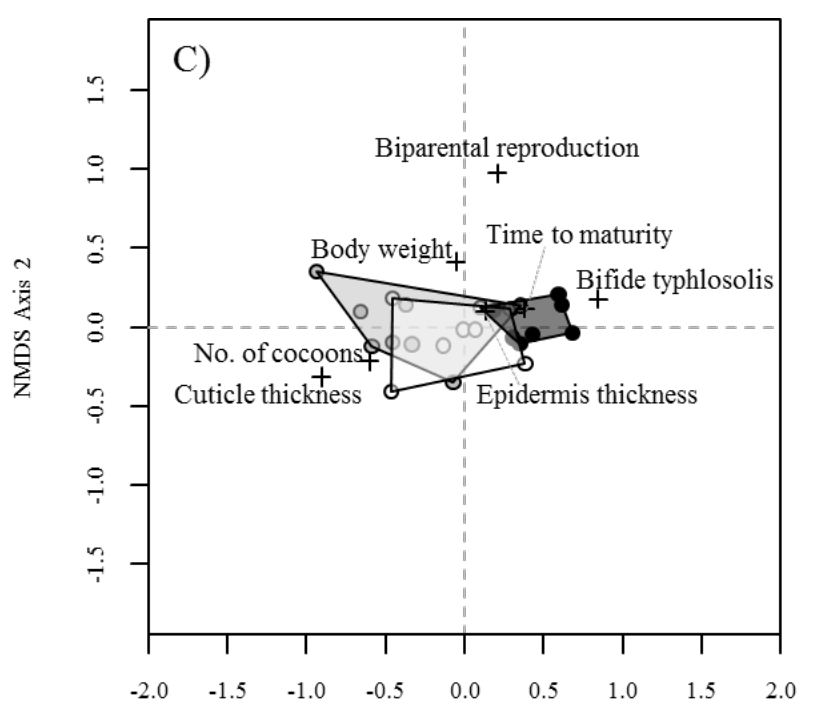

NMDS Axis 1

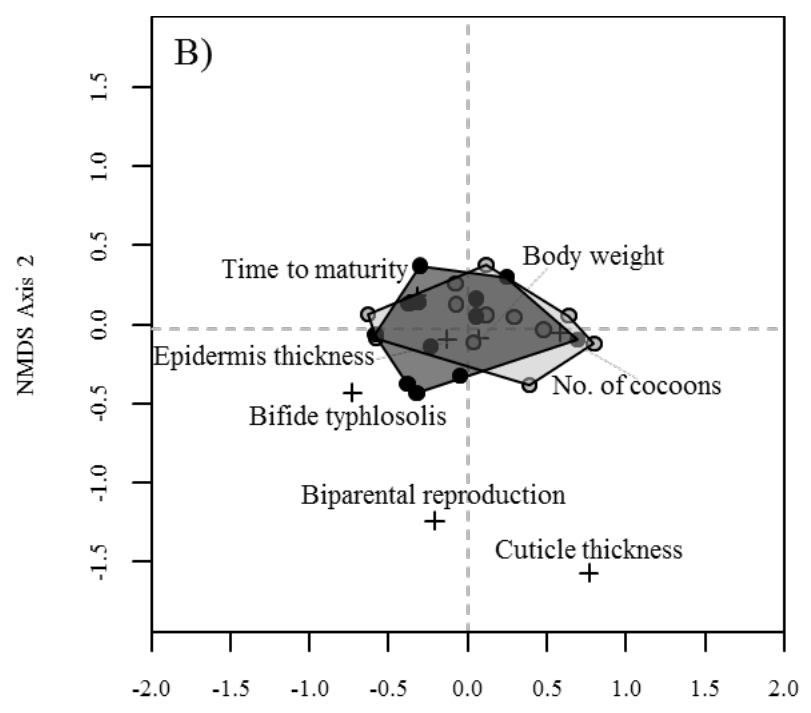

NMDS Axis 1

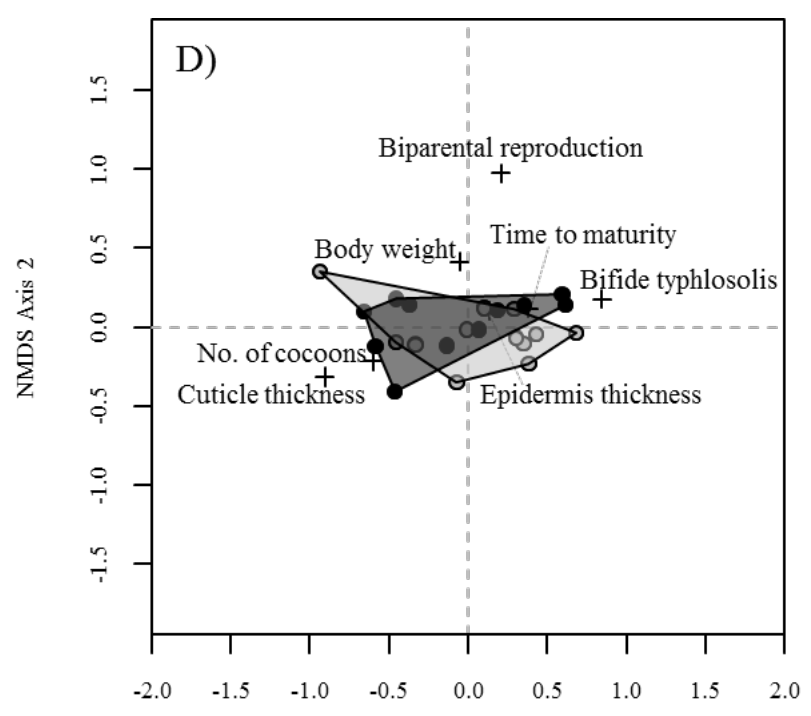

NMDS Axis 1

Figure 4.3 Nonmetric multidimensional scaling (NMDS) of CWM for the main factor crop residues (panels A) and C)) and main factor inoculation of L. terrestris (panels B) and D)) of the non-inversion $(\mathrm{NIT}$, panels $\mathrm{A})$ and $\mathrm{B})$, stress $=0.08$ ) and conventional tillage trials $(\mathrm{CT}$, panels $\mathrm{C})$ and $\mathrm{D})$, stress $=$ 0.05), in Fall 2015. Dissimilarity between CWM composition was determined through a Gower distance matrix. Inoculated $L$. terrestris was excluded from dissimilarity matrices. Polygons in different colours indicate different crop residues $\left(\mathrm{S}_{100}\right.$ : grey, $\mathrm{S}_{25} / \mathrm{I}_{100}$ : white, $\mathrm{S}_{0}$ : black) and inoculation levels (+: black, -: grey). 


\subsection{Discussion}

\subsubsection{Attainment of $\boldsymbol{L}$. terrestris inoculation in arable fields}

Particularly from a farmer's perspective, L. terrestris was successfully inoculated in both experiments, since this species has established and reproduced in both fields. However the success rate depended on tillage regime. The NIT trial provided better conditions for establishment of this species, considering that 1.7 times as many individuals were found compared to the CT trial (77 vs. 46 individuals of L. terrestris, respectively). Additionally, more reproduction took place in the NIT trial, as 1.7 times more juveniles were found compared to the CT trial (69 vs. 41 individuals, respectively). Our ratio of $L$. terrestris individuals collected between the CT and the NIT trials is much smaller than that of Nuutinen et al. (2011), who found an average of 0.6 ind $\mathrm{m}^{-2}$ and 4.3 ind. $\mathrm{m}^{-2}$ in conventional tillage and no-till systems, respectively. However, in their study, the time span between L. terrestris inoculation and sampling was 13 years. Surprisingly, in our study, L. terrestris was also found in non-inoculated plots, sometimes even at higher densities than in plots that had been inoculated. We could not enclose the experimental plots with physical barriers, as that would hamper the use of agricultural machinery. Therefore, to prevent contamination of non-inoculated plots, the distances between inoculated $v s$. non-inoculated plots were maximised (between 21 and $30 \mathrm{~m}$; Fig 4.1A). Although Mather and Christensen (1988) quantified the length of the surface movement of individuals of $L$. terrestris at $19 \mathrm{~m}$ in one night, Eijsackers (2011) reviewed that in grazed grasslands the population's areal expansion varied between 1.5 and $4 \mathrm{~m} \mathrm{yr}^{-1}$. Besides active surface dispersal, passive dispersal by tractor tires (Marinissen and van den Bosch, 1992) may also have promoted the occurrence of $L$. terrestris in non-inoculated plots.

In both of the two tillage systems in Spring and Fall 2014, crop residue amount or placement had no effect on L. terrestris density, suggesting that $L$. terrestris populations were not necessarily restricted by crop residue availability, in opposition to our first hypothesis. Instead of becoming established where crop residues were not limiting, it is likely that $L$. terrestris have burrowed elsewhere and initiated movement to forage (Butt et al., 2003) in the initial phase of experimentation. On the other hand, by the end of the study (i.e. Fall 2015), distribution patterns of $L$. terrestris, particularly juveniles, seemed to be related to crop residues application, suggesting that the response of this species to crop residue availability takes time. In the NIT 
trial, densities of juveniles were highest with full crop residue application, as well as in the CT trial, provided that residues were on the soil surface.

Our choice of crop residue for earthworms, both the local communities and the inoculated $L$. terrestris was pragmatic and conformed with common agricultural rotations, i.e., wheat or barley followed by radish as cover crop. Although indoor experiments have shown that earthworms can have good survival rates with those food sources (Al-Maliki and Scullion, 2013; Frazão et al., 2019, chapter 3; Giannopoulos et al., 2010), there is also evidence that earthworms, and in particular L. terrestris, show dislike for feeding on brassicas (Valckx et al., 2011), when subjected to food choice experiments. However, wheat and barley straw applications have been shown to increase L. terrestris densities in natural populations (Stroud et al., 2016), while cover cropping with radish has shown no effects on populations of this species (Stroud et al., 2017).

\subsubsection{Crop residue management and earthworm communities}

We investigated the effects of crop residue availability and position, as well as the effect of $L$. terrestris inoculation on earthworm communities in two parallel trials representing different tillage systems (NIT and CT). Our results demonstrate that the local community of adult earthworms was affected by crop residue availability and position, both in NIT and CT systems, although crop residue effects were not similar between the tillage types. We were not able to infer effects of the inoculation on the existing earthworm communities since L. terrestris colonized non-inoculated plots via active or passive dispersal.

In $\mathrm{CT}$, neither the amount nor the position of crop residues affected (sub)adult total earthworm density or Shannon diversity (Table 4.3). However, as long as crop residues were applied, either at the surface or incorporated at ploughing depth, epigeics' density was 3.5 to 5 times higher than in absence of residues. A similar response was found for species composition which differed between plots with and without crop residues (Fig. 4.2). These results suggest that under conventional tillage the application of crop residues, rather than the position in the soil profile, plays a larger role in shaping earthworm communities. These outcomes were unexpected as we hypothesized that epigeics, being known to feed on decaying litter (Bouché, 1977; Curry and Schmidt, 2007), would only profit from crop residues applied on the soil surface. Furthermore, as we anticipated that the most important responses in community composition due to crop residue 112 
availability would be found for epigeics, we had expected that when studying species composition in the multivariate space, plots without residue would be more similar to those in which the crop residue was incorporated. Incorporation of crop residues under conventional tillage is often claimed as a reason for the unsuitability of arable fields for epigeics (Kladivko, 2001). Furthermore, in a mesocosm experiment, Frazão et al. (2019), chapter 3, demonstrated that the growth and survival of L. rubellus was reduced when crop residues (mixture of wheat straw and radish) were incorporated at $30 \mathrm{~cm}$ soil depth.

In the NIT system, crop residue amount had a pronounced effect on earthworm density as well as density of epigeics (Table 4.3), whereas species composition did not differ among the crop residue treatments, which was rather surprising (Fig. 4.2). Crop roots that were not removed after harvest may have been a food source to the earthworm populations in the no residue treatments. However, this does not explain the differences in epigeic density among crop residue treatments, unless the duration of our trials was not long enough to pick effects on species composition.

In CT, crop residue stimulated trait diversity (Table 4.8) and modified the community trait profiles (Table 4.6). However, in analogy to the ecological group and community composition analyses, the trait based approach indicated that the location of crop residue application (soil surface and incorporated) was trivial, in respect to trait diversity and CWM. The observation in the CT trial that trait diversity (RaoQ) was positively affected by crop residue provision suggests some degree of niche differentiation in those communities. Lower competition for resources as well as higher efficiency in resource utilization have been linked to higher ecosystem function (Mason et al., 2005). Applying crop residues, either on the soil surface or incorporated in the profile, contributed to increased earthworm body weight, and shifted the earthworm community towards species with a thicker epidermis and cuticle, a feather shaped typhlosolis, and species with relative high average rates for cocoon production (Table 4.6). Moreover, earthworm species that, on average, produce more cocoons and that have a relatively thick cuticle profited even more when crop residues were applied on the surface. However, those effects were always smaller in magnitude than when compared to the no residue treatments (Table 4.6). These findings suggest that crop residue availability, irrespective of position in the soil profile, promotes earthworms with better burrowing abilities (i.e., larger tegument thickness, see Briones and Álvarez-Otero (2018)), higher recovery from disturbance (i.e., higher reproductive output, measured as average number of cocoons), higher nutrient uptake efficiency (i.e., larger 
proportion of species with a feathered typhlosolis, see Pelosi et al. (2013a)). These characteristics may contribute to a higher performance of the earthworm community (i.e., larger body weight). The suggestion of higher nutrient uptake efficiency by the community is surprising, as we expected that removing and not applying crop residues as a food source would select for species with high nutrient uptake efficiency, i.e. species with a feather shaped typhlosolis. However, typhlosolis morphology is unlikely to be the only trait to determine nutrient uptake efficiency. For example Thakuria et al. (2010) highlighted that earthworm species' gut wall-associated bacterial communities shifted according to food sources provided, although these shifts were more strongly determined by habitat type and ecological group.

In contrast to the CT trial, in the NIT trial crop residue treatments did not affect earthworm trait diversity (Table 4.8) nor modified the trait profiles, with the exception of typhlosolis shape (Table 4.5), where patterns were similar to those observed in the CT trial.

Functional responses have been amply studied in plants (e.g., Díaz and Cabido, 2001), while little attention has been given to soil organisms. Nevertheless, earthworm functional response to disturbances has been studied, in relation to tillage intensity (Pelosi et al., 2016; Pelosi et al., 2013a), flooding of floodplains (de Lange et al., 2013; Fournier et al., 2012), and soil pollution (Hedde et al., 2012b; Pérès et al., 2011). To our knowledge, this is the first study in the field focussing on earthworm functional responses to crop residue availability and position. Studies that have focussed on the relationship between earthworm communities and crop residue availability with more traditional approaches, such as community composition, ecological groups or total density are also rare (but see Eriksen-Hamel et al. (2009)). The latter authors did not find, however, any differences between high vs. low crop residues input in earthworm abundance or biomass. Contrary to Pelosi et al. (2013a) who obtained dissimilar results with different approaches in studying earthworm community responses to tillage, in our study, analysis of species composition, ecological groups and trait diversity and composition resulted in consistent outcomes in terms of response to crop residue availability and position in NIT and CT systems. Therefore, the additional value of trait-based approaches in assessing the response of earthworms to crop residues management was not fully confirmed with this study. Nevertheless, since functional traits represent explicit links between biology and environment, it remains useful to better understand which traits are affected by crop residues, and in that respect our trait-based 
approach has added value. In general, in $\mathrm{CT}$, the provision of residues had an effect on several facets of earthworm communities, whereas in NIT, residue quantity had small effects on earthworm communities.

Finally, further research should focus on the hypothesis that increasing earthworm functional diversity, mediated by crop residue application, enhances soil functioning. However, earthworm effects might be less straightforward, as Frazão et al. (2019), chapter 3, found evidence of tradeoffs between earthworm-mediated soil porosity and formation of large water-stable macroaggregates related to crop residue placement in the soil profile.

\subsection{Conclusions}

Our study clearly illustrates different earthworm community responses to crop residue availability in arable fields under contrasting tillage regimes. The inoculation of L. terrestris was successful, but the success was inconsistently related to crop residue management. In contrast, the type of tillage played an important role in terms of the success of inoculations, with less intensive tillage systems providing better conditions for this species than conventional mouldboard ploughing.

The largest differences in earthworm community responses were observed between no residues vs. available residues in the CT trial when using the species composition, ecological groups and trait-based approaches, whereas in the NIT trial, only the use of an ecological group approach enabled us to show an effect of crop residue amount on earthworms. Our results suggest that in arable fields earthworms are more affected by the amount of crop residue than by its position in the soil profile.

\section{Acknowledgements}

We are thankful to PPO Westmaas, in particular Marcel Tramper and Marian Vlaswinkel, who allowed us to perform these trials and helped with many of the field operations. We further thank students and technicians who helped in the field and in the lab, and in particular Dr. Esperanza Huerta for helping with the coordination of L. terrestris handling. Dr. Angela Straathof provided valuable help in editing the text. This work is part of the research programme Biodiversiteit 
Chapter 4

Werkt! with project number 841.11.003, financed by the Netherlands Organisation for Scientific Research (NWO). 


\section{Appendix 4A}

Table A4.1 Mean and standard error (SE) of earthworm (sub)adult density, density of epigeics and endogeics (ind. $\mathrm{m}^{-2}$ ) and Shannon diversity index of the non-inversion tillage (NIT) and conventional tillage (CT) trials in Spring 2014. For legend of the treatments, see Fig. 4.1. F-statistics and associated p-value of best fitted linear mixed model of earthworm densities and Shannon diversity index. Capital letters show significant pairwise differences within the main factor Crop residue application and small letters within the main factor L. terrestris inoculation. When only small letters are provided, significant differences refer to the interaction between both treatments.

\begin{tabular}{|c|c|c|c|c|c|c|c|c|c|c|c|c|c|c|c|c|}
\hline \multirow[b]{2}{*}{ Treatments } & \multicolumn{8}{|c|}{ NIT trial } & \multicolumn{8}{|c|}{ CT trial } \\
\hline & \multicolumn{2}{|c|}{$\begin{array}{l}\text { (Sub)adult } \\
\text { density }\end{array}$} & \multicolumn{2}{|c|}{$\begin{array}{l}\text { Shannon } \\
\text { diversity }\end{array}$} & \multicolumn{2}{|c|}{ Epigeics $†$} & \multicolumn{2}{|c|}{ Endogeics } & \multicolumn{2}{|c|}{$\begin{array}{l}\text { (Sub)adult } \\
\text { density }\end{array}$} & \multicolumn{2}{|c|}{$\begin{array}{l}\text { Shannon } \\
\text { diversity }\end{array}$} & \multicolumn{2}{|c|}{ Epigeics $\dagger$} & \multicolumn{2}{|c|}{ Endogeics $\$$} \\
\hline$S_{100-}$ & \multicolumn{2}{|c|}{$64.8(11.8)$} & \multicolumn{2}{|l|}{$0.6(0.1)$} & \multicolumn{2}{|c|}{$13.0(1.9) \mathrm{ab}$} & \multicolumn{2}{|c|}{$51.8(11.2)$} & \multicolumn{2}{|c|}{$33.3(12.7)$} & \multicolumn{2}{|c|}{$0.6(0.1)$} & \multicolumn{2}{|c|}{$8.3(2.3) \mathrm{Aa}$} & \multicolumn{2}{|c|}{$25.0(10.6)$} \\
\hline $\mathbf{S}_{100}+$ & \multicolumn{2}{|c|}{$44.4(10.4)$} & \multicolumn{2}{|l|}{$0.4(0.2)$} & \multicolumn{2}{|c|}{$9.3(5.3) \mathrm{ab}$} & \multicolumn{2}{|c|}{$35.2(5.8)$} & \multicolumn{2}{|c|}{$52.8(31.3)$} & \multicolumn{2}{|c|}{$0.3(0.2)$} & \multicolumn{2}{|c|}{$6.5(5.3) \mathrm{Aa}$} & \multicolumn{2}{|c|}{$46.3(26.1)$} \\
\hline $\mathbf{S}_{25}-/ \mathbf{I}_{100-}$ & \multicolumn{2}{|c|}{$44.4(1.5)$} & \multicolumn{2}{|l|}{$0.5(0.0)$} & \multicolumn{2}{|c|}{$7.4(0.0) a b$} & \multicolumn{2}{|c|}{$37.0(1.5)$} & \multicolumn{2}{|c|}{$27.8(4.7)$} & \multicolumn{2}{|c|}{$0.6(0.2)$} & \multicolumn{2}{|c|}{1.9 (1.1) $\mathrm{Aa}$} & \multicolumn{2}{|c|}{$25.9(5.0)$} \\
\hline $\mathbf{S}_{25}+/ \mathbf{I}_{100^{+}}+$ & 70.4 & & $0.8(0.1)$ & & 15.7 & & $54.6(9$ & & $45.4(7$ & & $0.6(0$. & & $4.6(2$. & & 40.7( & \\
\hline $\mathbf{S}_{0^{-}}$ & 39.8 & & $0.5(0.0)$ & & $6.5(3$. & & $33.3(7$ & & $23.1(8$ & & $0.5(0$. & & $3.7(1$. & & 19.4( & \\
\hline $\mathbf{S}_{0}+$ & 48.1 & $.1)$ & $0.7(0.2)$ & & $8.3(2$. & & $39.8(1$ & & $23.1(7$ & & $0.4(0$. & & $5.6(3$. & & 17.6( & \\
\hline & $\mathbf{F}$ & $\mathbf{p}$ & $\mathbf{F}$ & $\mathbf{p}$ & $\mathbf{F}$ & $\mathbf{p}$ & $\mathbf{F}$ & $\mathbf{p}$ & $\mathbf{F}$ & $\mathbf{p}$ & $\mathbf{F}$ & $\mathbf{p}$ & $\mathbf{F}$ & $\mathbf{p}$ & $\mathbf{F}$ & $\mathbf{p}$ \\
\hline $\begin{array}{l}\text { Crop } \\
\text { residue }\end{array}$ & 0.627 & 0.551 & 2.151 & 0.159 & 9.607 & 0.003 & 0.133 & 0.877 & 1.074 & 0.372 & 1.754 & 0.277 & 4.972 & $\underline{0.027}$ & 3.424 & 0.067 \\
\hline Inoculation & 2.465 & 0.214 & 5.811 & 0.095 & 5.417 & 0.102 & 0.588 & 0.499 & 2.422 & 0.218 & 0.767 & 0.486 & 1.036 & 0.384 & 1.845 & 0.267 \\
\hline $\begin{array}{l}\text { Crop } \\
\text { residue } x \\
\text { inoculation }\end{array}$ & 3.186 & 0.078 & 2.631 & 0.113 & 4.355 & $\underline{0.038}$ & 2.357 & 0.137 & 0.790 & 0.476 & 1.754 & 0.277 & 0.322 & 0.731 & 1.236 & 0.325 \\
\hline
\end{tabular}

$\uparrow$ Epigeic species: Eiseniella tetraedra, Lumbricus castaneus (only found in NIT), Lumbricus rubellus

+ Endogeic species Aporrectodea caliginosa, Allolobophora chlorotica, Aporrectodea rosea 
Table A4.2 Mean and standard error (SE) of earthworm (sub)adult density, density of epigeics and endogeics (ind. $\mathrm{m}^{-2}$ ) and Shannon diversity index of the non-inversion tillage (NIT) and conventional tillage (CT) trials in Fall 2014. For legend of the treatments, see Fig. 4.1. F-statistics and associated p-value of best fitted linear mixed model of earthworm densities and Shannon diversity index. Capital letters show significant pairwise differences within the main factor Crop residue application and small letters within the main factor $L$. terrestris inoculation. When only small letters are provided, significant differences refer to the interaction between both treatments.

\begin{tabular}{|c|c|c|c|c|c|c|c|c|c|c|c|c|c|c|c|c|}
\hline \multirow[b]{2}{*}{ Treatments } & \multicolumn{8}{|c|}{ NIT trial } & \multicolumn{8}{|c|}{ CT trial } \\
\hline & \multicolumn{2}{|c|}{$\begin{array}{l}\text { (Sub)adult } \\
\text { density }\end{array}$} & \multicolumn{2}{|c|}{$\begin{array}{l}\text { Shannon } \\
\text { diversity }\end{array}$} & \multicolumn{2}{|c|}{ Epigeics $\dagger$} & \multicolumn{2}{|c|}{ Endogeics $\$$} & \multicolumn{2}{|c|}{$\begin{array}{l}\text { (Sub)adult } \\
\text { density }\end{array}$} & \multicolumn{2}{|c|}{$\begin{array}{l}\text { Shannon } \\
\text { diversity }\end{array}$} & \multicolumn{2}{|c|}{ Epigeics $\dagger$} & \multicolumn{2}{|c|}{ Endogeics } \\
\hline $\mathbf{S}_{100-}$ & \multicolumn{2}{|c|}{$58.3(16.8) \mathrm{Aa}$} & \multicolumn{2}{|c|}{$0.6(0.1)$} & \multicolumn{2}{|c|}{$11.1(5.5)$} & \multicolumn{2}{|c|}{$47.2(14.1)$} & \multicolumn{2}{|c|}{$44.4(4.0)$} & \multicolumn{2}{|c|}{$0.8(0.1) \mathrm{Aa}$} & \multicolumn{2}{|c|}{$8.3(3.2)$} & \multicolumn{2}{|c|}{$36.1(4.9) \mathrm{ab}$} \\
\hline $\mathbf{S}_{100}+$ & \multicolumn{2}{|c|}{$68.5(6.8) \mathrm{Aa}$} & \multicolumn{2}{|c|}{$0.3(0.1)$} & \multicolumn{2}{|c|}{$2.8(1.8)$} & \multicolumn{2}{|c|}{$65.7(7.8)$} & \multicolumn{2}{|c|}{$39.8(3.2)$} & \multicolumn{2}{|c|}{$0.5(0.3) \mathrm{Ab}$} & \multicolumn{2}{|c|}{$1.9(1.9)$} & \multicolumn{2}{|c|}{$38.0(1.8) \mathrm{b}$} \\
\hline $\mathbf{S}_{25-} / \mathbf{I}_{100-}$ & \multicolumn{2}{|c|}{46.3 (15.7) Aa } & \multicolumn{2}{|c|}{$0.5(0.2)$} & \multicolumn{2}{|c|}{$7.4(3.4)$} & \multicolumn{2}{|c|}{$38.9(13.2)$} & \multicolumn{2}{|c|}{$45.4(6.3)$} & \multicolumn{2}{|c|}{$0.5(0.1) \mathrm{Aa}$} & \multicolumn{2}{|c|}{$6.5(3.2)$} & \multicolumn{2}{|c|}{$38.9(4.9) \mathrm{ab}$} \\
\hline $\mathbf{S}_{25}+/ \mathbf{I}_{100}+$ & 36.1 & $\mathrm{Aa}$ & $0.6(0$. & & $2.8(0$ & & 33.3( & & $34.3(2$ & & $0.8(0.1)$ & & $6.5(2$. & & 27.8 & \\
\hline$S_{0-}$ & 50.9 & $\mathrm{Aa}$ & $0.6(0$. & & $5.6(2$. & & 45.4 & & $55.6(7$ & & $0.6(0.1)$ & & $7.4(1$. & & 48.1( & \\
\hline $\mathbf{S}_{\mathbf{0}}+$ & $47.2(7$. & $\mathrm{Aa}$ & $0.7(0$. & & $4.6(2$. & & 42.6( & & $38.0(1$ & & $0.7(0.2)$ & & $4.6(2$. & & 33.3( & \\
\hline & $\mathbf{F}$ & $\mathbf{p}$ & $\mathbf{F}$ & $\mathbf{p}$ & $\mathbf{F}$ & $\mathbf{p}$ & $\mathbf{F}$ & $\mathbf{p}$ & $\mathbf{F}$ & $\mathbf{p}$ & $\mathbf{F}$ & $\mathbf{p}$ & $\mathbf{F}$ & $\mathbf{p}$ & $\mathbf{F}$ & $\mathbf{p}$ \\
\hline Crop residue & 30.253 & $\leq 0.001$ & 0.915 & 0.427 & 0.455 & 0.645 & 1.708 & 0.222 & 1.012 & 0.392 & 3.317 & 0.071 & 0.256 & 0.779 & 1.869 & 0.197 \\
\hline Inoculation & 0.251 & 0.650 & 0.002 & 0.965 & 3.699 & 0.150 & 0.140 & 0.733 & 3.239 & 0.170 & 31.140 & $\underline{0.011}$ & 1.230 & 0.348 & 0.331 & 0.605 \\
\hline $\begin{array}{l}\text { Crop residue } \\
\mathrm{x} \text { inoculation }\end{array}$ & 0.439 & 0.654 & 0.985 & 0.402 & 0.789 & 0.477 & 0.702 & 0.515 & 1.612 & 0.240 & 2.511 & 0.123 & 1.353 & 0.295 & 6.356 & $\underline{0.013}$ \\
\hline
\end{tabular}

$\uparrow$ Epigeic species: Lumbricus rubellus

+ Endogeic species Aporrectodea caliginosa, Allolobophora chlorotica, Aporrectodea rosea. 
Table A4.3 F and p-values from non-parametric permutational multivariate analysis of variance (Location) and from multivariate homogeneity of variances (Dispersion) of (sub)adult earthworm community composition for each of the main factors (crop residues and inoculation of $L$. terrestris) and their interaction in the case of Location, of the non-inversion tillage (NIT) and conventional tillage trials (CT), for Spring and Fall 2014. Inoculated L. terrestris was excluded from distance matrices. Dissimilarity matrix calculated using the Bray-Curtis distance, and densities were square-root transformed.

\begin{tabular}{|c|c|c|c|c|c|c|c|c|}
\hline \multicolumn{9}{|c|}{ NIT trial } \\
\hline & \multicolumn{4}{|c|}{ Spring 2014} & \multicolumn{4}{|c|}{ Fall 2014} \\
\hline & \multicolumn{2}{|c|}{ Location } & \multicolumn{2}{|c|}{ Dispersion } & \multicolumn{2}{|c|}{ Location } & \multicolumn{2}{|c|}{ Dispersion } \\
\hline & $\mathbf{F}$ & $\mathbf{p}$ & $\mathbf{F}$ & $\mathbf{p}$ & $\mathbf{F}$ & $\mathbf{p}$ & $\mathbf{F}$ & $\mathbf{p}$ \\
\hline Crop residue & 0.855 & 0.375 & 0.843 & 0.310 & 0.992 & 0.445 & 0.327 & 0.666 \\
\hline Inoculation & 0.269 & 0.895 & 7.003 & $\underline{0.001}$ & 0.741 & 0.595 & 0.369 & 0.653 \\
\hline $\begin{array}{l}\text { Crop residue } x \\
\text { inoculation }\end{array}$ & 1.650 & 0.077 & - & - & 0.356 & 0.878 & - & - \\
\hline \multicolumn{9}{|c|}{ CT trial } \\
\hline & \multicolumn{4}{|c|}{ Spring 2014} & \multicolumn{4}{|c|}{ Fall 2014} \\
\hline & \multicolumn{2}{|c|}{ Location } & \multicolumn{2}{|c|}{ Dispersion } & \multicolumn{2}{|c|}{ Location } & \multicolumn{2}{|c|}{ Dispersion } \\
\hline & $\mathbf{F}$ & $\mathbf{p}$ & $\mathbf{F}$ & $\mathbf{p}$ & $\mathbf{F}$ & $\mathbf{p}$ & $\mathbf{F}$ & $\mathbf{p}$ \\
\hline Crop residue & 0.952 & 0.369 & 0.456 & 0.697 & 0.489 & 0.543 & 0.220 & 0.560 \\
\hline Inoculation & 0.490 & 0.829 & 1.921 & 0.104 & 1.363 & 0.201 & 9.992 & $\underline{0.001}$ \\
\hline $\begin{array}{l}\text { Crop residue } x \\
\text { inoculation }\end{array}$ & 0.710 & 0.526 & - & - & 0.609 & 0.468 & - & - \\
\hline
\end{tabular}


Table A4.4 Mean and standard error (SE) of community weighted means (CWM) for the trait values in the non-inversion tillage trial (NIT), for Spring 2014. Earthworm community taken into account for the computation excluded inoculated L. terrestris. For legend of the treatments, see Fig. 4.1. F-statistics and associated p-value of best fitted linear mixed model of CWM. Both categorical traits only had two trait values, therefore, only one is shown.

\begin{tabular}{|c|c|c|c|c|c|c|c|c|c|c|c|c|c|c|}
\hline Treatments & \multicolumn{2}{|c|}{$\begin{array}{l}\text { Body weight } \\
\text { (g) }\end{array}$} & \multicolumn{2}{|c|}{$\begin{array}{l}\text { No. of cocoons } \\
\text { (per year) }\end{array}$} & \multicolumn{2}{|c|}{$\begin{array}{l}\text { Reproductive } \\
\text { strategy } \dagger\end{array}$} & \multicolumn{2}{|c|}{$\begin{array}{l}\text { Typhlosolis } \\
\text { shape }+\end{array}$} & \multicolumn{2}{|c|}{$\begin{array}{l}\text { Time to } \\
\text { maturity } \\
\text { (weeks) }\end{array}$} & \multicolumn{2}{|c|}{$\begin{array}{l}\text { Cuticle thickness } \\
(\mu \mathrm{m})\end{array}$} & \multicolumn{2}{|c|}{$\begin{array}{l}\text { Epidermis } \\
\text { thickness }(\mu \mathrm{m})\end{array}$} \\
\hline $\mathbf{S}_{100^{-}}$ & \multicolumn{2}{|c|}{$0.37(0.01)$} & \multicolumn{2}{|c|}{$44.89(4.27)$} & \multicolumn{2}{|c|}{$1.00(0.00)$} & \multicolumn{2}{|c|}{$0.77(0.05)$} & \multicolumn{2}{|c|}{$50.24(0.85)$} & \multicolumn{2}{|c|}{$1.12(0.13)$} & \multicolumn{2}{|c|}{$35.06(0.54)$} \\
\hline $\mathbf{S}_{100}+$ & \multicolumn{2}{|c|}{$0.35(0.01)$} & \multicolumn{2}{|c|}{$37.06(5.81)$} & \multicolumn{2}{|c|}{$1.00(0.00)$} & \multicolumn{2}{|c|}{$0.84(0.09)$} & \multicolumn{2}{|c|}{$51.51(2.21)$} & \multicolumn{2}{|c|}{$0.81(0.20)$} & \multicolumn{2}{|c|}{$34.22(0.21)$} \\
\hline $\mathbf{S}_{25}$ & \multicolumn{2}{|c|}{$0.37(0.00)$} & \multicolumn{2}{|c|}{$40.22(0.45)$} & \multicolumn{2}{|c|}{$1.00(0.00)$} & \multicolumn{2}{|c|}{$0.83(0.01)$} & \multicolumn{2}{|c|}{$51.99(0.10)$} & \multicolumn{2}{|c|}{$0.92(0.02)$} & \multicolumn{2}{|c|}{$34.81(0.39)$} \\
\hline $\mathbf{S}_{25}+$ & \multicolumn{2}{|c|}{$0.35(0.02)$} & \multicolumn{2}{|c|}{$43.74(4.87)$} & \multicolumn{2}{|c|}{$0.98(0.02)$} & \multicolumn{2}{|c|}{$0.77(0.05)$} & \multicolumn{2}{|c|}{$48.61(1.89)$} & \multicolumn{2}{|c|}{$1.15(0.17)$} & \multicolumn{2}{|c|}{$33.68(1.09)$} \\
\hline $\mathbf{S}_{0^{-}}$ & \multicolumn{2}{|c|}{$0.36(0.02)$} & 37.93 & 62) & 1.00 & 00) & 0.86 & 06) & 51.72 & 65) & 0.89 & & 34.43 & \\
\hline $\mathbf{S}_{\mathbf{0}}+$ & $0.34(($ & & 41.43 & 56) & 0.94 & 05) & 0.78( & 07) & 48.99 & 36) & $0.98(C$ & & 33.89 & \\
\hline & $\mathbf{F}$ & $\mathbf{p}$ & $\mathbf{F}$ & $\mathbf{p}$ & $\mathbf{F} \S$ & $\mathbf{p} \S$ & $\mathbf{F}$ & $\mathbf{p}$ & $\mathbf{F}$ & $\mathbf{p}$ & $\mathbf{F}$ & $\mathbf{p}$ & $\mathbf{F}$ & $\mathbf{p}$ \\
\hline $\begin{array}{l}\text { Crop } \\
\text { residues }\end{array}$ & 0.742 & 0.497 & 0.151 & 0.861 & NA & NA & 0.373 & 0.697 & 2.150 & 0.160 & 0.467 & 0.638 & 1.036 & 0.385 \\
\hline Inoculation & 1.583 & 0.297 & 0.109 & 0.763 & NA & NA & 1.011 & 0.389 & 2.200 & 0.235 & 0.388 & 0.578 & 8.892 & 0.059 \\
\hline $\begin{array}{l}\text { Crop } \\
\text { residues x } \\
\text { inoculation }\end{array}$ & 0.292 & 0.752 & 0.975 & 0.405 & NA & NA & 0.706 & 0.513 & 1.250 & 0.320 & 1.759 & 0.214 & 0.135 & 0.875 \\
\hline
\end{tabular}

$\dagger$ Results presented for the category of biparental reproductive strategy;

\pm Results presented for the category of bifide typhlosolis

$\S$ only 2 species are parthenogetic: $A$. rosea occurred only in $\mathrm{S}_{25}+$ and $\mathrm{S}_{0}+$ plots and E. tetraedra occurred only $\mathrm{S}_{0}+$ plots. Because the variation in reproductive strategies is very low, it is not possible to model this. 
Table A4.5 Mean and standard error (SE) of community weighted means (CWM) for the trait values in the non-inversion tillage trial (NIT), for Fall 2014. Earthworm community taken into account for the computation excluded inoculated L. terrestris. For legend of the treatments, see Fig. 4.1. F-statistics and associated p-value of best fitted linear mixed model of CWM. Both categorical traits only had two trait values, therefore, only one is shown. Capital letters show significant pairwise differences within the main factor Crop residue application and small letters within the main factor L. terrestris inoculation.

\begin{tabular}{|c|c|c|c|c|c|c|c|c|c|c|c|c|c|c|}
\hline Treatments & \multicolumn{2}{|c|}{$\begin{array}{l}\text { Body weight } \\
\text { (g) }\end{array}$} & \multicolumn{2}{|c|}{$\begin{array}{l}\text { No. of cocoons } \\
\text { (per year) }\end{array}$} & \multicolumn{2}{|c|}{$\begin{array}{l}\text { Reproductive } \\
\text { strategy } \dagger\end{array}$} & \multicolumn{2}{|c|}{$\begin{array}{l}\text { Typhlosolis } \\
\text { shape } \$\end{array}$} & \multicolumn{2}{|c|}{$\begin{array}{l}\text { Time to } \\
\text { maturity } \\
\text { (weeks) }\end{array}$} & \multicolumn{2}{|c|}{$\begin{array}{l}\text { Cuticle thickness } \\
(\mu \mathrm{m})\end{array}$} & \multicolumn{2}{|c|}{$\begin{array}{l}\text { Epidermis } \\
\text { thickness }(\mu \mathrm{m})\end{array}$} \\
\hline$S_{100^{-}}$ & \multicolumn{2}{|c|}{$0.36(0.02)$} & \multicolumn{2}{|c|}{$42.68(7.47)$} & \multicolumn{2}{|c|}{$0.95(0.03)$} & \multicolumn{2}{|c|}{$0.81(0.10)$} & \multicolumn{2}{|c|}{$51.36(1.76) \mathrm{Aa}$} & \multicolumn{2}{|c|}{$1.01(0.26) \mathrm{Aa}$} & \multicolumn{2}{|c|}{$35.06(0.54)$} \\
\hline $\mathbf{S}_{100^{+}}$ & \multicolumn{2}{|c|}{$0.33(0.01)$} & \multicolumn{2}{|c|}{$30.65(2.14)$} & \multicolumn{2}{|c|}{$0.98(0.02)$} & \multicolumn{2}{|c|}{$0.96(0.03)$} & \multicolumn{2}{|c|}{$53.73(0.53) \mathrm{Aa}$} & \multicolumn{2}{|c|}{$0.61(0.07) \mathrm{Aa}$} & \multicolumn{2}{|c|}{$34.22(0.21)$} \\
\hline $\mathbf{S}_{25^{-}}$ & \multicolumn{2}{|c|}{$0.36(0.01)$} & \multicolumn{2}{|c|}{$38.80(5.53)$} & \multicolumn{2}{|c|}{$0.99(0.01)$} & \multicolumn{2}{|c|}{$0.85(0.07)$} & \multicolumn{2}{|c|}{$51.95(1.34) \mathrm{Aa}$} & \multicolumn{2}{|c|}{$0.89(0.20) \mathrm{Aa}$} & \multicolumn{2}{|c|}{$34.81(0.39)$} \\
\hline $\mathbf{S}_{25}+$ & \multicolumn{2}{|c|}{$0.34(0.02)$} & \multicolumn{2}{|c|}{$36.79(5.74)$} & \multicolumn{2}{|c|}{$0.98(0.02)$} & \multicolumn{2}{|c|}{$0.88(0.07)$} & \multicolumn{2}{|c|}{$49.71(2.50) \mathrm{Aa}$} & \multicolumn{2}{|c|}{$0.99(0.21) \mathrm{Aa}$} & \multicolumn{2}{|c|}{$33.68(1.09)$} \\
\hline $\mathbf{S}_{0^{-}}$ & \multicolumn{2}{|c|}{$0.33(0.00)$} & 35.15 & 86) & $0.90(($ & & $0.91(C$ & & 53.10 & 75) Aa & $0.75(0$ & 1) $\mathrm{Aa}$ & 34.43 & \\
\hline $\mathbf{S}_{\mathbf{0}}+$ & $0.33(0$ & & 37.77 & 66) & $0.90(($ & & $0.87(C$ & & 50.47 & 05) $\mathrm{Aa}$ & $0.96(0$ & 4) $\mathrm{Aa}$ & 33.89 & \\
\hline & $\mathbf{F}$ & $\mathbf{p}$ & $\mathbf{F}$ & $\mathbf{p}$ & $\mathbf{F}$ & $\mathbf{p}$ & $\mathbf{F}$ & $\mathbf{p}$ & $\mathbf{F}$ & $\mathbf{p}$ & $\mathbf{F}$ & $\mathbf{p}$ & $\mathbf{F}$ & $\mathbf{p}$ \\
\hline $\begin{array}{l}\text { Crop } \\
\text { residues }\end{array}$ & 1.284 & 0.312 & 0.039 & 0.962 & 1.482 & 0.266 & 2.694 & 0.108 & 6.469 & $\underline{0.012}$ & 8.101 & $\underline{0.006}$ & 1.036 & 0.385 \\
\hline Inoculation & 1.246 & 0.346 & 0.813 & 0.434 & 0.000 & 0.998 & 0.005 & 0.950 & 2.553 & 0.208 & 0.968 & 0.398 & 8.892 & 0.059 \\
\hline $\begin{array}{l}\text { Crop } \\
\text { residues } x \\
\text { inoculation }\end{array}$ & 0.247 & 0.785 & 1.049 & 0.380 & 0.455 & 0.645 & 1.174 & 0.342 & 2.264 & 0.147 & 1.769 & 0.212 & 0.135 & 0.875 \\
\hline
\end{tabular}

$\uparrow$ Results presented for the category of biparental reproductive strategy;

t Results presented for the category of bifide typhlosolis. 
Table A4.6 Mean and standard error (SE) of community weighted means (CWM) for the trait values in the conventional tillage trial (CT), for Spring 2014. Earthworm community taken into account for the computation excluded inoculated L. terrestris. For legend of the treatments, see Fig. 4.1. F-statistics and associated p-value of best fitted linear mixed model of CWM. Both categorical traits only had two trait values, therefore, only one is shown. Capital letters show significant pairwise differences within the main factor Crop residue application and small letters within the main factor L. terrestris inoculation. When only small letters are provided, significant differences refer to the interaction between both treatments.

\begin{tabular}{|c|c|c|c|c|c|c|c|c|c|c|c|c|c|c|}
\hline Treatments & \multicolumn{2}{|c|}{$\begin{array}{l}\text { Body weight } \\
\text { (g) }\end{array}$} & \multicolumn{2}{|c|}{$\begin{array}{l}\text { No. of cocoons } \\
\text { (per year) }\end{array}$} & \multicolumn{2}{|c|}{$\begin{array}{l}\text { Reproductive } \\
\text { strategy } \dagger\end{array}$} & \multicolumn{2}{|c|}{$\begin{array}{l}\text { Typhlosolis } \\
\text { shape }+\end{array}$} & \multicolumn{2}{|c|}{$\begin{array}{l}\text { Time to } \\
\text { maturity } \\
\text { (weeks) }\end{array}$} & \multicolumn{2}{|c|}{$\begin{array}{l}\text { Cuticle thickness } \\
(\mu \mathrm{m})\end{array}$} & \multicolumn{2}{|c|}{$\begin{array}{l}\text { Epidermis } \\
\text { thickness }(\mu \mathrm{m})\end{array}$} \\
\hline $\mathbf{S}_{100^{-}}$ & \multicolumn{2}{|c|}{$0.39(0.02) \mathrm{a}$} & \multicolumn{2}{|c|}{$49.92(5.59) \mathrm{a}$} & \multicolumn{2}{|c|}{$1.00(0.00)$} & \multicolumn{2}{|c|}{$0.71(0.07) \mathrm{a}$} & \multicolumn{2}{|c|}{$49.53(1.20) \mathrm{Aa}$} & \multicolumn{2}{|c|}{$1.27(0.19) \mathrm{a}$} & \multicolumn{2}{|c|}{$35.62(0.41) \mathrm{a}$} \\
\hline $\mathbf{S}_{100}+$ & \multicolumn{2}{|c|}{$0.33(0.01) \mathrm{a}$} & \multicolumn{2}{|c|}{$31.21(2.91) \mathrm{a}$} & \multicolumn{2}{|c|}{$0.97(0.02)$} & \multicolumn{2}{|c|}{$0.94(0.04) \mathrm{ab}$} & \multicolumn{2}{|c|}{$52.77(1.29) \mathrm{Aa}$} & \multicolumn{2}{|c|}{$0.63(0.13) \mathrm{a}$} & \multicolumn{2}{|c|}{$34.03(0.18) \mathrm{a}$} \\
\hline $\mathbf{S}_{25^{-}}$ & \multicolumn{2}{|c|}{$0.32(0.02) \mathrm{a}$} & \multicolumn{2}{|c|}{$33.72(3.04) \mathrm{a}$} & \multicolumn{2}{|c|}{$0.86(0.09)$} & \multicolumn{2}{|c|}{$0.93(0.04) b$} & \multicolumn{2}{|c|}{$52.77(0.80) \mathrm{Aa}$} & \multicolumn{2}{|c|}{$0.74(0.10) \mathrm{a}$} & \multicolumn{2}{|c|}{$34.02(0.62) \mathrm{a}$} \\
\hline $\mathbf{S}_{25}+$ & \multicolumn{2}{|c|}{$0.33(0.02) \mathrm{a}$} & \multicolumn{2}{|c|}{$34.44(2.45) \mathrm{a}$} & \multicolumn{2}{|c|}{$0.91(0.07)$} & \multicolumn{2}{|c|}{$0.92(0.04) a b$} & \multicolumn{2}{|c|}{$52.80(0.88) \mathrm{Aa}$} & \multicolumn{2}{|c|}{$0.75(0.09) \mathrm{a}$} & \multicolumn{2}{|c|}{$34.25(0.35) \mathrm{a}$} \\
\hline $\mathbf{S}_{0^{-}}$ & \multicolumn{2}{|c|}{$0.36(0.01) \mathrm{a}$} & 38.21 & 14) a & 0.98 & 02) & $0.86(C$ & $05) \mathrm{ab}$ & 52.09 & 08) $\mathrm{Aa}$ & $0.87(($ & 5) a & 34.75 & ) $a$ \\
\hline $\mathbf{S}_{\mathbf{0}}+$ & $0.36(0$ & 2) a & 39.79 & 57) $\mathrm{a}$ & 1.00( & $00)$ & $0.84(C$ & 10) ab & 51.49 & 20) $\mathrm{Aa}$ & $0.94(($ & 9) a & 34.82 & 7) $a$ \\
\hline & $\mathbf{F}$ & $\mathbf{p}$ & $\mathbf{F}$ & $\mathbf{p}$ & $\mathbf{F}$ & $\mathbf{p}$ & $\mathbf{F}$ & $\mathbf{p}$ & $\mathbf{F}$ & $\mathbf{p}$ & $\mathbf{F}$ & $\mathbf{p}$ & $\mathbf{F}$ & $\mathbf{p}$ \\
\hline $\begin{array}{l}\text { Crop } \\
\text { residues }\end{array}$ & 2.513 & 0.123 & 2.194 & 0.154 & 1.648 & 0.233 & 1.941 & 0.186 & 4.931 & $\underline{0.027}$ & 1.711 & 0.222 & 2.360 & 0.136 \\
\hline Inoculation & 7.673 & 0.070 & 3.244 & 0.170 & 0.000 & 0.988 & 4.007 & 0.139 & 0.394 & 0.575 & 0.489 & 0.535 & 1.290 & 0.338 \\
\hline $\begin{array}{l}\text { Crop } \\
\text { residues x } \\
\text { inoculation }\end{array}$ & 10.663 & $\underline{0.002}$ & 5.198 & $\underline{0.024}$ & 1.596 & 0.243 & 4.964 & $\underline{0.027}$ & 1.903 & 0.192 & 5.229 & $\underline{0.023}$ & 3.940 & $\underline{0.048}$ \\
\hline
\end{tabular}

$\dagger$ Results presented for the category of biparental reproductive strategy;

+ Results presented for the category of bifide typhlosolis. 
Table A4.7 Mean and standard error (SE) of community weighted means (CWM) for the trait values in the conventional tillage trial (CT), for Fall 2014. Earthworm community taken into account for the computation excluded inoculated L. terrestris. For legend of the treatments, see Fig. 4.1. F-statistics and associated p-value of best fitted linear mixed model of CWM. Both categorical traits only had two trait values, therefore, only one is shown.

\begin{tabular}{|c|c|c|c|c|c|c|c|c|c|c|c|c|c|c|}
\hline Treatments & \multicolumn{2}{|c|}{$\begin{array}{l}\text { Body weight } \\
\text { (g) }\end{array}$} & \multicolumn{2}{|c|}{$\begin{array}{l}\text { No. of cocoons } \\
\text { (per year) }\end{array}$} & \multicolumn{2}{|c|}{$\begin{array}{l}\text { Reproductive } \\
\text { strategy } \dagger\end{array}$} & \multicolumn{2}{|c|}{$\begin{array}{l}\text { Typhlosolis } \\
\text { shape } †\end{array}$} & \multicolumn{2}{|c|}{$\begin{array}{l}\text { Time to } \\
\text { maturity } \\
\text { (weeks) }\end{array}$} & \multicolumn{2}{|c|}{$\begin{array}{l}\text { Cuticle thickness } \\
(\mu \mathrm{m})\end{array}$} & \multicolumn{2}{|c|}{$\begin{array}{l}\text { Epidermis } \\
\text { thickness }(\mu \mathrm{m})\end{array}$} \\
\hline $\mathbf{S}_{100^{-}}$ & \multicolumn{2}{|c|}{$0.35(0.02)$} & \multicolumn{2}{|c|}{$42.91(5.89)$} & \multicolumn{2}{|c|}{$0.90(0.04)$} & \multicolumn{2}{|c|}{$0.81(0.07)$} & \multicolumn{2}{|c|}{$51.09(1.44)$} & \multicolumn{2}{|c|}{$1.04(0.21)$} & \multicolumn{2}{|c|}{$34.86(0.40)$} \\
\hline $\mathbf{S}_{100}+$ & \multicolumn{2}{|c|}{$0.31(0.02)$} & \multicolumn{2}{|c|}{$30.75(3.24)$} & \multicolumn{2}{|c|}{$0.91(0.05)$} & \multicolumn{2}{|c|}{$0.96(0.04)$} & \multicolumn{2}{|c|}{$51.93(2.24)$} & \multicolumn{2}{|c|}{$0.73(0.16)$} & \multicolumn{2}{|c|}{$33.41(0.98)$} \\
\hline $\mathbf{S}_{25^{-}}$ & \multicolumn{2}{|c|}{$0.35(0.02)$} & \multicolumn{2}{|c|}{$37.60(4.57)$} & \multicolumn{2}{|c|}{$0.95(0.03)$} & \multicolumn{2}{|c|}{$0.87(0.06)$} & \multicolumn{2}{|c|}{$52.68(1.07)$} & \multicolumn{2}{|c|}{$0.83(0.16)$} & \multicolumn{2}{|c|}{$34.78(0.34)$} \\
\hline $\mathbf{S}_{25}+$ & \multicolumn{2}{|c|}{$0.34(0.03)$} & \multicolumn{2}{|c|}{$42.88(5.36)$} & \multicolumn{2}{|c|}{$0.82(0.12)$} & \multicolumn{2}{|c|}{$0.82(0.08)$} & \multicolumn{2}{|c|}{$50.75(1.20)$} & \multicolumn{2}{|c|}{$1.06(0.18)$} & \multicolumn{2}{|c|}{$34.53(0.61)$} \\
\hline $\mathbf{S}_{0^{-}}$ & \multicolumn{2}{|c|}{$0.35(0.00)$} & 38.02 & 45) & $0.91(($ & 04) & 0.87( & 02) & 52.65 & 28) & 0.84 & & 34.74 & \\
\hline $\mathbf{S}_{0}+$ & 0.32( & & 36.00 & 40) & $0.87(($ & 07) & 0.90( & 05) & 51.60 & 86) & $0.86(($ & & 33.96 & \\
\hline & $\mathbf{F}$ & $\mathbf{p}$ & $\mathbf{F}$ & $\mathbf{p}$ & $\mathbf{F}$ & $\mathbf{p}$ & $\mathbf{F}$ & $\mathbf{p}$ & $\mathbf{F}$ & $\mathbf{p}$ & $\mathbf{F}$ & $\mathbf{p}$ & $\mathbf{F}$ & $\mathbf{p}$ \\
\hline $\begin{array}{l}\text { Crop } \\
\text { residues }\end{array}$ & 0.322 & 0.731 & 0.552 & 0.590 & 0.261 & 0.774 & 0.362 & 0.704 & 1.060 & 0.378 & 0.191 & 0.829 & 1.426 & 0.278 \\
\hline Inoculation & 1.379 & 0.325 & 0.483 & 0.537 & 1.201 & 0.353 & 0.771 & 0.445 & 0.990 & 0.394 & 0.017 & 0.905 & 1.619 & 0.293 \\
\hline $\begin{array}{l}\text { Crop } \\
\text { residues } x \\
\text { inoculation }\end{array}$ & 0.482 & 0.629 & 2.869 & 0.096 & 0.805 & 0.470 & 1.669 & 0.229 & 0.420 & 0.663 & 1.586 & 0.245 & 1.887 & 0.194 \\
\hline
\end{tabular}

$\dagger$ Results presented for the category of biparental reproductive strategy;

$\$$ Results presented for the category of bifide typhlosolis. 
Table A4.8 Mean and standard error of RaoQ in the non-inversion tillage (NIT) and conventional tillage (CT) trials, for Spring and Fall 2014. Earthworm community taken into account for the computation excluded inoculated $L$. terrestris. For legend of the treatments, see Fig. 4.1. F-statistics and associated p-value of best fitted linear mixed model of RaoQ. Capital letters show significant pairwise differences within the main factor Crop residue application and small letters within the main factor L. terrestris inoculation.

\begin{tabular}{|c|c|c|c|c|c|c|c|c|}
\hline \multirow{2}{*}{ Treatments } & \multicolumn{4}{|c|}{ NIT } & \multicolumn{4}{|c|}{ CT } \\
\hline & \multicolumn{2}{|c|}{ Spring 2014} & \multicolumn{2}{|c|}{ Fall 2014} & \multicolumn{2}{|c|}{ Spring 2014} & \multicolumn{2}{|c|}{ Fall 2014} \\
\hline $\mathbf{S}_{100^{-}}$ & \multicolumn{2}{|c|}{$0.06(0.01)$} & \multicolumn{2}{|c|}{$0.07(0.02)$} & \multicolumn{2}{|c|}{$0.07(0.01) \mathrm{Aa}$} & \multicolumn{2}{|c|}{$0.08(0.03)$} \\
\hline $\mathbf{S}_{100}+$ & \multicolumn{2}{|c|}{$0.04(0.02)$} & \multicolumn{2}{|c|}{$0.02(0.01)$} & \multicolumn{2}{|c|}{$0.02(0.02) \mathrm{Aa}$} & \multicolumn{2}{|c|}{$0.03(0.02)$} \\
\hline $\mathbf{S}_{25^{-}} / / \mathbf{I}_{100^{-}}$ & \multicolumn{2}{|c|}{$0.05(0.00)$} & \multicolumn{2}{|c|}{$0.06(0.02)$} & \multicolumn{2}{|c|}{$0.03(0.01) \mathrm{Aa}$} & \multicolumn{2}{|c|}{$0.05(0.02)$} \\
\hline $\mathbf{S}_{25}+/ \mathbf{I}_{100}+$ & \multicolumn{2}{|c|}{$0.06(0.01)$} & \multicolumn{2}{|c|}{$0.05(0.02)$} & \multicolumn{2}{|c|}{$0.03(0.01) \mathrm{Aa}$} & \multicolumn{2}{|c|}{$0.08(0.02)$} \\
\hline$S_{0^{-}}$ & \multicolumn{2}{|c|}{$0.04(0.01)$} & \multicolumn{2}{|c|}{$0.05(0.02)$} & \multicolumn{2}{|c|}{$0.04(0.01) \mathrm{Aa}$} & \multicolumn{2}{|c|}{$0.06(0.01)$} \\
\hline \multirow[t]{2}{*}{$S_{0}+$} & \multicolumn{2}{|c|}{$0.07(0.02)$} & \multicolumn{2}{|c|}{$0.06(0.02)$} & \multicolumn{2}{|c|}{$0.04(0.02) \mathrm{Aa}$} & \multicolumn{2}{|c|}{$0.05(0.02)$} \\
\hline & $\mathbf{F}$ & $\mathbf{p}$ & $\mathbf{F}$ & $\mathbf{p}$ & $\mathbf{F}$ & $\mathbf{p}$ & $\mathbf{F}$ & $\mathbf{p}$ \\
\hline Crop residues & 0.377 & 0.694 & 0.179 & 0.838 & 4.271 & 0.040 & 0.210 & 0.813 \\
\hline Inoculation & 0.494 & 0.533 & 0.613 & 0.491 & 1.120 & $\overline{0.368}$ & 0.492 & 0.533 \\
\hline $\begin{array}{l}\text { Crop residues } x \\
\text { inoculation }\end{array}$ & 1.381 & 0.289 & 0.987 & 0.401 & 1.958 & 0.184 & 1.796 & 0.208 \\
\hline
\end{tabular}


Table A4.9 F and p-values from non-parametric permutational multivariate analysis of variance (Location) and from multivariate homogeneity of variances (Dispersion) of CWM for each of the main factors (crop residues and inoculation) and their interaction in the case of Location, of the non-inversion (NIT) and conventional tillage (CT) trials, for Spring and Fall 2014. Inoculated $L$. terrestris was excluded from distance matrices. Dissimilarity matrix calculated using the Gower distance.

\section{NIT trial}

Spring 2014

\begin{tabular}{llllllllll} 
& Location & \multicolumn{4}{c}{ Dispersion } & \multicolumn{2}{c}{ Location } & \multicolumn{2}{c}{ Dispersion } \\
\hline & $\mathbf{F}$ & $\mathbf{p}$ & $\mathbf{F}$ & $\mathbf{p}$ & $\mathbf{F}$ & $\mathbf{p}$ & $\mathbf{F}$ & $\mathbf{p}$ \\
\hline Crop residue & 0.493 & 0.698 & 0.877 & 0.471 & 0.411 & 0.783 & 0.129 & 0.931 \\
Inoculation & 0.806 & 0.713 & 4.733 & $\underline{\mathbf{0 . 0 0 1}}$ & 0.912 & 0.585 & 0.093 & 0.422 \\
$\begin{array}{l}\text { Crop residue } \mathbf{x} \\
\text { inoculation }\end{array}$ & 0.923 & 0.440 & - & - & 0.867 & 0.441 & - & - \\
\hline
\end{tabular}

\section{CT trial}

Spring 2014

\begin{tabular}{llllllllll} 
& Location & \multicolumn{4}{c}{ Dispersion } & \multicolumn{2}{c}{ Location } & \multicolumn{2}{c}{ Dispersion } \\
\hline & F & $\mathbf{p}$ & $\mathbf{F}$ & $\mathbf{p}$ & $\mathbf{F}$ & $\mathbf{p}$ & $\mathbf{F}$ & $\mathbf{p}$ \\
\hline Crop residue & 1.874 & 0.117 & 0.466 & 0.654 & 0.244 & 0.799 & 2.079 & 0.090 \\
$\begin{array}{l}\text { Inoculation } \\
\begin{array}{l}\text { Crop residue } \\
\text { inoculation }\end{array}\end{array}$ & 1.637 & 0.320 & 0.001 & 0.971 & 0.845 & 0.576 & 3.976 & $\underline{\mathbf{0 . 0 0 1}}$ \\
\hline
\end{tabular}




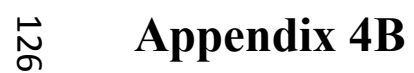

Table B4.1 Data used in this chapter.

\begin{tabular}{|c|c|c|c|c|c|c|c|c|c|c|c|c|c|}
\hline Tillage & Block & $\begin{array}{l}\text { Plot } \\
\text { no. }\end{array}$ & $\begin{array}{c}\text { Residue } \\
\text { Treatment }\end{array}$ & $\begin{array}{c}\text { Inoculation } \\
\text { Treatment }\end{array}$ & Season & $\begin{array}{c}A . \\
\text { caliginosa }\end{array}$ & $\begin{array}{c}A . \\
\text { chlorotica }\end{array}$ & $\begin{array}{l}A . \\
\text { rosea }\end{array}$ & $\begin{array}{c}E . \\
\text { tetraedra }\end{array}$ & $\begin{array}{c}\text { L. } \\
\text { castaneus }\end{array}$ & $\begin{array}{c}\text { L. } \\
\text { rubellus }\end{array}$ & $\begin{array}{l}\text { L. terrestris } \\
\text { (sub)adults }\end{array}$ & $\begin{array}{c}\text { L. terrestris } \\
\text { juveniles }\end{array}$ \\
\hline $\mathrm{CT}$ & 1 & 1 & $\mathrm{~S} 100$ & + & Fall 14 & 11.11 & 18.52 & 7.41 & 0 & 0 & 0 & 0 & 0 \\
\hline $\mathrm{CT}$ & 1 & 1 & $\mathrm{~S} 100$ & + & Fall 15 & 33.33 & 5.55 & 11.11 & 0 & 0 & 44.44 & 0 & 18.5 \\
\hline $\mathrm{CT}$ & 1 & 1 & $\mathrm{~S} 100$ & + & Spring 14 & 103.69 & 14.81 & 3.7 & 0 & 0 & 22.22 & 0 & 5.6 \\
\hline $\mathrm{CT}$ & 1 & 2 & $\mathrm{~S} 100$ & - & Fall 14 & 25.92 & 3.7 & 0 & 0 & 0 & 7.41 & 0 & 0 \\
\hline $\mathrm{CT}$ & 1 & 2 & $\mathrm{~S} 100$ & - & Fall 15 & 22.22 & 11.11 & 5.55 & 0 & 0 & 27.77 & 0 & 0 \\
\hline $\mathrm{CT}$ & 1 & 2 & $\mathrm{~S} 100$ & - & Spring 14 & 51.85 & 3.7 & 0 & 0 & 0 & 14.81 & 0 & 0 \\
\hline $\mathrm{CT}$ & 1 & 9 & I100 & + & Fall 14 & 22.22 & 3.7 & 7.41 & 0 & 0 & 0 & 3.7 & 11.1 \\
\hline $\mathrm{CT}$ & 1 & 9 & I100 & + & Fall 15 & 44.44 & 16.66 & 5.55 & 0 & 0 & 27.77 & 0 & 0 \\
\hline $\mathrm{CT}$ & 1 & 9 & I100 & + & Spring 14 & 40.74 & 7.41 & 0 & 0 & 0 & 3.7 & 3.7 & 0 \\
\hline $\mathrm{CT}$ & 1 & 10 & S0 & - & Fall 14 & 25.92 & 0 & 3.7 & 0 & 0 & 3.7 & 0 & 11.1 \\
\hline $\mathrm{CT}$ & 1 & 10 & S0 & - & Fall 15 & 44.44 & 5.55 & 5.55 & 0 & 0 & 5.55 & 0 & 0 \\
\hline $\mathrm{CT}$ & 1 & 10 & S0 & - & Spring 14 & 22.22 & 0 & 0 & 0 & 0 & 3.7 & 0 & 0 \\
\hline $\mathrm{CT}$ & 1 & 17 & S0 & + & Fall 14 & 14.81 & 11.11 & 3.7 & 0 & 0 & 3.7 & 0 & 7.4 \\
\hline $\mathrm{CT}$ & 1 & 17 & S0 & + & Fall 15 & 72.22 & 11.11 & 0 & 0 & 0 & 0 & 0 & 0 \\
\hline $\mathrm{CT}$ & 1 & 17 & S0 & + & Spring 14 & 14.81 & 3.7 & 0 & 0 & 0 & 11.11 & 0 & 0 \\
\hline $\mathrm{CT}$ & 1 & 18 & I100 & - & Fall 14 & 25.92 & 0 & 3.7 & 0 & 0 & 0 & 0 & 0 \\
\hline $\mathrm{CT}$ & 1 & 18 & $\mathrm{I} 100$ & - & Fall 15 & 61.1 & 0 & 5.55 & 0 & 0 & 22.22 & 0 & 5.6 \\
\hline $\mathrm{CT}$ & 1 & 18 & I100 & - & Spring 14 & 18.52 & 0 & 3.7 & 0 & 0 & 3.7 & 0 & 0 \\
\hline $\mathrm{CT}$ & 2 & 3 & S0 & - & Fall 14 & 51.85 & 0 & 3.7 & 0 & 0 & 7.41 & 0 & 0 \\
\hline $\mathrm{CT}$ & 2 & 3 & S0 & - & Fall 15 & 55.55 & 11.11 & 5.55 & 0 & 0 & 11.11 & 0 & 0 \\
\hline $\mathrm{CT}$ & 2 & 3 & S0 & - & Spring 14 & 29.63 & 3.7 & 3.7 & 0 & 0 & 7.41 & 0 & 7.4 \\
\hline $\mathrm{CT}$ & 2 & 4 & S0 & + & Fall 14 & 51.85 & 0 & 3.7 & 0 & 0 & 3.7 & 0 & 0 \\
\hline $\mathrm{CT}$ & 2 & 4 & S0 & + & Fall 15 & 66.66 & 0 & 0 & 0 & 0 & 16.66 & 0 & 5.6 \\
\hline $\mathrm{CT}$ & 2 & 4 & S0 & + & Spring 14 & 14.81 & 0 & 0 & 0 & 0 & 0 & 0 & 7.4 \\
\hline $\mathrm{CT}$ & 2 & 11 & I100 & - & Fall 14 & 51.85 & 0 & 0 & 0 & 0 & 3.7 & 0 & 0 \\
\hline $\mathrm{CT}$ & 2 & 11 & I100 & - & Fall 15 & 38.88 & 0 & 0 & 0 & 0 & 5.55 & 0 & 5.6 \\
\hline $\mathrm{CT}$ & 2 & 11 & I100 & - & Spring 14 & 7.41 & 3.7 & 7.41 & 0 & 0 & 0 & 0 & 0 \\
\hline $\mathrm{CT}$ & 2 & 12 & $\mathrm{~S} 100$ & + & Fall 14 & 33.33 & 0 & 7.41 & 0 & 0 & 7.41 & 0 & 7.4 \\
\hline $\mathrm{CT}$ & 2 & 12 & $\mathrm{~S} 100$ & + & Fall 15 & 49.99 & 0 & 0 & 0 & 0 & 5.55 & 0 & 5.6 \\
\hline $\mathrm{CT}$ & 2 & 12 & $\mathrm{~S} 100$ & + & Spring 14 & 3.7 & 0 & 0 & 0 & 0 & 0 & 0 & 0 \\
\hline
\end{tabular}


Table B4.1 (cont.)

\begin{tabular}{|c|c|c|c|c|c|c|c|c|c|c|c|c|c|}
\hline Tillage & Block & $\begin{array}{c}\text { Plot } \\
\text { no. }\end{array}$ & $\begin{array}{c}\text { Residue } \\
\text { Treatment }\end{array}$ & $\begin{array}{c}\text { Inoculation } \\
\text { Treatment }\end{array}$ & Season & $\begin{array}{c}\text { A. } \\
\text { caliginosa }\end{array}$ & $\begin{array}{c}\text { A. } \\
\text { chlorotica }\end{array}$ & $\begin{array}{c}A . \\
\text { rosea }\end{array}$ & $\begin{array}{c}E . \\
\text { tetraedra }\end{array}$ & $\begin{array}{c}\text { L. } \\
\text { castaneus }\end{array}$ & $\begin{array}{c}\text { L. } \\
\text { rubellus }\end{array}$ & $\begin{array}{l}\text { L. terrestris } \\
\text { (sub)adults }\end{array}$ & $\begin{array}{c}\text { L. terrestris } \\
\text { juveniles }\end{array}$ \\
\hline $\mathrm{CT}$ & 2 & 19 & S100 & - & Fall 14 & 37.03 & 0 & 7.41 & 0 & 0 & 0 & 0 & 3.7 \\
\hline $\mathrm{CT}$ & 2 & 19 & $\mathrm{~S} 100$ & - & Fall 15 & 44.44 & 0 & 11.11 & 0 & 0 & 33.33 & 0 & 0 \\
\hline $\mathrm{CT}$ & 2 & 19 & $\mathrm{~S} 100$ & - & Spring 14 & 22.22 & 0 & 0 & 0 & 0 & 7.41 & 0 & 0 \\
\hline $\mathrm{CT}$ & 2 & 20 & I100 & + & Fall 14 & 22.22 & 0 & 0 & 0 & 0 & 11.11 & 0 & 0 \\
\hline $\mathrm{CT}$ & 2 & 20 & I100 & + & Fall 15 & 38.88 & 0 & 0 & 0 & 0 & 27.77 & 0 & 5.6 \\
\hline $\mathrm{CT}$ & 2 & 20 & $\mathrm{I} 100$ & + & Spring 14 & 51.85 & 0 & 0 & 0 & 0 & 11.11 & 0 & 0 \\
\hline $\mathrm{CT}$ & 3 & 5 & $\mathrm{I} 100$ & + & Fall 15 & 72.22 & 0 & 5.55 & 0 & 0 & 22.22 & 0 & 0 \\
\hline $\mathrm{CT}$ & 3 & 5 & I100 & + & Spring 14 & 33.33 & 0 & 3.7 & 0 & 0 & 3.7 & 0 & 0 \\
\hline $\mathrm{CT}$ & 3 & 6 & $\mathrm{~S} 100$ & - & Fall 14 & 40.74 & 0 & 3.7 & 0 & 0 & 11.11 & 0 & 0 \\
\hline $\mathrm{CT}$ & 3 & 6 & $\mathrm{~S} 100$ & - & Fall 15 & 44.44 & 0 & 22.22 & 0 & 0 & 27.77 & 0 & 0 \\
\hline $\mathrm{CT}$ & 3 & 6 & $\mathrm{~S} 100$ & - & Spring 14 & 7.41 & 0 & 0 & 0 & 0 & 7.41 & 0 & 0 \\
\hline $\mathrm{CT}$ & 3 & 13 & S0 & + & Fall 14 & 37.03 & 0 & 0 & 0 & 0 & 11.11 & 0 & 0 \\
\hline $\mathrm{CT}$ & 3 & 13 & S0 & + & Fall 15 & 27.77 & 0 & 0 & 0 & 0 & 5.55 & 0 & 0 \\
\hline $\mathrm{CT}$ & 3 & 13 & S0 & + & Spring 14 & 7.41 & 0 & 0 & 0 & 0 & 0 & 0 & 0 \\
\hline $\mathrm{CT}$ & 3 & 14 & I100 & - & Fall 15 & 55.55 & 0 & 16.66 & 0 & 0 & 11.11 & 0 & 0 \\
\hline $\mathrm{CT}$ & 3 & 14 & I100 & - & Spring 14 & 22.22 & 0 & 0 & 0 & 0 & 3.7 & 0 & 0 \\
\hline $\mathrm{CT}$ & 3 & 21 & $\mathrm{~S} 100$ & + & Fall 14 & 40.74 & 0 & 0 & 0 & 0 & 0 & 0 & 7.4 \\
\hline $\mathrm{CT}$ & 3 & 21 & $\mathrm{~S} 100$ & + & Fall 15 & 72.22 & 0 & 0 & 0 & 0 & 44.44 & 0 & 0 \\
\hline $\mathrm{CT}$ & 3 & 21 & S100 & + & Spring 14 & 33.33 & 0 & 0 & 3.7 & 0 & 0 & 0 & 0 \\
\hline $\mathrm{CT}$ & 3 & 22 & S0 & - & Fall 14 & 55.55 & 0 & 0 & 0 & 0 & 7.41 & 0 & 0 \\
\hline $\mathrm{CT}$ & 3 & 22 & S0 & - & Fall 15 & 44.44 & 0 & 5.55 & 0 & 0 & 0 & 0 & 0 \\
\hline $\mathrm{CT}$ & 3 & 22 & S0 & - & Spring 14 & 11.11 & 0 & 0 & 0 & 0 & 3.7 & 0 & 0 \\
\hline $\mathrm{CT}$ & 4 & 7 & $\mathrm{I} 100$ & - & Fall 14 & 29.63 & 0 & 3.7 & 0 & 0 & 7.41 & 0 & 3.7 \\
\hline $\mathrm{CT}$ & 4 & 7 & I100 & - & Fall 15 & 66.66 & 0 & 0 & 0 & 0 & 16.66 & 0 & 0 \\
\hline $\mathrm{CT}$ & 4 & 7 & $\mathrm{I} 100$ & - & Spring 14 & 40.74 & 0 & 0 & 0 & 0 & 0 & 0 & 3.7 \\
\hline $\mathrm{CT}$ & 4 & 8 & S0 & + & Fall 14 & 7.41 & 0 & 3.7 & 0 & 0 & 0 & 0 & 0 \\
\hline $\mathrm{CT}$ & 4 & 8 & S0 & + & Fall 15 & 27.77 & 0 & 0 & 0 & 0 & 0 & 0 & 7.4 \\
\hline $\mathrm{CT}$ & 4 & 8 & S0 & + & Spring 14 & 29.63 & 0 & 0 & 0 & 0 & 11.11 & 0 & 0 \\
\hline $\mathrm{CT}$ & 4 & 15 & $\mathrm{~S} 100$ & - & Fall 14 & 18.52 & 0 & 7.41 & 0 & 0 & 14.81 & 3.7 & 0 \\
\hline $\mathrm{CT}$ & 4 & 15 & $\mathrm{~S} 100$ & - & Fall 15 & 16.66 & 0 & 0 & 0 & 0 & 27.77 & 0 & 5.6 \\
\hline $\mathrm{CT}$ & 4 & 15 & $\mathrm{~S} 100$ & - & Spring 14 & 14.81 & 0 & 0 & 0 & 0 & 3.7 & 0 & 3.7 \\
\hline $\mathrm{CT}$ & 4 & 16 & $\mathrm{~S} 100$ & + & Spring 14 & 25.92 & 0 & 0 & 0 & 0 & 0 & 0 & 3.7 \\
\hline
\end{tabular}


$\stackrel{\mapsto}{\infty}$

Table B4.1 (cont.)

\begin{tabular}{|c|c|c|c|c|c|c|c|c|c|c|c|c|c|}
\hline Tillage & Block & $\begin{array}{l}\text { Plot } \\
\text { no. }\end{array}$ & $\begin{array}{l}\text { Residue } \\
\text { Treatment }\end{array}$ & $\begin{array}{c}\text { Inoculation } \\
\text { Treatment }\end{array}$ & Season & $\begin{array}{c}\text { A. } \\
\text { caliginosa }\end{array}$ & $\begin{array}{c}\text { A. } \\
\text { chlorotica }\end{array}$ & $\begin{array}{c}A . \\
\text { rosea }\end{array}$ & $\begin{array}{c}E . \\
\text { tetraedra }\end{array}$ & $\begin{array}{c}\text { L. } \\
\text { castaneus }\end{array}$ & $\begin{array}{c}L . \\
\text { rubellus }\end{array}$ & $\begin{array}{l}\text { L. terrestris } \\
\text { (sub)adults }\end{array}$ & $\begin{array}{c}\text { L. terrestris } \\
\text { juveniles }\end{array}$ \\
\hline $\mathrm{CT}$ & 4 & 23 & S0 & - & Fall 14 & 40.74 & 0 & 11.11 & 0 & 0 & 11.11 & 0 & 0 \\
\hline $\mathrm{CT}$ & 4 & 23 & S0 & - & Fall 15 & 66.66 & 0 & 11.11 & 0 & 0 & 11.11 & 0 & 0 \\
\hline $\mathrm{CT}$ & 4 & 23 & So & - & Spring 14 & 7.41 & 0 & 0 & 0 & 0 & 0 & 0 & 0 \\
\hline $\mathrm{CT}$ & 4 & 24 & I100 & + & Fall 14 & 11.11 & 0 & 14.81 & 0 & 0 & 3.7 & 0 & 14.8 \\
\hline $\mathrm{CT}$ & 4 & 24 & I100 & + & Fall 15 & 22.22 & 0 & 22.22 & 0 & 5.55 & 33.33 & 0 & 0 \\
\hline $\mathrm{CT}$ & 4 & 24 & I100 & + & Spring 14 & 18.52 & 0 & 7.41 & 0 & 0 & 0 & 0 & 0 \\
\hline NIT & 5 & 25 & $\mathrm{~S} 25$ & + & Fall 14 & 7.41 & 0 & 0 & 0 & 0 & 3.7 & 0 & 3.7 \\
\hline NIT & 5 & 25 & S25 & + & Fall 15 & 38.88 & 11.11 & 0 & 0 & 0 & 5.55 & 0 & 0 \\
\hline NIT & 5 & 25 & S25 & + & Spring 14 & 33.33 & 7.41 & 0 & 0 & 0 & 25.92 & 0 & 0 \\
\hline NIT & 5 & 26 & S25 & - & Fall 14 & 22.22 & 0 & 0 & 0 & 0 & 0 & 0 & 22.2 \\
\hline NIT & 5 & 26 & S25 & - & Fall 15 & 72.22 & 22.22 & 5.55 & 0 & 0 & 22.22 & 0 & 5.6 \\
\hline NIT & 5 & 26 & S25 & - & Spring 14 & 33.33 & 0 & 0 & 0 & 0 & 7.41 & 0 & 0 \\
\hline NIT & 5 & 33 & $\mathrm{~S} 100$ & + & Fall 14 & 55.55 & 3.7 & 0 & 0 & 0 & 3.7 & 0 & 0 \\
\hline NIT & 5 & 33 & $\mathrm{~S} 100$ & + & Fall 15 & 49.99 & 0 & 0 & 0 & 0 & 11.11 & 0 & 5.6 \\
\hline NIT & 5 & 33 & $\mathrm{~S} 100$ & + & Spring 14 & 51.85 & 0 & 0 & 0 & 0 & 18.52 & 0 & 3.7 \\
\hline NIT & 5 & 34 & S0 & - & Fall 14 & 22.22 & 0 & 0 & 0 & 0 & 0 & 0 & 11.1 \\
\hline NIT & 5 & 34 & S0 & - & Fall 15 & 33.33 & 5.55 & 0 & 0 & 0 & 0 & 0 & 5.6 \\
\hline NIT & 5 & 34 & S0 & - & Spring 14 & 18.52 & 3.7 & 0 & 0 & 0 & 0 & 0 & 0 \\
\hline NIT & 5 & 41 & S0 & + & Fall 14 & 40.74 & 7.41 & 0 & 0 & 0 & 3.7 & 0 & 3.7 \\
\hline NIT & 5 & 41 & S0 & + & Fall 15 & 44.44 & 5.55 & 0 & 0 & 0 & 0 & 0 & 0 \\
\hline NIT & 5 & 41 & S0 & + & Spring 14 & 88.88 & 0 & 3.7 & 0 & 0 & 14.81 & 0 & 0 \\
\hline NIT & 5 & 42 & $\mathrm{~S} 100$ & - & Fall 14 & 74.07 & 3.7 & 7.41 & 0 & 0 & 22.22 & 3.7 & 0 \\
\hline NIT & 5 & 42 & $\mathrm{~S} 100$ & - & Fall 15 & 55.55 & 38.88 & 0 & 0 & 0 & 38.88 & 0 & 5.6 \\
\hline NIT & 5 & 42 & $\mathrm{~S} 100$ & - & Spring 14 & 55.55 & 11.11 & 0 & 0 & 0 & 11.11 & 0 & 0 \\
\hline NIT & 6 & 27 & $\mathrm{~S} 25$ & - & Fall 14 & 22.22 & 0 & 0 & 0 & 0 & 11.11 & 0 & 7.4 \\
\hline NIT & 6 & 27 & S25 & - & Fall 15 & 27.77 & 0 & 0 & 0 & 0 & 0 & 0 & 0 \\
\hline NIT & 6 & 27 & $\mathrm{~S} 25$ & - & Spring 14 & 37.03 & 0 & 0 & 0 & 0 & 7.41 & 3.7 & 11.1 \\
\hline NIT & 6 & 28 & $\mathrm{~S} 100$ & + & Fall 14 & 59.25 & 0 & 0 & 0 & 0 & 0 & 0 & 7.4 \\
\hline NIT & 6 & 28 & $\mathrm{~S} 100$ & + & Fall 15 & 66.66 & 0 & 0 & 0 & 0 & 38.88 & 0 & 11.1 \\
\hline NIT & 6 & 28 & $\mathrm{~S} 100$ & + & Spring 14 & 29.63 & 0 & 0 & 0 & 0 & 0 & 0 & 11.1 \\
\hline NIT & 6 & 35 & S100 & - & Fall 14 & 29.63 & 0 & 0 & 0 & 0 & 3.7 & 0 & 7.4 \\
\hline NIT & 6 & 35 & $\mathrm{~S} 100$ & - & Fall 15 & 83.32 & 0 & 0 & 0 & 0 & 27.77 & 0 & 5.6 \\
\hline NIT & 6 & 35 & S100 & - & Spring 14 & 18.52 & 0 & 0 & 0 & 0 & 11.11 & 0 & 3.7 \\
\hline NIT & 6 & 36 & $\mathrm{~S} 25$ & + & Fall 14 & 33.33 & 0 & 0 & 0 & 0 & 0 & 7.41 & 18.5 \\
\hline NIT & 6 & 36 & S25 & + & Fall 15 & 38.88 & 0 & 5.55 & 0 & 0 & 11.11 & 5.55 & 0 \\
\hline NIT & 6 & 36 & S25 & + & Spring 14 & 33.33 & 0 & 3.7 & 0 & 0 & 7.41 & 0 & 0 \\
\hline NIT & 6 & 43 & S0 & - & Fall 14 & 48.14 & 3.7 & 11.11 & 0 & 0 & 11.11 & 0 & 3.7 \\
\hline
\end{tabular}


Table B4.1 (cont.)

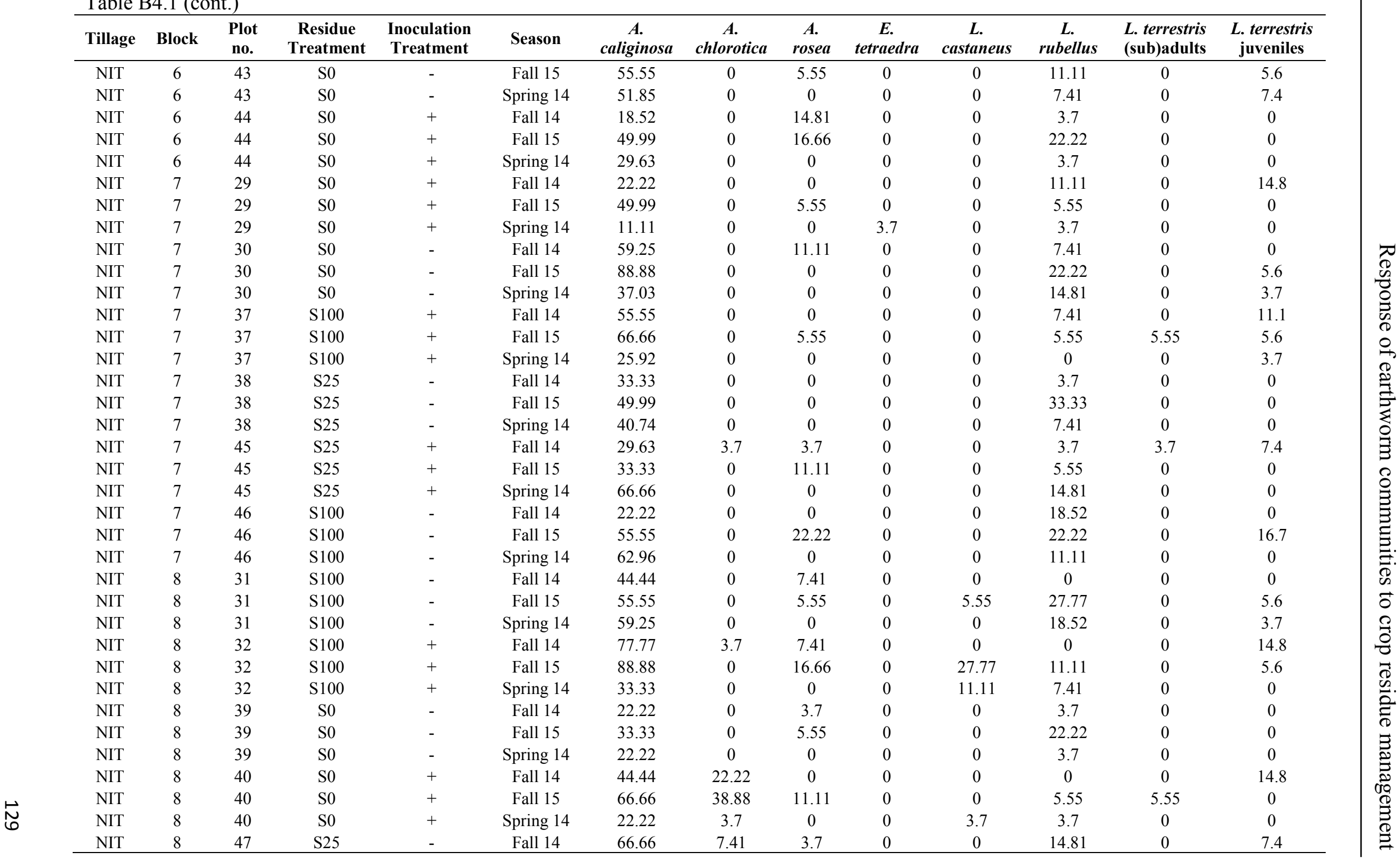


Table B4.1 (cont.)

\begin{tabular}{|c|c|c|c|c|c|c|c|c|c|c|c|c|c|}
\hline Tillage & Block & $\begin{array}{l}\text { Plot } \\
\text { no. }\end{array}$ & $\begin{array}{l}\text { Residue } \\
\text { Treatment }\end{array}$ & $\begin{array}{c}\text { Inoculation } \\
\text { Treatment }\end{array}$ & Season & $\begin{array}{c}\text { A. } \\
\text { caliginosa }\end{array}$ & $\begin{array}{c}\text { A. } \\
\text { chlorotica }\end{array}$ & $\begin{array}{c}A . \\
\text { rosea }\end{array}$ & $\begin{array}{c}E . \\
\text { tetraedra }\end{array}$ & $\begin{array}{c}\text { L. } \\
\text { castaneus }\end{array}$ & $\begin{array}{c}L . \\
\text { rubellus }\end{array}$ & $\begin{array}{l}\text { L. terrestris } \\
\text { (sub)adults }\end{array}$ & $\begin{array}{c}\text { L. terrestris } \\
\text { juveniles }\end{array}$ \\
\hline NIT & 8 & 47 & S25 & - & Fall 15 & 22.22 & 0 & 5.55 & 0 & 0 & 5.55 & 0 & 0 \\
\hline NIT & 8 & 47 & S25 & - & Spring 14 & 37.03 & 0 & 0 & 0 & 0 & 7.41 & 0 & 0 \\
\hline NIT & 8 & 48 & S25 & + & Fall 14 & 22.22 & 33.33 & 0 & 0 & 0 & 3.7 & 0 & 0 \\
\hline NIT & 8 & 48 & S25 & + & Fall 15 & 49.99 & 33.33 & 0 & 0 & 0 & 5.55 & 0 & 0 \\
\hline NIT & 8 & 48 & S25 & + & Spring 14 & 48.14 & 25.92 & 0 & 0 & 11.11 & 3.7 & 0 & 0 \\
\hline
\end{tabular}




\section{Chapter 5}

\section{Body-weight distributions of earthworm communities are affected by crop residue management under different tillage systems}

Joana Frazão, Valentina Sechi, Lijbert Brussaard, Jack H. Faber, Mirjam M.

Pulleman, Ron G.M. de Goede 



\title{
5 Body-weight distributions of earthworm communities
}

\section{are affected by crop residue management under different}

\section{tillage systems}

\begin{abstract}
Body weight is a life-history trait and has been identified as a synoptic trait explaining and predicting community assembly. It is also responsive to environmental change and easy to measure. In two parallel field experiments with contrasting tillage regimes - non-inversion (NIT) and conventional tillage (CT) - we investigated earthworm body-weight distributions in relation to crop residue amount and placement. Our results show that crop residue management affected body-weight distributions of litter feeding earthworms (i.e., epigeics and anecics) in both tillage trials, but not of soil feeders (i.e., endogeics). In NIT, higher amounts of crop residues on the soil surface affected epigeics, dominated by L. rubellus, through an increase of the proportion of the lightest earthworms, suggesting a higher reproductive output. L. terrestris were generally heavier where more crop residues were available on the soil surface. In CT, the heaviest L. rubellus were heavier when crop residues were supplied on the soil surface or incorporated than when no crop residues were provided. The lightest $L$. rubellus showed a higher proportion when no crop residues were present. Both observations indicate a lag in growth of $L$. rubellus. L. terrestris showed a body-weight distribution with a wider range when crop residues were provided, irrespective of residue placement, than when no crop residues were supplied. Our results showed that our trait-based approach complements methods most commonly found in the soil ecological literature which are based on averaged literature-based species specific trait values, since it allows identifying shifts in population processes due to disturbance.
\end{abstract}





\subsection{Introduction}

Earthworms are an important element of soil biodiversity, affecting important soil processes (Bertrand et al., 2015), such as organic matter decomposition (Keith and Robinson, 2012), nutrient cycling (van Groenigen et al., 2014) and soil structure formation and maintenance (Bossuyt et al., 2006; Capowiez et al., 2015). In arable fields, earthworm communities are dominated by endogeic earthworms (e.g. Crittenden et al., 2014; Frazão et al., 2017, chapter 2; Pelosi et al., 2015; Pérès et al., 2011) that feed on soil organic matter (Curry and Schmidt, 2007), whereas epigeics and particularly anecics (both ecological groups feeding on decaying plant litter on/near the soil surface (Curry and Schmidt, 2007) occur at low densities, if at all. Direct and indirect effects of conventional tillage have been referred to as plausible causes for the low abundance of litter feeding earthworms (Chan, 2001), as mouldboard ploughing displaces crop residues to deeper soil layers, destroys permanent burrows inhabited by anecics and increases the exposure of earthworms to predation.

Earthworm communities in arable fields have been described using metrics such as species richness and composition and total or ecological group density (counts or biomass per meter square) (e.g. Crittenden et al., 2014; Frazão et al., 2017, chapter 2; Roarty and Schmidt, 2013; Smith et al., 2008). Here, we focus on earthworm body size. Body size is associated with many life-history traits, reflecting life strategies and individual adaptations (Peters, 1983). Furthermore, as it is easy to measure, it has been identified as a synoptic trait for explaining and predicting community assembly, potentially well responding to environmental change (Sutherland et al., 2013). Recent studies on nematode communities showed that body size reflects environmental filtering within nematode trophic groups (Mulder and Maas, 2017; Sechi et al., 2018). In the case of the earthworm community literature, some studies on earthworm functional diversity have used body size data (de Lange et al., 2013; Fournier et al., 2012; Pelosi et al., 2016; Pelosi et al., 2013a; Pérès et al., 2011). These studies, however, used average data from literature and do not assess shifts in body-size distribution that may be induced by specific environmental stressors. As an exception, Frazão et al, in press, chapter 4, included measured body weight data in their functional diversity study of earthworm communities' response to crop residue management, although individually measured body weight was averaged per species before further analysis. In the present study, we use data measured at the individual level. 
Body weight has been referred to as the most important metric of body size, one that best reflects the functional impacts at the population level, as it explains a greater proportion of resource use, than, e.g., volume or length (Turnbull et al., 2014). Furthermore, Moretti et al. (2017) recommended the measurements of body weight in organisms with a flexible body, such as earthworms. One important determinant of body weight change is the acquisition of food and its metabolic transformations, in which resources are allocated to maintenance, growth or reproduction (Daniel et al., 1996). Thus, an increase of available resources is expected to affect the performance of communities and this may occur through shifts towards heavier individuals, higher densities and/or an increase of reproductive output.

In the present study, we investigated body-weight distributions in earthworm communities in relation to crop residue amount and placement in the soil profile, in arable fields under different tillage practices: conventional mouldboard ploughing (hereafter "CT") and non-inversion tillage (hereafter "NIT"). Anecics had been introduced in both tillage trials to improve functional diversity of earthworm communities in arable fields. Furthermore, farmers have a particular interest on this ecological group, which is usually absent in tilled arable fields, although there are indications that it can establish under reduced tillage intensity. Given that earthworm ecological groups represent different feeding guilds and can be expected to react differently to crop residue management, we considered them separately (i.e., epigeics vs. anecics vs. endogeics). We hypothesised that increasing amounts of crop residues on the soil surface coupled with reduced soil disturbance, would enhance epigeic and anecic performance (towards heavier individuals), whereas endogeics would not to be affected, except if anecics would incorporate significant amounts of residues. Incorporating crop residues under conventional tillage was hypothesised to, on the one hand, stimulate endogeics performance (measured through an increase of individual body weight), and, on the other hand, constrain epigeics and anecics performance (i.e., decreased body weight) compared to surface-applied crop residues. 


\subsection{Materials and Methods}

Details on the design of this study have been described elsewhere (Frazão et al, in press, chapter 4). In short, in 2013 residue treatments were installed in two parallel field trials with contrasting tillage practices. Both fields were adjacent to each other, one was conventionally tilled (CT), while the other had been under non-inversion tillage (NIT) since 2009.

In each field, 24 plots were established in four blocks, and in each block three crop residue treatments were set-up, comprised in CT of (i) no crop residues (hereafter "S0"), (ii) incorporation of crop residues (hereafter " $\mathrm{I}_{100}$ "), and (iii) soil surface applied residues (hereafter "S $\mathrm{S}_{100}$ "), and comprised in NIT of (i) no residues (hereafter "S $\mathrm{S}_{0}$ "), (ii) $25 \%$ of crop residues placed on the soil surface (hereafter " $\mathrm{S}_{25}$ "), and (iii) $100 \%$ of crop residues placed on the soil surface (hereafter "S $\mathrm{S}_{100}$ "). In half of the plots of each block, 20 ind. $\mathrm{m}^{-2}$ of the anecic Lumbricus terrestris (Linnaeus, 1758) were inoculated in October 2013. The distance between the inoculated and non-inoculated plots was between 21 and 30m. However, since the species colonized non-inoculated plots (Frazão et al, in press, chapter 4), for the purpose of this study, we pooled the earthworms sampled in inoculated and non-inoculated plots.

$\mathrm{S}_{100}$ (CT and NIT trials) and $\mathrm{I}_{100}$ received the same amount of crop residues, and the amendments were applied annually in both trials. We kept the crop residue types as similar as possible across the years, depending on availability. In 2013 a mixture of winter wheat stubble and radish (Raphanus sativus subsp. oleiferus) was applied, as those were the crops grown in both fields. In 2014 a mixture of winter wheat straw and radish was applied after the removal of sugar beet residues, which was the crop harvested at the time, and in 2015 only winter barley stubbles were applied. Grain crop residues were applied at a rate of $4.7 \mathrm{t} \mathrm{ha}^{-1}$ and radish at a rate of $1.1 \mathrm{t} \mathrm{ha}^{-1}$ (DW) in the treatments $\mathrm{S}_{100}$ and $\mathrm{I}_{100}$ of both trials, reflecting realistic amounts for Dutch arable farming systems. Both fields received similar rates of mineral fertilization and chemical crop protection and no animal manure was used during the experimental period.

Earthworms were sampled in Spring 2014, Fall 2014 and Fall 2015, but to avoid the effect of any seasonal differences in body weights, the data used in the current study was restricted to the Fall sampling events. Sampling took place with a combination of methods in both tillage trials:

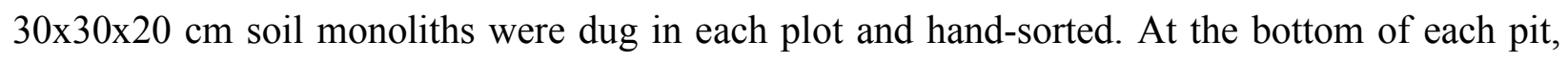
2.51 of allyl isothiocyanate (AITC) solution (1 $\mathrm{ml}$ AITC dispersed in $20 \mathrm{ml}$ 2-propanol added to 
101 of water and mixed thoroughly) was applied, to expel deep burrowing earthworms. In Fall 2014 three soil monoliths were taken per plot, whereas in 2015 only two monoliths were collected in each. Mature and juvenile earthworms were identified using Sims and Gerard (1999) and Stöp-Bowitz (1969), respectively.

In contrast to previous work (Frazão et al, in press, chapter 4), where only (sub)adult earthworms were examined, in the current study all developmental stages were considered. Specimens were weighed individually, after gut voidance for $48 \mathrm{hrs}$ at $16{ }^{\circ} \mathrm{C}$. Due to logistical constraints we could not weigh them alive throughout the sampling seasons, and individuals were killed and preserved in $70 \%$ alcohol until further identification and body weight measurements. Details regarding the weight mass corrections are described in Frazão et al, in press, chapter 4. Identification of about $6 \%$ (i.e. 646 out of 10416) and body weight measurements of about $19 \%$ (i.e. 1958 out of 10416) of the intact earthworms was not possible, as individuals were too small to be identified, or had started to decompose, respectively, and were therefore excluded from further study.

\subsubsection{Data analysis}

Earthworm body-weight distributions were analysed separately for endogeics, epigeic and anecic species and for each tillage trial (CT and NIT). The data per crop residue treatment were pooled for the two years and for the experimental blocks, as the abundances of epigeics and especially anecic specimens were very low. Additionally, the distributions of the most dominant species of each ecological group, as well as of $L$. terrestris were also analysed.

A bootstrapped version of the Kolmogorov-Smirnov test (number of bootstraps $=1000$ ) was used to compare earthworm body-weight distributions between crop residue treatments of each tillage trial. Kolmogorov-Smirnov test is considered suitable for this type of analysis as it is distribution-free and is responsive to differences in the whole shape of the distribution (Sokal and Rohlf, 1995). However, it does not allow ties, which was avoided by bootstrapping the test. Kernel density plots were used to visualize body-weight distributions (log-scaled body weight) for earthworm ecological groups of each crop residue treatment for each tillage trial. All analyses were performed using R 3.5.2 (R CoreTeam, 2014), using Matching 4.9-2. 


\subsection{Results}

In total seven earthworm species were collected. Soil feeder earthworms belonged to four species, Aporrectodea caliginosa (Savigny, 1826), Allolobophora chlorotica (Savigny, 1826), Aporrectodea rosea (Savigny, 1826), Aporrectodea limicola (Michaelsen, 1900) and litter feeder earthworms were Lumbricus castaneus (Savigny, 1826), Lumbricus rubellus (Hoffmeister, 1843) and L. terrestris. Histograms of body weight classes (epigeics and anecics) are given in the Appendix 5A (Figs. A5.1 for NIT and A5.2 for CT).

\subsubsection{Earthworm body-size distributions in the NIT trial}

In the NIT experiment, body-weight distributions of epigeic and anecic earthworms were affected by crop residue treatments, whereas residue amounts had no effects on the body weight distribution of endogeic species (Table 5.1, Fig. 5.1). In particular, the body-weight distribution differed significantly between $\mathrm{S}_{100}$ and $\mathrm{S}_{25}$, and between $\mathrm{S}_{100}$ and $\mathrm{S}_{0}$. The body-weight distribution of epigeic species revealed three peaks in the Kernel density plots in each of the crop residue treatments, most likely corresponding to earthworm developmental stages (juveniles, subadults and adults) (Fig. 5.1A). The log-scaled body weight distribution in $\mathrm{S}_{100}$ (highest level of surface residue application) displayed the first peak at about -4.8 log body weight $(0.01 \mathrm{~g})$. Similarly, with $25 \%$ of the surface-applied crop residues $\left(\mathrm{S}_{25}\right)$ and without residues $\left(\mathrm{S}_{0}\right)$, the first peak was displayed in the same position of the log-scaled body weight. However, the proportion of earthworm individuals with $0.01 \mathrm{~g}$ (-4.8g log body weight) was lower in $\mathrm{S}_{25}$ and $\mathrm{S}_{0}$ than in $\mathrm{S}_{100}$, as indicated by the differences in peak heights. The second peak was shown at about -2.2 $\log$ body weight $(0.11 \mathrm{~g})$ in $\mathrm{S}_{100}$, whereas in $\mathrm{S}_{25}$ and $\mathrm{S}_{0}$, individuals were a bit lighter, with a peak at $-3 \log$ body weight $(0.05 \mathrm{~g})$. The proportion of epigeics in $\mathrm{S}_{25}$ with $0.05 \mathrm{~g}$ was however higher, although not significantly, than in $\mathrm{S}_{0}$. Finally, the heaviest epigeics were found at about $-0.8 \log$ body weight $(0.45 \mathrm{~g})$ in all crop residue treatments, and the width of all peaks was similar across treatments (Fig. 5.1A). The observed effect for epigeics was strongly determined by the bodyweight distribution of L. rubellus (Table 5.2, Fig. 5.1B), as shown by its kernel density plot that resembled the one of epigeics. The only anecic found during both sampling campaigns was $L$. terrestris, and the kernel density plot showed a bimodal body-weight distribution for each of the crop residue treatments (Fig. 5.1C). In $\mathrm{S}_{100}$, the log body weight peak of the lightest $L$. terrestris 
was found at $-1.5(0.22 \mathrm{~g})$, while in $\mathrm{S}_{25}$ and $\mathrm{S}_{0}$, at -2.7 and $-2.8 \log$ body weight (0.07 and $\left.0.06 \mathrm{~g}\right)$, respectively. Furthermore, in $\mathrm{S}_{100}$ the proportion of L. terrestris individuals with a log body weight heavier than $0(1 \mathrm{~g})$ was higher than in $\mathrm{S}_{25}$ and $\mathrm{S}_{0}$.

\subsubsection{Earthworm body-size distribution in the CT trial}

In the CT experiment, similarly to the NIT experiment, body-weight distribution of epigeic and anecic earthworms were affected by crop residue treatments, while no effects were found for endogeic species (Table 5.1, Fig. 5.2). Body-weight distribution of epigeic species significantly differed between treatments with and without crop residue supply $\left(\mathrm{S}_{0}\right)$, irrespective of whether residues were surface-applied $\left(\mathrm{S}_{100}\right)$ or incorporated $\left(\mathrm{I}_{100}\right)$ by conventional tillage, whereas in the case of anecics, their body-weight distribution only significantly differed between incorporated crop residue $\left(\mathrm{I}_{100}\right)$ and no crop residue treatments $\left(\mathrm{S}_{0}\right)$ (Table 5.1). The kernel density plots showed a first peak at $-4.8 \log$ body weight $(0.01 \mathrm{~g})$ when crop residues were surface-applied $\left(\mathrm{S}_{100}\right)$ or not applied at all $\left(\mathrm{S}_{0}\right)$, which was higher in $\mathrm{S}_{0}$ meaning that the proportion of individuals with about $0.1 \mathrm{~g}$ was larger in $\mathrm{S}_{0}$ than in $\mathrm{S}_{100}$ (Fig. 5.2A). The second body weight peak of epigeics in $\mathrm{S}_{100}$ was at $\log$ body weight $-2.2(0.11 \mathrm{~g})$, similarly to the one of $\mathrm{S}_{0}$, but it occurred at heavier weight than in $\mathrm{I}_{100}$, which was positioned at log body weight $-3(0.05 \mathrm{~g})$. The third peak of epigeics in $\mathrm{S}_{100}$ and $\mathrm{I}_{100}$ was found at $-0.8 \mathrm{log}$ body weight $(0.45 \mathrm{~g})$, while in $\mathrm{S}_{0}$ epigeics peaked at a lighter body weight (-1 log body weight, or $0.37 \mathrm{~g}$ ) (Fig. 5.2A). The dominant epigeic species, L. rubellus, strongly determined the body-weight distribution of epigeics (Table 5.2, Fig. 5.2B), as indicated by its kernel density plot that mirrored the one of epigeics. L. terrestris bodyweight distributions only differed between $\mathrm{S}_{0}$ and $\mathrm{I}_{100}$, whereas no significant differences were found between the other treatments (Table 5.2). However, body-weight distributions of $L$. terrestris look rather different in $\mathrm{S}_{100}$ and $\mathrm{S}_{0}$, although the peak at lowest weight was in the same position (-2.5 log body weight, i.e., 0.8g) (Fig. 5.2C). In $\mathrm{S}_{100}$, body-weight distribution of $L$. terrestris was smooth and broad, whereas both $\mathrm{I}_{100}$ and $\mathrm{S}_{0}$ treatments revealed bimodal $\log$ scaled body weight distributions (Fig. 5.2C). Clearly, both peaks of L. terrestris in $\mathrm{I}_{100}(-1.5$ and $1.3 \log$ body weight $\left(0.22\right.$ and $3.7 \mathrm{~g}$, respectively) ) were heavier than those in $\mathrm{S}_{0}(-2.5$ and -1.5 $\log$ body weight (0.08 and $0.22 \mathrm{~g}$, respectively)). Furthermore, the range of body-weight distribution of L.terrestris in $\mathrm{S}_{0}(-3$ to $-0.3 \mathrm{log}$ body weight, i.e. 0.05 to $0.7 \mathrm{~g}$ ) was much narrower than in $\mathrm{S}_{100}(-5$ to 2, i.e. 0.01 to about $7 \mathrm{~g})$ ) and in $\mathrm{I}_{100}$ (-4 to 2, i.e. 0.02 to about $7 \mathrm{~g}$ ) (Fig. 5.2C). 
Table 5.1 - P-values of the bootstrapped Kolmogorov-Smirnov test comparing effects of crop residue treatments on the body-weight distributions of epigeic, anecic and endogeic earthworms for the two seasons combined (Fall 2014 and Fall 2015) in the non-inversion tillage (NIT) and conventional tillage (CT) trials.

\section{Epigeics Anecics Endogeics}

Non-inversion tillage trial (NIT)

\begin{tabular}{|c|c|c|c|}
\hline $\mathbf{S}_{100}$ vS. $\mathbf{S}_{25}$ & $<0.001$ & 0.027 & 0.177 \\
\hline$S_{100}$ vs. $S_{0}$ & 0.015 & $\overline{0.018}$ & 0.785 \\
\hline $\mathbf{S}_{25}$ vs. $\mathbf{S}_{0}$ & 0.368 & $\overline{0.510}$ & 0.502 \\
\hline & \multicolumn{3}{|c|}{ Conventional tillage trial (CT) } \\
\hline S100 VS. I100 & 0.062 & 0.237 & 0.307 \\
\hline$S_{100}$ Vs. $S_{0}$ & 0.035 & 0.216 & 0.523 \\
\hline$I_{100}$ vs. $S_{0}$ & $\overline{0.026}$ & 0.029 & 0.477 \\
\hline
\end{tabular}

Table 5.2 - P-values of the bootstrapped Kolmogorov-Smirnov test comparing effects of crop residue treatments on the body-weight distributions of the dominant epigeic (L. rubellus), anecic (L. terrestris) and endogeic species (A. caliginosa) for the two seasons combined (Fall 2014 and Fall 2015) in the noninversion tillage (NIT) and conventional tillage (CT) trials.

\section{L. rubellus L. terrestris A. caliginosa}

Non-inversion tillage trial (NIT)

\begin{tabular}{|c|c|c|c|}
\hline $\mathbf{S}_{100}$ VS. $\mathbf{S}_{25}$ & $\underline{0.002}$ & $\underline{0.027}$ & 0.122 \\
\hline$S_{100}$ vs. $S_{0}$ & 0.039 & $\overline{0.018}$ & 0.843 \\
\hline $\mathbf{S}_{25}$ vS. $\mathbf{S}_{0}$ & 0.364 & 0.510 & 0.403 \\
\hline & \multicolumn{3}{|c|}{ Conventional tillage trial (CT) } \\
\hline S100 VS. I100 $_{10}$ & 0.064 & 0.237 & 0.487 \\
\hline $\mathbf{S}_{100}$ VS. $\mathbf{S}_{0}$ & $\underline{0.021}$ & 0.216 & 0.580 \\
\hline$I_{100}$ vs. So & 0.015 & 0.029 & 0.503 \\
\hline
\end{tabular}



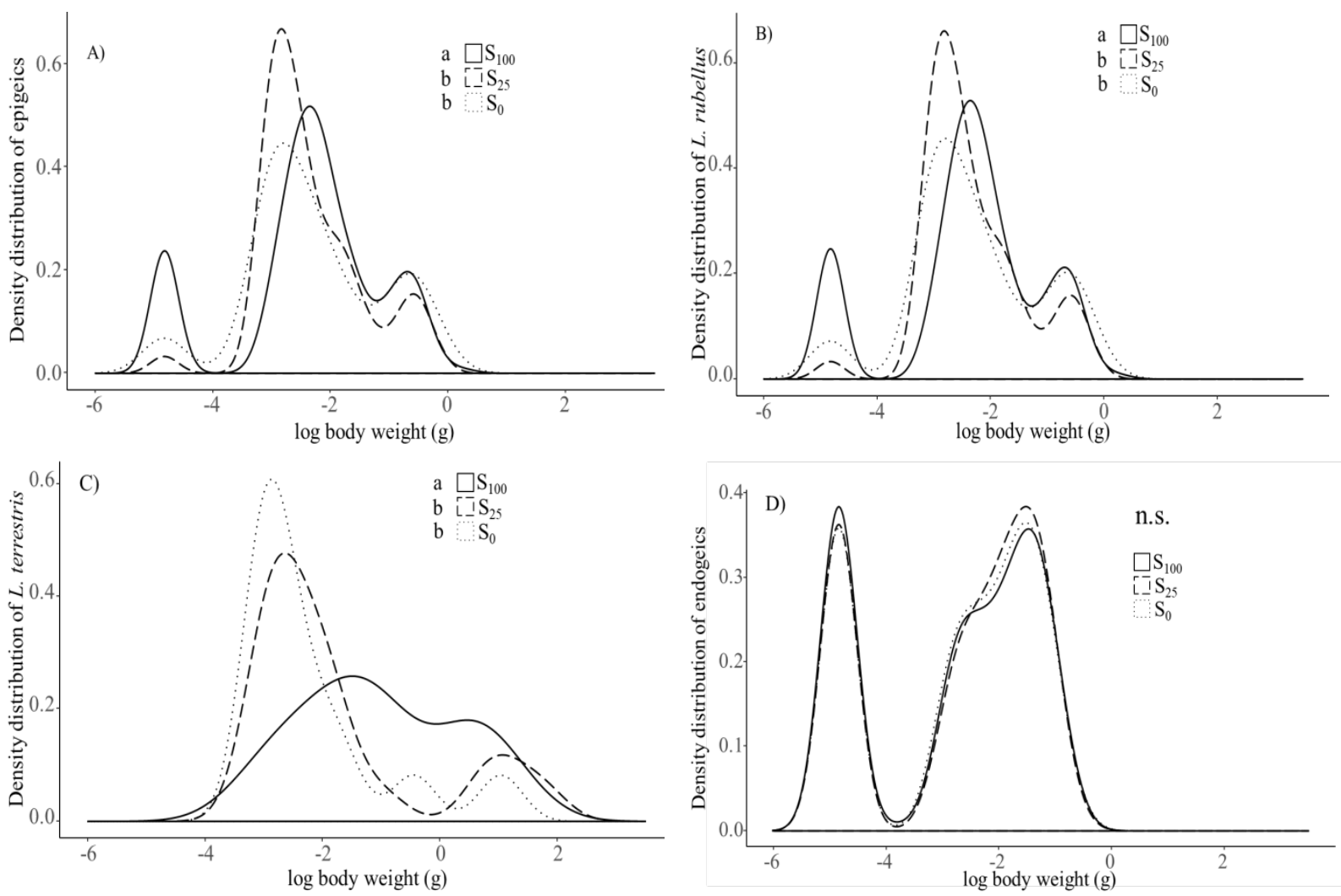

Figure 5.1 - Kernel density plots of log body weight (g) of earthworms in the non-inversion tillage (NIT) trial found in Fall 2014 and Fall 2015: A) of epigeics; B) L. rubellus; C) L. terrestris; and D) endogeics. $\mathrm{S}_{100}$ : crop residues on the soil surface $(100 \%), \mathrm{S}_{25}$ : crop residues on the soil surface $(25 \%)$ and $\mathrm{S}_{0}$ : no crop residues. Letters indicate significant differences between treatments at $\mathrm{p}<0.05$; n.s., not significant effect (bootstrapped Kolmogorov-Smirnov test). 

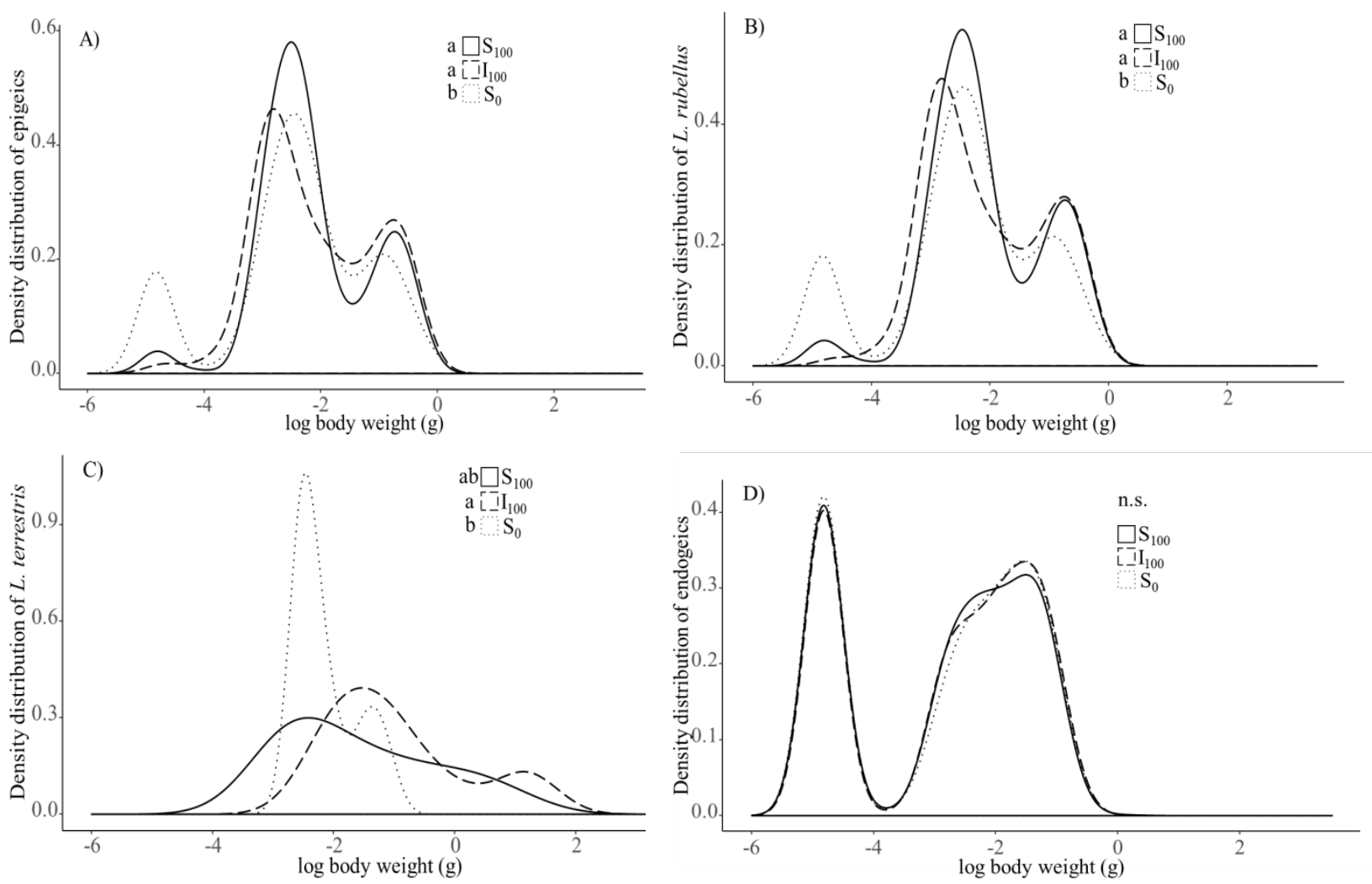

Figure 5.2 - Kernel density plots of log body weight (g) of earthworms in the conventional tillage (CT) trial found in Fall 2014 and Fall 2015: A) of epigeics; B) L. rubellus; C) L. terrestris; and D) endogeics. $\mathrm{S}_{100}$ : crop residues on the soil surface $(100 \%), \mathrm{I}_{100}$ : incorporated crop residues at ploughing depth $(100 \%)$ and $\mathrm{S}_{0}$ : no crop residues. Letters indicate significant differences between treatments at $\mathrm{p}<0.05$; n.s., not significant effect (bootstrapped Kolmogorov-Smirnov test).

\subsection{Discussion}

Under two contrasting tillage systems (NIT and CT) we found crop residue management to affect earthworm body-weight distributions of both ecological groups that feed on surface litter (epigeics and anecics) (Bouché, 1977; Curry and Schmidt, 2007). No effects were found for endogeics.

In NIT, three peaks in the body-weight distributions of epigeic earthworms were distinguished across crop residue treatments. One peak reflected the presence of relatively heavier epigeic earthworms with $100 \%$ crop residues provided on the soil surface ( $\mathrm{S}_{100}$ treatment) than when $25 \%\left(\mathrm{~S}_{25}\right)$ or no crop residues $\left(\mathrm{S}_{0}\right)$ treatments were applied $(0.11 v s .0 .05 \mathrm{~g})$. The remaining two peaks, which corresponded to the lightest and heaviest epigeics, were found at the same weight across crop residue treatments $(0.01 \mathrm{~g}$ and $0.45 \mathrm{~g}$, respectively). Strikingly, the proportion of the 
lightest peak of epigeic earthworms was higher in $\mathrm{S}_{100}$ compared to the other two crop residue treatments, suggesting that a new generation developed earlier with ample food in $\mathrm{S}_{100}$ than in $\mathrm{S}_{25}$ or $\mathrm{S}_{0}$. L. rubellus, the numerically dominant epigeic in our earthworm community, strongly determined the body-weight distribution of epigeics (Figs. 5.1A and 5.1B). It is a fast reproducer with high fecundity (in optimal conditions it produces up to 106 cocoons per year on average (Edwards and Bohlen, 1996)) and showed a body-weight distribution very different from $L$. terrestris (Figs. 5.1B and 5.1C), a long-lived species with a low reproductive output (up to 38 cocoons per year (de Lange et al., 2013)). In $\mathrm{S}_{100}$, the body-weight distribution of L. terrestris was more even and displayed heavier individuals than in $\mathrm{S}_{25}$ and $\mathrm{S}_{0}$. Furthermore, unlike the case of L. rubellus, the proportion of the lightest L. terrestris was found to be highest with limited $\left(\mathrm{S}_{25}\right)$ or no $\left(\mathrm{S}_{0}\right)$ crop residues available on the soil surface. Since we did not observe a high peak of heavier L. terrestris in those treatments, which would correspond to the adults producing the new generation, we conclude that the increased proportion of lighter individuals matches a lag in growth of L. terrestris caused by the scarcity of available crop residues on the soil surface.

In the conventional tillage trial (CT), similarly to NIT, the body-weight distribution of epigeic earthworms was dominated by the distribution of L. rubellus (Figs. 5.2A and 5.2B). However, contrary to our findings in NIT, the heaviest L. rubellus were heavier in treatments with crop residues $\left(\mathrm{S}_{100}\right.$ and $\left.\mathrm{I}_{100}\right)$ than without $\left(\mathrm{S}_{0}\right)$. Simultaneously, a higher proportion of the lightest earthworms was found for $\mathrm{S}_{0}$, which could be the result of a new generation, although no crop residues were applied, or reflect a slower growth of L. rubellus due to the lack of crop residues. The latter explanation is more likely, because the heaviest earthworms were lighter in $\mathrm{S}_{0}$ than in the treatments where crop residues were supplied. Fewer L. rubellus individuals were found in $\mathrm{I}_{100}$ than when surface-applied (Figs. A5.2 A) and B) in the Appendix 5A), which reflects the inaccessibility of crop residues to that species when crop residues are incorporated. Hence, we conclude that crop residue supply can affect both the body weight and the total amount of $L$. rubellus. In the CT trial, L. terrestris displayed a body-weight distribution that was very different from the one for L. rubellus earthworms (Figs. 5.2B and 5.2C), which is similar to the findings in NIT. Providing crop residues (incorporated or surface-applied) resulted in a more even distribution of body weight of this species, whereas absence of crop residues resulted in a narrower body-weight distribution of L. terrestris with lighter earthworms than in the other treatments. This suggests that the availability of crop residues, irrespective of placement in the 
soil profile, is very important for L. terrestris growth. Furthermore, it suggests that this species is able to acquire crop residues also when incorporated, which contradicts the categorization of $L$. terrestris as a soil surface feeding earthworm (Bouché, 1977; Curry and Schmidt, 2007).

Few studies have focussed on the effects of crop residue management on earthworm communities in the field and those that did, found contrasting results. Eriksen-Hamel et al. (2009) found no effects of different crop residue application rates on earthworm communities under different tillage systems, while Schmidt et al. (2003) suggested that cereal-legume intercrops promoted larger earthworm populations due to the higher quantity and quality of available litter, when compared to conventionally cropped wheat and direct drilled wheat. Furthermore, despite the ecological importance of body weight as a response trait that is sensitive to disturbance (e.g. Gardner et al., 2011; Lindo, 2015), little effort has been made to assess the response of earthworms by actually measuring it. Resource availability has been shown to affect e.g., nematode communities, including their body size (Andriuzzi and Wall, 2018; Sechi et al., 2017). In our earthworm study, endogeics body-weight distributions did not change at all in response to different crop residue management (Figs. 1D and 2D). In contrast, epigeics and anecics (litter feeders) were more responsive. Yet, their response varied from a tendency towards heavier individuals when crop residues were surface-applied to a relative increase of lighter individuals, which we interpret as a boost in reproductive output. These results suggest that crop residue management of arable fields could enhance earthworm-mediated soil functions. Especially litter feeding earthworms (anecics and epigeics), the feeding habit that is less abundant in cultivated fields, will benefit from increased availability of crop residues on the soil surface.

Our approach focusing on body-weight distributions of soil fauna is not common within traitbased approaches (but see Sechi et al., 2018; Sechi et al., 2017 who used similar approaches in nematode and nematode and enchytraeid communities, respectively), neither in terms of using real measurements of a single trait (in this case, body-weight), nor in terms of studying the full trait distribution instead of computing averages or community weighted means. Our method complements other approaches that focus on literature data (e.g., de Lange et al., 2013; Pelosi et al., 2013a), allowing a better understanding of population shifts that take place in a community (e.g., potential boosts in reproduction). In fact, it was only possible to include the juvenile part of 
the earthworm communities, because we measured their body weight, as extrapolating literature trait data that corresponds to adult individuals to juveniles would have resulted in a serious flaw. Furthermore, in opposition to using average literature data, our approach has the advantage of unraveling shifts that might occur in trait values arising from environmental pressures (Mathieu, 2018).

\subsection{Conclusions}

Our study illustrates that resource availability in arable fields, i.e. crop residue amounts and placement, affects earthworm feeding groups differently depending on tillage regime. Applying crop residues on the surface or incorporating residues in the soil did not result in any shift in body-weight distributions of endogeics, at least during the time frame of our experiments. Epigeics responded positively to an increase of crop residues available on the soil surface. Their response was, however, different in the conventional (CT) and the non-inversion tillage (NIT) trials: L. rubellus (and litter feeders, in general) showed an increase in the proportion of lighter individuals when higher amounts of crop residues were provided on the soil surface in NIT, suggesting a boost in reproductive output. In CT, the same species (and litter feeders in general) showed a shift towards heavier individuals, at least within the heaviest earthworms. The latter pattern was also observed for $L$. terrestris in both tillage trials. These results suggest that earthworm-mediated soil functions, especially those mediated by litter feeders (epigeics and anecics), can be improved through crop residue management that promotes the feeding of earthworms, which may result in heavier individuals and/or higher abundance.

Our study confirms and strengthens the validity of a trait-based approach in identifying community responses to environmental changes. It also allows detecting changes in population processes that could not be identified by studying species abundance or averaged species-specific trait values. 


\section{Acknowledgements}

We are thankful to Wageningen University \& Research - Field Crops Westmaas, in particular Marcel Tramper and Marian Vlaswinkel, who allowed us to perform our research and helped with many of the field operations. We further thank in particular Dr. Esperanza Huerta for helping with the coordination of $L$. terrestris handling and Tamás Salánki for identifying the earthworms. The help of students and technicians in the field and in the lab is also gratefully acknowledged. This work is part of the research programme Biodiversiteit Werkt! with project number 841.11.003, financed by the Netherlands Organisation for Scientific Research (NWO). 


\section{Appendix 5A}

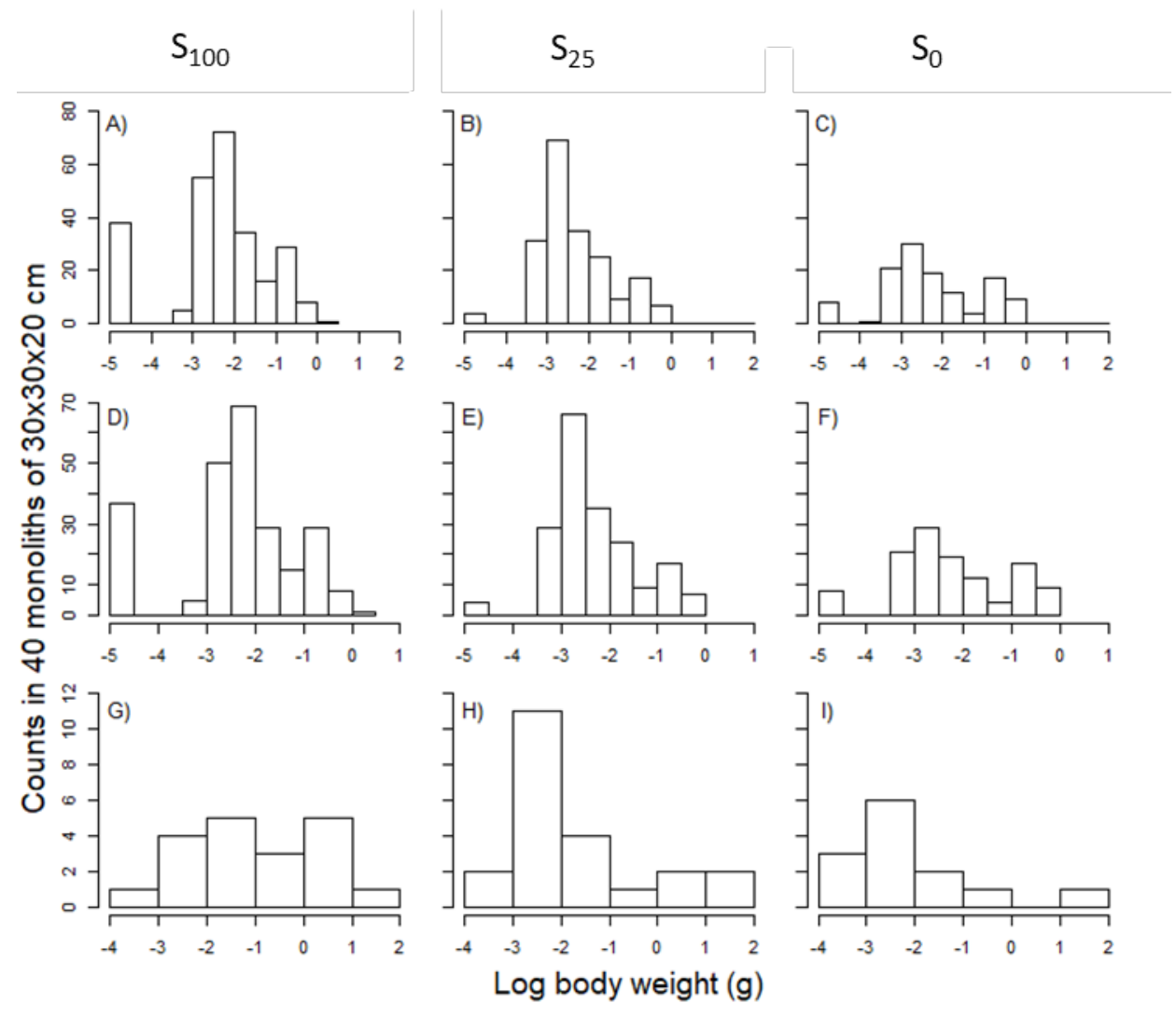

Figure A5.1- Frequencies of collected litter feeders (epigeics, L. rubellus and the anecic L. terrestris) during Fall 2014 and Fall 2015, in the non-inversion tillage trial (NIT), per body weight class (logscaled). A), B) and C) consist of all epigeics collected, D), E) and F) of L. rubellus, and G), H) and I) of L. terrestris. 

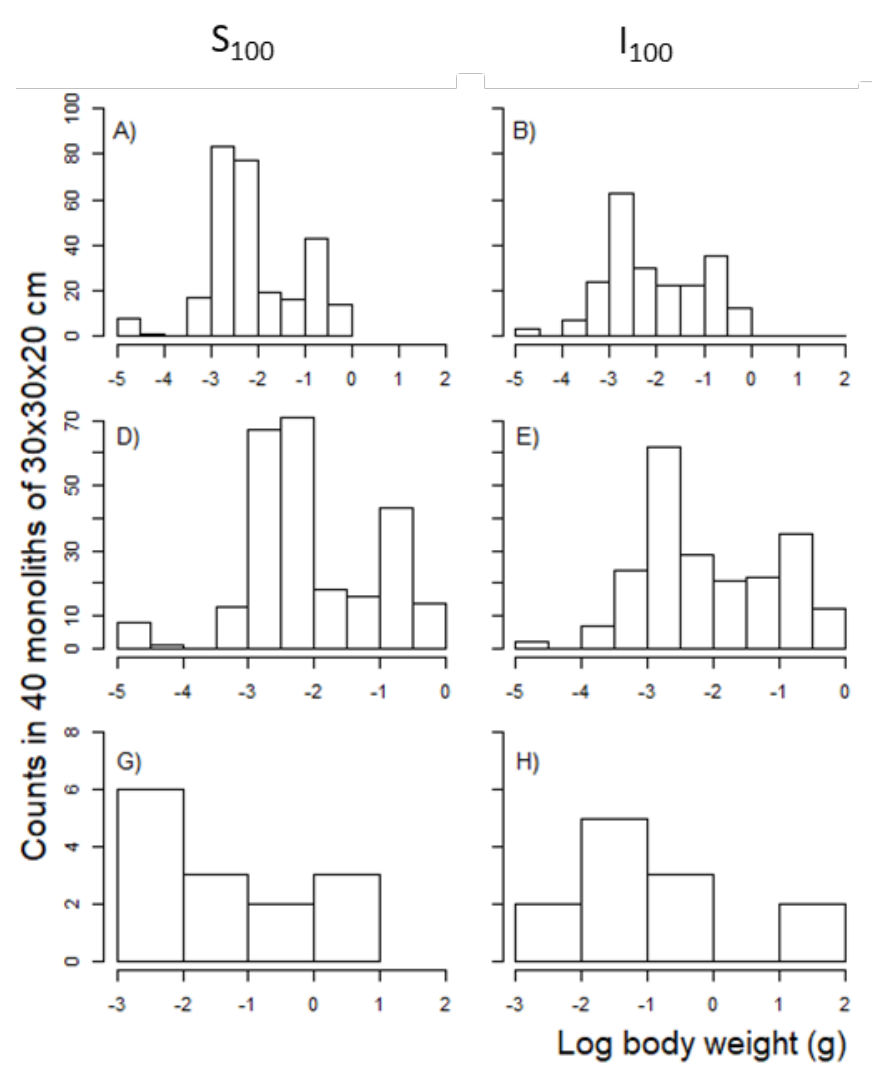

$\mathrm{S}_{0}$
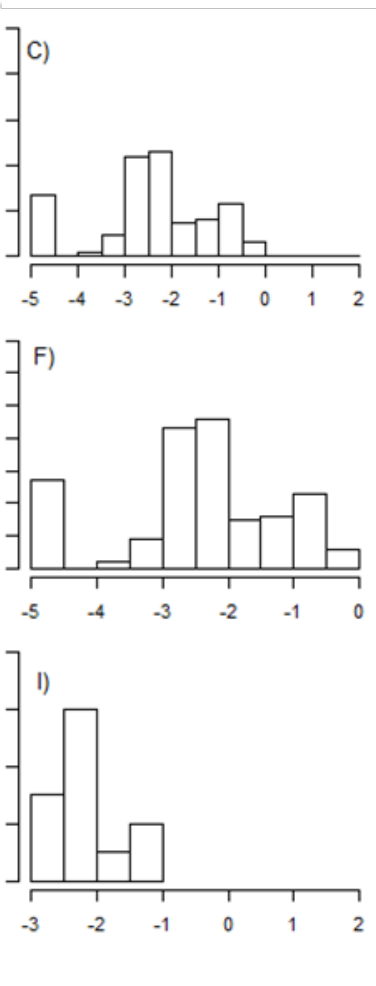

Figure A5.2 - Frequencies of collected litter feeders (epigeics, L. rubellus and the anecic L. terrestris) during Fall 2014 and Fall 2015, in the conventional tillage trial (CT), per body weight class (log-scaled). A), B) and C) consist of all epigeics collected, D), E) and F) of L. rubellus, and G), H) and I) of $L$. terrestris. 

Chapter 6

General Discussion 



\section{General Discussion}

\subsection{Landscape effects on earthworm communities}

Large areas of land have been converted from natural areas and are currently in use for arable cropping (Fahrig et al., 2011; Smith et al., 2016; Tscharntke et al., 2005). Those consist of intensively managed areas in order to enhance crop production, and less intensively managed habitats. Typical examples of the former are arable fields, and of the latter are field margin strips. Whereas arable fields are subjected to many types of disturbance due to intensive management (synthetic fertilization and crop protection, as well as intensive tillage), field margin strips, particularly those sown with grasses or herbs, are less frequently and less intensively disturbed. The work presented in chapter 2 of this thesis aimed at understanding the roles of three environmental filters, the surrounding landscape, soil properties and management, on earthworm communities of arable fields and of field margin strips. While the increase in proportion of arable land was demonstrated to affect negatively earthworm communities of field margin strips, no effects were found on the communities of arable fields. In fact, management was the only environmental filter that explained significantly the variation of earthworm communities of arable fields, suggesting that the effects of the surrounding landscape could be overshadowed by intensive management activities. The role of landscape on earthworm communities in chapter 2 was focused on landscape composition, which addresses the diversity and proportion of land-use types. However, according to Fahrig et al. (2011), the framework of landscape ecology should also consider the configuration of landscapes, which deals with the spatial arrangement of landuse types. In the case of earthworms, there is an urge to first understand how they use and perceive the landscape, including their dispersal abilities. It is well recognized that earthworms have limited active dispersal abilities and that those are species-specific and depend on the landuse. Eijsackers (2011) reviewed the dispersal rates of several species inoculated in earthwormfree polders in the Netherlands. For example, L. rubellus dispersed 7 to $8 \mathrm{~m}$ per year in grazed grasslands, whereas in arable fields its dispersal rate was higher, about $14 \mathrm{~m}$ per year. Additionally, Caro et al. (2013) and Mathieu et al. (2010) studied under laboratory conditions, a

few earthworm dispersal triggers (habitat quality, conspecific density and habitat pre-use by other earthworms). Both studies concluded that the lack of habitat quality (i.e., soils with low 
$\mathrm{pH}$, low organic matter and nitrogen contents and high $\mathrm{C} / \mathrm{N}$ ratio) and the increase of earthworm population densities triggered the dispersal of subadult and adult individuals of all ecological groups. It remains, however, difficult to translate those results to real landscapes, since the laboratory set-up consisted of only $1 \mathrm{~m}$ long mesocosms and the experiment lasted only a week. Furthermore, earthworms are also known to disperse passively, e.g., by tractor tires (Marinissen and van den Bosch, 1992), waterways or birds (Schwert, 1980; Schwert and Dance, 1979). Earthworm dispersal in real landscapes is therefore a hard subject to tackle, and therefore, a mechanistic understanding of earthworm use and perception of landscape composition and configuration is not trivial. In order to move forward it would be interesting to understand the relationships between dispersal and earthworm population and community dynamics, therefore also improving knowledge on juvenile dispersal rates. Recently developed techniques, such as the visible implant elastomer (VIE) (Butt and Lowe, 2007) could be used to tag earthworms and follow their movement through the landscape. The VIE consists of a polymer commercially available (Northwest Marine Technology NMT, Inc., Washington, DC) in several colours, that is injected into the muscle of the organism as a liquid substance and solidifies within 24 hours. In earthworms, Butt and Lowe (2007) have shown that tagged L. terrestris have kept the VIE for at least 12 months, without any negative effects on individual development to maturity, mating or cocoon production. Studies involving tagged earthworms could be further complemented with genetic tools, such as environmental DNA, which has efficiently detected earthworm distribution patterns related to land-use types (Pansu et al., 2015).

\subsection{Crop residue management in arable fields}

Since the results of chapter 2 indicated that management was the most important filter shaping earthworm community diversity and composition of arable fields, and that it overruled potential positive effects of the surrounding landscape, adjacent field margins and soil properties, the focus of my thesis was further developed to better understand the effects of arable field management on earthworm communities. Although applications of insecticides, herbicides and fungicides were the variables that explained most variation of earthworm composition in arable fields and deserve further research, the remaining chapters of my thesis were focused on crop residue management. This decision was taken since farmers and managers in the Hoeksche 
Waard have a strong interest in, and are open to adjust crop residue management if science provides conclusive results.

The work described in this thesis focussed on the response of earthworms to crop residue placement under controlled conditions in the laboratory (chapter 3), as well as the response of earthworm communities to both crop residue placement and amounts (chapters 4 and 5) in arable fields with contrasting tillage intensities (NIT: non-inversion tillage and CT: conventional tillage). Although the choice of crop residues for the experimental work was pragmatic and based on literature with earthworm survival rates above 85\% (Al-Maliki and Scullion, 2013; Giannopoulos et al., 2010), earthworms may also show preferences for litter of different qualities. Valckx et al. (2011) indicated that L. terrestris preferred residues of ryegrass over mustard, phacelia and rapeseed, which in turn were preferred over oats, but could not find a relationship between those preferences and residue quality. Yet, Hendriksen (1990) showed that Lumbricus spp. preferred litter with a low $\mathrm{C} / \mathrm{N}$ ratio, whereas no correlations were found between litter quality and endogeic earthworms. Furthermore, Schmidt et al. (2003) found earthworm communities to be positively affected by direct-drilled wheat-clover intercrops compared to conventionally cropped wheat and direct drilled wheat. The authors suggested that cereal-legume intercrops promoted larger earthworm populations due to the higher quantity and quality of available litter. So, it seems that earthworms prefer low $\mathrm{C} / \mathrm{N}$ ratio litter types, although less palatable litter types are also ingested. What is also of relevance in relation to the quality of litter is that earthworms seem to increase their activity with higher litter quality and therefore, positively affect aspects of soil functioning. For example, Al-Maliki and Scullion (2013), Coq et al., (2007) and Loranger-Merciris et al. (2008) showed an increase in earthworm-mediated stable aggregate formation when they were fed with higher quality crop residues (grass-clover hay $v s$. wheat straw). On the other hand, Pérès et al. (2010) suggested that the high earthworm-mediated soil porosity in low organic matter cropped systems with maize was due to increased earthworm activity in search for food. The results of my laboratory experiment (chapter 3), are in line with both studies since incorporating crop residues increased soil porosity with depth, suggesting that earthworms were more active digging through the soil in order to find food sources. However, trade-offs with other soil structural properties may arise, since in my study, while the porosity 
increased in incorporated crop residue treatments, earthworm-mediated water-stable aggregate formation decreased.

The findings from my laboratory trial triggered me to test how crop residue management affected earthworm communities in arable fields, but unfortunately no soil structure related functions were assessed in my field experiments. It would have been interesting, however, to study the effects of crop residue management on earthworm-mediated soil functioning (and related tradeoffs) under realistic field conditions. While integrating the results found for earthworm performance and survival during the indoor experiment (chapter 3) with the ones found for earthworm communities of arable fields under contrasting tillage intensities (NIT: non-inversion tillage and CT: conventional tillage) (chapter 4), it became clear that crop residue management acted as an environmental filter for earthworms. However, some of the results were also unexpected, such as the fact that reducing the amount of crop residues with lower tillage intensity (NIT trial) was less beneficial for subadult and adult epigeics than incorporating a larger amount of crop residues under higher tillage intensity (CT trial). In fact, in the CT trial, incorporating crop residues or providing them at the soil surface affected the (sub)adult earthworms positively, compared to not providing crop residues at all, across the different methods used to study the community response. Since L. rubellus represented the dominant epigeic species in the arable fields studied in chapter 4, the insights provided by my laboratory experiment (chapter 3) that showed a decrease of L. rubellus performance with incorporated residues, are in contrast with those of the CT field experiment. However, L. rubellus individuals used in the indoor experiment were collected in soils that were not disturbed by tillage (city parks in Wageningen, The Netherlands), and Briones and Schmidt (2017) emphasized that landuse history may affect the response of earthworms to environmental filters, in their case tillage. As such, the capacity of earthworms, and in particular L. rubellus, to adapt to soils where crop residues have been incorporated through ploughing is likely to increase over time, and the arable fields where my experiments were conducted are under arable cropping for over 20 years. Genetic tools could aid in the interpretation of this type of contrasting results, since it is known, for example, that two distinct lineages of L. rubellus show different tolerances to arsenic pollution (Kille et al., 2013). Similarly, earthworm species that inhabit soils with contrasting disturbance regimes could belong to different lineages and be tolerant to disturbances inherent to the land-uses where they naturally occur. 
This issue became relatively more complicated while integrating the results of chapter 5 with the ones of the previous two chapters, since the lack of crop residue provision in the CT trial appeared to hamper the growth of L. rubellus. Crop residue management seemed therefore to act as an environmental filter, which could affect earthworm communities in terms of their trait values and ecological group densities, but also in terms of population dynamics, which would most likely also affect community trait values. In chapter 5 a focus on the total earthworm community (including juveniles) was enabled by the fact that the body weight of individual earthworms had been measured. In contrast, the analysis performed in chapter 4 was done using trait values obtained mostly in literature databases (Briones and Álvarez-Otero, 2018; Hedde et al., 2012a). Since those databases refer to trait values of adult individuals, it would have been insensible to include the juveniles in the data analysis, because trait values may be distinct across different developmental stages (Lowe and Butt, 2002; Schmidt, 1999). My results of chapters 4 and 5 have thus drawn the attention to an important reflection in relation to the use of trait-based approaches in studying community responses to disturbance. As already suggested by Lavorel and Garnier (2002) trait values may change with environmental conditions, and therefore extra caution should be taken while interpreting the results that are based on trait data acquired from literature databases.

Finally, a last remark regarding my work about crop residue management as an environmental filter to earthworm communities refers to the relatively short duration of the studies, both in the laboratory and in the field. Earthworm communities of arable fields are highly dynamic and are regulated by several abiotic factors, but also management practices (Curry, 2004), and therefore their responses to disturbance may be very sudden, but may also take several years to be noticeable (Briones and Schmidt, 2017). It would be very helpful to increase the duration of the studies in order to obtain a better understanding of their responses to disturbance. This is also claimed by other authors in relation to other disturbance types, e.g., tillage (e.g., Briones and Schmidt, 2017) or pesticides (e.g., Pelosi et al., 2014), as well as authors that investigate effects of earthworms on soil functioning (Lubbers et al., 2013). Only then will one be able to draw realistic conclusions about the effects of arable management on earthworms, as well as the consequent earthworm-mediated roles for soil functioning. 


\subsection{Community research approaches}

Community responses can be studied using a multitude of metrics. While traditionally such metrics were based on the identity of species or taxonomic groups (e.g., richness and composition), recently, alternative methods have emerged (e.g., trait-based approaches, ecological groups). Trait-based approaches aim to unravel a mechanistic understanding of community responses to disturbance (Mouchet et al., 2010; Naeem and Wright, 2003), but also to disentangle how those responses are linked to ecosystem functioning (Gagic et al., 2015; Petchey and Gaston, 2002). For these reasons, the use of functional traits has even been mentioned as the "Holy Grail" in ecology (Lavorel and Garnier, 2002). In my thesis I used several approaches (taxonomic, ecological groups and trait-based) to understand earthworm community assembly of arable fields. Trait-based approaches can complement and improve knowledge acquired by taxonomic approaches, but are currently dependent on the latter, since in general one first needs to identify a species in order to obtain its literature-available trait values. The work presented in this thesis, particularly in chapters 4 and 5, aimed at improving the mechanistic understanding of the effects of environmental filters, in this case crop residue management, on earthworm communities. Several authors criticize the use of a priori defined functional groups (Naeem and Wright, 2003; Petchey and Gaston, 2002, 2006), which in the case of earthworms correspond to their ecological groups, as defined by Bouché (1977). In chapter 4 of my thesis, however, the earthworm ecological groups approach described similar effects of crop residue management on the response of earthworm communities when compared to the trait-based approach. Evidently, the use of community weighted means (CWM) and trait diversity (RaoQ) did provide the mechanistic links of earthworm responses to crop residue management. For example, it was clear that (sub)adult earthworms were on average heavier and trait diversity was higher when crop residues were provided in the CT trial. However, and despite the ongoing debate regarding the ecological categorization of some species, the fact that epigeic density was higher under those circumstances, also added valuable information for the interpretation of the effects of crop residue management on earthworm communities. It is worthwhile mentioning that the ecological groups classification also has its limitations. For example, Pelosi et al. (2013a) argued that the utility of their trait-based approach (also based on CWM and RaoQ) in assessing the responses of earthworm communities to agricultural tillage 
practices was strengthened, since it unravelled effects that were not revealed by the analysis of the response of ecological groups.

Little effort is made in measuring community trait values, and instead scientists often resort to literature databases. Yet, the response of communities may be only detectable through those measurements, since trait values may change with environmental conditions (Lavorel and Garnier, 2002). Furthermore, earthworms present high plasticity in behaviour (see e.g., $L$. rubellus response to crop residue provision in chapters 3 and 4), but also different auto-ecology characteristics according to developmental stage (Lowe and Butt, 2002; Schmidt, 1999). While I recognize the logistical difficulties of such, I argue that only the measurement of traits in individuals collected from the location of interest can solve this dilemma. Having measured earthworm body weight allowed studying the full (i.e., including juveniles) community response to crop residue provision in chapter 5, while lacking measurements related to the reproductive output in chapters 3 and 5, lead to only speculative interpretations of some of the results.

Lastly, my thesis presents evidence that taxonomic (chapters 2 and 4), ecological group and functional trait approaches (chapters 4 and 5) can be used to investigate the response of earthworm communities to disturbance. In fact, I argue that the taxonomic, ecological group and functional trait approaches are complementary methods in understanding community assembly. The incorporation of the ecological group allowed the interpretation of the results in chapter 2 , which was based on taxonomic analytical methods. Additionally, the incorporation of functional and ecological group approaches in chapters 4 and 5 provided further insights into the response of earthworms to crop residue management, which remained occluded using the taxonomic approach in chapter 4.

\subsection{General conclusions and recommendations}

The work presented in this thesis did not only provide answers to some questions, but also raised questions that deserve scientific attention in future work. The landscape approach used in chapter 2 revealed that while landscape composition (in terms of proportion of area of arable fields) affected earthworm communities of field margins, this was not the case for neighbouring arable fields. Despite my further focus on earthworm communities of arable fields, I recognize the usefulness of exploring the mechanisms that link the surrounding landscape of field margins and 
their earthworm communities. Although there are indications for earthworm passive and active dispersal, it remains unclear how earthworms disperse through it, either passively or actively, and establish in new sites. This is relevant now for earthworm communities of less intensively managed soils, but also for the future, as arable management practices evolve through time under societal pressure and stricter environmental and food safety regulations. Then, the surrounding landscape will most likely also play a role in shaping earthworm communities of arable fields and the mechanistic knowledge gained between landscape and field margins can eventually be used to promote landscape designs that stimulate optimal earthworm communities.

Crop residue management of arable fields under contrasting tillage practices (NIT: non-inversion tillage, and CT: conventional tillage) was identified in chapters 3 to 5 as an important environmental filter of earthworm communities. Several community research approaches were employed to study the effects of crop residue placement and amount on the assembly of earthworms, both in the field and in the laboratory. While the results of the laboratory experiment regarding L. rubellus contradicted those of the arable fields in terms of adult performance, specimens used for the indoor experiment originated from soils from urban parks that were not disturbed, in contrast to the specimens present in the arable fields. Genetic markers could aid in unravelling distinct lineages within this species, and could bring insights into evolutionary processes that could have taken place in enhancing this species adaptation to soil disturbance.

As I demonstrated that the availability of resources affects earthworm performance (measured by body weight) it could very well be that other earthworm life-history components were also affected by crop residues. Although I acknowledge the difficulties inherent to trait measurements other than body weight, I emphasize the need to do so, especially in animals that are subjected to the environmental conditions under study. Scientific literature and databases are valuable sources for a first approach in studying earthworm community responses to any environmental filter. However, the information acquired from those sources is usually obtained from indoor experiments performed under optimal conditions. Therefore, plastic trait values, e.g., cocoon production, are maximized, and most likely unrealistic. Moreover, the response of communities may go through changes in the values of those plastic traits. Furthermore, it is imperative within earthworm ecology that juveniles are given due attention, since they comprise approximately $70 \%$ to $90 \%$ of earthworm communities (e.g., Blackshaw et al., 2007; Crittenden et al., 2014; 
Whalen et al., 1998), at least in soils under intensive crop production. Little is known about the roles of juveniles in soil functioning and little is known on their responses to environmental filters, since information regarding their trait values is lacking.

Lastly, I would like to end my thesis with some management recommendations that aim at promoting earthworms in arable fields. My work and other soil ecologists' work has shown that decreasing tillage intensity, together with adjusting crop residue management to "feed" earthworms promote more diverse earthworm communities. Furthermore, inoculating anecics, that do not seem to colonize arable fields under the current management practices, also proved to be feasible, as long as the intensity of tillage is decreased. It is, however, very laborious and expensive.

It is only a matter of time until intensive tillage, pesticides and fertilizers become more strictly regulated in the European Union, but also elsewhere in the world. This will create opportunities to improve sustainable arable management practices. Then, it will be sensible to improve the design of arable landscapes to promote earthworm communities of arable fields. Soil biodiversity in general, as well as earthworms in particular, will then play even more important roles in soil functioning of arable fields than they currently do. 



\section{References}





\section{References}

Al-Maliki, S., Scullion, J., 2013. Interactions between earthworms and residues of differing quality affecting aggregate stability and microbial dynamics. Applied Soil Ecology 64, 5662.

Anderson, M.J., 2001. A new method for non-parametric multivariate analysis of variance. Austral Ecology 26, 32-46.

Anderson, M.J., 2006. Distance-based tests for homogeneity of multivariate dispersions. Biometrics 62, 245-253.

Andriuzzi, W.S., Pulleman, M.M., Cluzeau, D., Pérès, G., 2017. Comparison of two widely used sampling methods in assessing earthworm community responses to agricultural intensification. Applied Soil Ecology 119, 145-151.

Andriuzzi, W.S., Pulleman, M.M., Schmidt, O., Faber, J.H., Brussaard, L., 2015. Anecic earthworms (Lumbricus terrestris) alleviate negative effects of extreme rainfall events on soil and plants in field mesocosms. Plant Soil 397, 103-113.

Andriuzzi, W.S., Wall, D.H., 2018. Grazing and resource availability control soil nematode body size and abundance-mass relationship in semi-arid grassland. Journal of Animal Ecology 87, 1407-1417.

Baveco, J.M., de Roos, A.M., 1996. Assessing the impact of pesticides on lumbricid populations: an individual-based modelling approach. Journal of Applied Ecology 33, 1451-1468.

Belyea, L.R., Lancaster, J., 1999. Assembly rules within a contingent ecology. Oikos 86, 402416.

Bertrand, M., Barot, S., Blouin, M., Whalen, J., de Oliveira, T., Roger-Estrade, J., 2015. Earthworm services for cropping systems. A review. Agronomy for Sustainable Development 35, 553-567.

Bianchi, F.J.J.A., Mikos, V., Brussaard, L., Delbaere, B., Pulleman, M.M., 2013. Opportunities and limitations for functional agrobiodiversity in the European context. Environmental Science and Policy 27, 223-231.

Blackshaw, R.P., Donovan, S.E., Hazarika, S., Bol, R., Dixon, E.R., 2007. Earthworm responses to long term agricultural management practices: Spatial relationships with soil properties. European Journal of Soil Biology 43, Supplement 1, S171-S175. 
Blanchet, F.G., Legendre, P., Borcard, D., 2008. Forward selection of explanatory variables. Ecology 89, 2623-2632.

Borcard, D., Gillet, F., Legendre, P., 2011. Numerical ecology with R. Springer Science \& Business Media, New York.

Bossuyt, H., Six, J., Hendrix, P.F., 2004. Rapid incorporation of carbon from fresh residues into newly formed stable microaggregates within earthworm casts. European Journal of Soil Science 55, 393-399.

Bossuyt, H., Six, J., Hendrix, P.F., 2006. Interactive effects of functionally different earthworm species on aggregation and incorporation and decomposition of newly added residue carbon. Geoderma 130, 14-25.

Botta-Dukát, Z., 2005. Rao's quadratic entropy as a measure of functional diversity based on multiple traits. Journal of Vegetation Science 16, 533-540.

Bouché, M.B., 1977. Strategies lombriciennes. Ecological Bulletins 25, 122-132.

Briones, M.J.I., Álvarez-Otero, R., 2018. Body wall thickness as a potential functional trait for assigning earthworm species to ecological categories. Pedobiologia 67, 26-34.

Briones, M.J.I., Schmidt, O., 2017. Conventional tillage decreases the abundance and biomass of earthworms and alters their community structure in a global meta-analysis. Global Change Biology 23, 4396-4419.

Butt, K.R., Lowe, C.N., 2007. A viable technique for tagging earthworms using visible implant elastomer. Applied Soil Ecology 35, 454-457.

Butt, K.R., Nuutinen, V., Sirén, T., 2003. Resource distribution and surface activity of adult Lumbricus terrestris L. in an experimental system. Pedobiologia 47, 548-553.

Buurman, P., Paper, T., Reijneveld, J.A., de Jong, F., van Gelder, E., 2001. Laser-diffraction and pipette-method grain size of Dutch sediments: correlations for fine fractions of marine, fluvial, and loess samples. Geologie en Mijnbouw 80, 49-57.

Cameron, E.K., Bayne, E.M., 2014. Spatial patterns and spread of exotic earthworms at local scales. Canadian Journal of Zoology 93, 721-726.

Capowiez, Y., Bottinelli, N., Sammartino, S., Michel, E., Jouquet, P., 2015. Morphological and functional characterisation of the burrow systems of six earthworm species (Lumbricidae). Biology and Fertility of Soils 51, 869-877. 
Capowiez, Y., Monestiez, P., Belzunces, L., 2001. Burrow systems made by Aporrectodea nocturna and Allolobophora chlorotica in artificial cores: morphological differences and effects of interspecific interactions. Applied Soil Ecology 16, 109-120.

Caro, G., Abourachid, A., Decaëns, T., Buono, L., Mathieu, J., 2012. Is earthworms' dispersal facilitated by the ecosystem engineering activities of conspecifics? Biology and Fertility of Soils 48, 961-965.

Caro, G., Decaëns, T., Lecarpentier, C., Mathieu, J., 2013. Are dispersal behaviours of earthworms related to their functional group? Soil Biology and Biochemistry 58, 181-187.

Chan, K.Y., 2001. An overview of some tillage impacts on earthworm population abundance and diversity - implications for functioning in soils. Soil and Tillage Research 57, 179-191.

Coq, S., Barthès, B.G., Oliver, R., Rabary, B., Blanchart, E., 2007. Earthworm activity affects soil aggregation and organic matter dynamics according to the quality and localization of crop residues-An experimental study (Madagascar). Soil Biology and Biochemistry 39, 2119-2128.

Crittenden, S.J., Eswaramurthy, T., de Goede, R.G.M., Brussaard, L., Pulleman, M.M., 2014. Effect of tillage on earthworms over short- and medium-term in conventional and organic farming. Applied Soil Ecology 83, 140-148.

Crittenden, S.J., Huerta, E., de Goede, R.G.M., Pulleman, M.M., 2015. Earthworm assemblages as affected by field margin strips and tillage intensity: An on-farm approach. European Journal of Soil Biology 66, 49-56.

Cuendet, G., 1983. Predation on earthworms by the black-headed gull (Larus ridibundus L.), in: Satchell, J.E. (Ed.), Earthworm Ecology: From Darwin to Vermiculture. Springer Netherlands, Dordrecht, pp. 415-424.

Curry, J.P., 2004. Factors affecting the abundance of earthworms in soils, in: Edwards, C. (Ed.), Earthworm ecology, second ed. CRC Press, Boca Raton, pp. 91-113.

Curry, J.P., Byrne, D., Schmidt, O., 2002. Intensive cultivation can drastically reduce earthworm populations in arable land. European Journal of Soil Biology 38, 127-130.

Curry, J.P., Schmidt, O., 2007. The feeding ecology of earthworms - A review. Pedobiologia 50, 463-477. 
Daniel, O., Kohli, L., Bieri, M., 1996. Weight gain and weight loss of the earthworm Lumbricus terrestris L. at different temperatures and body weights. Soil Biology and Biochemistry 28, 1235-1240.

de Bakker, H., Schelling, J., 1966. Systeem van bodemclassificatie voor Nederland: de hogere niveaus. Centrum voor Landbouwpublikaties en Landbouwdocumentatie, Wageningen.

de Haan, J.J., van Geel, W., 2013. Adviesbasis voor de bemesting van akkerbouwgewassen Kengetallen organische stof.

http://www.kennisakker.nl/kenniscentrum/handleidingen/adviesbasis-voor-de-bemestingvan-akkerbouwgewassen-kengetallen (accessed May 2016).

de Lange, H.J., Kramer, K., Faber, J.H., 2013. Two approaches using traits to assess ecological resilience: A case study on earthworm communities. Basic and Applied Ecology 14, 64-73. de Oliveira, T., Bertrand, M., Roger-Estrade, J., 2012. Short-term effects of ploughing on the abundance and dynamics of two endogeic earthworm species in organic cropping systems in northern France. Soil and Tillage Research 119, 76-84.

Decaëns, T., Margerie, P., Aubert, M., Hedde, M., Bureau, F., 2008. Assembly rules within earthworm communities in North-Western France-A regional analysis. Applied Soil Ecology 39, 321-335.

Díaz, S., Cabido, M., 2001. Vive la différence: plant functional diversity matters to ecosystem processes. Trends in Ecology and Evolution 16, 646-655.

Edwards, C.A., 2004. The importance of earthworms as key representatives of the soil fauna, in: Edwards, C. (Ed.), Earthworm ecology. CRC Press, Boca Raton, pp. 3-11.

Edwards, C.A., Bohlen, P.J., 1996. Biology and ecology of earthworms. Chapman and Hall, London.

Eijsackers, H., 2011. Earthworms as colonizers of natural and cultivated soil environments. Applied Soil Ecology 50, 1-13.

Elliott, E.T., 1986. Aggregate structure and Carbon, Nitrogen, and Phosphorus in native and cultivated soils. Soil Science Society of America Journal 50, 627-633.

Eriksen-Hamel, N.S., Speratti, A.B., Whalen, J.K., Légère, A., Madramootoo, C.A., 2009. Earthworm populations and growth rates related to long-term crop residue and tillage management. Soil and Tillage Research 104, 311-316. 
Ernst, G., Emmerling, C., 2009. Impact of five different tillage systems on soil organic carbon content and the density, biomass, and community composition of earthworms after a ten year period. European Journal of Soil Biology 45, 247-251.

Ernst, G., Felten, D., Vohland, M., Emmerling, C., 2009. Impact of ecologically different earthworm species on soil water characteristics. European Journal of Soil Biology 45, 207213.

Ettema, C.H., Wardle, D.A., 2002. Spatial soil ecology. Trends in Ecology and Evolution 17, 177-183.

EU-Commission, 2005. Agri-environment Measures - Overview on General Principles. Types of Measures, and Application. EAFRD.

Fahrig, L., Baudry, J., Brotons, L., Burel, F.G., Crist, T.O., Fuller, R.J., Sirami, C., Siriwardena, G.M., Martin, J.-L., 2011. Functional landscape heterogeneity and animal biodiversity in agricultural landscapes. Ecology Letters 14, 101-112.

Feld, C.K., Martins da Silva, P., Paulo Sousa, J., De Bello, F., Bugter, R., Grandin, U., Hering, D., Lavorel, S., Mountford, O., Pardo, I., Pärtel, M., Römbke, J., Sandin, L., Bruce Jones, K., Harrison, P., 2009. Indicators of biodiversity and ecosystem services: a synthesis across ecosystems and spatial scales. Oikos 118, 1862-1871.

Fischer, C., Thies, C., Tscharntke, T., 2011. Small mammals in agricultural landscapes: opposing responses to farming practices and landscape complexity. Biol. Conserv. 144, 1130-1136.

Flohre, A., Rudnick, M., Traser, G., Tscharntke, T., Eggers, T., 2011. Does soil biota benefit from organic farming in complex vs. simple landscapes? Agriculture, Ecosystems and Environment 141, 210-214.

Fonte, S.J., Kong, A.Y.Y., van Kessel, C., Hendrix, P.F., Six, J., 2007. Influence of earthworm activity on aggregate-associated carbon and nitrogen dynamics differs with agroecosystem management. Soil Biology and Biochemistry 39, 1014-1022.

Fournier, B., Samaritani, E., Shrestha, J., Mitchell, E.A.D., Le Bayon, R.-C., 2012. Patterns of earthworm communities and species traits in relation to the perturbation gradient of a restored floodplain. Applied Soil Ecology 59, 87-95.

Francis, G.S., Fraser, P.M., 1998. The effects of three earthworm species on soil macroporosity and hydraulic conductivity. Applied Soil Ecology 10, 11-19. 
Frazão, J., de Goede, R.G.M., Brussaard, L., Faber, J.H., Groot, J.C.J., Pulleman, M.M., 2017. Earthworm communities in arable fields and restored field margins, as related to management practices and surrounding landscape diversity. Agriculture, Ecosystems and Environment 248, 1-8.

Frazão, J., de Goede, R.G.M., Capowiez, Y., Pulleman, M.M., 2019. Soil structure formation and organic matter distribution as affected by earthworm species interactions and crop residue placement. Geoderma 338, 453-463.

Gagic, V., Bartomeus, I., Jonsson, T., Taylor, A., Winqvist, C., Fischer, C., Slade, E.M., SteffanDewenter, I., Emmerson, M., Potts, S.G., Tscharntke, T., Weisser, W., Bommarco, R., 2015. Functional identity and diversity of animals predict ecosystem functioning better than species-based indices. Proceedings of the Royal Society of London. Series B: Biological Sciences 282, 20142620.

Gardner, J.L., Peters, A., Kearney, M.R., Joseph, L., Heinsohn, R., 2011. Declining body size: a third universal response to warming? Trends in Ecology and Evolution 26, 285-291.

Garnier, E., Cortez, J., Billès, G., Navas, M.-L., Roumet, C., Debussche, M., Laurent, G., Blanchard, A., Aubry, D., Bellmann, A., Neill, C., Toussaint, J.-P., 2004. Plant functional markers capture ecosystem properties during secondary succession. Ecology 85, 2630-2637.

Giannopoulos, G., Pulleman, M.M., Van Groenigen, J.W., 2010. Interactions between residue placement and earthworm ecological strategy affect aggregate turnover and N2O dynamics in agricultural soil. Soil Biology and Biochemistry 42, 618-625.

Gotelli, N.J., Colwell, R.K., 2001. Quantifying biodiversity: procedures and pitfalls in the measurement and comparison of species richness. Ecology Letters 4, 379-391.

Grubert, D., Butenschoen, O., Maraun, M., Scheu, S., 2016. Understanding earthworm Collembola interactions and their importance for ecosystem processes needs consideration of species identity. European Journal of Soil Biology 77, 60-67.

Hedde, M., Bureau, F., Delporte, P., Cécillon, L., Decaëns, T., 2013. The effects of earthworm species on soil behaviour depend on land use. Soil Biology and Biochemistry 65, 264-273. 
Hedde, M., Pey, B., Auclerc, A., Capowiez, Y., Cluzeau, D., Cortet, J., Decaëns, T., Deharveng, L., Dubs, F., Grumiaux, F., Guernion, M., Joimel, S., Laporte, M.-A., Pasquet, A., Pelosi, C., Pernin, C., Ponge, J.-F., Salmon, S., Santorufo, L., Nahmani, J., 2012a. BETSI, a complete framework for studying soil invertebrate functional traits, XVI ICSZ International Colloquium on Soil Zoology, Coimbra, Portugal.

Hedde, M., van Oort, F., Lamy, I., 2012b. Functional traits of soil invertebrates as indicators for exposure to soil disturbance. Environmental Pollution 164, 59-65.

Hendriksen, N.B., 1990. Leaf litter selection by detritivore and geophagous earthworms. Biology and Fertility of Soils 10, 17-21.

Hendrix, P.F., Callaham Jr, M.A., Lachnicht, S.L., Blair, J.M., James, S.W., Zou, X., 1999. Stable isotopic studies of resource utilization by nearctic earthworms (Diplocardia, Oligochaeta) in subtropical savanna and forest ecosystems. Pedobiologia 43, 818-823.

Hurlbert, S.H., 1984. Pseudoreplication and the design of ecological field experiments. Ecological Monographs 54, 187-211.

Jones, C.G., Lawton, J.H., Shachak, M., 1994. Organisms as Ecosystem Engineers. Oikos 69, 373-386.

Keith, A.M., Robinson, D.A., 2012. Earthworms as natural capital: ecosystem service providers in agricultural soils. Economology Journal 2, 91-99.

Kille, P., Andre, J., Anderson, C., Ang, H.N., Bruford, M.W., Bundy, J.G., Donnelly, R., Hodson, M.E., Juma, G., Lahive, E., Morgan, A.J., Stürzenbaum, S.R., Spurgeon, D.J., 2013. DNA sequence variation and methylation in an arsenic tolerant earthworm population. Soil Biology and Biochemistry 57, 524-532.

Kladivko, E.J., 2001. Tillage systems and soil ecology. Soil and Tillage Research 61, 61-76.

Lavelle, P., 1983. The structure of earthworm communities, Earthworm ecology. Springer, pp. 449-466.

Lavelle, P., Bignell, D., Lepage, M., Wolters, V., Roger, P., Ineson, P., Heal, O., Dhillion, S., 1997. Soil function in a changing world: the role of invertebrate ecosystem engineers. European Journal of Soil Biology 33, 159-193. 
Lavelle, P., Charpentier, F., Villenave, C., Rossi, J.-P., Derouard, L., Pashanasi, B., André, J., Ponge, J.-F., Bernier, N., 2004. Effects of earthworms on soil organic matter and nutrient dynamics at a landscape scale over decades, in: Edwards, C. (Ed.), Earthworm ecology, second ed. CRC Press, Boca Raton, pp. 145-160.

Lavelle, P., Spain, A., 2001. Soil ecology. Springer Science \& Business Media.

Lavorel, S., Garnier, E., 2002. Predicting changes in community composition and ecosystem functioning from plant traits: revisiting the Holy Grail. Functional Ecology 16, 545-556.

Lavorel, S., Grigulis, K., McIntyre, S., Williams, N.S.G., Garden, D., Dorrough, J., Berman, S., Quétier, F., Thébault, A., Bonis, A., 2008. Assessing functional diversity in the field methodology matters! Functional Ecology 22, 134-147.

Le Couteulx, A., Wolf, C., Hallaire, V., Pérès, G., 2015. Burrowing and casting activities of three endogeic earthworm species affected by organic matter location. Pedobiologia 58, 97103.

Lee, K., Foster, R., 1991. Soil fauna and soil structure. Soil Research 29, 745-775.

Lemtiri, A., Colinet, G., Alabi, T., Cluzeau, D., Zirbes, L., Haubruge, É., Francis, F., 2014. Impacts of earthworms on soil components and dynamics. A review. Biotechnol. Agron. Soc. Environ. 18, 121-133.

Leps, J., De Bello, F., Lavorel, S., Berman, S., 2006. Quantifying and interpreting functional diversity of natural communities: practical considerations matter. Preslia 78, 481-501.

Lindo, Z., 2015. Warming favours small-bodied organisms through enhanced reproduction and compositional shifts in belowground systems. Soil Biology and Biochemistry 91, 271-278.

Loranger-Merciris, G., Laossi, K.-R., Bernhard-Reversat, F., 2008. Soil aggregation in a laboratory experiment: Interactions between earthworms, woodlice and litter palatability. Pedobiologia 51, 439-443.

Lowe, C.N., Butt, K.R., 1999. Interspecific interactions between earthworms: A laboratory-based investigation. Pedobiologia 43, 808-817.

Lowe, C.N., Butt, K.R., 2002. Growth of hatchling earthworms in the presence of adults: interactions in laboratory culture. Biology and Fertility of Soils 35, 204-209. 
Lowe, C.N., Butt, K.R., 2003. Influence of food particle size on inter- and intra-specific interactions of Allolobophora chlorotica (Savigny) and Lumbricus terrestris: The 7th international symposium on earthworm ecology, Cardiff, Wales, 2002. Pedobiologia 47, 574-577.

Lubbers, I.M., Groenigen, K.J.v., Fonte, S.J., Six, J., Brussaard, L., Groenigen, J.W.v., 2013. Greenhouse-gas emissions from soils increased by earthworms. Nature Climate Change 3, 187-194.

Lubbers, I.M., Pulleman, M.M., Van Groenigen, J.W., 2017. Can earthworms simultaneously enhance decomposition and stabilization of plant residue carbon? Soil Biology and Biochemistry 105, 12-24.

Lubbers, I.M., van Groenigen, J.W., 2013. A simple and effective method to keep earthworms confined to open-top mesocosms. Applied Soil Ecology 64, 190-193.

Lüscher, G., Jeanneret, P., Schneider, M.K., Turnbull, L.A., Arndorfer, M., Balázs, K., Báldi, A., Bailey, D., Bernhardt, K.G., Choisis, J.-P., Elek, Z., Frank, T., Friedel, J.K., Kainz, M., Kovács-Hostyánszki, A., Oschatz, M.-L., Paoletti, M.G., Papaja-Hülsbergen, S., Sarthou, J.P., Siebrecht, N., Wolfrum, S., Herzog, F., 2014. Responses of plants, earthworms, spiders and bees to geographic location, agricultural management and surrounding landscape in European arable fields. Agriculture, Ecosystems and Environment 186, 124-134.

Marinissen, J.C.Y., 1994. Earthworm populations and stability of soil structure in a silt loam soil of a recently reclaimed polder in the Netherlands. Agriculture, Ecosystems and Environment $51,75-87$.

Marinissen, J.C.Y., Dexter, A.R., 1990. Mechanisms of stabilization of earthworm casts and artificial casts. Biology and Fertility of Soils 9, 163-167.

Marinissen, J.C.Y., van den Bosch, F., 1992. Colonization of new habitats by earthworms. Oecologia 91, 371-376.

Martin, N.A., 1982. The interaction between organic-matter in soil and the burrowing activity of 3 species of earthworms (Oligochaeta, Lumbricidae). Pedobiologia 24, 185-190.

Mason, N.W.H., Mouillot, D., Lee, W.G., Wilson, J.B., 2005. Functional richness, functional evenness and functional divergence: the primary components of functional diversity. Oikos $111,112-118$. 
Mather, J.G., Christensen, O., 1988. Surface movements of earthworms in agricultural land. Pedobiologia 32, 399-405.

Mathieu, J., 2018. EGrowth: A global database on intraspecific body growth variability in earthworm. Soil Biology and Biochemistry 122, 71-80.

Mathieu, J., Barot, S., Blouin, M., Caro, G., Decaëns, T., Dubs, F., Dupont, L., Jouquet, P., Nai, P., 2010. Habitat quality, conspecific density, and habitat pre-use affect the dispersal behaviour of two earthworm species, Aporrectodea icterica and Dendrobaena veneta, in a mesocosm experiment. Soil Biology and Biochemistry 42, 203-209.

Millennium Ecosystem Assessment, 2005. Ecosystems and Human Well-being: Biodiversity Synthesis, Washington, DC, USA.

Moretti, M., Dias, A.T.C., de Bello, F., Altermatt, F., Chown, S.L., Azcarate, F.M., Bell, J.R., Fournier, B., Hedde, M., Hortal, J., Ibanez, S., Ockinger, E., Sousa, J.P., Ellers, J., Berg, M.P., 2017. Handbook of protocols for standardized measurement of terrestrial invertebrate functional traits. Functional Ecology 31, 558-567.

Mouchet, M.A., Villéger, S., Mason, N.W.H., Mouillot, D., 2010. Functional diversity measures: an overview of their redundancy and their ability to discriminate community assembly rules. Functional Ecology 24, 867-876.

Mulder, C., Maas, R., 2017. Unifying the functional diversity in natural and cultivated soils using the overall body-mass distribution of nematodes. BMC Ecol 17, 36.

Naeem, S., Wright, J.P., 2003. Disentangling biodiversity effects on ecosystem functioning: deriving solutions to a seemingly insurmountable problem. Ecology Letters 6, 567-579.

Nieminen, M., Ketoja, E., Mikola, J., Terhivuo, J., Sirén, T., Nuutinen, V., 2011. Local land use effects and regional environmental limits on earthworm communities in Finnish arable landscapes. Ecological Applications 21, 3162-3177.

Nuutinen, V., Butt, K.R., Hyväluoma, J., Ketoja, E., Mikola, J., 2017. Soil faunal and structural responses to the settlement of a semi-sedentary earthworm Lumbricus terrestris in an arable clay field. Soil Biology and Biochemistry 115, 285-296.

Nuutinen, V., Butt, K.R., Jauhiainen, L., 2011. Field margins and management affect settlement and spread of an introduced dew-worm (Lumbricus terrestris L.) population. Pedobiologia 54, Supplement, S167-S172. 
Olszewski, T.D., 2004. A unified mathematical framework for the measurement of richness and evenness within and among multiple communities. Oikos 104, 377-387.

Pansu, J., De Danieli, S., Puissant, J., Gonzalez, J.M., Gielly, L., Cordonnier, T., Zinger, L., Brun, J.J., Choler, P., Taberlet, P., Cecillon, L., 2015. Landscape-scale distribution patterns of earthworms inferred from soil DNA. Soil Biology and Biochemistry 83, 100-105.

Paul, B.K., Lubbers, I.M., van Groenigen, J.W., 2012. Residue incorporation depth is a controlling factor of earthworm-induced nitrous oxide emissions. Global Change Biology $18,1141-1151$.

Pelosi, C., Barot, S., Capowiez, Y., Hedde, M., Vandenbulcke, F., 2014. Pesticides and earthworms. A review. Agronomy for Sustainable Development 34, 199-228.

Pelosi, C., Bertrand, M., Thenard, J., Mougin, C., 2015. Earthworms in a 15 years agricultural trial. Applied Soil Ecology 88, 1-8.

Pelosi, C., Pey, B., Caro, G., Cluzeau, D., Peigné, J., Bertrand, M., Hedde, M., 2016. Dynamics of earthworm taxonomic and functional diversity in ploughed and no-tilled cropping systems. Soil and Tillage Research 156, 25-32.

Pelosi, C., Pey, B., Hedde, M., Caro, G., Capowiez, Y., Guernion, M., Peigné, J., Piron, D., Bertrand, M., Cluzeau, D., 2013a. Reducing tillage in cultivated fields increases earthworm functional diversity. Applied Soil Ecology 83, 79-87.

Pelosi, C., Toutous, L., Chiron, F., Dubs, F., Hedde, M., Muratet, A., Ponge, J.F., Salmon, S., Makowski, D., 2013b. Reduction of pesticide use can increase earthworm populations in wheat crops in a European temperate region. Agriculture, Ecosystems and Environment 181, 223-230.

Pérès, G., Bellido, A., Curmi, P., Marmonier, P., Cluzeau, D., 2010. Relationships between earthworm communities and burrow numbers under different land use systems. Pedobiologia 54, 37-44.

Pérès, G., Vandenbulcke, F., Guernion, M., Hedde, M., Beguiristain, T., Douay, F., Houot, S., Piron, D., Richard, A., Bispo, A., Grand, C., Galsomies, L., Cluzeau, D., 2011. Earthworm indicators as tools for soil monitoring, characterization and risk assessment. An example from the national Bioindicator programme (France). Pedobiologia 54, Supplement, S77-S87. 
Petchey, O.L., Gaston, K.J., 2002. Functional diversity (FD), species richness and community composition. Ecology Letters 5, 402-411.

Petchey, O.L., Gaston, K.J., 2006. Functional diversity: back to basics and looking forward. Ecology Letters 9, 741-758.

Peters, R.H., 1983. The ecological implications of body size. Cambridge University Press, Cambridge (Cambridgeshire), UK.

Petersen, H., Luxton, M., 1982. A comparative analysis of soil fauna populations and their role in decomposition processes. Oikos 39, 288-388.

Postma-Blaauw, M.B., Bloem, J., Faber, J.H., Groenigen, J.W.v., Goede, R.G.M.d., Brussaard, L., 2006. Earthworm species composition affects the soil bacterial community and net nitrogen mineralization. Pedobiologia 50, 243-256.

Postma-Blaauw, M.B., de Goede, R.G.M., Bloem, J., Faber, J.H., Brussaard, L., 2010. Soil biota community structure and abundance under agricultural intensification and extensification. Ecology 91, 460-473.

Pulleman, M., Jongmans, A., Marinissen, J., Bouma, J., 2003. Effects of organic versus conventional arable farming on soil structure and organic matter dynamics in a marine loam in the Netherlands. Soil Use and Management 19, 157-165.

Pulleman, M.M., Six, J., Uyl, A., Marinissen, J.C.Y., Jongmans, A.G., 2005. Earthworms and management affect organic matter incorporation and microaggregate formation in agricultural soils. Applied Soil Ecology 29, 1-15.

R Core Team, 2014. R: A language and environment for statistical computing. R Foundation for Statistical Computing, Vienna, Austria.

Ricotta, C., Moretti, M., 2011. CWM and Rao's quadratic diversity: a unified framework for functional ecology. Oecologia 167, 181-188.

Rizhiya, E., Bertora, C., van Vliet, P.C.J., Kuikman, P.J., Faber, J.H., van Groenigen, J.W., 2007. Earthworm activity as a determinant for $\mathrm{N} 2 \mathrm{O}$ emission from crop residue. Soil Biology and Biochemistry 39, 2058-2069.

Roarty, S., Schmidt, O., 2013. Permanent and new arable field margins support large earthworm communities but do not increase in-field populations. Agriculture, Ecosystems and Environment 170, 45-55. 
Royal Netherlands Meteorological Institute, Daily weather data of the Netherlands.

http://www.knmi.nl/nederland-nu/klimatologie/daggegevens (Accessed November 2016).

Scheu, S., 20.03. Effects of earthworms on plant growth: patterns and perspectives. Pedobiologia 47, 846-856.

Schmidt, O., 1999. Intrapopulation variation in carbon and nitrogen stable isotope ratios in the earthworm Aporrectodea longa. Ecological Research 14, 317-328.

Schmidt, O., Clements, R.O., Donaldson, G., 2003. Why do cereal-legume intercrops support large earthworm populations? Applied Soil Ecology 22, 181-190.

Schwert, D.P., 1980. Active and passive dispersal of lumbricid earthworms, in: Dindal, D.L. (Ed.), Soil Biology as Related to Land Use Practices. Proceedings of the 7th Soil Zoology Colloquium. EPA, Washington, D.C., pp. 182-189.

Schwert, D.P., Dance, K.W., 1979. Earthworm cocoons as a drift component in a Southern Ontario stream. Canadian Field-Naturalist 93, 180-183.

Sechi, V., De Goede, R.G.M., Rutgers, M., Brussaard, L., Mulder, C., 2018. Functional diversity in nematode communities across terrestrial ecosystems. Basic and Applied Ecology 30, 7686.

Sechi, V., Goede, D.R.G.M., Rutgers, M., Brussaard, L., Mulder, C., 2017. A community traitbased approach to ecosystem functioning in soil. Agriculture, Ecosystems and Environment $239,265-273$.

Shipitalo, M., Protz, R., 1988. Factors influencing the dispersibility of clay in worm casts. Soil Science Society of America Journal 52, 764-769.

Sims, R.W., Gerard, B.M., 1999. Earthworms: Notes for the identification of British species. Field Studies Council, Shrewsbury, UK.

Six, J., Bossuyt, H., Degryze, S., Denef, K., 2004. A history of research on the link between (micro) aggregates, soil biota, and soil organic matter dynamics. Soil and Tillage Research 79, 7-31.

Six, J., Callewaert, P., Lenders, S., De Gryze, S., Morris, S.J., Gregorich, E.G., Paul, E.A., Paustian, K., 2002. Measuring and understanding Carbon storage in afforested soils by physical fractionation. Soil Science Society of America Journal 66, 1981-1987. 
Smith, J., Potts, S., Eggleton, P., 2008. The value of sown grass margins for enhancing soil macrofaunal biodiversity in arable systems. Agriculture, Ecosystems and Environment 127, $119-125$.

Smith, P., House, J.I., Bustamante, M., Sobocka, J., Harper, R., Pan, G.X., West, P.C., Clark, J.M., Adhya, T., Rumpel, C., Paustian, K., Kuikman, P., Cotrufo, M.F., Elliott, J.A., McDowell, R., Griffiths, R.I., Asakawa, S., Bondeau, A., Jain, A.K., Meersmans, J., Pugh, T.A.M., 2016. Global change pressures on soils from land use and management. Global Change Biology 22, 1008-1028.

Sokal, R.R., Rohlf, F.J., 1995. Biometry: the principles and practice of statistics, Third ed. W. H. Freeman and Company, New York, USA.

Southwood, T.R., 1977. Habitat, the templet for ecological strategies? Journal of Animal Ecology 46, 337-365.

Spurgeon, D., Keith, A., Schmidt, O., Lammertsma, D., Faber, J., 2013. Land-use and landmanagement change: relationships with earthworm and fungi communities and soil structural properties. BMC Ecol 13, 1-13.

Stearns, S.C., 1976. Life-history tactics: a review of the ideas. The Quarterly Review of Biology $51,3-47$.

Steingröver, E., Geertsema, W., van Wingerden, W., 2010. Designing agricultural landscapes for natural pest control: a transdisciplinary approach in the Hoeksche Waard (The Netherlands). Landscape Ecology 25, 825-838.

Stöp-Bowitz, C., 1969. A contribution to our knowledge of the systematics and zoography of Norwegian earthworms (Annelida Oligochaeta: Lumbricidae). Nytt Mag. Zool. 17, 169-280. Stroud, J.L., Irons, D.E., Watts, C.W., Storkey, J., Morris, N.L., Stobart, R.M., Fielding, H.A., Whitmore, A.P., 2017. Cover cropping with oilseed radish (Raphanus sativus) alone does not enhance deep burrowing earthworm (Lumbricus terrestris) midden counts. Soil and Tillage Research 165, 11-15.

Stroud, J.L., Irons, D.E., Watts, C.W., White, R.P., McGrath, S.P., Whitmore, A.P., 2016. Population collapse of Lumbricus terrestris in conventional arable cultivations and response to straw applications. Applied Soil Ecology 108, 72-75. 
Sutherland, W.J., Freckleton, R.P., Godfray, H.C.J., Beissinger, S.R., Benton, T., Cameron, D.D., Carmel, Y., Coomes, D.A., Coulson, T., Emmerson, M.C., Hails, R.S., Hays, G.C., Hodgson, D.J., Hutchings, M.J., Johnson, D., Jones, J.P.G., Keeling, M.J., Kokko, H., Kunin, W.E., Lambin, X., Lewis, O.T., Malhi, Y., Mieszkowska, N., Milner-Gulland, E.J., Norris, K., Phillimore, A.B., Purves, D.W., Reid, J.M., Reuman, D.C., Thompson, K., Travis, J.M.J., Turnbull, L.A., Wardle, D.A., Wiegand, T., 2013. Identification of 100 fundamental ecological questions. Journal of Ecology 101, 58-67.

Syers, J.K., Springett, J.A., 1984. Earthworms and soil fertility. Plant Soil 76, 93-104.

ter Braak, C.J.F., Šmilauer, P., 2014. Topics in constrained and unconstrained ordination. Plant Ecol. 216, 683-696.

Thakuria, D., Schmidt, O., Finan, D., Egan, D., Doohan, F.M., 2010. Gut wall bacteria of earthworms: a natural selection process. The ISME Journal 4, 357-366.

Tscharntke, T., Klein, A.M., Kruess, A., Steffan-Dewenter, I., Thies, C., 2005. Landscape perspectives on agricultural intensification and biodiversity - ecosystem service management. Ecology Letters 8, 857-874.

Turnbull, M.S., George, P.B.L., Lindo, Z., 2014. Weighing in: size spectra as a standard tool in soil community analyses. Soil Biology and Biochemistry 68, 366-372.

Uvarov, A.V., 2009. Inter- and intraspecific interactions in lumbricid earthworms: Their role for earthworm performance and ecosystem functioning. Pedobiologia 53, 1-27.

Valckx, J., Pina, A.C., Govers, G., Hermy, M., Muys, B., 2011. Food and habitat preferences of the earthworm Lumbricus terrestris L. for cover crops. Pedobiologia 54, Supplement, S139S144.

van Capelle, C., Schrader, S., Brunotte, J., 2012. Tillage-induced changes in the functional diversity of soil biota - A review with a focus on German data. European Journal of Soil Biology 50, 165-181.

van Groenigen, J.W., Lubbers, I.M., Vos, H.M.J., Brown, G.G., de Deyn, G.B., van Groenigen, K.J., 2014. Earthworms increase plant production: a meta-analysis. 4, 6365. van Vliet, P.C.J., de Goede, R.G.M., 2006. Effects of slurry application methods on soil faunal communities in permanent grassland. European Journal of Soil Biology 42, S348-S353. 
Violle, C., Navas, M.-L., Vile, D., Kazakou, E., Fortunel, C., Hummel, I., Garnier, E., 2007. Let the concept of trait be functional! Oikos 116, 882-892.

Vos, H.M.J., Ros, M.B.H., Koopmans, G.F., van Groenigen, J.W., 2014. Do earthworms affect phosphorus availability to grass? A pot experiment. Soil Biology and Biochemistry 79, 3442.

Whalen, J.K., Parmelee, R.W., Edwards, C.A., 1998. Population dynamics of earthworm communities in corn agroecosystems receiving organic or inorganic fertilizer amendments. Biology and Fertility of Soils 27, 400-407.

WRB, I.W.G., 2006. World reference base for soil resources 2006: a framework for international classification, correlation and communication. FAO, Rome.

Zuur, A., Ieno, E.N., Walker, N., Saveliev, A.A., Smith, G.M., 2009. Mixed effects models and extensions in ecology with R. Springer, New York. 
Summary 



\section{Summary}

Earthworms are important for the sustainable management of arable land. Although a considerable amount of research has been devoted to earthworm communities of arable fields, many knowledge gaps remain. This thesis aimed at improving knowledge on two of those gaps: i) the effects of the surrounding landscape; and ii) the effects of crop residue management.

Chapter 2 was dedicated to earthworm communities in an arable landscape, as affected by different soil and management factors at the scale of the arable field up to the landscape level. We first assessed whether earthworm communities differed among habitats that were under different disturbance intensities, i.e., arable fields and field margin strips and if so, how these differences could be explained. We therefore determined the relative contribution of several environmental filters that were grouped as soil properties, arable management, and surrounding landscape, in shaping earthworm community composition of the two habitats. We found that earthworm communities of arable fields were only significantly affected by field level arable management-related variables, whereas in field margins, earthworm communities were shaped by all three sets of filters together.

Chapter 3 described a mesocosm experiment, that studied the effects of crop residue placement (surface-applied vs. incorporated between 20 and $30 \mathrm{~cm}$ soil depth) on earthworms, and the subsequent effects on earthworm-mediated soil structure formation. The survival and performance of earthworms was first tested under controlled conditions, using representative species of each of the ecological groups (epigeic, endogeic and anecic). Earthworms were present in single species or in species mixtures combining the anecics with each of the other two ecological groups. The subsequent effects of earthworms on soil structure formation were evaluated, under the same crop residue placements, focusing on soil organic matter (SOM) incorporation, aggregate stability and soil porosity. We found that crop residue incorporation led to lower survival of epigeics and body weight of epigeics and anecics, when present alone. In the presence of anecics, epigeics lost even more weight when crop residues were incorporated, indicating competition among species of these two ecological groups. In relation to soil structure formation, we found that POM and large water-stable macroaggregates in the upper $20 \mathrm{~cm}$ soil increased when crop residues were surface-applied and anecics were present. In contrast, incorporation of residues constrained the formation of large water-stable macroaggregate by 
earthworms, although it increased soil porosity between 2.5 and $30 \mathrm{~cm}$ soil depth. Irrespective of crop residue placement, species mixture treatments enhanced the formation of small water-stable aggregates at all soil depths, whereas their formation was hampered by single species treatments. In chapters 4 and 5 the response of earthworm communities to crop residue management was studied under field conditions. We included two neighbouring arable fields with contrasting tillage intensity: non-inversion tillage (NIT) and conventional tillage (CT) Anecics were absent from these fields at the start of the experiments and we assessed the feasibility of inoculating this ecological group in arable fields by introducing $L$. terrestris. There is a wide variety of methods to quantify community responses, and in chapter 4 we made use of several quantification approaches for the (sub)adult part of the community: earthworm total density, ecological group density, species composition and diversity, and trait composition and functional diversity. In chapter 5 we explored further earthworm body-weight distributions of each of the ecological groups in relation to crop residue management, using the total community datasets (including juveniles). The results of chapter 4 suggested that in NIT, the highest residue application rate increased epigeic density compared to a low rate (25\%) of crop residue application, while the remaining effects were negligible or absent. In CT, crop residues, either incorporated or surfaceapplied, had strong effects on species composition, ecological groups and functional traits. Both epigeic density and trait diversity increased when residues were available, and the communities shifted towards heavier individuals, with a thicker tegument, a feather-shaped typhlosolis and a higher average cocoon production rate. When including juveniles in the assessment of community response, body-weight distribution of endogeic species was not affected by crop residue management in both tillage trials. The response of epigeics was largely driven by $L$. rubellus in both tillage trials, but the effects differed between the two systems. In NIT, ample food resulted in a larger proportion of the lightest individuals compared to limited or no crop residue availability, suggesting an increase in reproductive output with abundant food. In CT, crop residue availability, irrespective of its placement resulted in a shift towards heavier individuals, at least within the heaviest earthworms. The results of chapters 4 and 5 suggest that crop residue management is important for earthworm communities of arable fields, but that the effects differ between tillage systems.

In conclusion, we found that earthworm communities of arable fields are strongly shaped by arable management, and that the decision of farmers on crop residue management affect soil life 
and subsequent earthworm-mediated soil functions (soil aggregation and SOM cycling) in their land. 

Samenvatting 



\section{Samenvatting}

Regenwormen zijn van groot belang voor duurzaam agrarisch bodembeheer. Hoewel er veel onderzoek aan regenwormgemeenschappen in akkerbouw is gedaan, blijven er nog veel vraagstukken onbeantwoord. Dit proefschrift richt zich op twee belangrijke vraagstukken over regenwormen in akkerland, namelijk de effecten van het omringende landschap en van het beheer van gewasresten op regenwormgemeenschappen.

Hoofdstuk 2 richt zich op de vraag hoe regenwormgemeenschappen worden beïnvloed door bodemeigenschappen, het agrarisch beheer, en de inrichting van de akkerpercelen en het omringende landschap. Hiervoor is onderzoek verricht in de Hoeksche Waard, een gebied van $324 \mathrm{~km}^{2}$ in het zuidwesten van Nederland. Allereerst richtte het onderzoek zich op de verschillen in voorkomen van regenwormen tussen akkers en akkerranden, vanuit de veronderstelling dat akkerranden minder intensief verstoord worden dan de akkers zelf. In de akkerranden vonden we een rijkere regenwormgemeenschap dan in de naastgelegen akkers en de diversiteit van regenwormen in de akkerranden werd beïnvloed door zowel bodemeigenschappen, het beheer van de akkerranden als door de diversiteit aan omliggende landschapselementen, dat wil zeggen de complexiteit van het landschap. In de akkers daarentegen vonden we een lagere diversiteit aan regenwormen en bleek het beheer van de akker van dominant belang, terwijl de samenstelling van het omringende landschap geen significante invloed had.

In hoofdstuk 3 worden de resultaten van een laboratoriumexperiment beschreven. In grote PVC kolommen gevuld met grond afkomstig uit akkerland werden regenwormen uitgezet en werd onderzocht hoe regenwormen reageren op de beschikbaarheid van gewasresten en welke gevolgen dit heeft voor hun bijdrage aan bodemstructuurvorming. Gewasresten werden aangeboden aan het bodemoppervlak (model voor een systeem met niet-kerende grondbewerking) of ingewerkt op een diepte van 20-30 cm onder de grond (model voor een traditioneel geploegd systeem). Verschillende regenwormensoorten werden alléén of in combinatie met één andere soort uitgezet. De verschillende soorten behoorden tot verschillende ecologische groepen, die verschillende functies in de bodem bedienen, namelijk pendelaars met strooiseleters of pendelaars met grondeters. We vonden dat het inwerken van gewasresten leidt tot een lagere overleving van strooiseleters en dat zowel strooiseleters als pendelaars afnamen in lichaamsgewicht. Bovendien verloren strooiseleters die in combinatie met pendelaars werden 
gehouden extra veel lichaamsgewicht. Dit duidt op competitie om voedsel tussen deze twee ecologische groepen: zowel de strooiseleters als de pendelaars verzamelen hun voedsel aan het bodemoppervlak, terwijl grondeters ondergronds foerageren. Wanneer de gewasresten op het bodemoppervlak werden aangeboden en er tevens pendelaars aanwezig waren, bleken er meer grotere stabiele bodemaggregaten en meer als organisch materiaal herkenbare deeltjes (POM) voor te komen in de bovenste $20 \mathrm{~cm}$ van de bodem. Het inwerken van gewasresten, daarentegen, leidde tot minder vorming van grotere bodemaggregaten, maar verhoogde wel de porositeit van de bodem. Ongeacht de manier waarop gewasresten werden aangeboden, werden in de grond waarin twee soorten regenwormen voorkwamen meer (kleinere) stabiele bodemaggregaten gevormd dan in grond waarin slechts één soort tegelijk voorkwam.

In hoofdstukken 4 en 5 werden de effecten van gewasresten op regenwormen onderzocht in het veld. Het onderzoek vond plaats in twee naastgelegen stroken akkerland binnen eenzelfde perceel, waarbij in de ene strook werd geploegd (kerende grondbewerking) en in de andere niet (niet-kerende grondbewerking). In dit akkerbouwperceel waren bij eerdere metingen, voorafgaand aan het onderzoek, geen pendelaars aangetroffen. Er is daarom onderzocht of het haalbaar is om wormen van deze ecologische groep in akkers te introduceren. Dit is gedaan door de pendelaar Lumbricus terrestris uit te zetten in een veldproef. In deze veldproef lag de nadruk wederom op het effect van het aanbieden van gewasresten op regenwormen. Bij kerende grondbewerking worden gewasresten ingewerkt, terwijl ze bij niet-kerende grondbewerking dicht op het bodemoppervlak blijven liggen. In de strook met niet-kerende grondbewerking werden drie hoeveelheden gewasresten aangeboden: $0 \%, 25 \%$, en $100 \%$ van de beschikbare gewasresten. Bij kerende grondbewerking werden álle gewasresten óf ondergeploegd $(100 \%$ ingewerkt), óf verwijderd vóór het ploegen en daarna teruggeplaatst op het bodemoppervlak ( $100 \%$ oppervlakkig), óf helemaal verwijderd $(0 \%)$.

In hoofdstuk 4 hebben we gekeken naar de effecten op (jong-)volwassen regenwormen en dan met name naar hun totale aantallen, hun verdeling over de drie ecologische groepen, hun soortensamenstelling, diversiteit en een selectie van soort-specifieke functionele kenmerken. In hoofdstuk 5 werden alle regenwormindividuen, dus ook de juvenielen meegenomen. Hier hebben we de effecten van de gewasrestbehandelingen op de opbouw van de regenwormpopulaties onderzocht op basis van veranderingen in lichaamsgewicht. De resultaten van hoofdstuk 4 maakten duidelijk dat vooral de strooiseleters weten te profiteren van het aanbod van 
gewasresten bij niet-kerende grondbewerking. Als alle gewasresten na de oogst achterbleven in het veld werden hogere dichtheden strooiseleters gevonden dan wanneer slechts een kwart van de gewasresten achter bleef. Bij kerende grondbewerking had het aanbod van de gewasresten ook een effect. Binnen dit systeem werd, in aanwezigheid van gewasresten, een hogere dichtheid aan strooiseleters gevonden dan in de afwezigheid van gewasresten en ook werd een effect gevonden op soort-specifieke functionele kenmerken, zoals een groter aandeel van zwaardere regenwormen met een dikkere huid, een veervormige tyflosolis (een onderdeel van de darm) en een hoger gemiddelde coconproductie. Wanneer ook de juvenielen werden meegenomen in de analyse bleek dat er, afhankelijk van de gewasrestbehandelingen, opmerkelijke verschillen optraden in de lichaamsgewichtverdeling van de regenwormenpopulaties, tenminste voor de strooiseleters en de pendelaars. Geen enkele behandeling had effect op de lichaamsgewichtsverdeling van de grondeters. In beide grondbewerkingssystemen werden de grootste effecten van de gewasrestenbehandelingen gevonden voor $L$. rubellus. Echter, bij nietkerende grondbewerking resulteerde hogere voedselbeschikbaarheid in een groter aandeel van de aller lichtste individuen, duidend op een versnelde voortplanting, terwijl een hogere beschikbaarheid van gewasresten onder kerende grondbewerking resulteerde in een verschuiving naar zwaardere individuen, ten minste voor de zwaarste regenwormen (waarschijnlijk de (jong)adulten). Hierbij maakte het niet uit of de gewasresten bovengronds of ondergronds werden aangeboden.

De resultaten van de hoofdstukken 4 en 5 laten zien dat het specifieke beheer van gewasresten belangrijk is voor regenwormpopulaties in de akkerbouw, en dat deze effecten bovendien afhankelijk zijn van de manier van grondbewerking.

We concluderen dat regenwormgemeenschappen in akkerland sterk worden beïnvloed door het landbouwkundig beheer, waarbij de keuzes van boeren ten aanzien van de hoeveelheden gewasresten die worden achtergelaten, en de daaropvolgende grondbewerking sterk doorwerken in het bodemleven, in dit geval regenwormen, en de daaraan gerelateerde bodemfuncties. Bovendien tonen de ontwikkeling van regenwormpopulaties in akkerranden en de vestiging van pendelaars in akkers aan dat weloverwogen maatregelen ten aanzien van het landbouwkundig beheer potentie hebben voor het verbeteren van de biologische bodemkwaliteit in het agrarisch landschap. 

Sumário 



\section{Sumário}

As minhocas são importantes para a gestão sustentável de áreas agrícolas pois produzem serviços essenciais a estes sistemas. Apesar de já existir uma quantidade considerável de investigação dedicada ao estudo de comunidades de minhocas de terrenos agrícolas, muitas lacunas de conhecimento permanecem. Esta tese tentou melhorar o conhecimento em relação a duas dessas lacunas: i) os efeitos da paisagem circundante e ii) os efeitos da gestão dos restolhos.

O capítulo 2 foi dedicado ao estudo de comunidades de minhocas de uma região agrícola, no que respeita a factores do solo e de gestão agrícola à escala espacial do campo agrícola até à da paisagem. Primeiramente avaliou-se se as comunidades de minhocas eram diferentes em habitats cuja intensidade de distúrbios diferia, i.e., campos agrícolas e margens de campos agrícolas, e no caso de existirem differenças significativas entre as comunidades, como se poderiam explicar essas diferenças. Foi então determinada a contribuição relativa de vários filtros ambientais, agrupados em propriedades do solo, gestão agrícola e paisagem circundante, na composição de comunidades de minhocas em ambos os habitats. As comunidades de minhocas de campos agrícolas foram apenas afectadas significativamente por variáveis associadas à gestão agrícola à escala do campo agrícola, enquanto que no que se refere às comunidades de minhocas existentes em margens de campos agrícolas, estas foram afectadas por variáveis relativas aos três grupos de filtros ambientais em conjunto.

No capítulo 3 descreveu-se uma experiência em laboratório que visou estudar os efeitos da localização dos restolhos no solo (aplicado à superfície vs. incorporado entre 20 a $30 \mathrm{~cm}$ de profundidade) em minhocas, e os efeitos consequentes na formação de estrutura do solo através de minhocas. A sobrevivência e performance das minhocas foram testada sob condições controladas, utilizando espécies representativas de cada grupo ecológico (epigeicas, endogeicas e anécicas). As minhocas presentes nas unidades experimentais eram indivíduos pertencentes a uma ou duas espécies, sendo que no último caso, combinaram-se as anécicas com um dos restantes grupos ecológicos. Avaliaram-se os efeitos consequentes de minhocas na formação da estrutura do solo, no mesmo desenho experimental, com ênfase na incorporação de matéria orgânca do solo (SOM), estabilidade de agregados e porosidade do solo. A incorporação de restolhos no solo levou ao decréscimo de sobrevivência das epigeicas, assim como à perda de peso das epigeicas e anécicas quando presentes como espécie única. Na presença de anécicas, as 
epigeicas perderam ainda mais peso com a incoporação dos restolhos, indicando competição entre espécies pertencentes a ambos os grupos ecológicos. Em relação à formação de estrutura do solo, tanto a matéria orgânica particulada (POM) como os macroagregados estáveis em água de grandes dimensões aumentaram nos $20 \mathrm{~cm}$ superiores quando os restolhos foram aplicados à superfície do solo e na presença de anécicas. Por oposição, a incorporação de restolhos no solo constrangeu o papel das minhocas na formação de macroagregados estáveis em água de grandes dimensões, mas simultaneamente aumentou a porosidade do solo entre 2.5 e $30 \mathrm{~cm}$. Independentemente da localização dos restolhos, as unidades experimentais com duas espécies apresentaram um aumento de macroagregados estáveis em água de pequenas dimensões a todas as profundidades do solo consideradas, enquanto que o oposto se verificou em unidades experimentais com apenas uma espécie.

Nos capítulos 4 e 5 estudou-se a resposta de comunidades de minhocas à gestão agrícola de restolhos sob condições naturais. Incluíram-se dois campos agrícolas adjacentes cuja intensidade de lavoura era distinta: lavoura sem inversão do solo (NIT) e lavoura convencional (CT). Devido ao facto de as espécies pertencentes ao grupo das anécicas se encontrarem ausentes em ambos os campos, testou-se a viabilidade de inocular este grupo em campos agrícolas através da introdução da espécie L. terrestris. Existe uma ampla gama de métodos ecológicos que visam a quantificação de respostas de comunidades, e, no capítulo 4, abordaram-se vários destes métodos quantificativos no estudo das respostas da parte (sub)adulta das comunidades de minhocas: densidade de minhocas total, densidade dos grupos ecológicos de minhocas, composição e diversidade de espécies, composição de características funcionais de minhocas, e finalmente, diversidade funcional de minhocas. No capítulo 5 exploraram-se as distribuições dos pesos de cada grupo ecológico em relação à gestão dos restolhos, utilizando os dados referentes às comunidades completas (incluindo juvenis). Os resultados do capítulo 4 desta tese sugerem que, em NIT, a maior taxa da aplicação de restolhos fez aumentar a densidade de epigeicas em comparação com uma taxa de aplicação de restolhos menor (25\%), sendo os restantes efeitos de gestão de restolhos, no que toca às minhocas, foram negligenciáveis ou ausentes. Em CT, os restolhos, incoporados ou aplicados à superfície do solo, apresentaram efeitos fortes na composição de espécies, nos grupos ecológicos e nas características funcionais das comunidades de minhocas. Tanto a densidade de epigeicas, como a diversidade funcional de minhocas aumentaram com a disponibilidade de restolhos, e, simultaneamente, as comunidades alteraram- 
se para comunidades com indivíduos mais pesados, com um tegumento mais grosso, um typhlosolis em forma de pena e uma taxa de produção de casulos mais alta. Ao incluir os juvenis na avaliação das respostas das comunidades de minhocas, a distribuição de pesos das espécies endogeicas não se mostrou afectada pela gestão dos restolhos em ambos os campos (NIT e CT). A resposta das epigeicas foi largamente influenciada por L. rubellus em ambos os campos, sendo que os efeitos foram distintos em NIT e CT. Em NIT, restolhos em abundâcia resultaram numa maior proporção dos indivíduos mais leves, sugerindo um aumento no output reproductivo de espécies epigeicas com alimento em abundância. Em CT, a disponibilidade de restolhos, independentemente da sua posição resultou em indivíduos mais pesados, sobretudo nas minhocas de maior peso. Os resultados dos capítulos 4 e 5 sugerem que a gestão dos restolhos é muito importante para as comunidades de minhocas de campos agrícolas, no que se refere à quantidade de restolho, localização da sua aplicação e tipo de lavoura.

Conclui-se que as comunidades de minhocas de campos agrícolas são fortemente influenciadas pela gestão agrícola, e que as decisões de agricultores em relação à gestão dos restolhos afecta a vida dos solos e os consequentes serviços do solo mediados por minhocas. 

Acknowledgements 



\section{Acknowledgements}

My $\mathrm{PhD}$ was a challenging journey, with many wonderful but also tough moments that have helped me grow both personally and scientifically. Looking back I see many exciting, insightful and challenging moments, that often (but not only) arose due to dilemmas and difficulties. Just like in any life situation, those were solved to the best I could. Needless to say, I could not have done it all just by myself, and even if I could, I am sure that this thesis, the publications and my development as an independent scientist would not be a small fraction of what they are now. Therefore, I take the opportunity to thank the persons who have inspired, helped and supported me throughout this period, in very many different ways.

To start with, thank you to all my supervisors, Lijbert Brussaard, Mirjam Pulleman, Jack Faber, Ron de Goede and Jeroen Groot. It was not always easy to deal with such a large supervisory team, but I learned a lot from each of you individually and collectively.

Lijbert, you pushed through my scientific independence, and supported me in tough moments throughout my PhD. Simultaneously, your down-to-earth attitude helped me to bring perspective on difficulties and challenges. You have contributed to my development as a scientist and I am much grateful to that.

Mirjam, you gave me space and time to develop my own ideas, therefore allowing me to grow as an independent scientist. I am very grateful for the opportunity to be part of the Agrobiodiversity course "staff". Assisting the course over the years was an important experience for me. You also introduced me to working with farmers, with many useful tips regarding their agendas and habits. That was highly appreciated! Despite different time zones, you always made an effort to make my issues part of your agenda, even if the discussion had to happen on a Sunday afternoon. Furthermore, your sharpness and enthusiasm about my written work, together with your constructive and positive feedback helped me to improve the clarity and structure of my writing. Jack, your sharp, knowledgeable, enthusiastic and insightful comments on the drafts of my work were essential to push them to higher standards! Furthermore, you always gave me a feeling of calm, which in very many moments, was important to make me go through.

Ron, I was lucky enough that you became my official supervisor somewhere halfway my project. Already before that, your door was always open, either to chat about the birding adventures of the previous weekend, or to discuss some very important and difficult "problem" in the data 
analysis of what is now Chapter $x$. I really appreciated that and your suggestions were always inspiring and made me think! When I returned to Portugal, our skype meetings allowed me to keep a foot in Wageningen, which was also much appreciated and useful!

Jeroen, my project took a different turn than what had been initially envisaged, but despite that, I really appreciated your feedback on the manuscript that turned out to be my first publication as leading author and chapter of this thesis.

I would also like to thank my co-authors, which were not part of my supervising team, Mickael Hedde, Yvan Capowiez, Valentina Sechi and Tamas Salanki.

Mickael, you funded my participation in one of the BETSI workshops, and made me feel welcome to the team! In that meeting I had the opportunity to meet Yvan, and a nice collaboration naturally occurred. It was a pleasure to have met you both, and your feedback was precious to improve the quality of the draft manuscripts that resulted in two nice publications and chapters 3 and 4 of my thesis.

Tamas, your help throughout my $\mathrm{PhD}$ was of major relevance. You were involved in most of my field work, one way or the other, and I am much thankful for that. You've sampled with me, identified my fantastic earthworms, and spent many hours weighing them! Always in a good mood, often tired, but always in a good mood, and with something funny to add!

Vale, I always thought it was a pity you were not based in Wageningen, but that made the weekly day you showed up, always a bit nicer! Thank you for being there for me in the multiple ways you were, from frolleague, to co-author, to paranymph!

I am also much grateful to all farmers, who kindly allowed me to work on their farms and who made time for my questions and interviews: Mr. van den Hoek, Mr. Scheele, Mr. Schelling, Mr. B. Ampt, Mr. L.W. Ampt, Mr and Mrs. de Geus, Mr. de Jong, Mr. Noordam, Mr. van Dueren den Hollander, Mr. Ravestijn, Mr. Niemansverdriet, Mr. Westerlaken, Mr. van de Maas, Mr. Tramper and Ms. Vlasswinkel, and Mr. Klompe. An additional thanks to Mr. A. Klompe, who put me in contact with all the other farmers through HWodKa Foundation. Hartstikke bedankt!!

The Soil Biology chairgroup (SBL) was a very stimulating and inspiring work place, thanks to the staff, PhD candidates, and MSc, BSc and internship students. A special thanks to Marnella, Carolyn, Esther and Anita for all the help with administrative tasks! Your patience was simply precious! I am also much indebted to the technicians, both from SBL, Unifarm and Soil Chemistry, who helped me processing my samples (Willeke and Jaap, what would I have done 
without you?), who were creative in finding field solutions to set up my experimental plots as I wanted to have them (John, Frans and Wim, many thanks!!), who taught me some lab protocols (Gerlinde, Erna and Miranda, much grateful!!) and to the late Arie who helped me in the field, as well as in the greenhouse experiment. Also many thanks to the students and student assistants, who worked hard in the field and in the lab, sampling earthworms (Gerdine, Lara), preparing experimental plots (Lucas, Deivid), setting up the greenhouse experiment or working in the lab (Naira, and especially Lur, Gwen and Gwen). I am also much thankful to all the fellow PhD's and Postdocs for their precious help in the field (Walter, Karst, Ita, Tatiana, Ingrid, Diederik, Carmen) and Dr Esperanza Huerta. Those L. terrestris inoculation days only went so well because you were there to support me in all the tasks (including calming me down (:))! Back in Wageningen, I have really enjoyed the coffee and lunch breaks, as well as drinks and parties, with interesting discussions, as well as nice chit-chats about everything and nothing. Angie, Tatiana, Pelin, Xinxin, Giulia, Rima, Hannah, Susan, Young, Peipei, Guusje, Diego, Andreas, Carlos, Natalie, Mart, Walter, Carmen, Valentina, Mirjam B., Karst, Laura, Janna, Steve (and I am probably forgetting to name someone, apologies), thanks!!!! I am also much indebted to Steve, Edvaldo, Walter, Carmen, Laura and Janna for the thinking help, either R-related, analytical approach-related or experimental design-related. And, Carmen, many thanks for being my paranymph and for all the shared drives Nijmegen-WUR and WUR-Nijmegen! My life quality improved enormously after you started your PhD!

I would also like to thank Pedro and David from 2AdaPt, who welcomed me so warmly in their office when I moved back to Lisbon to finish my thesis. Thanks for all the nice discussions, coffee breaks, PermaLab activities, good mood and of course for making space for me in your tiny office.

Going through a PhD demands a lot of work, dedication and motivation, and some friends were very good at reminding me that I should also focus on other things. Loes, Inge, Gemma and Arnold in Holland and Ana (all three of them), Joni, Sara, Diana, Mariana and David in Portugal, thanks for everything!

Finally, I am forever indebted to my parents, who supported me in very many different ways and continued encouraging me, as they always have. Obrigada, muito obrigada! 

Short biography 



\section{Short biography}

Joana Frazão was born in Funchal (Madeira Island) on 18 March 1982. In 2005 she obtained her (preBologna) degree in Environmental Engineering from the New University of Lisbon, Portugal. During her studies she enrolled as an Erasmus student in the Radboud University of Nijmegen, the Netherlands, where she discovered her passion for Ecology. After completing her studies in Portugal, she travelled to Sweden to enrol in a post-graduate course on Insect Ecology in the Swedish Agricultural University (SLU) in Uppsala. She decided to return to the Netherlands to start a master's degree in Environmental Science with focus on Ecology, which was obtained in 2009,

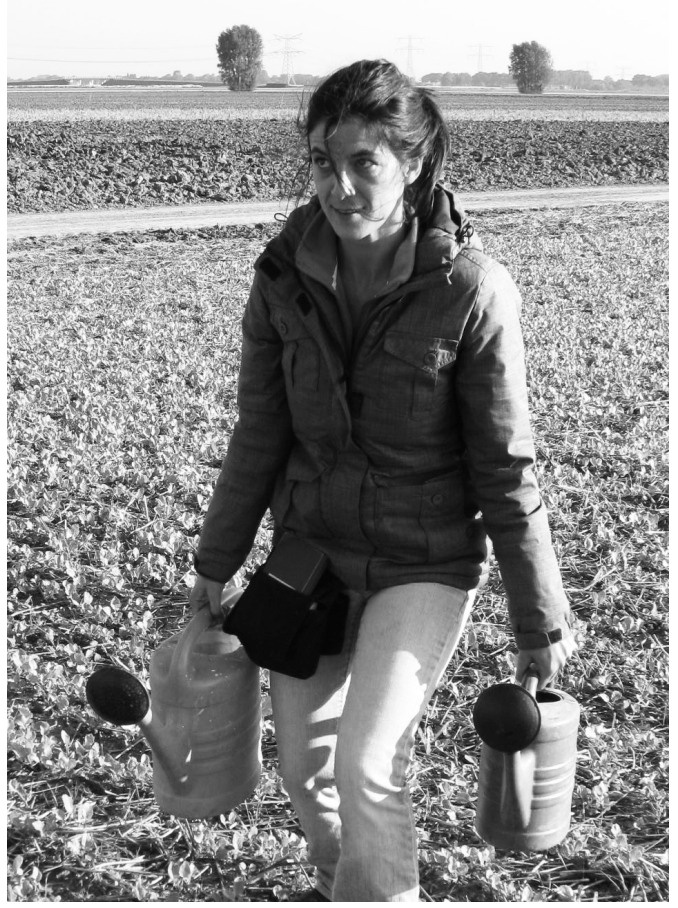
from the Radboud University of Nijmegen, the Netherlands. For her final MSc thesis, she studied the effects of nature restoration management schemes on gastropod fauna of Dutch chalk grasslands. From 2009 to the end of 2011 she was a research assistant in Bargerveen Foundation, where she developed tasks mainly related to field and lab work within (mostly) heathland restoration projects.

In 2012, she started her $\mathrm{PhD}$ project on earthworm communities in arable systems at the Department of Soil Quality (currently Department of Soil Biology) of Wageningen University, funded by the research programme Biodiversiteit Werkt! from the Netherlands Organisation for Scientific Research (NWO). She defended her thesis in June 2019.

\section{$\underline{\text { PEER-REVIEWED PUBLICATIONS }}$}

Aimi A., Larsson S., Ronnås C., Frazão J., Battisti A. 2008. Growth and survival of larvae of Thaumetopoea pinivora inside and outside a local outbreak area. Agricultural and Forest Entomology 10: 225 - 232. 
Frazão, J., de Goede, R.G.M., Brussaard, L., Faber, J.H., Groot, J.C.J., Pulleman, M.M., 2017. Earthworm communities in arable fields and restored field margins, as related to management practices and surrounding landscape diversity. Agriculture, Ecosystems and Environment 248, 18.

Frazão, J., de Goede, R.G.M., Capowiez, Y., Pulleman, M.M., 2019. Soil structure formation and organic matter distribution as affected by earthworm species interactions and crop residue placement. Geoderma 338, 453-463.

Frazão, J., de Goede, R.G.M., Salánki, T.E. Brussaard, L., Faber, J.H., Hedde, M., Pulleman, M.M. Responses of earthworm communities to crop residue management after inoculation of the earthworm Lumbricus terrestris (Linnaeus, 1758). Accepted for publication in Applied Soil Ecology. 


\section{PE\&RC Training and Education Statement}





\section{PE\&RC Training and Education}

\section{Statement}

With the training and education activities listed below the $\mathrm{PhD}$ candidate has complied with the requirements set by the C.T. de

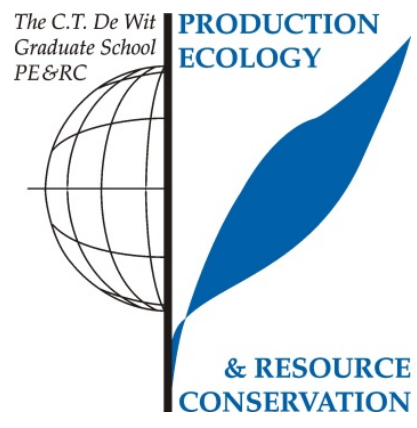
Wit Graduate School for Production Ecology and Resource Conservation (PE\&RC) which comprises of a minimum total of 32 ECTS (= 22 weeks of activities)

\section{Review of literature (4.5 ECTS)}

- Earthworm effect and response traits in arable systems

\section{Post-graduate courses (12.1 ECTS)}

- Soil, biodiversity and life: the contribution of soil to sustainability of life; PE\&RC (2012)

- Multivariate analysis of ecological data; University of South Bohemia (2013)

- i-GIS; PE\&RC (2013)

- Mixed linear models; PE\&RC (2014)

- The use of trait based approaches in community ecology and stress ecology; University of Coimbra (2015)

\section{Invited review of (unpublished) journal manuscript (2 ECTS)}

- Agriculture, Ecosystems and Environment: cropping systems' influence on carabid, spiders and earthworm communities (2014)

- Geoderma: earthworm communities and their macroporosity in differently tilled arable systems (2016)

\section{Deficiency, refresh, brush-up courses (6 ECTS)}

- Ecological modelling and data analysis in R; CSA (2015)

\section{Competence strengthening / skills courses (2.8 ECTS)}

- Competence assessment; WGS (2012)

- PhD WGS Carousel; WGS (2015)

- Techniques for writing and presenting a scientific paper; WGS (2016)

- Information literacy PhD including EndNote introduction; WGS (2016)

- PhD career coaching programme; ESG (2017) 
PE\&RC Annual meetings, seminars and the PE\&RC weekend (2.4 ECTS)

- PE\&RC Weekend first years (2012)

- PE\&RC Day $(2012,2013,2014)$

- PE\&RC Weekend last years (2016)

Discussion groups / local seminars / other scientific meetings (4.6 ECTS)

- $\quad$ Roundtable discussion during ICSZ with 15 soil ecologists about PhD plans (2012)

- Modelling and statistics network (2013)

- Trait-based approaches in soil biodiversity; BETSI Workshop, INRA, Aix-en-Provence (2013)

- R-users meeting (2013-2016)

- Ecological theory and application (2013-2017)

International symposia, workshops and conferences (14.9 ECTS)

- International Colloquium of Soil Zoology; poster presentation (2012)

- Netherlands Annual Ecology Meeting; poster presentation (2013)

- International Symposium of Earthworm Ecology; poster presentation (2014)

- Global Soil Biodiversity Initiative Meeting; poster presentation (2015)

- Wageningen Soil Conference; poster presentation (2015)

- Netherlands Annual Ecology Meeting; poster presentation (2016)

Lecturing / Supervision of practicals / tutorials (4.95 ECTS)

- Agrobiodiversity (2012, 2013, 2015) 





The research described in this thesis was financially supported by the Netherlands Organisation for Scientific Research (NWO) under grant no. 841.11.003 of the special programme Biodiversiteit Werkt!

Financial support from Wageningen University \& Research for printing this thesis is gratefully acknowledged.

Cover design by João Boucinha Thesis printed by Digiforce / ProefschriftMaken on FSC-certified paper 